Vivian Suzano Medeiros

Determinação de trajetórias ótimas em circuitos fechados com restrições dinâmicas e geométricas

Dissertação apresentada como requisito parcial para obtenção do título de Mestre pelo Programa de Pós-Graduação em Engenharia Mecânica do Departamento de Engenharia Mecânica da PUC-Rio.

Orientador: Prof. Ivan Fábio Mota de Menezes Co-Orientador: Prof. Mauro Speranza Neto 
Vivian Suzano Medeiros

\section{Determinação de trajetórias ótimas em circuitos fechados com restrições dinâmicas e geométricas}

Dissertação apresentada como requisito parcial para obtenção do grau de Mestre pelo Programa de PósGraduação em Engenharia Mecânica do Centro Técnico Científico da PUC-Rio. Aprovada pela Comissão Examinadora abaixo assinada.

Prof. Ivan Fábio Mota de Menezes

Orientador

Departamento de Engenharia Mecânica - PUC-Rio

Prof. Mauro Speranza Neto

Co-Orientador

Departamento de Engenharia Mecânica - PUC-Rio

Prof. Marco Antônio Meggiolaro

Departamento de Engenharia Mecânica - PUC-Rio

Prof. Francisco José da Cunha Pires Soeiro Universidade Estadual do Rio de Janeiro - UERJ

Prof. José Eugênio Leal Coordenador Setorial do Centro Técnico Científico - PUC-Rio 
Todos os direitos reservados. É proibida a reprodução total ou parcial do trabalho sem autorização da universidade, da autora e do orientador.

\section{Vivian Suzano Medeiros}

É formada em Engenharia de Controle e Automação pela Pontifícia Universidade Católica do Rio de Janeiro (2012). É engenheira de pesquisa do Centro de Pesquisa em Tecnologia de Inspeção (CPTI) da PUC-Rio. Atua em pesquisa na área de sistemas embarcados e de controle.

Ficha Catalográfica

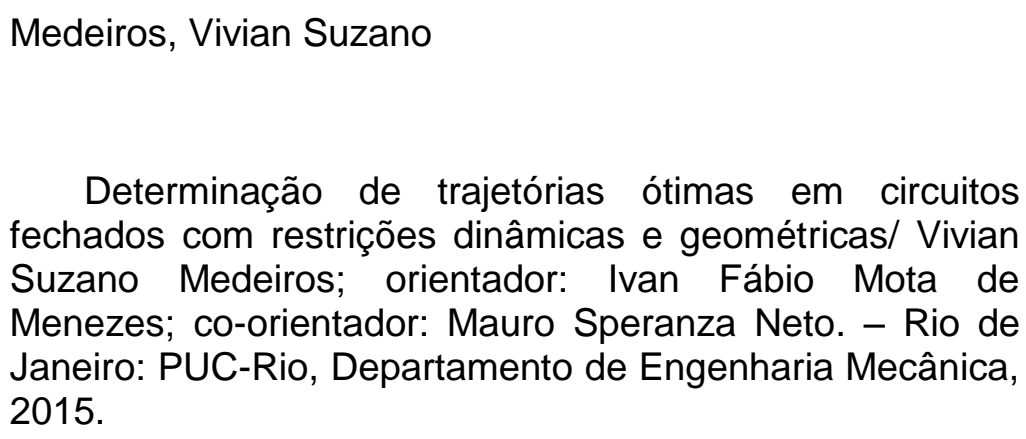

Determinação de trajetórias ótimas em circuitos fechados com restrições dinâmicas e geométricas/ Vivian Suzano Medeiros; orientador: Ivan Fábio Mota de Menezes; co-orientador: Mauro Speranza Neto. - Rio de Janeiro: PUC-Rio, Departamento de Engenharia Mecânica, 2015.

128 f.; il. (color), $29,7 \mathrm{~cm}$

Dissertação de Mestrado - Pontifícia Universidade Católica do Rio de Janeiro, Departamento de Engenharia Mecânica, 2015.

Inclui referências bibliográficas.

1. Engenharia mecânica - Teses. 2. Trajetória Ótima. 3. Otimização com Restrição. 4. Controle Ótimo. 5. Pista de Corrida. I. Menezes, Ivan Fábio Mota de. II. Speranza Neto, Mauro. III. Pontifícia Universidade Católica do Rio de Janeiro. Departamento de Engenharia Mecânica. IV. Título. 
Para meи pai e minha mãe, que não estão mais aqui, mas me acompanham sempre no meu coração. Para minhas irmãs, pelo amor e apoio incondicional. 


\section{Agradecimentos}

Agradeço a Deus pela vida e pelas oportunidades oferecidas.

Agradeço ao meu pai, pessoa que mais admirei, por todo amor e dedicação.

Agradeço às minhas irmãs Viviane e Vitória, pelo apoio constante.

Agradeço ao meu amor, Rodrigo Oliveira, pelo suporte e paciência durante todo o desenvolvimento deste trabalho.

Ao meu orientador Ivan Menezes pelo apoio, disponibilidade, paciência e orientação durante a elaboração desta dissertação.

Ao meu co-orientador, professor Mauro Speranza, por toda a ajuda e confiança desde a graduação.

Ao CNPQ, à FAPERJ e à PUC-Rio, pelos auxílios concedidos, que foram de extrema importância para a realização deste trabalho.

Aos meus amigos, que me acompanharam e me apoiaram durante a composição desta dissertação.

Aos professores e funcionários departamento de Engenharia Mecânica da PUC-Rio, pela qualidade do ensino e excelente infraestrutura, essenciais para a execução do curso de mestrado. 


\section{Resumo}

Medeiros, Vivian Suzano; Menezes, Ivan Fábio Mota de; Speranza Neto, Mauro. Determinação de trajetórias ótimas em circuitos fechados com restrições dinâmicas e geométricas. Rio de Janeiro, 2015. 128p. Dissertação de Mestrado - Departamento de Engenharia Mecânica, Pontifícia Universidade Católica do Rio de Janeiro.

O presente projeto de pesquisa objetiva desenvolver um procedimento para determinação de trajetórias ótimas em pistas de corrida baseado em técnicas de otimização, considerando os limites geométricos da pista e as características dinâmicas do veículo. O veículo será representado por meio de um modelo simplificado de partícula orientada, mas que inclui as capacidades de tração, frenagem e aceleração normal típicas de um veículo terrestre de competição. Primeiramente, é determinada a trajetória de tempo mínimo para uma curva de $90^{\circ}$ por meio da análise geométrica do problema e em seguida, é obtida a solução analítica geral para aplicação a qualquer ângulo. Em seguida, técnicas de otimização com restrição são empregadas de forma a obter a curva de menor tempo que concatena as trajetórias ótimas individuais de cada curva, previamente determinadas. São estudadas, ainda, as características dinâmicas de algumas curvas polinomiais para inferir aquela que melhor pode ser aplicada no processo de concatenação. A trajetória de menor tempo da pista de corrida obtida pelo procedimento de concatenação é apresentada e é feita uma análise das vantagens e desvantagens do método proposto. Como alternativa, é apresentada uma visão geral do problema de controle ótimo e é formulada a modelagem completa do problema de trajetória de mínimo tempo utilizando esta abordagem, incluindo as restrições dinâmicas do veículo e as restrições geométricas da pista. Algumas técnicas possíveis para solução do problema de controle ótimo são sugeridas.

\section{Palavras-chave}

Trajetória Ótima; Otimização com Restrição; Controle Ótimo; Pista de Corrida. 


\section{Abstract}

Medeiros, Vivian Suzano; Menezes, Ivan Fábio Mota de (Advisor); Speranza Neto, Mauro (Co-advisor). Determination of the optimal trajectories on race tracks with dynamic and geometric constraints. Rio de Janeiro, 2015. 128p. MSc Dissertation - Departamento de Engenharia Mecânica, Pontifícia Universidade Católica do Rio de Janeiro.

This work proposes a new procedure to determine the optimal trajectory on race tracks based on constrained optimization techniques, where the constraints are defined by means of the dynamic characteristics of the vehicle and the geometrical limits of the track. The vehicle is represented by an oriented particle with the capabilities of traction, braking and normal acceleration, which are typical in a competition vehicle. First, the minimum-time trajectory for a 90 degree curve is obtained through a geometrical analysis of the problem. The solution is then expanded to be applied to all angles. Starting from the individual minimum-time trajectory for each curve of the track, constrained optimization techniques are employed in order to obtain the shorter curve that concatenates these individual optimal trajectories. The dynamic characteristics of some polynomial curves are analyzed to infer the one that can best be applied in the concatenation process. The minimum-time trajectory for the race track obtained by the concatenation procedure is presented and the advantages and disadvantages of the proposed method are discussed. Alternatively, an overview of the optimal control problem is presented and a complete model of the minimum-time trajectory problem is developed using this approach, including the dynamic constraints of the vehicle and the geometric constraints of the track. Some possible methods for the solution of the optimal control problem are suggested.

\section{Keywords}

Optimal Trajectory; Constrained Optimization; Optimal Control; Race Tracks. 


\section{Sumário}

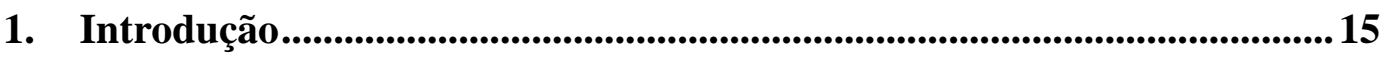

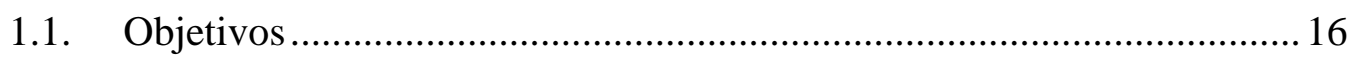

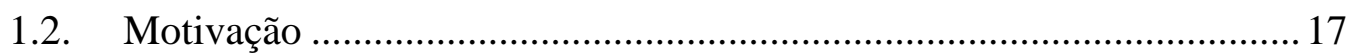

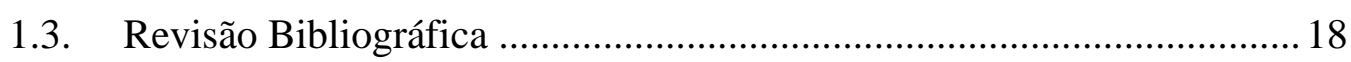

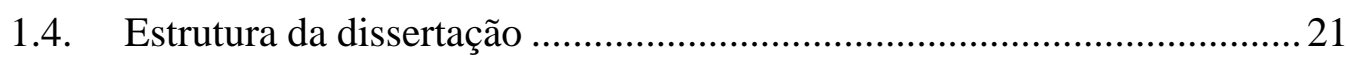

2. Modelagem do Veículo............................................................................223

2.1. Equações diferenciais do modelo ....................................................... 24

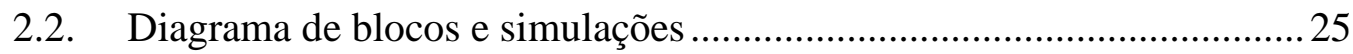

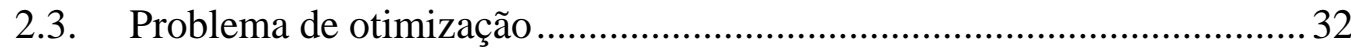

2.3.1. Círculo de Aderência ....................................................................... 33

3. Trajetória Ótima para Curvas Independentes..........................................36

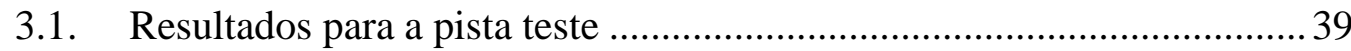

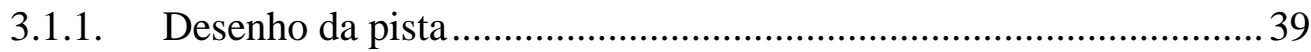

3.1.2. Resultado das trajetórias ótimas independentes ............................. 40

3.2. Resultados para a pista de Barcelona.................................................... 42

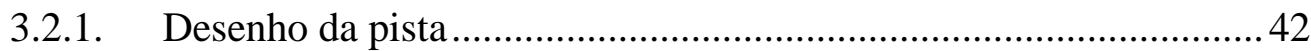

3.2.2. Resultado das trajetórias ótimas independentes para a pista de

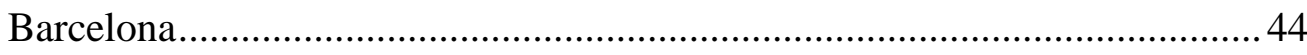

4. Concatenação dos Trechos Ótimos Independentes ................................. 47

4.1. Curva de Hermite ............................................................................ 47

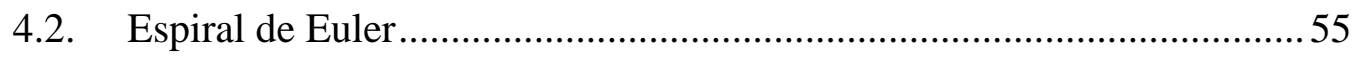

4.3. Análise dinâmica das curvas propostas ...............................................59

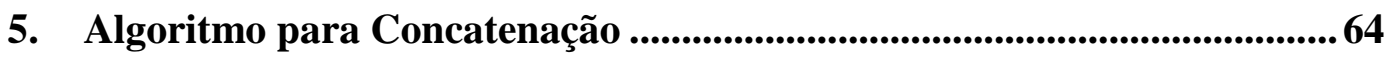

5.1. Algoritmo para sub-rotina do processo de otimização ...............................6 67

5.2. Concatenação dos trechos em curva: modelo sem restrições de aceleração

5.3. Concatenação dos trechos em curva: modelo com restrições de

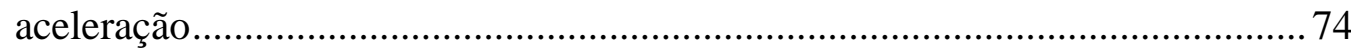

5.3.1. Verificação das acelerações no Círculo de Aderência .......................... 77

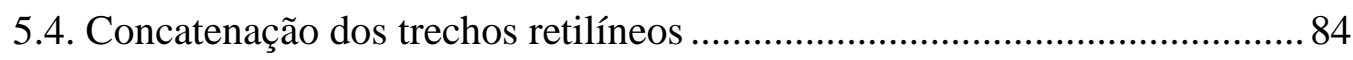

5.5. Resultado final para a concatenação da pista teste ................................... 93

5.6. Resultados para a pista de Barcelona ......................................................... 95 
5.6.1. Verificação das acelerações e velocidades na pista de Barcelona ..... 100

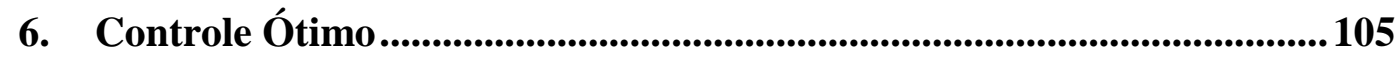

6.1. O problema geral de controle ótimo .................................................. 105

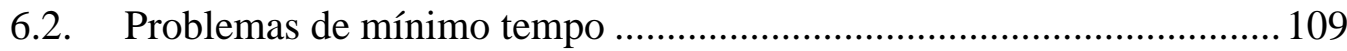

6.3. Modelagem do problema de controle ótimo ........................................ 111

6.3.1. Variáveis de estado e restrições do problema................................. 111

6.3.2. Função objetivo e condições de fronteira ..................................... 117

6.3.3. Formalização do modelo e técnicas para a solução ........................ 119

7. Conclusões e Trabalhos Futuros ............................................................... 123

8. Referências Bibliográficas ................................................................126 


\section{Lista de figuras}

Figura 1.1: Simulação do circuito de Adria, Itália [1] ......................................... 16

Figura 1.2: Trechos ótimos de curvas independentes........................................... 16

Figura 2.1: Representação do veículo............................................................... 23

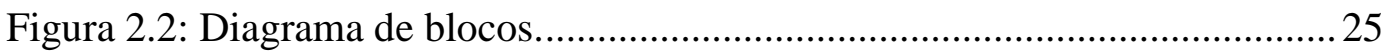

Figura 2.3: Diagrama de blocos do modelo no Simulink ${ }^{\circledR}$.................................... 26

Figura 2.4: Resultados para $\mathrm{x}_{0}=\mathrm{y}_{0}=\psi_{0}=0, \mathrm{v}_{0}=10 \mathrm{~m} / \mathrm{s}, \mathrm{a}_{\mathrm{n}}=9,81 \mathrm{~m} / \mathrm{s}^{2}$,

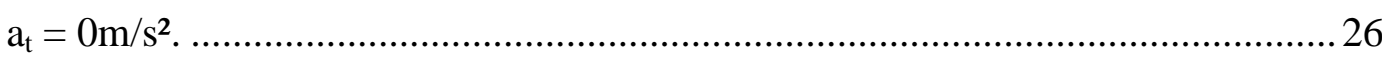

Figura 2.5: Resultados para $\mathrm{x}_{0}=\mathrm{y}_{0}=\psi_{0}=0, \mathrm{v}_{0}=10 \mathrm{~m} / \mathrm{s}, \mathrm{a}_{\mathrm{n}}=9,81 \mathrm{~m} / \mathrm{s}^{2}$,

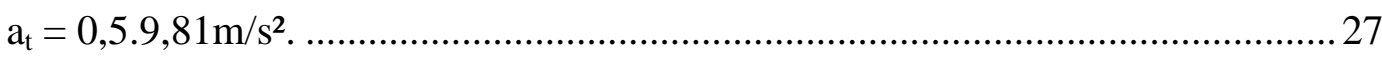

Figura 2.6: Simulação para diversos valores de aceleração tangencial................. 28

Figura 2.7: Simulação para diversos valores de aceleração normal...................... 28

Figura 2.8: Diagrama de blocos para aceleração variável no tempo..................... 30

Figura 2.9: Resultados para aceleração tangencial exponencial............................ 31

Figura 2.10: Resultados de aceleração normal e tangencial.................................. 31

Figura 2.11: Medidas de aceleração longitudinal e normal de um veículo de

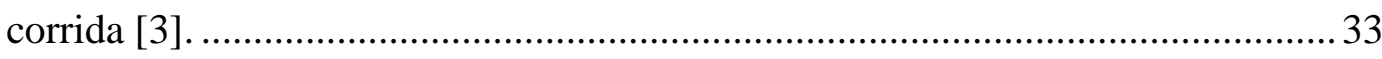

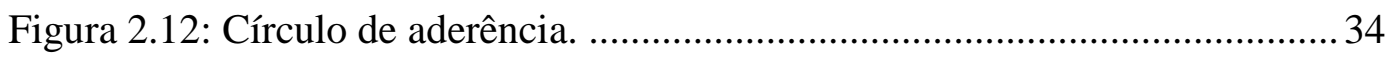

Figura 2.13: Ilustração das capacidades máximas de aceleração numa curva. ..... 35

Figura 3.1: Problema de otimização para curva independente.............................. 36

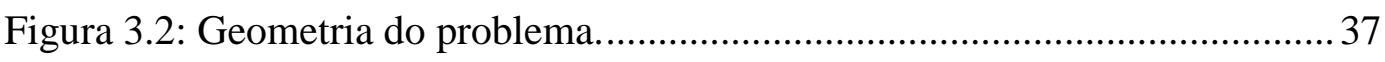

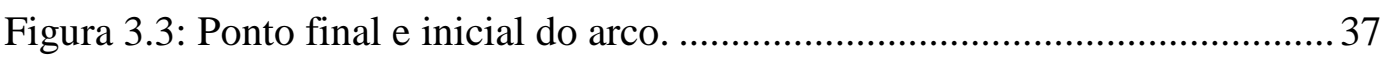

Figura 3.4: Determinação da linha de corrida para uma curva circular de $90^{\circ}$

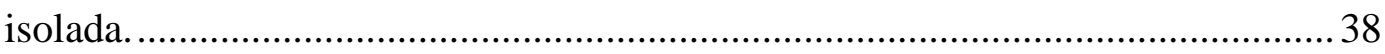

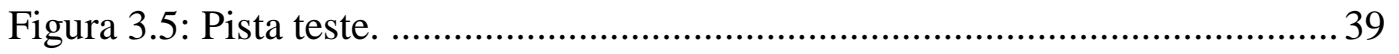

Figura 3.6: Linhas de corrida independentes em várias curvas circulares de um circuito fechado, sem concatenação. ......................................................... 40

Figura 3.7: Aproximação do Circuito de Catalunha, Barcelona............................. 42

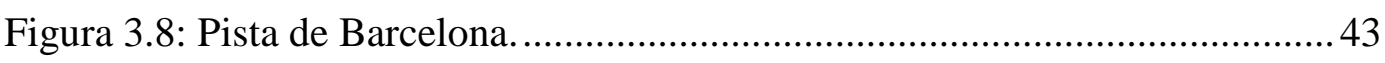

Figura 3.9: Resultados para a pista de Barcelona................................................ 44

Figura 4.1: Exemplos de curvas de Hermite....................................................... 48

Figura 4.2: Pontos e derivadas para geração da curva de Hermite........................ 49 
Figura 4.3: Resultado inicial da concatenação por curvas de Hermite. .51

Figura 4.4: Derivada no ponto $\mathrm{P}_{1}$ do trecho 4 ..................................................... 51

Figura 4.5: Curvas de Hermite para diversos módulos de derivada...................... 52

Figura 4.6: Curvas para cada matriz de Hermite.................................................... 55

Figura 4.7: Trajetória ótima utilizando a espiral de Euler [5] ..............................56

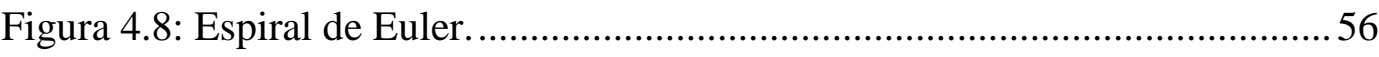

Figura 4.9: Espiral de Euler e Polinômio de Hermite. ........................................... 58

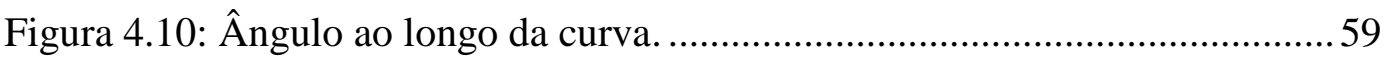

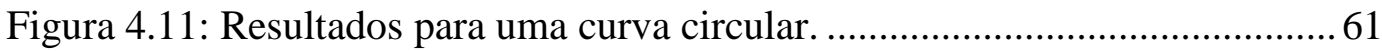

Figura 4.12: Resultados para uma espiral de Euler. ..............................................62

Figura 4.13: Resultados para uma curva de Hermite............................................. 63

Figura 5.1: Resultados da geração de trajetórias ótima para curvas....................... 66

Figura 5.2: Modelo do problema de otimização - achar o ponto mais perto do

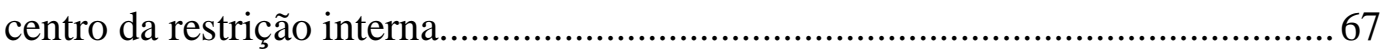

Figura 5.3: Resultado do fminbnd para algumas curvas de Hermite. 69

Figura 5.4: Resultado do fmincon para as curvas da pista teste. .......................... 71

Figura 5.5: Trechos concatenados sem restrição de aceleração mais detalhados.. 71 Figura 5.6: Resumo dos trechos concatenados da pista teste. ............................... 72

Figura 5.7: Velocidade e acelerações para o trecho concatenado 3..................... 72

Figura 5.8: Velocidade e acelerações para o trecho concatenado 5..................... 73

Figura 5.9: Resultado para a modelagem com restrições de aceleração. .............. 74

Figura 5.10: Trechos concatenados mais detalhados.......................................... 75

Figura 5.11: Relatório de concatenação para otimização com restrições de aceleração.

Figura 5.12: Velocidade e acelerações para o trecho concatenado 3 com

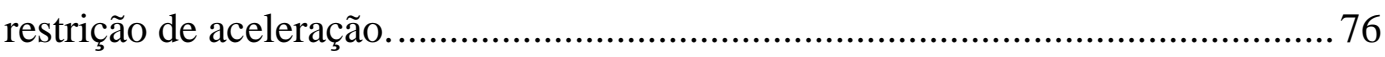

Figura 5.13: Velocidade e acelerações para o trecho concatenado 5 com

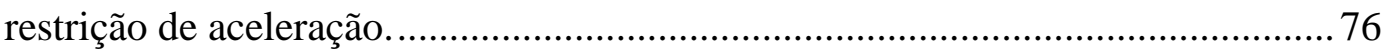

Figura 5.14: Acelerações e Círculo de Aderência para o trecho 3. ....................... 78

Figura 5.15: Acelerações e Círculo de Aderência para o trecho 5....................... 78

Figura 5.16: Círculo de Aderência para as acelerações limites deste modelo....... 79

Figura 5.17: Resultado para o modelo com as restrições do círculo de aderência. 
Figura 5.18: Resumo dos trechos concatenados com restrição do círculo de aderência. 80

Figura 5.19: Velocidade e acelerações para o trecho concatenado 3 com restrição do círculo de aderência. 81

Figura 5.20: Acelerações do trecho 3 com restrição do círculo de aderência. .......82

Figura 5.21: Gráfico das acelerações obtidas para diversos valores de $\tau$...............8 82

Figura 5.22: Acelerações do trecho 5 com restrição do círculo de aderência. ...... 83

Figura 5.23: Velocidade e acelerações para o trecho concatenado 5 com restrição do círculo de aderência. 84

Figura 5.24: Trecho reto entre curvas de direções diferentes............................... 84

Figura 5.25: Resultado da concatenação para o trecho destacado.......................... 86

Figura 5.26: Características dinâmicas da curva obtida. ....................................... 86

Figura 5.27: Resultado para concatenações com trechos retos. ……………......... 87

Figura 5.28: Resumo dos trechos concatenados em reta....................................... 88

Figura 5.29: Acelerações para concatenação do trecho 9 da pista teste. 89

Figura 5.30: Acelerações para concatenação do trecho 7 da pista teste. ................90

Figura 5.31: Resultados para a concatenação com velocidade reduzida............... 91

Figura 5.32: Novo resultado para o trecho concatenado 7 .................................. 92

Figura 5.33: Novo resultado para o trecho concatenado 9.................................. 92

Figura 5.34: Resultado completo para a pista teste............................................. 93

Figura 5.35: Resultados dinâmicos para a pista teste.......................................... 94

Figura 5.36: Resultado completo para a concatenação da pista de Barcelona. ..... 96

Figura 5.37: Trecho concatenado 22 da pista de Barcelona................................97

Figura 5.38: Trechos numerados da pista de Barcelona ......................................... 98

Figura 5.39: Resumo das trajetórias ótimas independentes da pista de

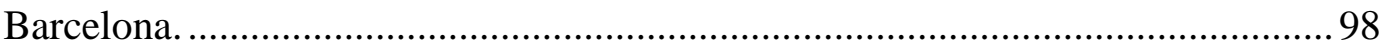

Figura 5.40: Resumo dos trechos concatenados da pista de Barcelona. ............... 99

Figura 5.41: Dinâmica dos trechos concatenados 3, 5, 6 e 8.............................. 101

Figura 5.42: Dinâmica dos trechos concatenados 10, 12, 14 e 16....................... 101

Figura 5.43: Dinâmica dos trechos concatenados 17, 19, 20 e 22 _..................... 102

Figura 5.44: Dinâmica dos trechos concatenados 24, 26, 27 e 1........................ 102

Figura 5.45: Trajetória da pista de Barcelona obtida pela computação do problema de controle ótimo [11]. 
Figura 5.46: Comparação entre o traçado obtido por concatenação e por controle ótimo. 104

Figura 5.47: Trajetória do circuito de Barcelona obtida no site do campeonato de Fórmula 1 [21] 104

Figura 6.1: Variáveis do modelo dinâmico do veículo

Figura 6.2: Coordenadas $\mathrm{s}_{1}$ e $\mathrm{s}_{2}$ do veículo através do centro da linha da pista.. 113 Figura 6.3: Representação do ângulo $\alpha$ 114 


\section{Lista de tabelas}

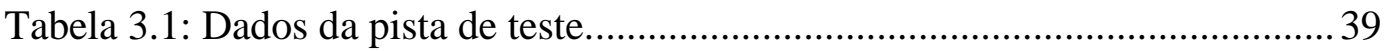

Tabela 3.2: Pontos da trajetória ótima em cada curva circular da Figura 3.6. ...... 40

Tabela 3.3: Resultados para trajetória ótima de cada curva da Figura 3.6............ 41

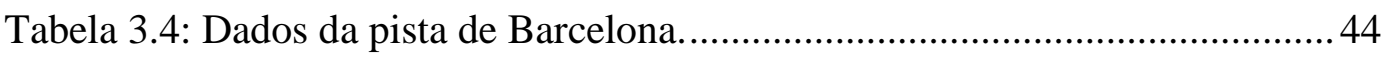

Tabela 3.5: Tabela de pontos das trajetórias ótimas individuais da pista de

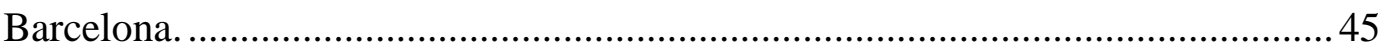

Tabela 3.6: Resultados das trajetórias independentes para a pista de Barcelona. . 46 


\section{Introdução}

Atualmente, nos encontramos em um cenário de grande avanço para a área automobilística, onde muitas empresas têm empregado inúmeros esforços para desenvolver veículos cada vez mais eficientes e seguros. Uma das modalidades automobilísticas que constantemente evolui com descobertas inovadoras é a indústria de desenvolvimento de carros de corrida para competições em circuitos fechados. Com o passar dos anos, a popularização deste esporte contribuiu para a necessidade de se criar carros de alto desempenho e, com isso, minimizar o tempo gasto para percorrer os mais diversos circuitos. Assim, fica evidente que o conhecimento prévio da trajetória de menor tempo destes circuitos implica em diversos avanços e facilidades no processo de desenvolvimento, controle e estudo da dinâmica de veículos de corrida, além de tornar simulações e testes muito mais realistas. Neste contexto, esta dissertação propõe o desenvolvimento de um algoritmo que permitirá calcular a trajetória de mínimo tempo (ótima) para um determinado circuito de corrida.

O cálculo da trajetória ótima de uma pista de corrida envolve diversas etapas, de diferentes áreas de conhecimento. Primeiramente, será desenvolvido um modelo simplificado do veículo de corrida, considerando suas limitações de velocidade, aceleração e frenagem. Uma vez definido o modelo, serão analisados os limites geométricos da pista de corrida e então, serão calculadas as trajetórias ótimas para os trechos curvilíneos independentes. Em seguida, será estudada uma função de interpolação para obter a trajetória ótima da pista a partir da concatenação das trajetórias ótimas independentes. A trajetória obtida será comparada com trajetórias obtidas por pilotos reais, através de sensores embarcados nos veículos.

Além disso, uma modelagem do problema utilizando controle ótimo também é desenvolvida e apresentada. $\mathrm{O}$ modelo proposto inclui as restrições dinâmicas do veículo e geométricas da pista como penalidade na função objetivo, como alternativa para a aplicação de inequações. Alguns métodos para a solução do problema também são sugeridos. 


\subsection{Objetivos}

O objetivo desta pesquisa é desenvolver um algoritmo, preferencialmente no ambiente Matlab $^{\circledR}$, de baixo custo computacional (pequeno tempo de execução), que possibilite determinar a trajetória ótima de um veículo em um circuito fechado, tal como ilustrado na Figura 1.1 [1].

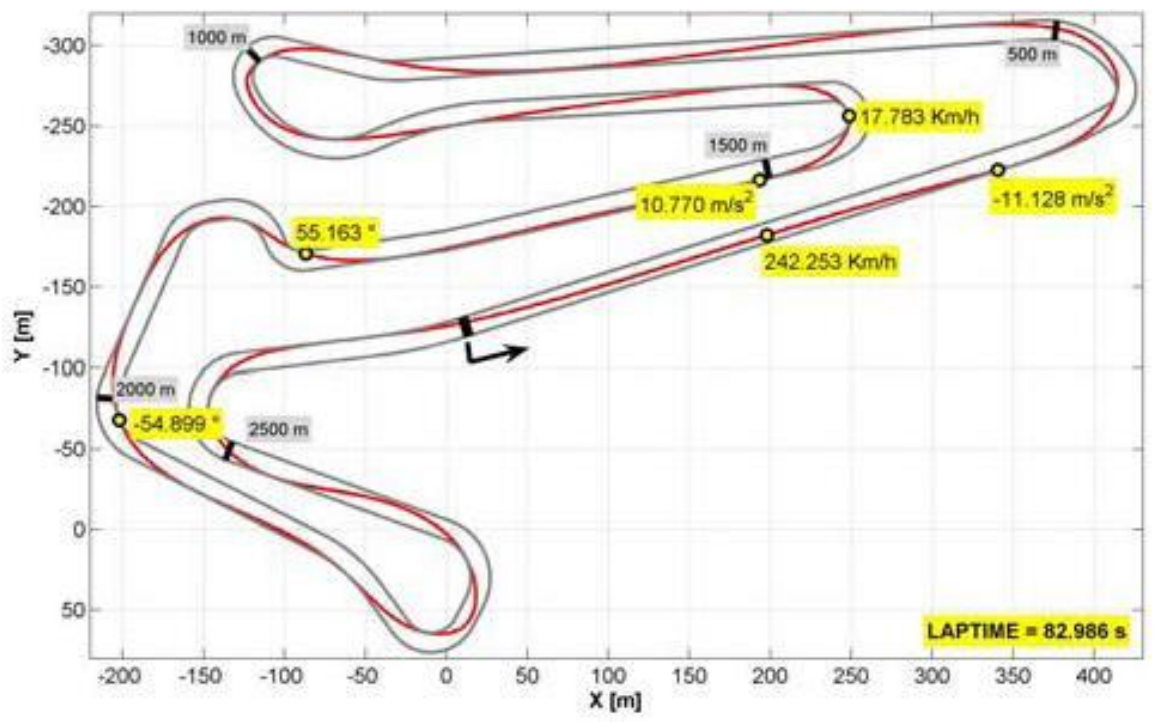

Figura 1.1: Simulação do circuito de Adria, Itália [1].

Dadas as trajetórias ideais, determinadas analiticamente, de trechos curvilíneos independentes (como mostra o exemplo simples da Figura 1.2), o procedimento proposto consiste em utilizar técnicas de otimização com restrições para obter a concatenação desses trechos determinados isoladamente, respeitando as limitações da pista e do veículo, representadas por meio de modelos analíticos.

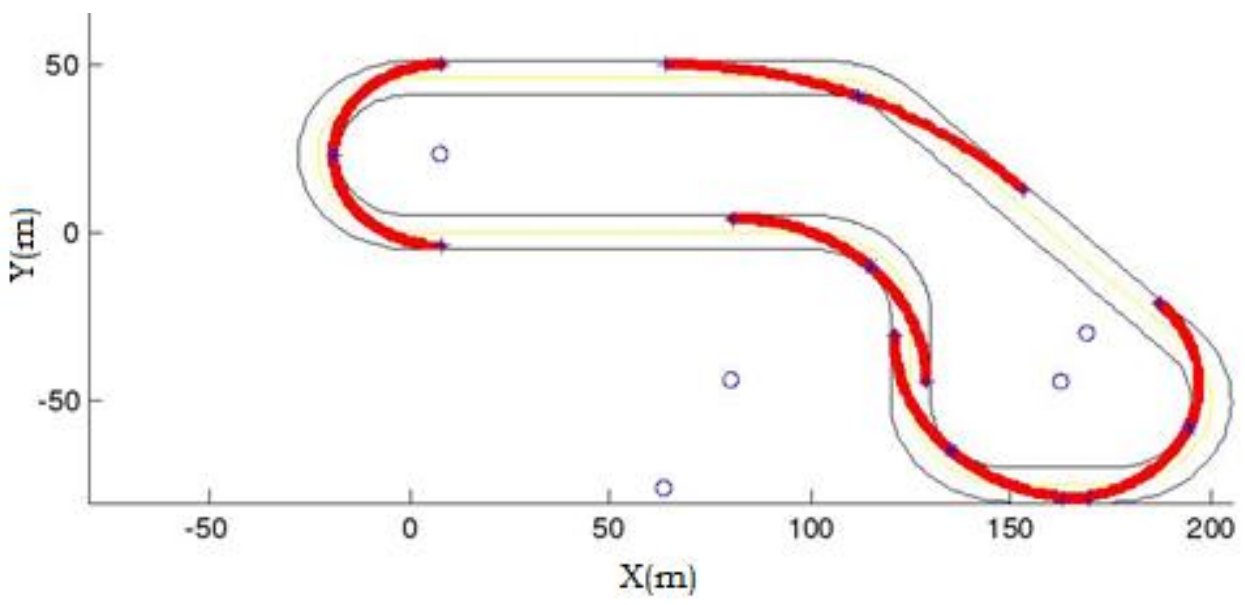

Figura 1.2: Trechos ótimos de curvas independentes 
Os resultados obtidos serão analisados e validados por meio do cálculo do tempo total de percurso e o traçado das trajetórias ótimas obtidas será comparado com outros similares obtidos por técnicas diferentes apresentadas na literatura, e com trajetórias obtidas com uma instrumentação embarcada em carros de corrida.

A trajetória assim encontrada será usada para a simulação do comportamento dinâmico do veículo com controle pelo ser humano e autônomo, com modelos de diversos graus de liberdade, visando estabelecer futuramente as leis de controle necessárias para o movimento autônomo de um veículo de corrida.

\subsection{Motivação}

Uma das principais motivações para o desenvolvimento deste trabalho é a importância de trajetórias ótimas de pistas de corrida para a realização de simulações e testes em veículos de corrida, ou mesmo em veículos de passeio.

Um passo importante no processo de desenvolvimento de qualquer veículo de corrida é o teste do seu comportamento dinâmico com diversos níveis de complexidade em diferentes ambientes. Estes testes devem garantir que o veículo execute com rapidez e eficiência trajetórias de qualquer tipo, sejam elas curvilíneas ou retas. Mas, além disso, ele deve ser capaz de executar com precisão a trajetória ótima, ou seja, aquela de menor tempo. Esta pode ser previamente calculada e validada para viabilizar testes mais precisos, o que é um dos objetivos do procedimento que será desenvolvido neste projeto.

É importante ressaltar que a primeira parte deste processo de teste é feita a partir de simulações computacionais, onde é possível simular situações pouco usuais e muito difíceis de serem reproduzidas na prática sem afetar a segurança do condutor, como grandes aclives e declives, e ainda impor as dificuldades que o carro terá que enfrentar, como resistência do vento e atrito. A inclusão de trajetórias ótimas existentes neste processo torna os resultados dessas simulações ainda mais próximos dos obtidos em condições reais.

Além disso, o conhecimento prévio da trajetória ótima de uma pista de corrida pode viabilizar a simulação de veículos de corrida autônomos, controlados apenas por sistemas de sensoriamento e controle. A partir da trajetória ótima, pode se estabelecer, mesmo que futuramente, as estratégias de controle e 
comandos necessários para o movimento totalmente autônomo de um veículo em alta velocidade em uma pista predefinida.

\subsection{Revisão Bibliográfica}

Diversos trabalhos na área de modelagem de veículos e otimização têm sido desenvolvidos com o objetivo de propor uma técnica eficiente para obtenção da trajetória ótima de um veículo em circuitos fechados. A parte mais complicada deste processo é garantir que a trajetória obtida seja a de menor tempo e simultaneamente, também respeite todas as restrições dinâmicas do modelo empregado. Por este motivo, as acelerações aplicadas no trajeto devem garantir a maior velocidade possível, mas sem ultrapassar os limites de aderência e estabilidade do veículo. Algumas estratégias de otimização, com suas vantagens e desvantagens, já foram empregadas na literatura de forma a alcançar esses objetivos.

Aplicando funções de otimização com restrição da biblioteca Optimization Toolbox do Matlab ${ }^{\circledR}$, Carrera [2] propõe um algoritmo para obtenção da trajetória ótima onde as variáveis de otimização são as acelerações tangencial e normal durante a trajetória e as posições na pista onde serão aplicadas essas acelerações durante o movimento do veículo ao percorrer um traçado específico. O modelo do veículo utilizado por Carrera [2] é mais simples, o considerando como uma partícula orientada e as acelerações longitudinal e normal empregadas no modelo são restritas à perfis exponenciais. As restrições dinâmicas do veículo são baseadas no Círculo de Aderência, explicado detalhadamente em Edmonson [3] e Milliken e Milliken [4], onde são estudados em todos os aspectos do movimento de um veículo de corrida na pista.

Também aplicando técnicas de otimização com restrição, Xiong [5] desenvolve um algoritmo iterativo que visa determinar os parâmetros de uma espiral de Euler (Arakawa [6] e Ávila [7]) que esteja completamente contida dentro da pista, de forma que a trajetória ótima seja formada por trechos de espirais. Além disso, ele também propõe a solução do problema utilizando programação dinâmica.

Assim como Carrera [2], Ribeiro [8] também utiliza a modelagem de partícula orientada do veículo e o círculo de aderência para estudar as restrições 
de aceleração do veículo. No entanto, a técnica utilizada é bastante diferente, já que ele desenvolve um algoritmo de otimização de trajetória baseado em algoritmos genéticos. As restrições do problema e a função objetivo são descritas na função de adaptação dos indivíduos no modelo do algoritmo genético. Paralelamente, Ribeiro [8] descreve o piloto do veículo como um controlador Fuzzy. Os resultados obtidos não foram satisfatórios com a utilização destas técnicas de inteligência computacional, em especial porque a restrição da pista não foi satisfeita e o algoritmo é pouco eficiente, tendo um custo computacional muito grande.

A aplicação de técnicas de otimização com restrições para a solução do problema de trajetória ótima pode ser vista também no trabalho de Ramanata [9]. Neste, é utilizado um modelo mais complexo que prevê as variações nos três eixos de movimento. Para a solução do problema de trajetória ótima é proposto um modelo de minimização cuja função objetivo seja o tempo e as variáveis são: taxa de variação do ângulo de navegação (yaw), velocidade longitudinal, velocidade lateral, posição longitudinal em relação ao eixo inercial, posição lateral em relação ao eixo longitudinal e o ângulo de navegação (yaw). As restrições do modelo consistem em restrições geométricas da pista e restrições dinâmicas como a força máxima de tração. Para a solução do problema, é utilizada a função fmincon da biblioteca Optimization Toolbox do Matlab ${ }^{\circledR}$. Apesar de serem obtidos bons resultados, o modelo de otimização só previa valores constantes de aceleração ao longo dos trechos, o que não representa bem o movimento de um veículo em uma corrida.

Outra abordagem que vem sendo amplamente utilizada na solução de problemas de trajetória ótima é o controle ótimo. Nesta técnica, descreve-se o problema de trajetória ótima como um problema de tempo mínimo, onde o índice de desempenho a ser minimizado é o tempo total da trajetória. A dificuldade desta técnica está na quantidade de equações diferenciais que devem ser resolvidas para a solução do problema, já que incluem as equações diferenciais da modelagem do veículo, as equações que garantem a otimalidade da solução e as restrições do problema. Além disso, apesar de problemas de controle ótimo estarem bem consolidados do ponto de vista teórico, sua solução numérica ainda é um desafio computacional. 
Casanova et al [10] apresentam um modelo do veículo bastante realista, com sete graus de liberdade. O chassi é tratado como um corpo rígido com três graus de liberdade e as rodas são incluídas podendo cada uma girar em relação ao chassi no eixo de rolagem, adicionando mais quatro graus de liberdade ao modelo. Este é o modelo do veículo mais completo para este propósito encontrado na pesquisa bibliográfica. Quanto ao problema de otimização, Casanova et al [10] divide a pista em pequenos trechos e garante a continuidade da trajetória aplicando as devidas condições iniciais para cada trecho. A função objetivo é o tempo total de todos os trechos e as restrições descrevem os limites da pista e de tração do veículo. O problema de tempo mínimo é resolvido utilizando-se o algoritmo Sequential Quadratic Programming, da biblioteca Optimization Toolbox do Matlab ${ }^{\circledR}$. Com os resultados, é feita uma análise de como a inércia do veículo no ângulo de navegação (yaw) afeta a trajetória de mínimo tempo. É importante ressaltar que outra importante contribuição deste artigo para esta dissertação foi a definição das restrições geométricas utilizando duas variáveis: a posição ao longo da linha central da pista e a posição lateral em relação a mesma. Na sua tese de doutorado, Casanova [11] estuda a utilização de outros métodos na solução do problema de controle ótimo. Em ambos os trabalhos, a trajetória ótima obtida é comparada com trajetórias reconstruídas através de instrumentação embarcada no veículo, feitas pelo próprio Casanova et al [12].

Simon et al [1] e Cossalter et al [13] também modelam o problema de trajetória de tempo mínimo entre dois pontos fixos como um problema de controle ótimo. Apesar de o veículo estudado ser uma motocicleta, muito foi aprendido com o modelo de otimização utilizado. A função objetivo é modelada como a distância total percorrida, de forma que, para um período de tempo já definido, quanto mais curto o percurso, mais perto do ótimo está. As restrições de tração e frenagem e de limites geométricos da pista são acrescentados como penalidades na função objetivo, ponderadas por coeficientes multiplicativos ajustados experimentalmente. O problema então é resolvido como um problema de minimização com restrições de fronteira. Os resultados mostram que a motocicleta consegue atingir altas velocidades longitudinais, através da redução da aceleração lateral.

Em Zhang et al [14], a modelagem em controle ótimo é utilizada para solucionar o problema de melhor perfil de velocidade. Utilizando dinâmica 
inversa de veículos, o problema de velocidade é descrito como um problema de tempo mínimo e são avaliados os resultados para diferentes tipos de trajetória. $\mathrm{O}$ problema com os resultados obtidos é que se baseiam na solução bang-bang de um problema de controle ótimo, onde, para se obter um melhor índice de desempenho, a entrada deve ser variada entre o valor máximo permitido e o valor mínimo algumas vezes ao longo da trajetória, mas sempre aplicando a força máxima em um sentido ou em outro. Neste caso, ou o piloto está aplicando aceleração máxima ou frenagem máxima. Apesar da solução bang-bang ser reconhecida teoricamente como a mais simples para o problema de controle ótimo de mínimo tempo, não descreve de forma realista o movimento de um veículo ao longo de uma pista de corrida.

Quanto à aplicação de polinômios de Hermite na concatenação de trajetórias ótimas de curvas independentes, não foram achados trabalhos publicados utilizando esta metodologia. A utilização mais comum das curvas de Hermite se dá na área de computação gráfica, como em Rogers e Adams [15] e Azevedo e Conci [16].

\subsection{Estrutura da dissertação}

No capítulo 2 é apresentada a modelagem do veículo utilizada neste trabalho. Esta modelagem vai influenciar em como serão impostas as restrições dinâmicas no processo de otimização de trajetória. O modelo considerado adequado para o processo de otimização é testado e validado através de simulações no Matlab ${ }^{\circledR}$.

No capítulo 3 é apresentado o problema de otimização que consiste em calcular as trajetórias ótimas para cada trecho curvilíneo da pista individualmente. É a partir destas curvas que será desenvolvido o algoritmo de concatenação para se obter a trajetória de menor tempo. Também são apresentados os resultados do cálculo das trajetórias ótimas individuais para as pistas de teste.

No capítulo 4 são apresentadas as curvas estudadas para aplicação no processo de concatenação dos trechos ótimos individuais. Para cada curva estão apresentadas suas características e equações e ainda, são discutidas as vantagens e desvantagens na utilização de cada uma. 
No capítulo 5 é apresentado o desenvolvimento do algoritmo de concatenação, sua aplicação nas pistas de teste e a discussão dos resultados obtidos a partir deste método.

No capítulo 6 são introduzidos os conceitos teóricos de controle ótimo e a modelagem do problema de ótimo.

No capítulo 7 são apresentadas as conclusões do trabalho e sugestões para trabalhos futuros.

No capítulo 8 são apresentadas as referências bibliográficas utilizadas para o desenvolvimento desta dissertação. 


\section{Modelagem do Veículo}

A modelagem das características dinâmicas de um veículo de corrida envolvem diversas variáveis e equações, dependendo da complexidade do modelo desenvolvido. Em Casanova et al [10], foi desenvolvido um modelo completo do veículo, incluindo os 7 graus de liberdade, com o intuito de analisar a influência de uma variável específica na trajetória de menor tempo do veículo, o ângulo de elevação (yaw angle). Para outras aplicações, no entanto, basta um modelo mais simples, representado por apenas 4 equações, como o que será apresentado neste capítulo.

Para este projeto, o veículo será modelado como uma partícula orientada, de forma mais simplificada, mas que inclui as capacidades de tração, frenagem e aceleração normal típicas de um veículo terrestre de competição. A Figura 2.1 ilustra as variáveis incluídas no modelo de um veículo de competição.

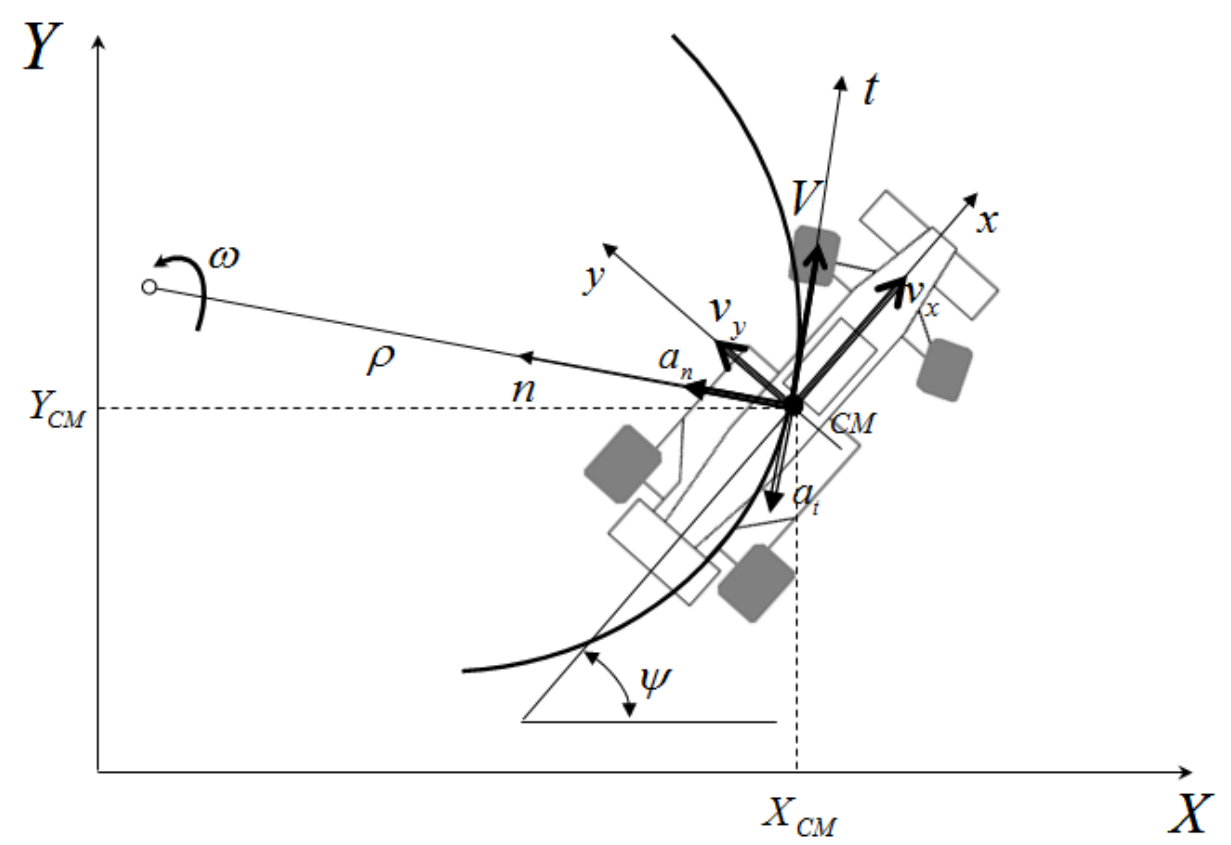

Figura 2.1: Representação do veículo.

Na Figura 2.1, está representado o referencial global do sistema XY, e o referencial solidário ao veículo $x y$. A direção tangencial da trajetória do veículo está representada pelo vetor $t$ e a direção radial pelo vetor $n$. Apesar de ser um 
modelo simplificado, que não considera de fato algumas características do comportamento dinâmico do veículo, ele é suficiente para determinar a trajetória ótima desejada, especialmente porque representa muito bem suas caraterísticas geométricas, incluindo as limitações do veículo, bem como as acelerações máximas admissíveis.

\subsection{Equações diferenciais do modelo}

As equações diferenciais que compõem o modelo do veículo podem ser obtidas facilmente a partir das equações dinâmicas que descrevem um movimento acelerado. Primeiramente, descrevem-se as acelerações tangencial e normal, em seguida, define-se o ângulo do veículo em relação à pista $\psi$ (psi) e, por fim, as coordenadas da trajetória do veículo $\mathrm{X}$ e $\mathrm{Y}$. As equações diferenciais que descrevem essas variáveis estão apresentadas em (2.1)-(2.2)-(2.3)-(2.4).

$\frac{d V}{d t}=a_{t} \rightarrow V=\int a_{t} d t+V(0)$

$a_{n}=\frac{V^{2}}{\rho}=V \cdot \frac{V}{\rho}=V \cdot \omega \rightarrow \omega=\frac{a_{n}}{V}$

$\frac{d \psi}{d t}=\omega=\frac{a_{n}}{V} \rightarrow \psi=\int \frac{a_{n}}{V} d t+\psi(0)$

$\frac{d X}{d t}=V \cos (\psi) \rightarrow X=\int V \cos (\psi) d t+X(0)$

$\frac{d Y}{d t}=V \operatorname{sen}(\psi) \rightarrow Y=\int V \operatorname{sen}(\psi) d t+Y(0)$

Como as equações que descrevem o movimento da partícula no referencial XY são não lineares, isso representará alguns desafios na manipulação e solução das equações diferenciais, especialmente no desenvolvimento do modelo de controle ótimo, como será discutido adiante neste trabalho. 


\subsection{Diagrama de blocos e simulações}

A montagem do diagrama de blocos das equações constituintes de um modelo dinâmico é muito útil para visualizar com mais facilidade as entradas e saídas do sistema, bem como as dependências entre as variáveis envolvidas. Além disso, com o diagrama de blocos do sistema, simulações podem ser executadas e analisadas mais facilmente, utilizando um software apropriado. O diagrama da Figura 2.2 representa as equações diferenciais do modelo proposto em um diagrama de blocos. Observe que a partir deste modelo, tendo como entradas as acelerações tangencial e normal do trajeto, é possível obter como saída a posição $(\mathrm{x}, \mathrm{y})$ do veículo.

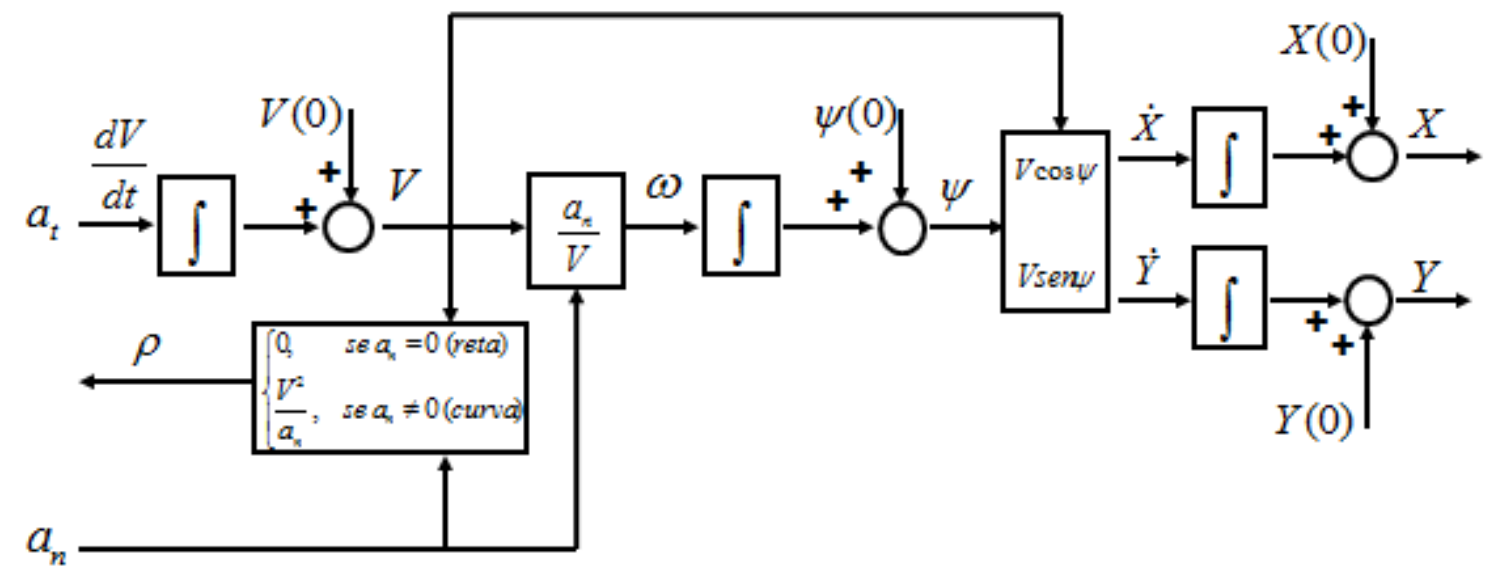

Figura 2.2: Diagrama de blocos.

Para validar o modelo proposto, o diagrama de blocos da Figura 2.2 foi montado no Simulink/Matlab ${ }^{\circledR}$ e foram feitas simulações para algumas combinações de valores constantes de aceleração tangencial e normal, e depois para valores não constantes. Os resultados de $X(t), Y(t), \rho(t)$ e $\psi(t)$ foram discutidos e analisados de acordo com a sua coerência em relação aos dados de entrada. O diagrama de blocos montado no Matlab ${ }^{\circledR}$ está representado na Figura 2.3. Este foi montado apenas com blocos simples de operações matemáticas e uma operação lógica para garantir que o cálculo de $\rho(t)$ só fosse executado para valores de aceleração normal diferentes de zero, caso contrário, a conta $\rho=\frac{V^{2}}{a_{n}}$ resultaria em uma indeterminação matemática. 


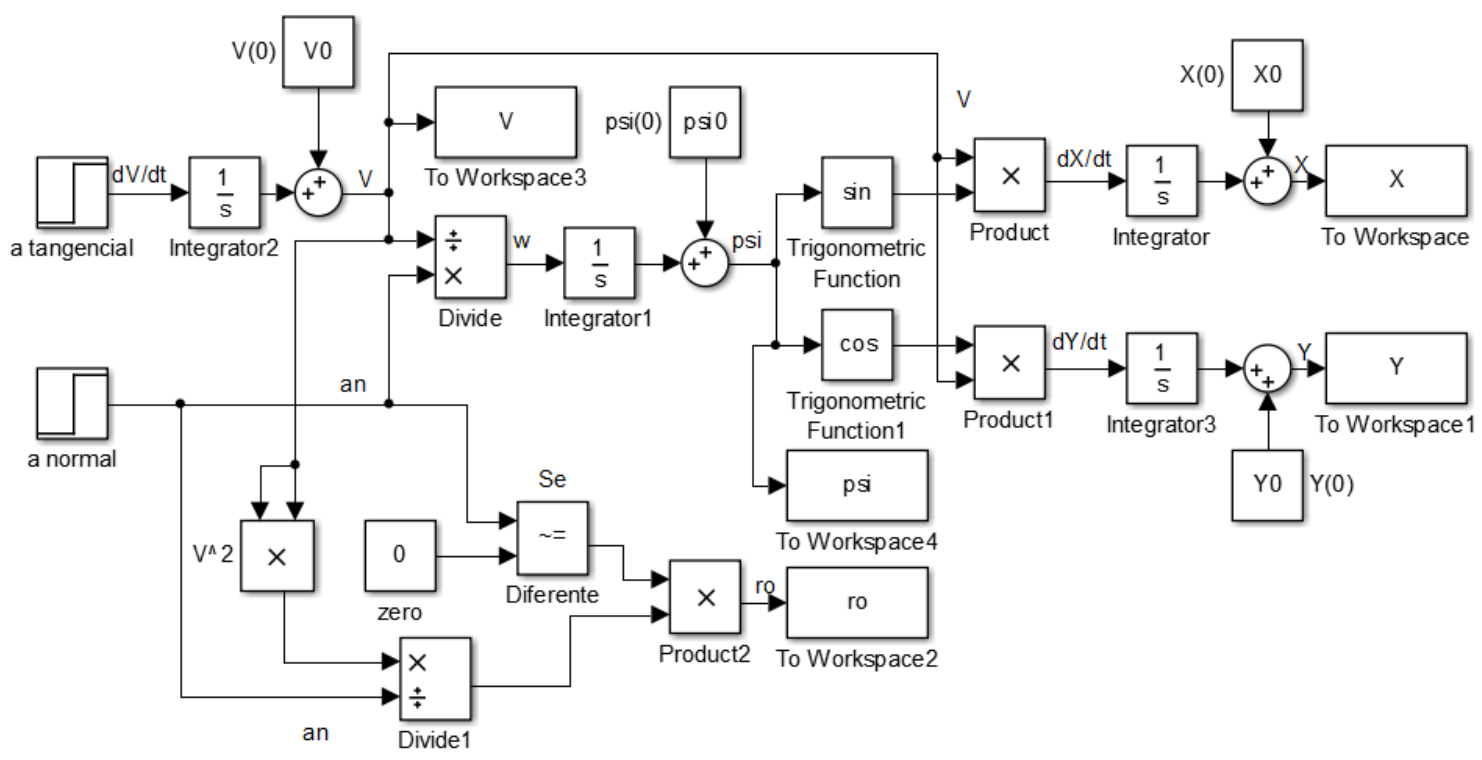

Figura 2.3: Diagrama de blocos do modelo no Simulink ${ }^{\circledR}$.

Os resultados obtidos comprovam que o modelo descreve corretamente o movimento de um veículo. A Figura 2.4 mostra a trajetória, a velocidade, o ângulo e o raio obtidos para as seguintes entradas:

$$
x_{0}=y_{0}=\psi_{0}=0, v_{0}=10 \mathrm{~m} / \mathrm{s}, a_{n}=9.81 \mathrm{~m} / \mathrm{s}^{2}, a_{t}=0 \mathrm{~m} / \mathrm{s}^{2}
$$
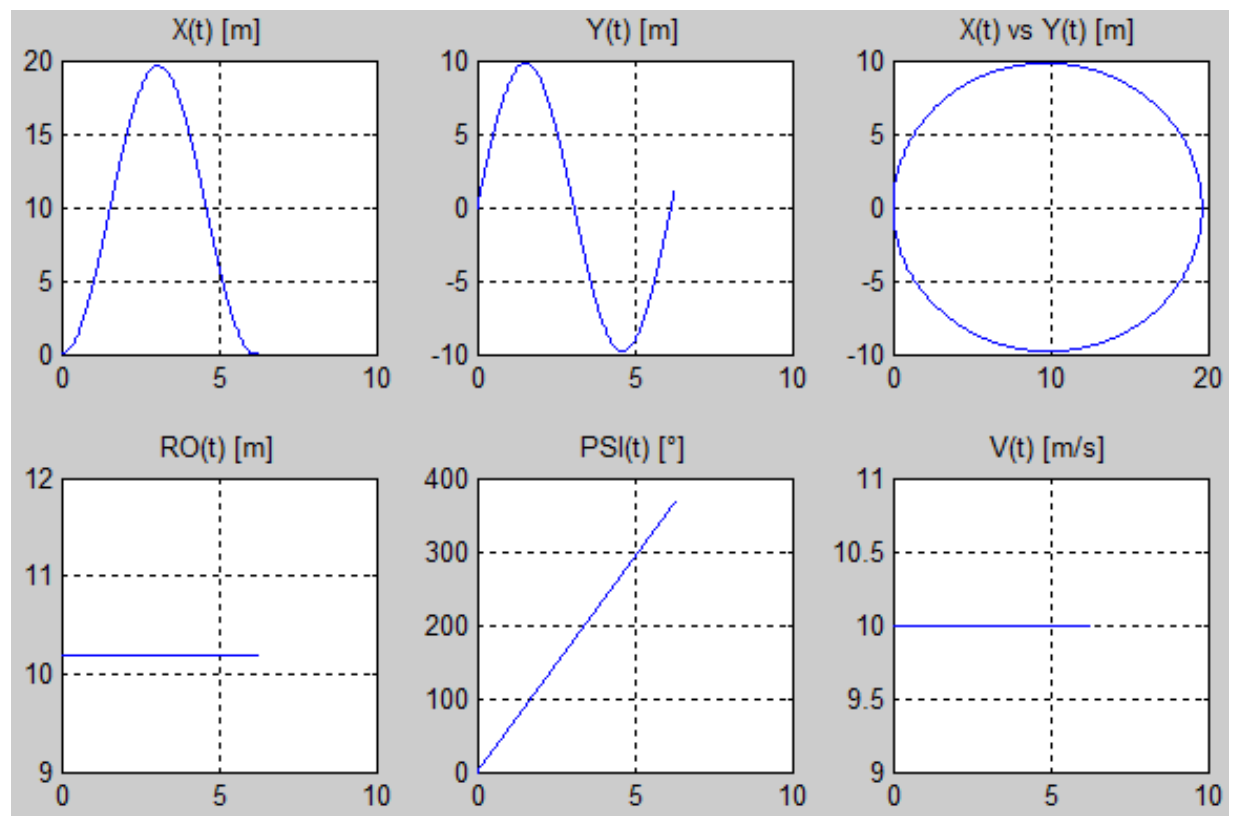

Figura 2.4: Resultados para $\mathrm{x}_{0}=\mathrm{y}_{0}=\psi_{0}=0, \mathrm{v}_{0}=10 \mathrm{~m} / \mathrm{s}, \mathrm{a}_{\mathrm{n}}=9,81 \mathrm{~m} / \mathrm{s}^{2}, \mathrm{a}_{\mathrm{t}}=0 \mathrm{~m} / \mathrm{s}^{2}$.

Com essa escolha de parâmetros espera-se um movimento circular uniforme com velocidade constante igual a $v_{0}$ e também raio constante. Observe na Figura 2.4 que o resultado obtido na simulação está de acordo com o esperado. 
Na Figura 2.5, são apresentados os resultados da simulação com outro conjunto de entradas, mostrado a seguir:

$$
x_{0}=y_{0}=\psi_{0}=0, v_{0}=2 \mathrm{~m} / \mathrm{s}, a_{n}=9.81 \mathrm{~m} / \mathrm{s}^{2}, a_{t}=0.5 \cdot 9.81 \mathrm{~m} / \mathrm{s}^{2}
$$
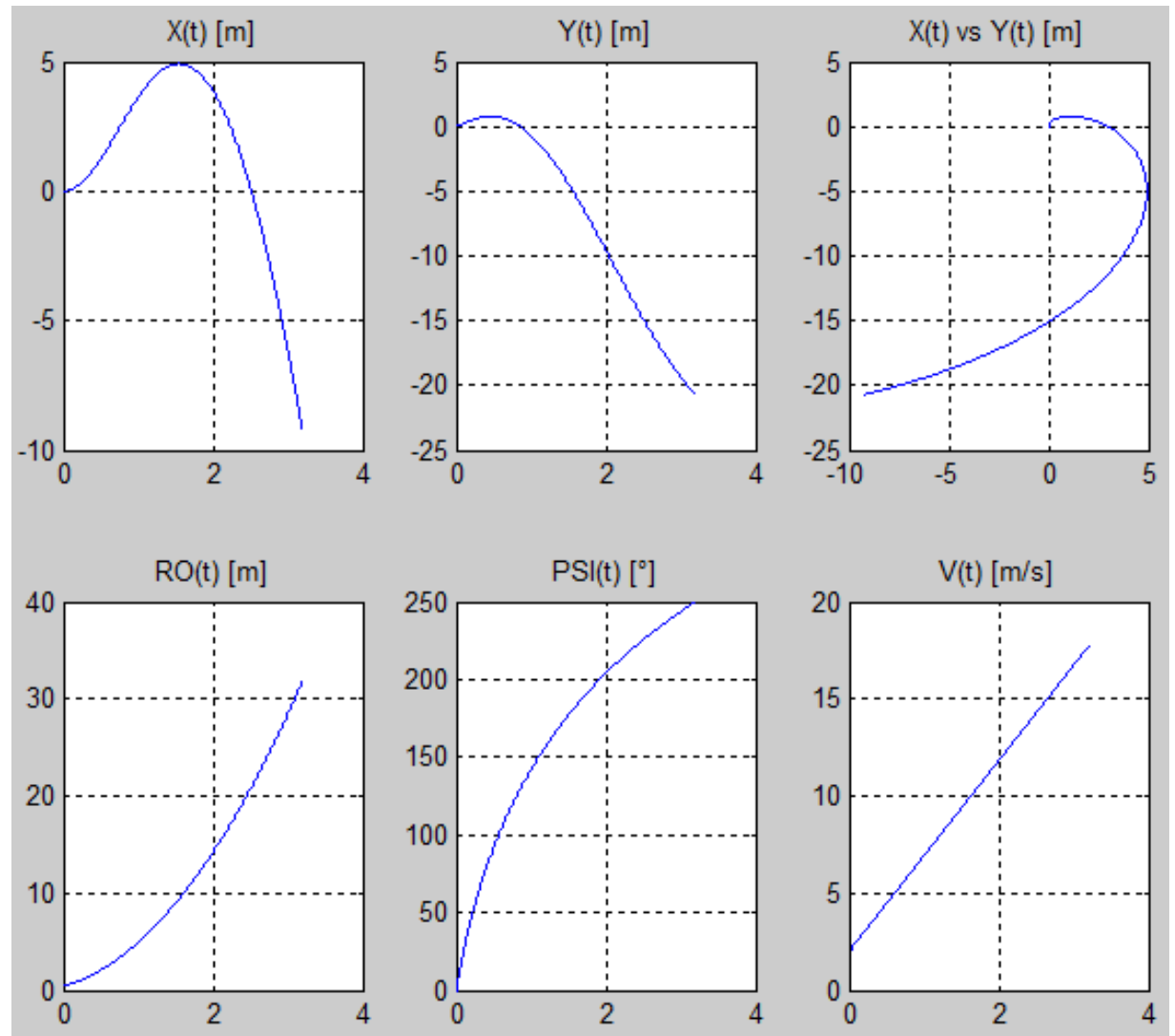

Figura 2.5: Resultados para $\mathrm{x}_{0}=\mathrm{y}_{0}=\psi_{0}=0, \mathrm{v}_{0}=10 \mathrm{~m} / \mathrm{s}, \mathrm{a}_{\mathrm{n}}=9,81 \mathrm{~m} / \mathrm{s}^{2}, \mathrm{a}_{\mathrm{t}}=0,5.9,81 \mathrm{~m} / \mathrm{s}^{2}$.

Observa-se que a trajetória resultante consiste em uma curva de raio variável e velocidade tangencial variando linearmente no tempo, uma vez que a aceleração tangencial não é nula. Ao invés de uma trajetória circular, têm-se um movimento próximo a uma espiral, pois a velocidade tangencial aumenta no tempo, fazendo com que o veículo saia na sua trajetória circular até que, no limite, o raio tenda a infinito.

É interessante também avaliar a influência das acelerações tangencial e normal na trajetória obtida pelo modelo. Ambas as acelerações serão variáveis importantes no processo de otimização e deverão ser definidas com base em restrições dinâmicas inerentes ao veículo e à pista escolhidos para os testes. Já foi mostrado que, para valores de acelerações constantes, a trajetória obtida se aproxima de uma espiral. Foi realizada então, uma simulação para diversos valores de aceleração tangencial e normal, apresentados nas Figuras 2.6 e 2.7. 


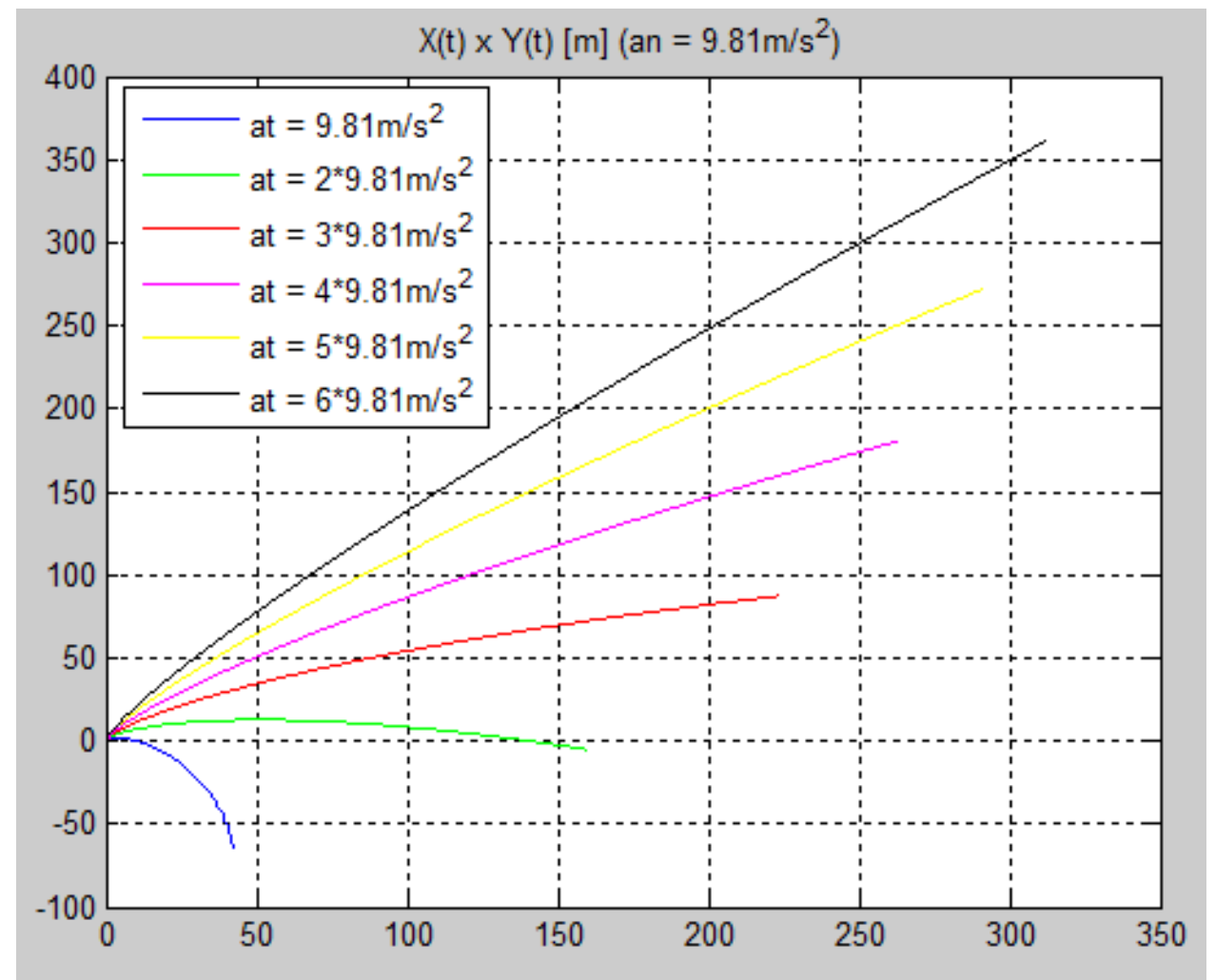

Figura 2.6: Simulação para diversos valores de aceleração tangencial.

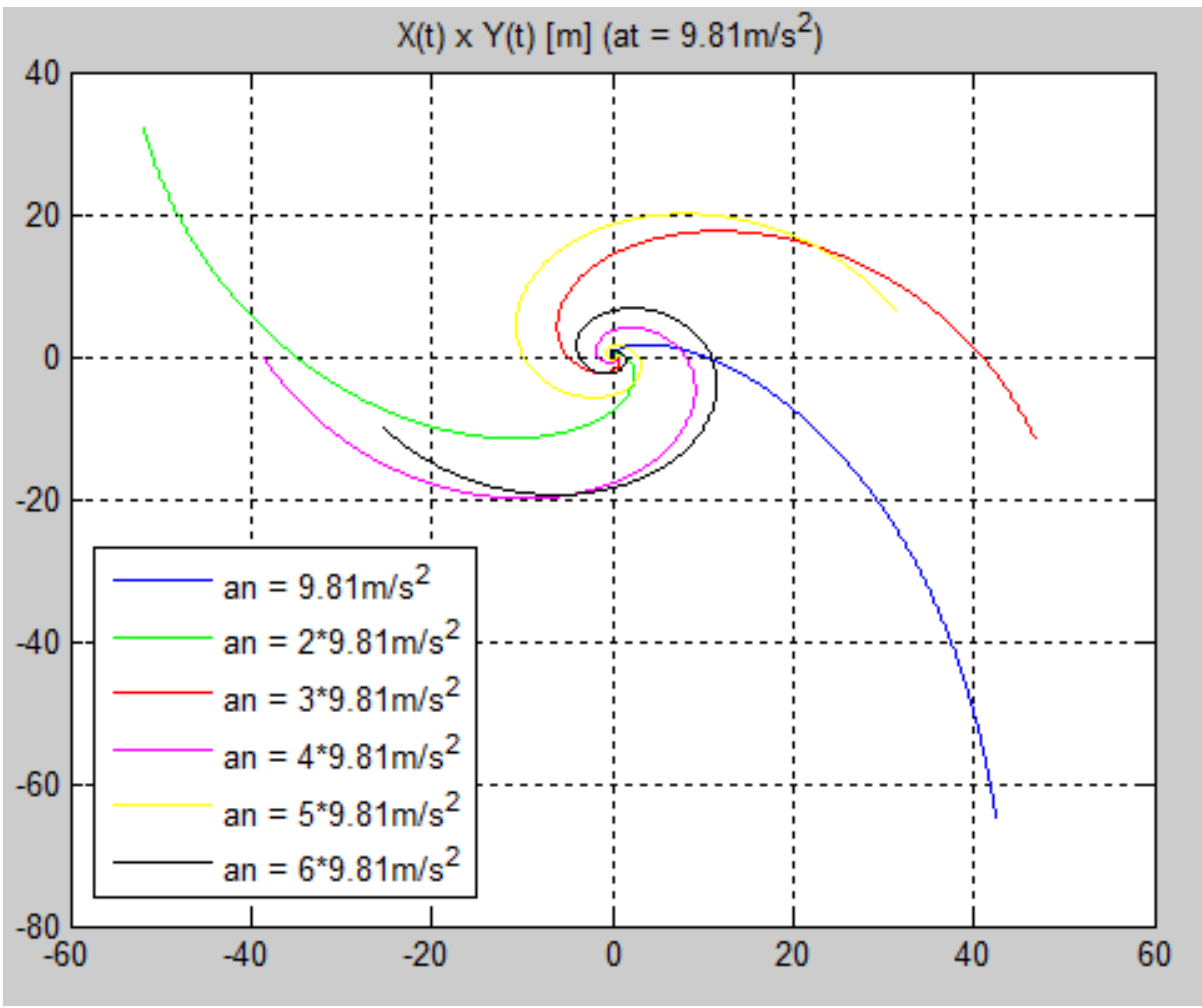

Figura 2.7: Simulação para diversos valores de aceleração normal.

$\mathrm{Na}$ Figura 2.6 manteve-se o valor da aceleração normal constante em $9,81 \mathrm{~m} / \mathrm{s}^{2}$ e variou-se as acelerações tangenciais de $1 \mathrm{~g}$ até $6 \mathrm{~g}$. Já na Figura 2.7 foi 
feito o oposto, a aceleração tangencial permaneceu constante em 9,81m/s $\mathrm{s}$ e variou-se a aceleração normal. Observe que, quanto maior o valor da aceleração tangencial em relação à aceleração normal, menor é a curvatura da trajetória, se aproximando cada vez mais de uma reta. O contrário acontece para grandes valores de aceleração normal, onde a curvatura aumenta à medida que a aceleração aumenta. Para o processo de otimização, as acelerações deverão variar de forma a compor uma curva dentro das restrições geométricas impostas.

Para complementar a análise, foram simulados os resultados para valores de acelerações tangencial e normal não constantes. Essa é uma abordagem importante para análise, pois se espera que nos trechos concatenados as acelerações não se mantenham constantes, de forma que possam representar com mais precisão o movimento real de um veículo de corrida nas condições impostas.

Para o primeiro caso, considere o perfil de aceleração tangencial como uma exponencial negativa de forma que, para $t=0, a_{t}(t)=a_{0}$ e para $t \rightarrow \infty$, $a_{t}(t)=0$, representada na Equação 2.5.

$$
a_{t}(t)=a_{0} \cdot e^{-\frac{t}{\tau_{0}}}
$$

Onde $\tau_{0}$ é uma constante de tempo que determina o quão rápido é o decrescimento da função e $a_{0}$ é o valor máximo de aceleração tangencial.

Para definir o perfil de aceleração normal, foi definida a curvatura da trajetória, de forma que a aceleração normal fosse calculada por meio da relação entre a velocidade total da trajetória e a curvatura. A relação entre a curvatura $\kappa(\mathrm{t})$ e o raio de uma trajetória é:

$$
\kappa(t)=\frac{1}{\rho(t)}
$$

Logo,

$$
a_{n}=\frac{V^{2}}{\rho}=V^{2} \cdot \kappa(t)
$$


Para os testes, considere uma curvatura linearmente crescente, como mostra a Equação 2.8.

$\kappa(t)=\kappa_{0} \cdot t$

Onde $\kappa_{0}$, como coeficiente linear da função, indica a taxa de crescimento da curvatura no tempo.

Para se ajustar ao cálculo da aceleração normal, foi montado um novo diagrama de blocos, onde a entrada do sistema é a curvatura ao invés da aceleração normal. O novo diagrama está representado na Figura 2.8.

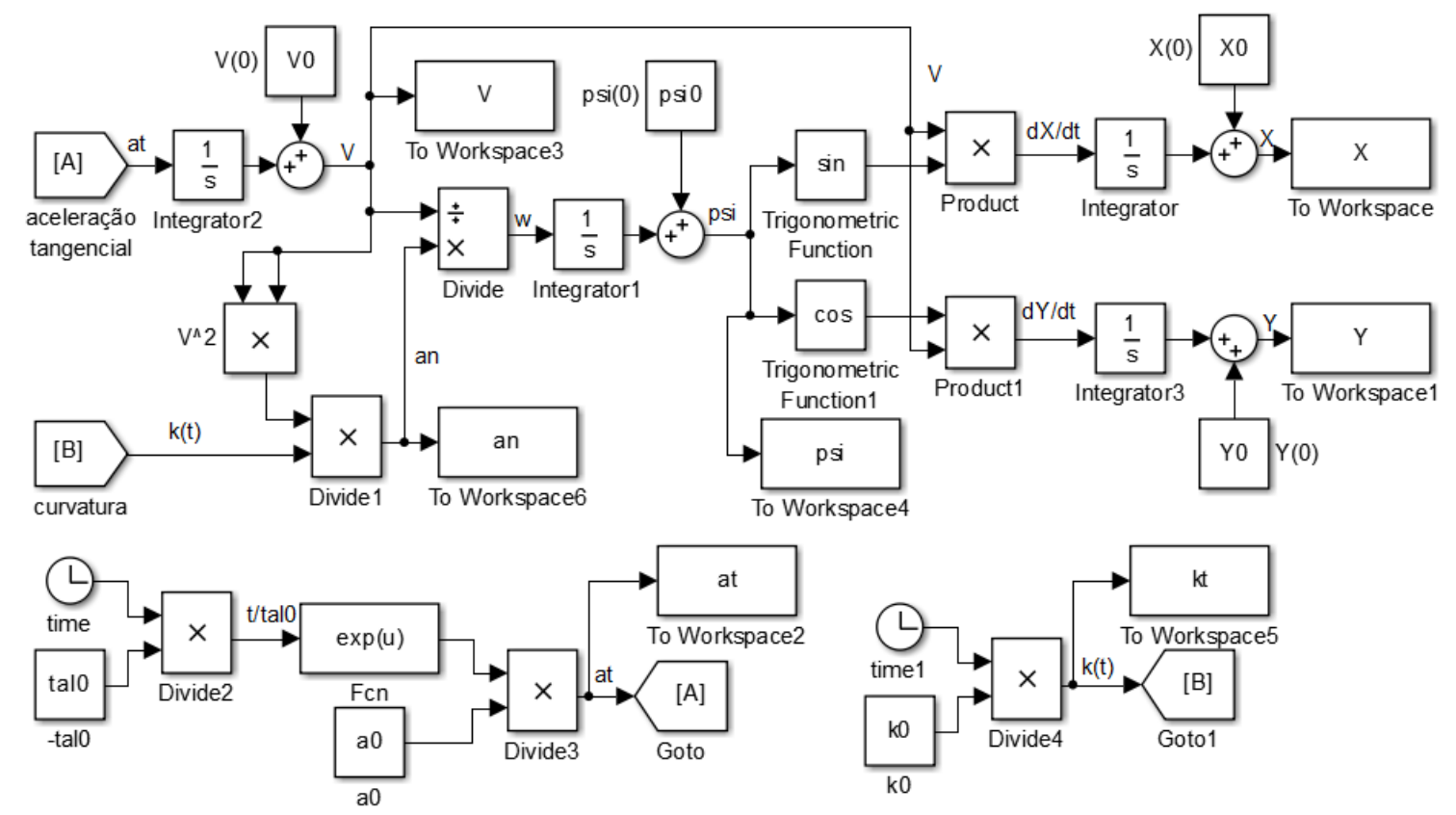

Figura 2.8: Diagrama de blocos para aceleração variável no tempo.

A simulação foi feita com os seguintes parâmetros:

$a_{0}=4.905 \mathrm{~m} / \mathrm{s}^{2}, \kappa_{0}=2 \mathrm{~m}^{-1}, \tau_{0}=1 \mathrm{~s}, V_{0}=2 \mathrm{~m} / \mathrm{s}, X_{0}=Y_{0}=\psi_{0}=0$

Os resultados obtidos estão representados na Figura 2.9 e comprovam a coerência do modelo. Como a curvatura foi definida crescente no tempo, o raio decresce com a mesma proporção. Observe na Figura 2.9 que a trajetória se aproxima de uma clotoide, com o raio decrescente. Isso é esperado, já que uma curvatura linear é a característica mais importante de uma clotoide. A velocidade tangencial cresce exponencialmente, a partir da velocidade inicial $V_{0}$ e atinge um valor limite, para a qual a aceleração tangencial chega muito perto de zero. 

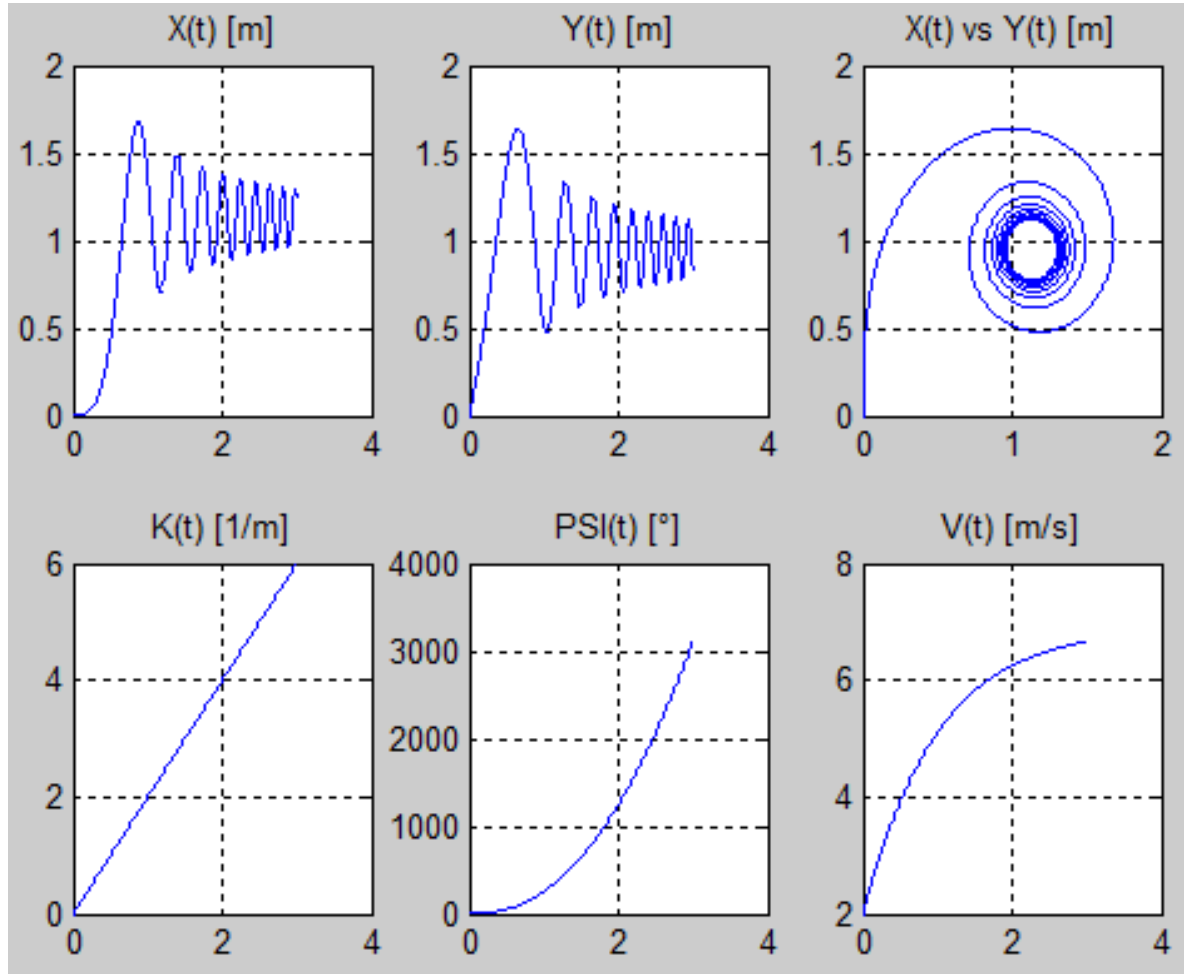

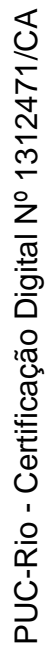

Figura 2.9: Resultados para aceleração tangencial exponencial.

Os perfis de aceleração tangencial e normal utilizados como entrada para o modelo estão representados na Figura 2.10.

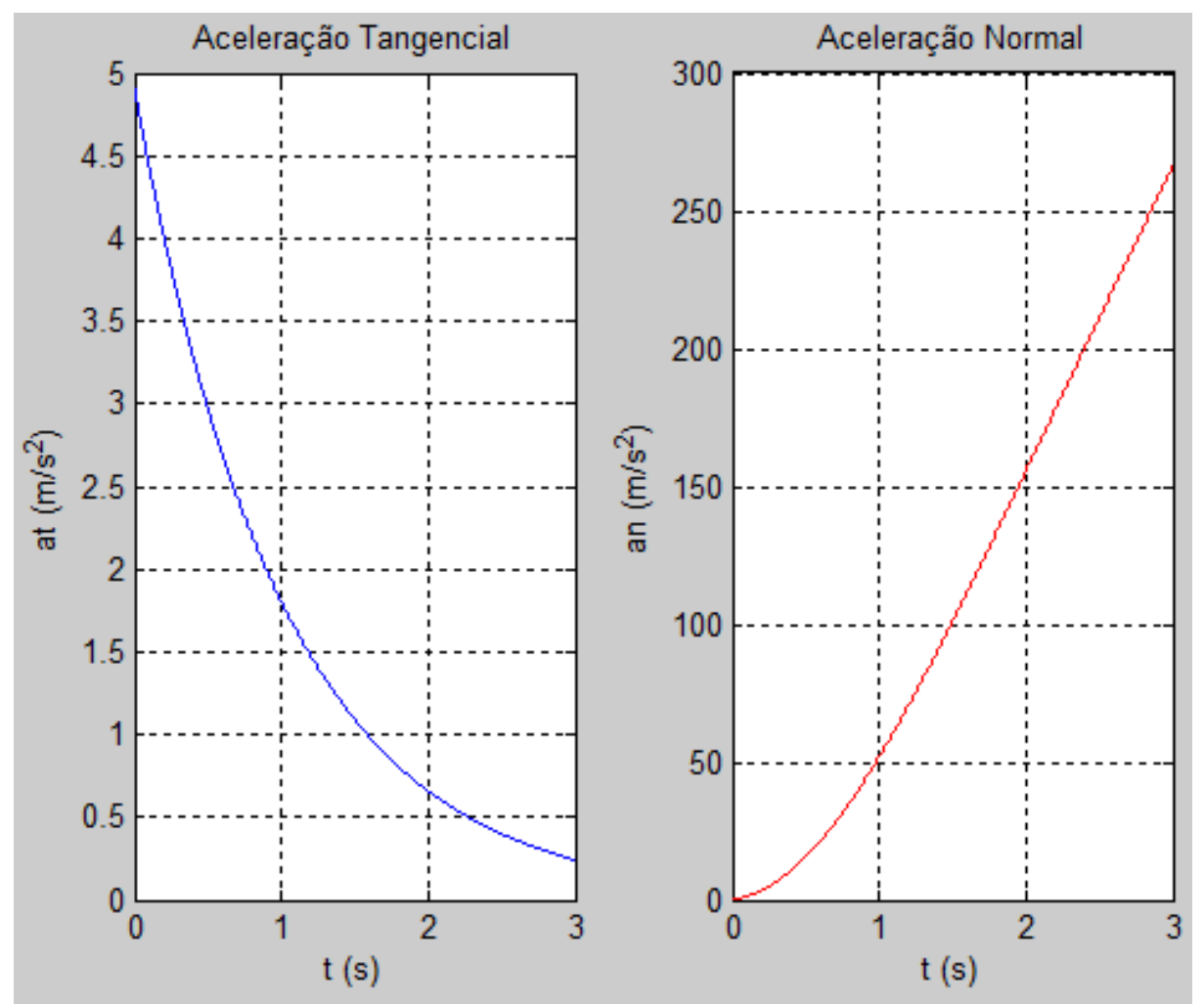

Figura 2.10: Resultados de aceleração normal e tangencial. 
A aceleração normal atinge uma relação aproximadamente linear depois de $\tau_{0}$ segundos. Depois deste ponto, a velocidade tangencial se aproxima de um valor constante e como o raio decresce linearmente, a aceleração normal, que é função dessas duas variáveis, apresenta uma variação linear também.

\subsection{Problema de otimização}

Uma vez proposto e validado o modelo do veículo, é necessário definir o problema de otimização que consiste em obter a trajetória de menor tempo. A função objetivo será o próprio tempo de percurso, em função da velocidade e do espaço percorrido. As restrições são de dois tipos: geométricas, para garantir que a trajetória ótima obtida esteja dentro dos limites da pista, e dinâmicas, para limitar os valores de aceleração do veículo. Estas restrições são características do veículo utilizado para o trajeto. O modelo matemático do problema de otimização está descrito na Equação 2.9.

$$
\left\{\begin{array}{cl} 
& \min \quad \Delta t=\frac{\Delta \mathrm{s}}{\Delta V} \\
\text { s.t. } & \sqrt{a_{t}^{2}+a_{n}^{2}} \leq a_{\text {máx }} \\
& (X, Y) \in\left(X_{\text {pista }}, Y_{\text {pista }}\right)
\end{array}\right.
$$

Para garantir que as acelerações obtidas estejam satisfazendo os limites impostos, elas devem estar dentro do chamado Círculo de Aderência. Trata-se de um círculo que define as capacidades máximas de aceleração centrípeta, frenagem e tração do veículo com base nas suas limitações físicas de aderência à pista e o limite de tração do veículo a ser estudado [4], apresentado com detalhes na seção seguinte.

Tão importante quanto preservar os limites de aceleração do veículo, é também respeitar os limites geométricos da pista. Estas restrições são, no entanto, complicadas de serem modeladas matematicamente. Na primeira parte da dissertação, onde serão utilizadas curvas geométricas para obtenção das trajetórias ótimas, a restrição será descrita de forma que possa ser verificada em apenas um ponto. Este ponto é escolhido tal que, se este ponto estiver dentro da restrição, toda curva estará. 
Já na segunda parte, quando o problema é modelado como um problema de controle ótimo, a restrição geométrica é incluída se utilizando de uma mudança de coordenadas, onde uma coordenada indica a variação de posição ao longo da trajetória central da pista e a outra, o deslocamento normal em relação à trajetória.

\subsubsection{Círculo de Aderência}

Este círculo é de extrema importância na análise do comportamento dinâmico do veículo e no estudo da trajetória do veículo. Ele representa graficamente os limites de aceleração que podem ser impostas ao veículo para que ele não perca a estabilidade e deslize. A Figura 2.11 mostra as medidas das acelerações longitudinais e laterais de um veículo de corrida, obtidas através de instrumentação eletrônica embarcada no veículo, onde o eixo horizontal representa a aceleração normal (centrípeta) e o eixo vertical representa a aceleração longitudinal tangencial à trajetória.

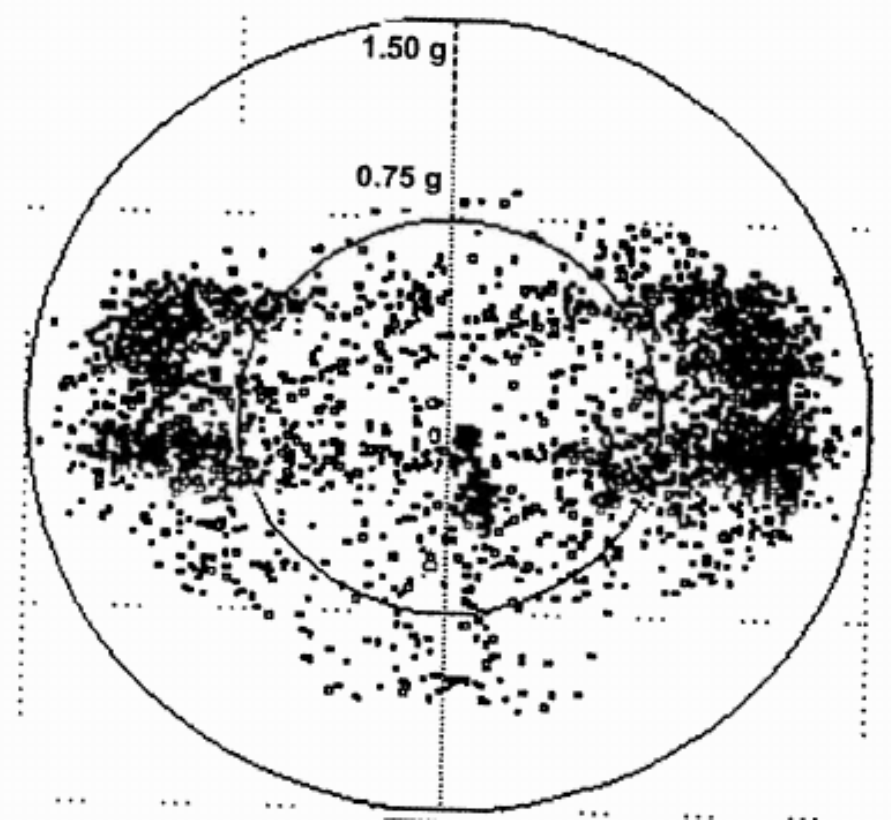

Figura 2.11: Medidas de aceleração longitudinal e normal de um veículo de corrida [3].

Observe que todas as acelerações aconteceram dentro de um círculo limite e que a aceleração tangencial de tração máxima executada pelo condutor é menor que a aceleração normal máxima. Isso acontece porque, como todos os veículos possuem potência limitada, o limite para a aceleração longitudinal positiva é 
normalmente menor que os limites de aceleração normal, que são limitados apenas pelo coeficiente de aderência na interface pneu-pista, fazendo com que o círculo de aderência não seja exatamente circular [3]. Esse círculo limite é o círculo de aderência.

Além disso, o limite de aceleração longitudinal negativa também é maior que o de aceleração positiva, pois a capacidade de frenagem de um veículo de corrida deve ser maior que a de tração, por motivos de segurança. Com base nessas informações, a Figura 2.12 mostra o como é montado tipicamente um círculo de aderência. Os limites podem variar de acordo com o coeficiente de atrito da pista, potência máxima do motor, pneus utilizados, entre outros fatores.

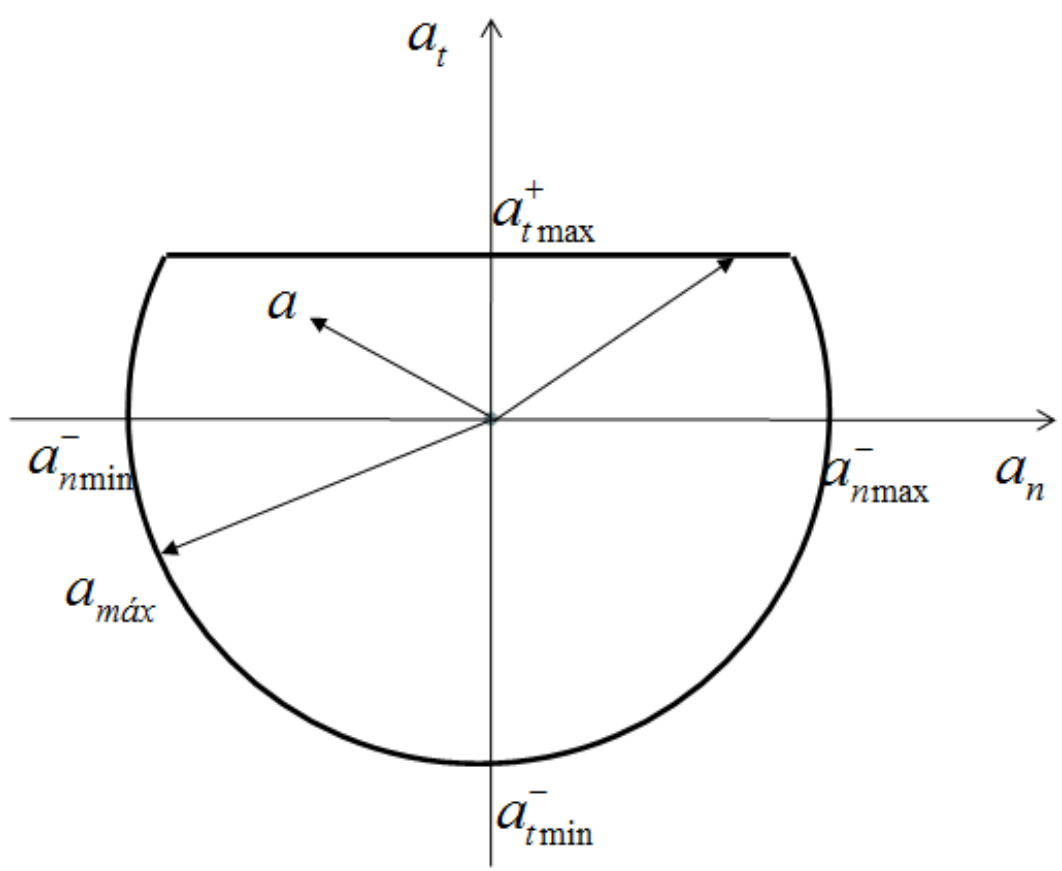

Figura 2.12: Círculo de aderência.

É importante que as acelerações obtidas no processo de otimização estejam dentro do círculo de aderência, pois é esta informação que estabelece a possibilidade física de execução da trajetória obtida, mantendo a estabilidade e controle do veículo, especialmente se tratando de veículos de corrida, onde o objetivo é sempre manter-se no limite da sua capacidade. Para estes casos, o limite de desempenho deve estar bem definido para que não ocorra instabilidade ou perda de controle do veículo pelo condutor. 
A Figura 2.13 ilustra como o círculo de aderência mostra as capacidades máximas de aceleração e desaceleração do veículo combinadas nas manobras curvilíneas. Primeiramente, o veículo desacelera ao entrar na curva e à medida que a curva é sendo feita, a desaceleração diminui devido ao surgimento da força lateral. No ápice da curva, a aceleração normal é máxima e não há mais desaceleração. Deste ponto em diante, o condutor passa a acelerar, até que na saída da curva a aceleração de tração longitudinal é a máxima. É importante ressaltar que em uma corrida o condutor tende a fazer todas as manobras no limite de aderência para obter o melhor desempenho possível.

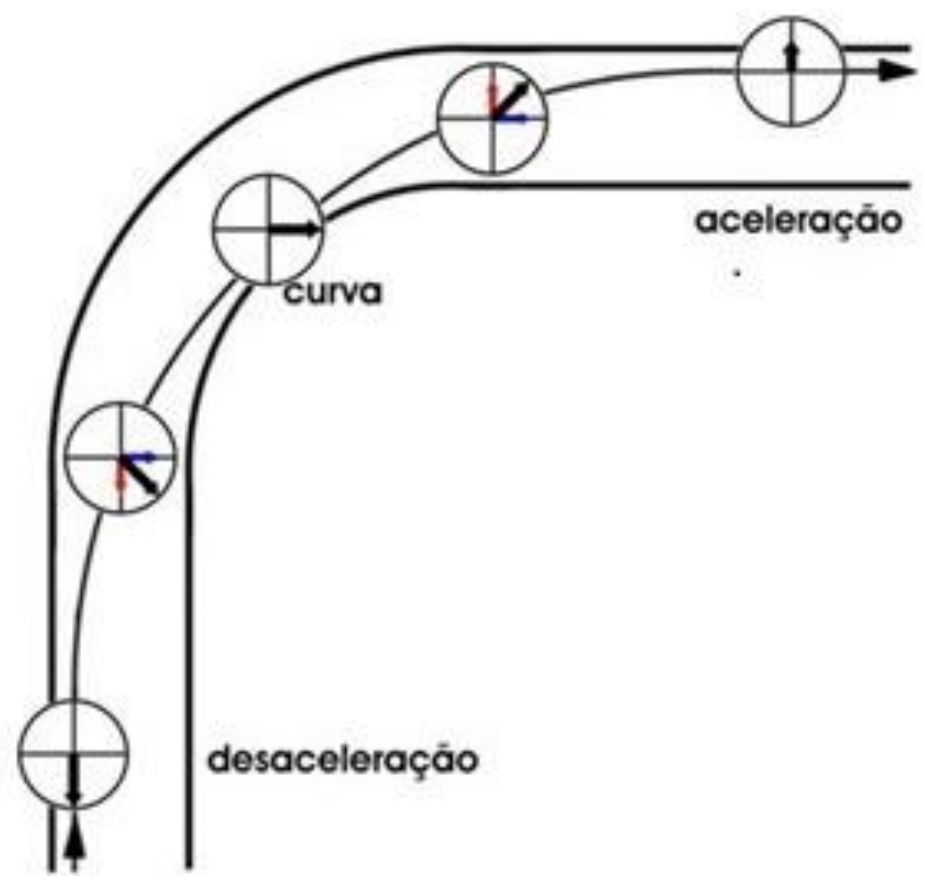

Figura 2.13: Ilustração das capacidades máximas de aceleração numa curva. 


\section{Trajetória Ótima para Curvas Independentes}

Neste capítulo, serão estudadas as trajetórias ótimas para cada curva individualmente. E, posteriormente, será estudado o processo de concatenação destas trajetórias individuais. A trajetória ótima para curvas independentes é razoavelmente simples de ser obtida, uma vez que se trata de um problema de otimização com uma solução analítica [19]. O problema de otimização consiste em obter o maior raio possível dentro dos limites geométricos da pista, considerando o ápice - ponto de maior aproximação do limite interno - no centro geométrico da curva. Desta forma, o ângulo percorrido até o ápice é a metade do arco total. A Figura 3.1 mostra as variáveis envolvidas no problema para um caso particular de uma curva de $90^{\circ}$.

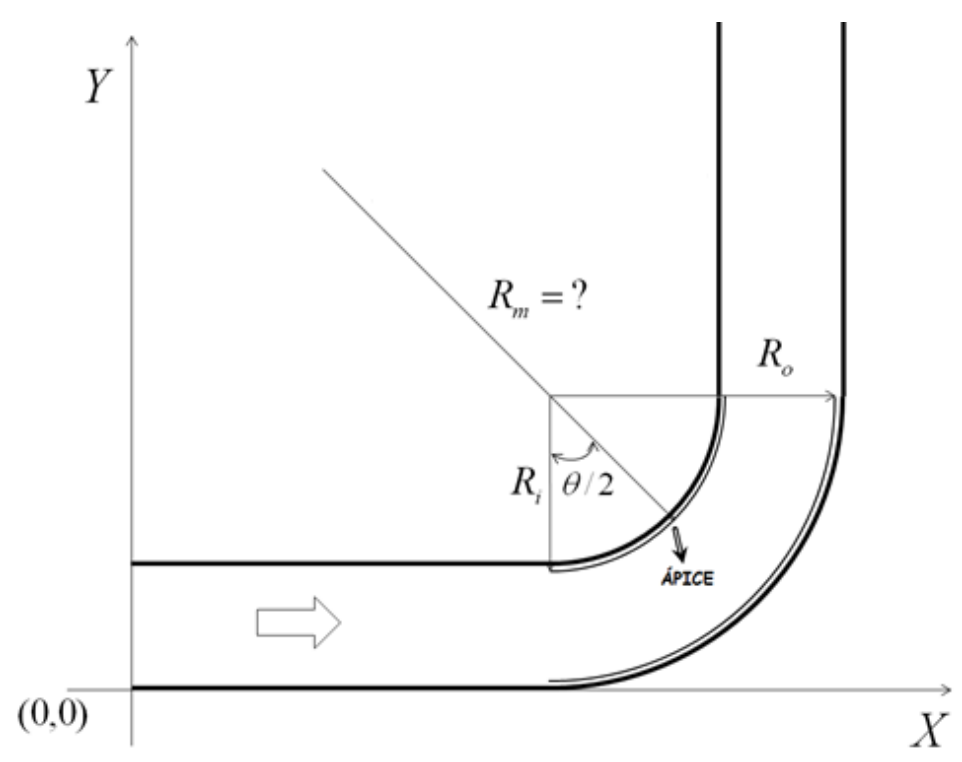

Figura 3.1: Problema de otimização para curva independente.

Na Figura 3.1, $R_{o}$ é o raio externo da pista, $R_{i}$ é o raio interno da pista e $\theta$ é o ângulo da curva. Sabe-se que a trajetória ótima para esta curva independente é um arco de circunferência e deseja-se saber qual deve ser o raio $R_{m}$. A solução para este problema é um arco com ângulo equivalente ao da curva, que deve tangenciar o ápice na largura mínima possível - determinada pelo raio interno - e ser limitado pela largura máxima admissível, determinada pelo raio externo [19]. 
Para calcular o ponto inicial e final da trajetória, basta analisar a geometria do problema a partir dos triângulos retângulos mostrados na Figura 3.2.

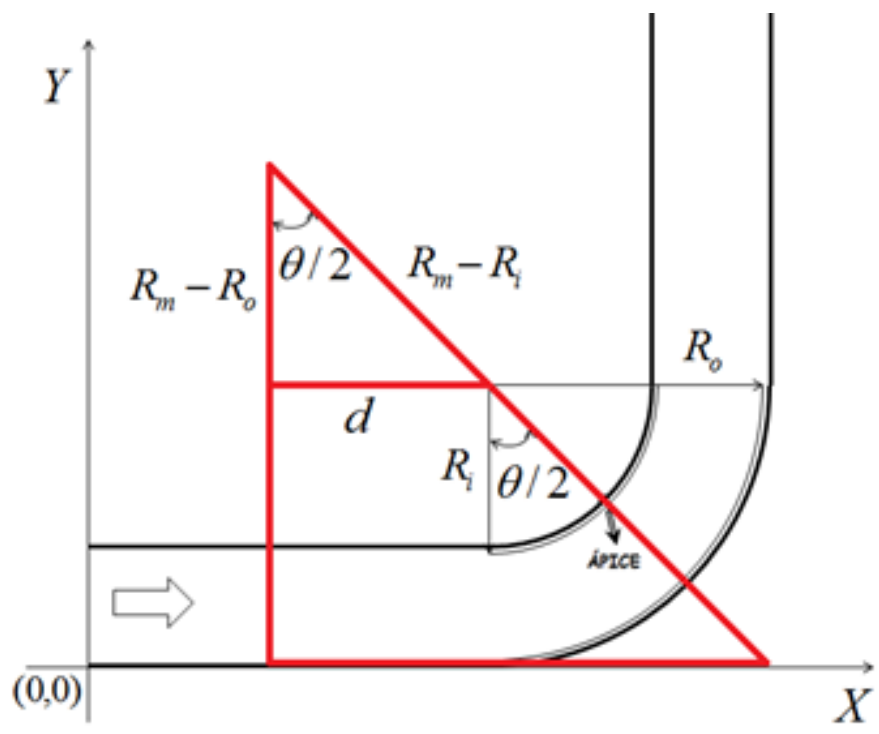

Figura 3.2: Geometria do problema.

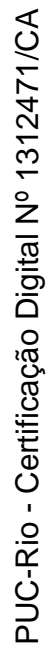

Na Figura 3.2, observe que:

$\operatorname{tg} \frac{\theta}{2}=\frac{d}{R_{m}-R_{o}} \therefore d=\left(R_{m}-R_{o}\right) \operatorname{tg} \frac{\theta}{2}$

Desta forma, estão determinados os pontos de início e fim do arco a partir do início curva da pista, como mostra a Figura 3.3.

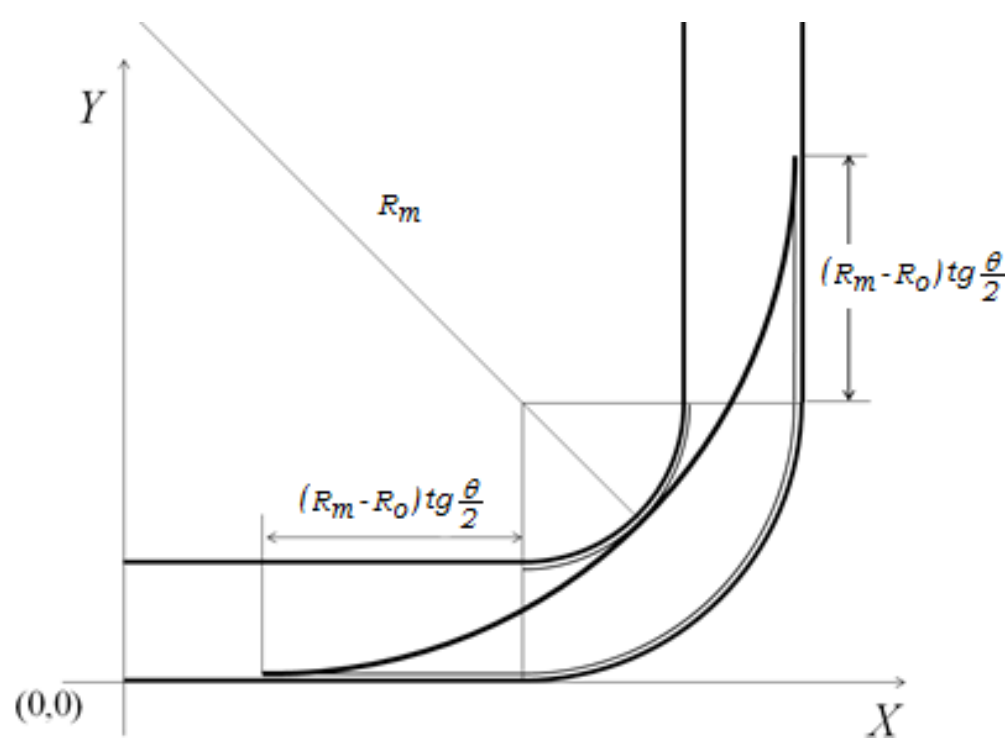

Figura 3.3: Ponto final e inicial do arco. 
A partir da Figura 3.2, também é possível calcular o valor de $R_{m}$. A Equação 3.2 mostra os cálculos efetuados utilizando as relações trigonométricas do triângulo retângulo.

$R_{m}-R_{o}=\left(R_{m}-R_{i}\right) \cos \frac{\theta}{2}$

$R_{m}\left(1-\cos \frac{\theta}{2}\right)=R_{o}-R_{i} \cos \frac{\theta}{2}$

$R_{m}=\frac{\left(R_{o}-R_{i} \cos \frac{\theta}{2}\right)}{\left(1-\cos \frac{\theta}{2}\right)}$

Uma vez feitos os cálculos, o raio $R_{m}$ e o ponto de início e fim da trajetória ótima são determinados pelas equações mostradas na Figura 3.4.

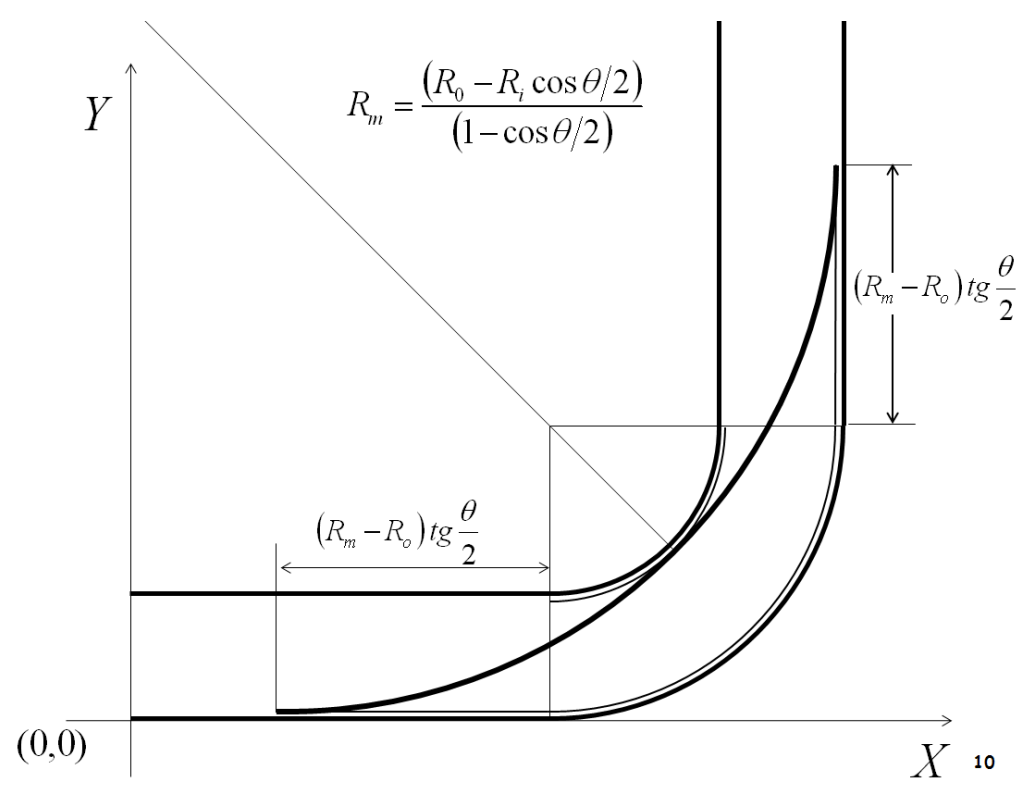

Figura 3.4: Determinação da linha de corrida para uma curva circular de $90^{\circ}$ isolada.

Apesar de a Figura 3.4 mostrar a solução para uma curva de $90^{\circ}$, essa solução é genérica para trechos curvilíneos de qualquer ângulo mudando o valor de $\theta$ na expressão para o ângulo correspondente. 


\subsection{Resultados para a pista teste}

As equações obtidas no item anterior para o traçado da trajetória ótima de uma curva independente em uma pista de corrida foram utilizadas em uma pista teste para análise dos resultados e para o desenvolvimento do algoritmo de concatenação destas trajetórias.

\subsubsection{Desenho da pista}

O desenho da pista apresentado na Figura 3.5 pode ser feito a partir de uma tabela que contenha, para cada trecho da pista, os seguintes dados: ângulo inicial, arco (se trecho curvilíneo), comprimento ou raio, ponto inicial x, e ponto inicial y. A Tabela 3.1 mostra os dados para pista de teste e a Figura 3.5 mostra o traçado da pista.

\begin{tabular}{|c|c|c|c|c|c|}
\hline Trecho & $\begin{array}{c}\text { Angulo } \\
\text { Total } \\
\text { Inicial }\end{array}$ & $\begin{array}{c}\text { Arco } \\
\left({ }^{\circ}\right)\end{array}$ & $\begin{array}{c}\text { Comprimento } \\
\text { ou Raio } \\
(\mathrm{m})\end{array}$ & $\begin{array}{c}\text { Início em X (Xi) } \\
(\text { linha central }) \\
(\mathrm{m})\end{array}$ & $\begin{array}{c}\text { Início em Y (Yi) } \\
\text { (linha central) } \\
(\mathrm{m})\end{array}$ \\
\hline 1 & 0 & 0 & 100 & 0 & 0 \\
\hline 2 & 0 & -90 & -25 & 100 & 0 \\
\hline 3 & -90 & 0 & 25 & 125 & -25 \\
\hline 4 & -90 & 90 & 25 & 125 & -50 \\
\hline 5 & 0 & 0 & 25 & 150 & -75 \\
\hline 6 & 0 & 135 & 25 & 175 & -75 \\
\hline 7 & 135 & 0 & 100 & 192,68 & $-32,32$ \\
\hline 8 & 135 & 45 & 25 & 121,98 & 38,39 \\
\hline 9 & 180 & 0 & 104,29 & 104,29 & 45,71 \\
\hline 10 & 180 & 180 & 22,85 & 0 & 45,71 \\
\hline
\end{tabular}

Tabela 3.1: Dados da pista de teste.

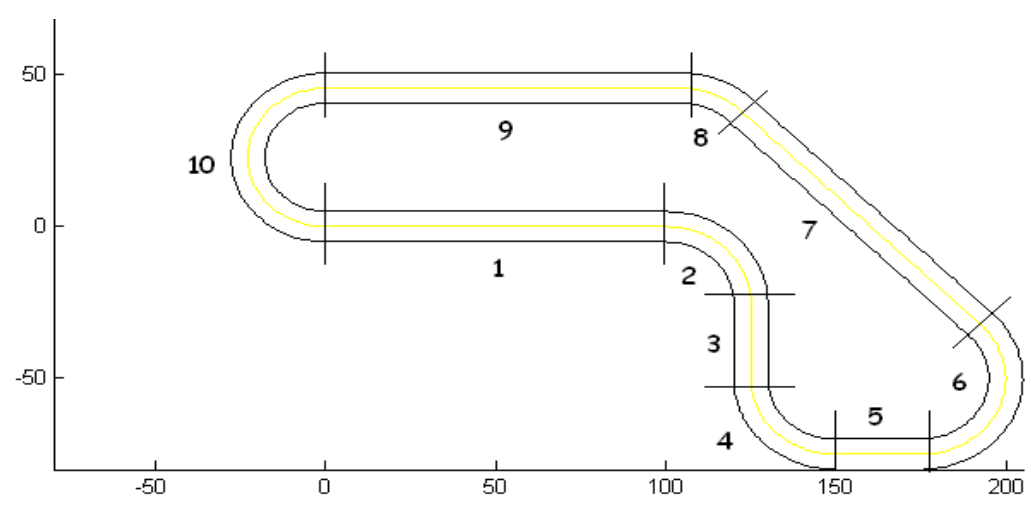

Figura 3.5: Pista teste. 


\subsubsection{Resultado das trajetórias ótimas independentes}

Baseando-se nos ângulos e comprimentos descritos na Tabela 3.1 e nas fórmulas analíticas já apresentadas para o cálculo dos parâmetros de uma trajetória ótima em curva, é possível determinar as trajetórias ótimas independentes para os trechos curvilíneos da pista. A Figura 3.6 mostra os resultados obtidos. Nela, as bolas marcam os centros das trajetórias ótimas circulares individuais, as cruzes marcam os pontos de início e fim das trajetórias e os ápices são marcados por asteriscos.

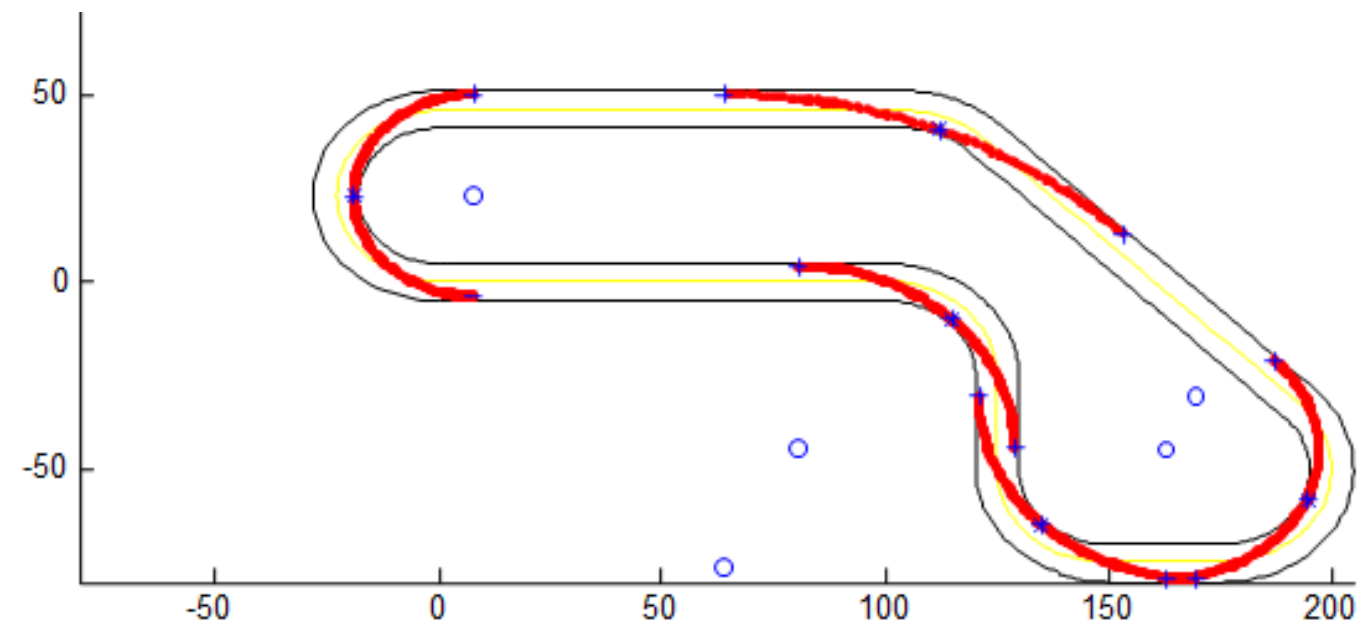

Figura 3.6: Linhas de corrida independentes em várias curvas circulares de um circuito fechado, sem concatenação.

A Tabela 3.2 mostra os pontos de entrada, saída e ápice da trajetória ótima encontrada para cada trecho curvilíneo da pista teste.

\begin{tabular}{|c|c|c|c|c|c|c|c|c|c|}
\hline \multirow{2}{*}{ Trecho } & \multirow{2}{*}{$\begin{array}{c}\text { Arco } \\
\left({ }^{\circ}\right)\end{array}$} & \multicolumn{2}{|c|}{$\begin{array}{c}\text { Coordenadas } \\
\text { Entrada }(\mathrm{m})\end{array}$} & \multicolumn{2}{c|}{$\begin{array}{c}\text { Origem } \\
\text { do Círculo }(\mathrm{m})\end{array}$} & \multicolumn{2}{|c|}{$\begin{array}{c}\text { Coordenadas } \\
\text { Ápice }(\mathrm{m})\end{array}$} & \multicolumn{2}{c|}{$\begin{array}{c}\text { Coordenadas } \\
\text { Saída }(\mathrm{m})\end{array}$} \\
\cline { 5 - 11 } & Xe & Ye & Xm & Ym & Xa & Ya & Xs & Ys \\
\hline 1 & RETA & & & & & & & & \\
\hline 2 & -90 & 80.68 & 4.00 & 80.68 & -44.31 & 114.84 & -10.15 & 129.00 & -44.31 \\
\hline 3 & RETA & & & & & & & & \\
\hline 4 & 90 & 121.00 & -30.68 & 169.31 & -30.68 & 135.15 & -64.84 & 169.31 & -79.00 \\
\hline 5 & RETA & & & & & & & & \\
\hline 6 & 135 & 163.02 & -79.00 & 163.02 & -45.04 & 194.40 & -58.03 & 187.04 & -21.02 \\
\hline 7 & RETA & & & & & & & & \\
\hline 8 & 45 & 153.23 & 12.77 & 64.07 & -76.38 & 112.32 & 40.11 & 64.07 & 49.71 \\
\hline 9 & RETA & & & & & & & & \\
\hline 10 & 180 & 7.99 & 49.71 & 7.99 & 22.86 & -18.85 & 22.86 & 7.99 & -3.98 \\
\hline
\end{tabular}

Tabela 3.2: Pontos da trajetória ótima em cada curva circular da Figura 3.6. 
Para análises dinâmicas do veículo, é importante que tenhamos as informações de velocidade e a aceleração ao longo da trajetória ótima obtida. Considerando que as trajetórias ótimas independentes sejam realizadas em movimento circular uniforme, tem-se que:

$a_{n}=\frac{v^{2}}{R_{m}} \rightarrow v=\sqrt{a_{n} * R_{m}}$

Esta velocidade é mantida constante durante todo o trajeto independente, porque a aceleração normal é mantida no valor máximo para garantir o menor tempo no trajeto circular. Desta forma, o tempo levado para concluir o trajeto consiste em:

$t=\frac{\Delta s}{v}=\frac{\operatorname{arco}[\mathrm{rad}] \cdot R[\mathrm{~m}]}{v[\mathrm{~m}]}$

Para o cálculo da velocidade em cada trecho, como parâmetros de projeto para os testes iniciais, assumiu-se que:

- Aceleração normal máxima: $a_{n}=1,1 * g$

- Aceleração da gravidade: $g=9,81 \mathrm{~m} / \mathrm{s}^{2}$

Utilizando-se esses parâmetros, foi possível calcular a velocidade e o tempo de percurso de cada trajetória ótima encontrada, como mostra a Tabela 3.3.

\begin{tabular}{|c|c|c|c|c|c|}
\hline Trecho & $\begin{array}{c}\text { Raio } \\
\text { Máximo } \\
(\mathrm{m})\end{array}$ & $\begin{array}{c}\text { Arco } \\
\left(^{\circ}\right)\end{array}$ & $\begin{array}{c}\text { Distância d } \\
\text { entre m e i/o } \\
(\mathrm{m})\end{array}$ & $\begin{array}{c}\text { Velocidade } \\
\text { Máxima } \\
(\mathrm{m} / \mathrm{s})\end{array}$ & $\begin{array}{c}\text { Tempo de } \\
\text { Percurso } \\
(\mathrm{s})\end{array}$ \\
\hline 1 & RETA & & & & \\
\hline 2 & 48.31 & -90 & 19.31 & 22.83 & 3.32 \\
\hline 3 & RETA & & & & \\
\hline 4 & 48.31 & 90 & 19.31 & 22.83 & 3.32 \\
\hline 5 & RETA & & & & \\
\hline 6 & 33.95 & 135 & 11.97 & 19.14 & 4.17 \\
\hline 7 & RETA & & & & \\
\hline 8 & 126.09 & 45 & 40.21 & 36.88 & 2.68 \\
\hline 9 & RETA & & & & \\
\hline 10 & 26.85 & 180 & 8.00 & 17.02 & 4.95 \\
\hline
\end{tabular}

Tabela 3.3: Resultados para trajetória ótima de cada curva da Figura 3.6. 
Os outros parâmetros que serão utilizados no processo de otimização ao longo deste trabalho foram determinados como:

- Aceleração (tração) longitudinal máxima: $a_{t}=0,5 * g$

- Aceleração (frenagem) longitudinal máxima: $a_{f}=1,1 * g$

\subsection{Resultados para a pista de Barcelona}

Além da pista teste apresentada na seção anterior, outra pista foi desenhada para teste e análise dos algoritmos desenvolvidos ao longo deste trabalho. Para representar um circuito mais realista, foi desenhada uma pista que aproxima o circuito de Fórmula 1 de Catalunha - Barcelona, Espanha - por meio de retas e arcos de circunferências. Apesar de ser uma aproximação, a pista desenhada em Matlab $^{\circledR}$ aproxima muito bem a pista original, como mostra a Figura 3.7.

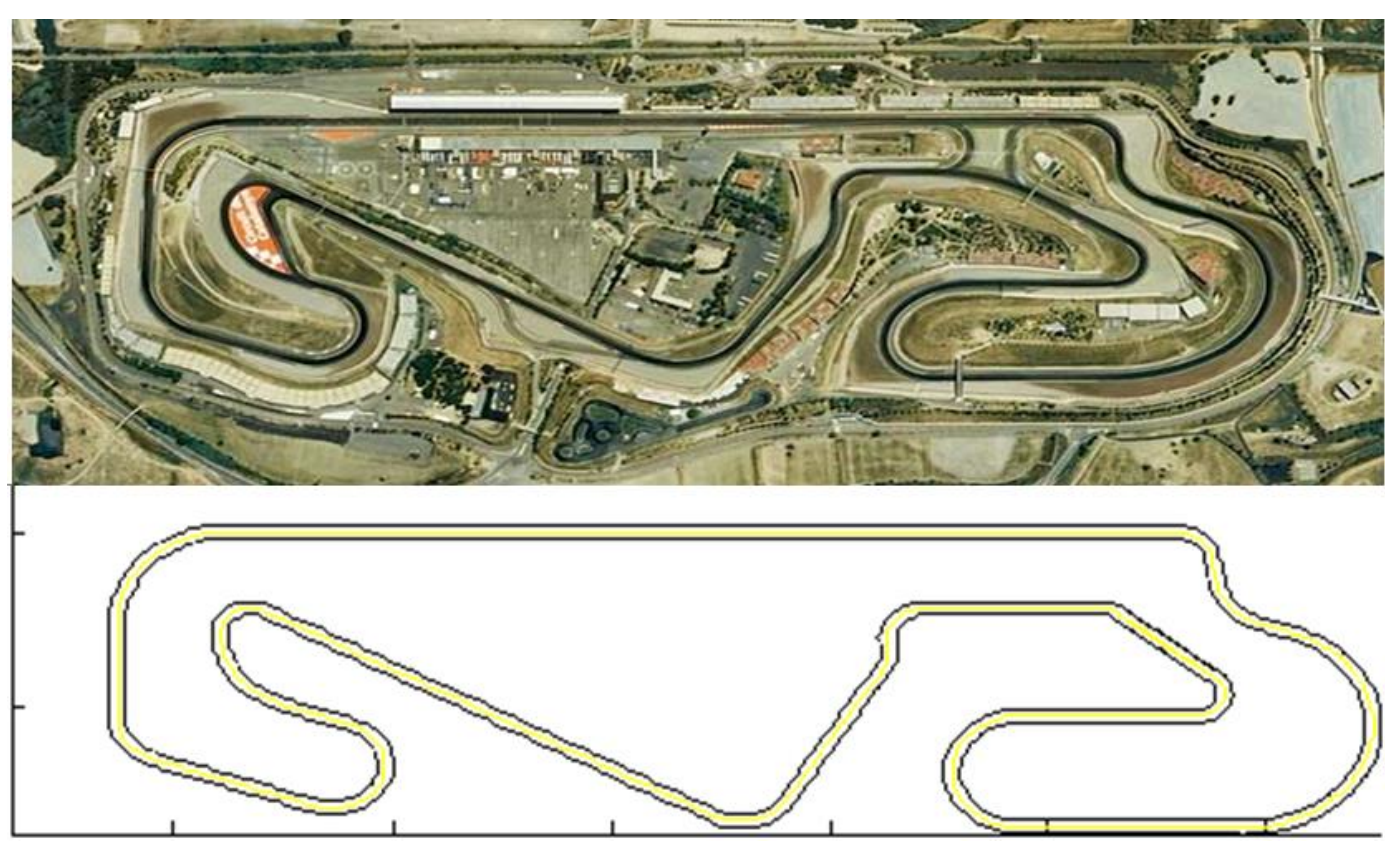

Figura 3.7: Aproximação do Circuito de Catalunha, Barcelona.

\subsubsection{Desenho da pista}

Similarmente ao que foi feito para a pista teste, o desenho apresentado na Figura 3.7 pode ser obtido a partir de uma tabela que contenha os seguintes dados: ângulo inicial, arco (se o trecho for curvilíneo), comprimento ou raio e ponto 
inicial $(x, y)$ para cada trecho da pista. A Tabela 3.4 apresenta os dados para a pista de Barcelona e a Figura 3.8 ilustra o traçado da pista e seus respectivos trechos.

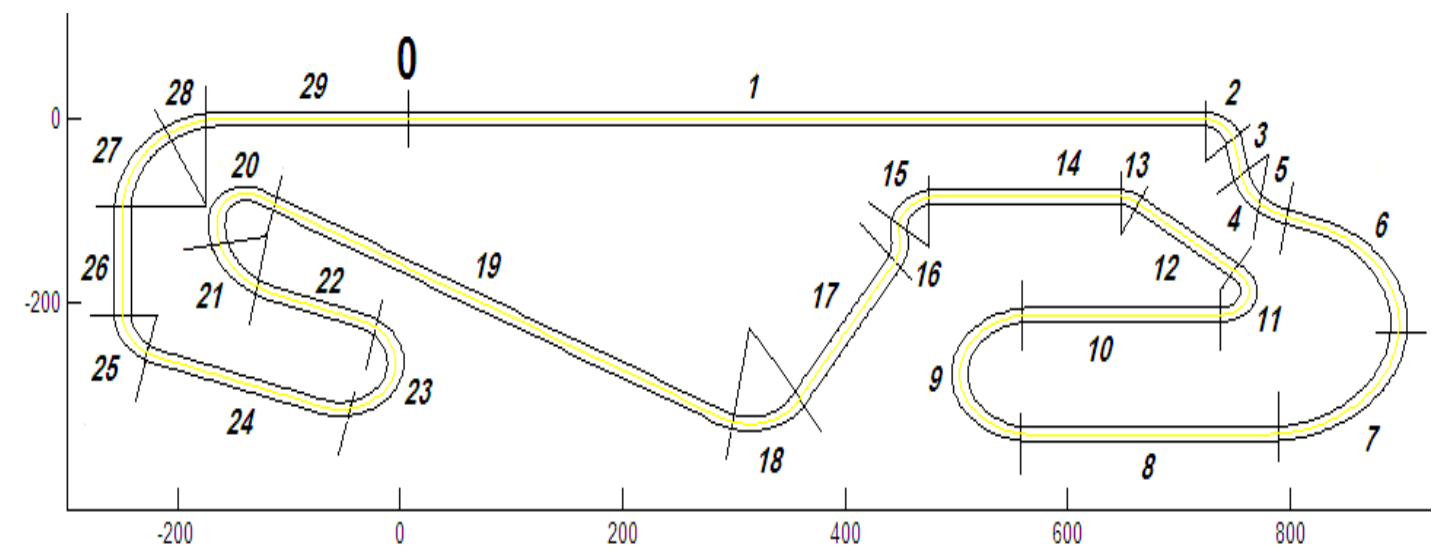

Figura 3.8: Pista de Barcelona.

\begin{tabular}{|c|c|c|c|c|c|}
\hline Trecho & $\begin{array}{c}\text { Ângulo } \\
\text { Total } \\
\text { Inicial }\end{array}$ & $\begin{array}{c}\text { Arco } \\
\left({ }^{\circ}\right)\end{array}$ & $\begin{array}{l}\text { Comprimento } \\
\text { ou Raio } \\
\text { (m) }\end{array}$ & $\begin{array}{c}\text { Início em X (Xi) } \\
\text { (linha central) } \\
(\mathrm{m})\end{array}$ & $\begin{array}{c}\text { Início em Y (Yi) } \\
\text { (linha central) } \\
(\mathrm{m})\end{array}$ \\
\hline 1 & 0 & 0 & 720 & 0 & 0 \\
\hline 2 & 0 & -80 & -30 & 720 & 0 \\
\hline 3 & -80 & 0 & 35 & 749,54 & $-24,79$ \\
\hline 4 & -80 & 60 & 60 & 755,62 & $-59,25$ \\
\hline 5 & -20 & 0 & 30 & 794,18 & $-105,22$ \\
\hline 6 & -20 & -80 & -115 & 822,38 & $-115,48$ \\
\hline 7 & -100 & -80 & -120 & 896,30 & $-243,51$ \\
\hline 8 & -180 & 0 & 210 & 778,12 & $-342,67$ \\
\hline 9 & -180 & -180 & -65 & 568,12 & $-342,67$ \\
\hline 10 & -360 & 0 & 170 & 568,12 & $-212,67$ \\
\hline 11 & -360 & 140 & 25 & 738,12 & $-212,67$ \\
\hline 12 & -220 & 0 & 120 & 754,19 & $-168,52$ \\
\hline 13 & -220 & 40 & 30 & 662,26 & $-91,39$ \\
\hline 14 & -180 & 0 & 160 & 642,98 & $-84,37$ \\
\hline 15 & -180 & 100 & 35 & 482,98 & $-84,37$ \\
\hline 16 & -80 & -40 & -50 & 448,51 & $-125,45$ \\
\hline 17 & -120 & 0 & 170 & 442,57 & $-159,13$ \\
\hline 18 & -120 & -90 & -50 & 357,57 & $-306,35$ \\
\hline 19 & -210 & 0 & 480 & 289,27 & $-324,66$ \\
\hline 20 & -210 & 110 & 25 & $-126,41$ & $-84,65$ \\
\hline 21 & -100 & 80 & 80 & $-163,53$ & $-101,96$ \\
\hline 22 & -20 & 0 & 80 & $-112,11$ & $-191,03$ \\
\hline 23 & -20 & -180 & -50 & $-36,94$ & $-218,39$ \\
\hline 24 & -200 & 0 & 155 & $-71,14$ & $-312,36$ \\
\hline 25 & -200 & -70 & -50 & $-216,79$ & $-259,35$ \\
\hline
\end{tabular}




\begin{tabular}{|c|c|c|c|c|c|}
\hline 26 & -270 & 0 & 110 & $-249,69$ & $-212,37$ \\
\hline 27 & -270 & -30 & -115 & $-249,69$ & $-102,37$ \\
\hline 28 & -300 & -60 & $-89,87$ & $-234,28$ & $-44,86$ \\
\hline 29 & -360 & 0 & 171 & $-156,45$ & 0,07 \\
\hline
\end{tabular}

Tabela 3.4: Dados da pista de Barcelona.

\subsubsection{Resultado das trajetórias ótimas independentes para a pista de Barcelona}

Utilizando o mesmo método empregado para a pista teste, foram calculadas as trajetórias ótimas para cada curva da pista de Barcelona de forma independente. A Figura 3.9 mostra os resultados obtidos. Nela, os pontos marcam os centros das trajetórias ótimas circulares individuais e as cruzes marcam os pontos de início e fim das trajetórias e os ápices.

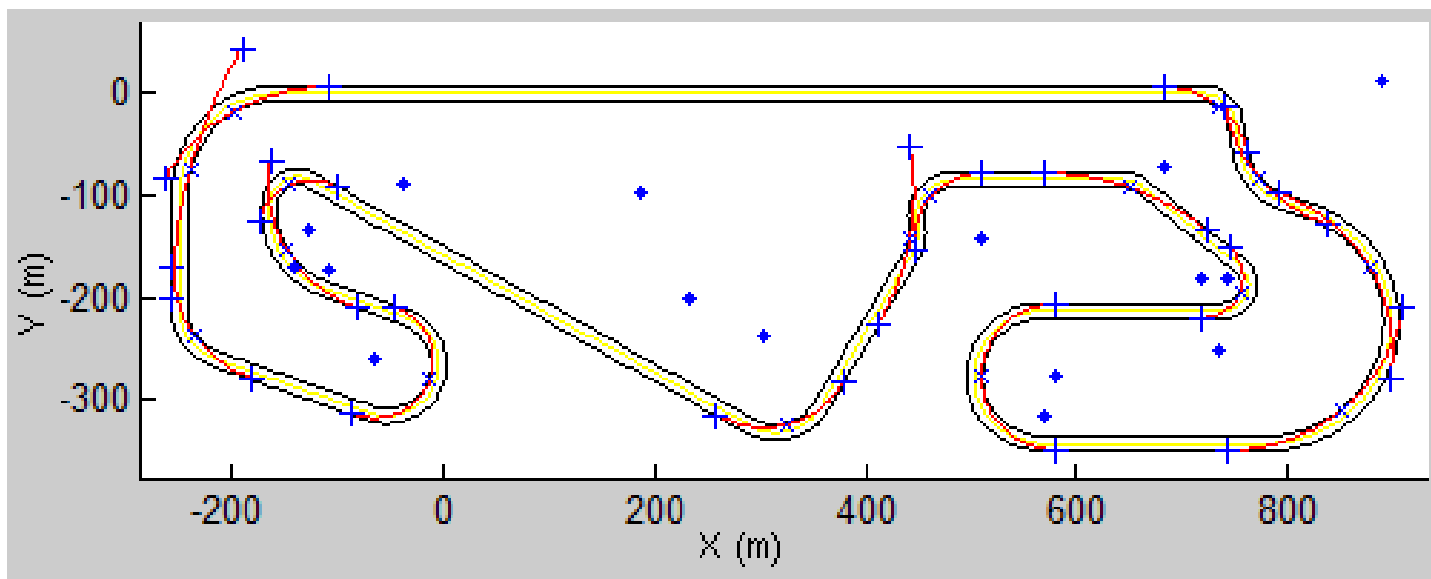

Figura 3.9: Resultados para a pista de Barcelona.

$\mathrm{Na}$ Tabela 3.5 estão apresentadas as coordenadas de entrada, de origem do círculo, do ápice e de saída da trajetória ótima individual de cada curva, calculadas de acordo com as Equações 3.1 e 3.2.

\begin{tabular}{|c|c|c|c|c|c|c|c|c|c|}
\hline \multirow{2}{*}{ Trecho } & \multirow{2}{*}{$\begin{array}{c}\text { Arco } \\
\left.{ }^{\circ}\right)\end{array}$} & \multicolumn{2}{c|}{$\begin{array}{c}\text { Coordenadas } \\
\text { Entrada }(\mathrm{m})\end{array}$} & \multicolumn{2}{c|}{$\begin{array}{c}\text { Origem } \\
\text { do Círculo }(\mathrm{m})\end{array}$} & \multicolumn{2}{c|}{$\begin{array}{c}\text { Coordenadas } \\
\text { Ápice }(\mathrm{m})\end{array}$} & \multicolumn{2}{c|}{$\begin{array}{c}\text { Coordenadas } \\
\text { Saída (m) }\end{array}$} \\
\cline { 3 - 10 } & & $\mathrm{Xe}$ & $\mathrm{Ye}$ & $\mathrm{Xm}$ & $\mathrm{Ym}$ & $\mathrm{Xa}$ & Ya & $\mathrm{Xs}$ & Ys \\
\hline 1 & RETA & & & & & & & & \\
\hline 2 & -80 & 684,28 & 6,5 & 684,28 & $-72,56$ & 735,10 & $-11,99$ & 762,14 & $-58,83$ \\
\hline 3 & RETA & & & & & & & & \\
\hline 4 & 60 & 740,79 & $-12,60$ & 889,04 & 13,53 & 773,72 & $-83,22$ & 837,55 & $-127,92$ \\
\hline
\end{tabular}




\begin{tabular}{|c|c|c|c|c|c|c|c|c|c|}
5 & RETA & & & & & & & & \\
\hline 6 & -80 & 791,04 & $-97,15$ & 734,92 & $-251,33$ & 877,01 & $-169,30$ & 896,50 & $-279,82$ \\
\hline 7 & -80 & 908,90 & $-209,47$ & 742,40 & $-180,11$ & 851,08 & $-309,62$ & 742,40 & $-349,18$ \\
\hline 8 & RETA & & & & & & & & \\
\hline 9 & -180 & 581,12 & $-349,18$ & 581,12 & $-277,68$ & 509,62 & $-277,68$ & 581,12 & $-206,18$ \\
\hline 10 & RETA & & & & & & & & \\
\hline 11 & 140 & 719,55 & $-219,18$ & 719,55 & $-180,92$ & 755,50 & $-194,01$ & 744,14 & $-151,61$ \\
\hline 12 & RETA & & & & & & & & \\
\hline 13 & 40 & 722,92 & $-133,8$ & 569,25 & $-316,94$ & 651,02 & $-92,29$ & 569,25 & $-77,87$ \\
\hline 14 & RETA & & & & & & & & \\
\hline 15 & 100 & 510,86 & $-77,87$ & 510,86 & $-142,77$ & 461,15 & $-101,05$ & 446,95 & $-154,04$ \\
\hline 16 & -40 & 442,11 & $-51,71$ & 186,98 & $-96,70$ & 442,11 & $-141,69$ & 411,34 & $-226,23$ \\
\hline 17 & RETA & & & & & & & & \\
\hline 18 & -90 & 378,89 & $-282,43$ & 302,78 & $-238,49$ & 325,53 & $-323,38$ & 258,84 & $-314,60$ \\
\hline 19 & RETA & & & & & & & & \\
\hline 20 & 110 & $-101,54$ & $-91,51$ & $-126,03$ & $-133,94$ & $-146,73$ & $-89,54$ & $-174,27$ & $-125,43$ \\
\hline 21 & 80 & $-163,74$ & $-65,66$ & $-36,63$ & $-88,08$ & $-148,40$ & $-152,61$ & $-80,77$ & $-209,36$ \\
\hline \multirow{2}{*}{$\frac{1}{22}$} & RETA & & & & & & & & \\
\hline
\end{tabular}

Tabela 3.5: Tabela de pontos das trajetórias ótimas individuais da pista de Barcelona.

Observe que, para a pista de Barcelona, como existem alguns trechos de ângulos muito pequenos, as trajetórias ótimas individuais de cada curva tendem a sair do limite da pista. No algoritmo de concatenação, os casos em que isso ocorre deverão ser tratados de forma especial.

Considerando que as trajetórias individuais são realizadas com aceleração normal máxima constante e aceleração tangencial nula (trajetórias circulares compatíveis com o movimento circular uniforme), é possível calcular a velocidade com que os trechos são realizados e o tempo necessário para realizar o trajeto ótimo, apresentado na cor vermelha na Figura 3.9. Os cálculos foram feitos utilizando os mesmos valores de aceleração normal e tangencial que foram utilizados para a pista teste.

Os resultados estão apresentados na Tabela 3.6. 


\begin{tabular}{|c|c|c|c|c|c|}
\hline Trecho & $\begin{array}{l}\text { Raio } \\
\text { Máximo } \\
(\mathrm{m})\end{array}$ & $\begin{array}{c}\text { Arco } \\
\left({ }^{\circ}\right)\end{array}$ & $\begin{array}{c}\text { Distância d } \\
\text { entre m e i/o } \\
(\mathrm{m})\end{array}$ & $\begin{array}{c}\text { Velocidade } \\
\text { Máxima } \\
(\mathrm{m} / \mathrm{s}) \\
\end{array}$ & $\begin{array}{c}\text { Tempo de } \\
\text { Percurso } \\
(\mathrm{s}) \\
\end{array}$ \\
\hline 1 & RETA & & & & \\
\hline 2 & 79,06611 & -80 & 35,71 & 29,21 & 3,77 \\
\hline 3 & RETA & & & & \\
\hline 4 & 150,5333 & 60 & 48,51 & 40,30 & 3,911 \\
\hline 5 & RETA & & & & \\
\hline 6 & 164,0661 & -80 & 35,71 & 42,07 & 5,44 \\
\hline 7 & 169,0661 & -80 & 35,71 & 42,71 & 5,52 \\
\hline 8 & RETA & & & & \\
\hline 9 & 71,5 & -180 & 13,00 & 27,77 & 8,08 \\
\hline 10 & RETA & & & & \\
\hline 11 & 38,25744 & 140 & 18,56 & 20,31 & 4,60 \\
\hline 12 & RETA & & & & \\
\hline 13 & 239,0623 & 40 & 73,72 & 50,79 & 3,28 \\
\hline 14 & RETA & & & & \\
\hline 15 & 64,89291 & 100 & 27,87 & 26,46 & 4,28 \\
\hline 16 & 259,0623 & -40 & 73,72 & 52,87 & 3,42 \\
\hline 17 & RETA & & & & \\
\hline 18 & 87,88478 & -90 & 31,38 & 30,79 & 4,482 \\
\hline 19 & RETA & & & & \\
\hline 20 & 48,98612 & 110 & 24,97 & 22,99 & 4,09 \\
\hline 21 & 129,0661 & 80 & 35,71 & 37,31 & 4,82 \\
\hline 22 & RETA & & & & \\
\hline 23 & 56,5 & -180 & 13,00 & 24,69 & 7,18 \\
\hline 24 & RETA & & & & \\
\hline 25 & 115,3836 & -70 & 41,23 & 35,28 & 3,99 \\
\hline 26 & RETA & & & & \\
\hline 27 & 490,0206 & -30 & 98,74 & 72,71 & 3,52 \\
\hline 28 & 180,4083 & -60 & 48,51 & 44,12 & 4,28 \\
\hline 29 & RETA & & & & \\
\hline
\end{tabular}

Tabela 3.6: Resultados das trajetórias independentes para a pista de Barcelona. 


\section{Concatenação dos Trechos Ótimos Independentes}

Nesta etapa, foi desenvolvido um algoritmo que parte das trajetórias ótimas de curvas independentes para determinar a trajetória ótima de toda a pista. O objetivo é concatenar esses trechos independentes de forma que o trajeto final seja o de menor tempo. Existem algumas curvas cujas características as tornam aplicáveis para este tipo de problema. A primeira alternativa seria concatenar essas curvas utilizando arcos de circunferência, no entanto, essa opção não se mostrou muito eficiente por alguns motivos. Primeiramente, considerando trajetórias em movimento circular uniforme, toda a trajetória na pista teria aceleração tangencial nula, o que não representa bem o movimento de um veículo correndo em uma pista de corrida. Além disso, o problema de otimização que envolve a determinação do menor arco de circunferência entre dois pontos dentro do limite geométrico da pista envolve a utilização de funções raiz quadradas, não muito simples de manipular.

Neste item serão analisadas duas outras opções de curvas, a curva de Hermite e a espiral de Euler. A seção 4.1 explica as características e os métodos de construção da curva de Hermite, enquanto que a seção 4.2 estuda a construção e aplicação da espiral de Euler para este problema. Após a apresentação das curvas, a seção 4.3 avalia os aspectos dinâmicos de cada uma delas e as compara para verificar qual é a melhor opção de curva para concatenação destes trechos. Ao longo do capítulo 4, serão apresentadas as conclusões sobre os diferentes tipos de concatenação.

\subsection{Curva de Hermite}

Sendo uma das primeiras representações matemáticas de curvas complexas, Hermite definiu uma curva utilizando uma equação polinomial, dois pontos e dois vetores tangentes que determinam sua forma [15], como ilustra a Figura 4.1. 


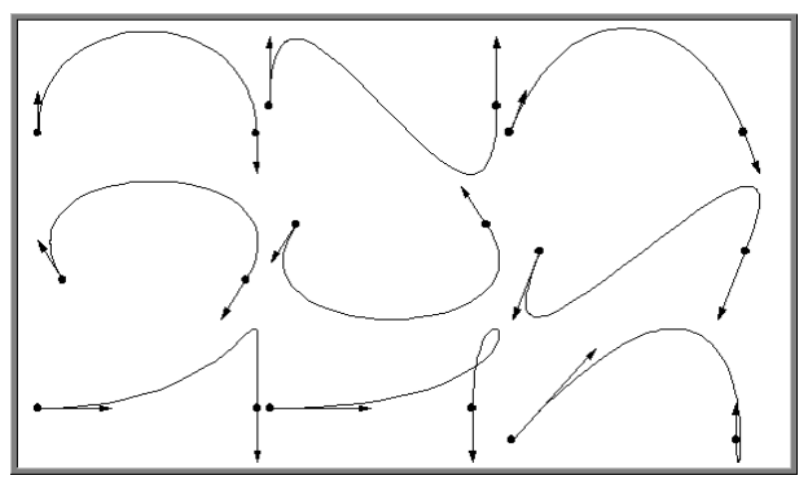

Figura 4.1: Exemplos de curvas de Hermite.

Na Figura 4.1, é possível observar um aspecto importante do polinômio de Hermite: cada curva é gerada de forma a respeitar o vetor tangente em cada um dos seus pontos extremos. A curva de Hermite é utilizada em diversas áreas da engenharia, especialmente em computação gráfica e visão computacional [16]. Esta técnica foi considerada apropriada para a solução deste problema devido à semelhança com os dados disponíveis. Após a definição das trajetórias ótimas independentes, os pontos de entrada e saída da curva de concatenação são conhecidos, assim como a velocidade em cada ponto da curva.

Para aplicação na concatenação dos trechos ótimos independentes, a melhor abordagem seria escolher os pontos de concatenação por curvas de Hermite de forma a manter os pontos de saída das trajetórias independentes na posição original. Esta escolha é embasada na famosa frase de corrida "slow in, fast out", que mostra a importância de priorizar maior velocidade na saída da curva, mesmo que a entrada seja um pouco comprometida [3].

A Figura 4.2 ilustra, para um trecho, como seriam escolhidos os pontos $P_{1} \mathrm{e}$ $P_{4}$ e os vetores $\overrightarrow{R_{1}}$ e $\overrightarrow{R_{4}}$ para parametrizar a curva de Hermite que irá concatenar esses dois trechos. Os módulos dos vetores $\overrightarrow{R_{1}}$ e $\overrightarrow{R_{4}}$ são as velocidades das respectivas curvas. A partir daí, a determinação da curva de Hermite consiste em encontrar os coeficientes a, b, c e d de um polinômio de terceiro grau parametrizado no intervalo [0,1], que satisfaça a Equação 4.1.

$$
\begin{aligned}
& x(0)=P_{1_{x}}, x(1)=P_{4_{x}}, x^{\prime}(0)=R_{1_{x}}, x^{\prime}(1)=R_{4_{x}} \\
& y(0)=P_{1_{y}}, y(1)=P_{4_{y}}, y^{\prime}(0)=R_{1_{y}}, y^{\prime}(1)=R_{4_{y}}
\end{aligned}
$$




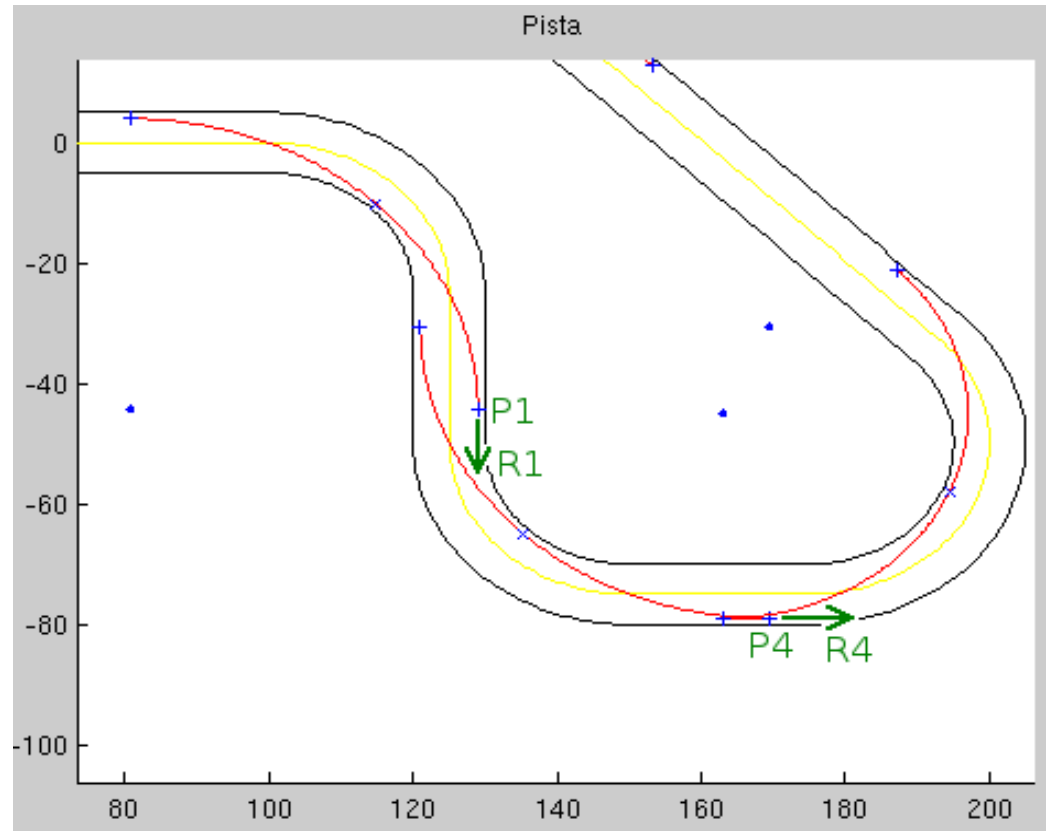

Figura 4.2: Pontos e derivadas para geração da curva de Hermite.

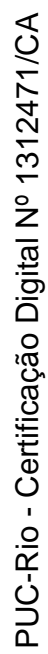

A estrutura do sistema a ser resolvido é:

$\overrightarrow{x(t)}=\left[\begin{array}{llll}t^{3} & t^{2} & t & 1\end{array}\right] \cdot \overrightarrow{C_{x}}$

Onde:

$\overrightarrow{C_{x}}=\left[\begin{array}{l}a \\ b \\ c \\ d\end{array}\right]_{x}$

Observe que:

$x(0)=P_{1_{x}}=\left[\begin{array}{llll}0 & 0 & 0 & 1\end{array}\right] \cdot \overrightarrow{C_{x}}$

$x(1)=P_{4_{x}}=\left[\begin{array}{llll}1 & 1 & 1 & 1\end{array}\right] \cdot \overrightarrow{C_{x}}$

$x^{\prime}(0)=R_{1_{x}}=\left[\begin{array}{llll}0 & 0 & 1 & 0\end{array}\right] \cdot \overrightarrow{C_{x}}$

$x^{\prime}(1)=R_{4_{x}}=\left[\begin{array}{llll}3 & 2 & 1 & 0\end{array}\right] \cdot \overrightarrow{C_{x}}$

Expressando todas as condições de primeira e segunda ordem em uma mesma matriz, tem-se: 
$\left[\begin{array}{l}P_{1} \\ P_{4} \\ R_{1} \\ R_{4}\end{array}\right]_{x}=\left[\begin{array}{llll}0 & 0 & 0 & 1 \\ 1 & 1 & 1 & 1 \\ 0 & 0 & 1 & 0 \\ 3 & 2 & 1 & 0\end{array}\right] \cdot\left[\begin{array}{l}a \\ b \\ c \\ d\end{array}\right]_{x}$

Os coeficientes podem ser obtidos invertendo-se a matriz do sistema acima, ou seja:

$$
\left[\begin{array}{l}
a \\
b \\
c \\
d
\end{array}\right]_{x}=\left[\begin{array}{cccc}
2 & -2 & 1 & 1 \\
-3 & 3 & -2 & 1 \\
0 & 0 & 1 & 0 \\
1 & 0 & 0 & 0
\end{array}\right] \cdot\left[\begin{array}{l}
P_{1} \\
P_{4} \\
R_{1} \\
R_{4}
\end{array}\right]_{x}=M_{H} \cdot G_{H_{x}}
$$

Onde, nesta expressão, $M_{H}$ representa a Matriz de Hermite.

De forma similar, para a outra coordenada:

$$
\left[\begin{array}{l}
a \\
b \\
c \\
d
\end{array}\right]_{y}=\left[\begin{array}{cccc}
2 & -2 & 1 & 1 \\
-3 & 3 & -2 & 1 \\
0 & 0 & 1 & 0 \\
1 & 0 & 0 & 0
\end{array}\right] \cdot\left[\begin{array}{l}
P_{1} \\
P_{4} \\
R_{1} \\
R_{4}
\end{array}\right]_{y}=M_{H} \cdot G_{H_{y}}
$$

Uma vez calculados os coeficientes, o resultado é uma curva paramétrica com início em $P_{1}$ e final em $P_{4}$, com derivadas nestes pontos $\overrightarrow{R_{1}}$ e $\overrightarrow{R_{4}}$, respectivamente. A equação paramétrica da curva fica como mostrada na Equação 4.8 .

$$
\begin{aligned}
& x(t)=a_{x} t^{3}+b_{x} t^{2}+c_{x} t+d_{x} \\
& y(t)=a_{y} t^{3}+b_{y} t^{2}+c_{y} t+d_{y}
\end{aligned}
$$

Uma vez definidos os pontos e as derivadas que parametrizam a curva de Hermite, a técnica foi aplicada na pista de teste para análise. Para a concatenação de trechos curvilíneos, os pontos de concatenação escolhidos são os pontos de saída de cada trecho ótimo independente de forma a manter as saídas das curvas mais rápidas. Para os trechos retos (ou que não se interceptam em nenhum ponto), os pontos de concatenação escolhidos são a saída da curva atual e a entrada da curva seguinte. Apesar da utilização da curva de Hermite parecer a melhor 
abordagem para a concatenação das curvas ótimas, os primeiros testes mostraram resultados incompatíveis com os esperados. A Figura 4.3 ilustra os primeiros resultados.

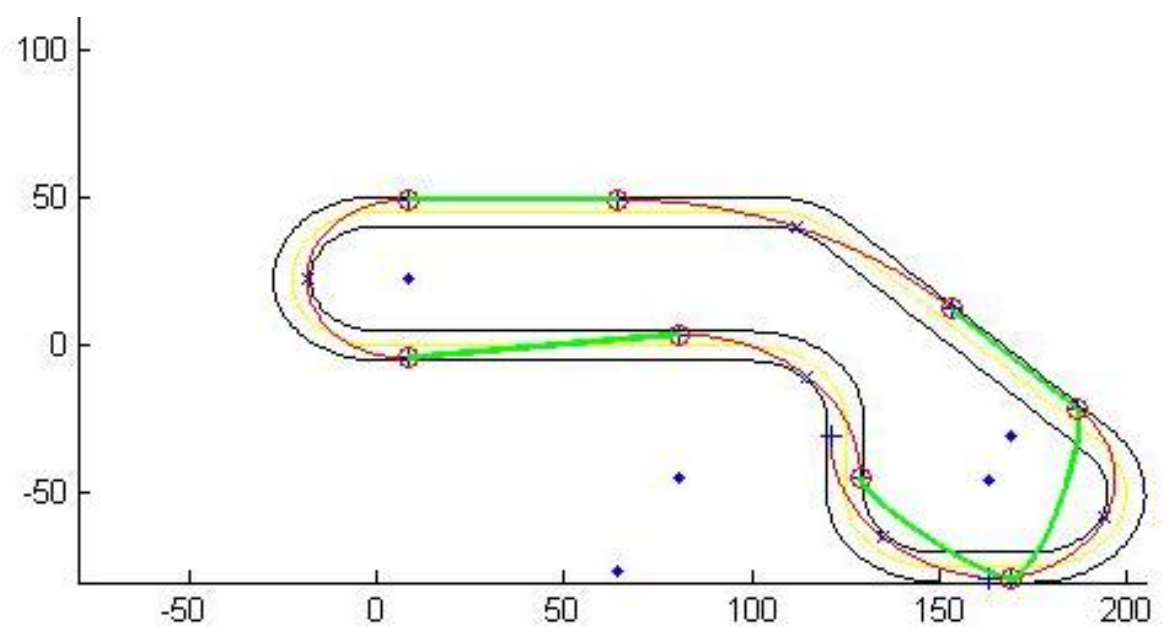

Figura 4.3: Resultado inicial da concatenação por curvas de Hermite.

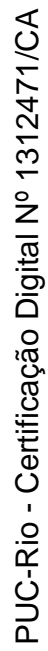

Apesar de esses resultados estarem corretos, visualmente eles parecem errados, como se a direção da derivada no ponto não tivesse sido respeitada. Para entender o que acontece, basta olhar de perto a derivada nos pontos $P_{1}$ e $P_{4}$ e verificar que ela é respeitada nos pontos, porém com uma curvatura muito pequena, como mostra a Figura 4.4.

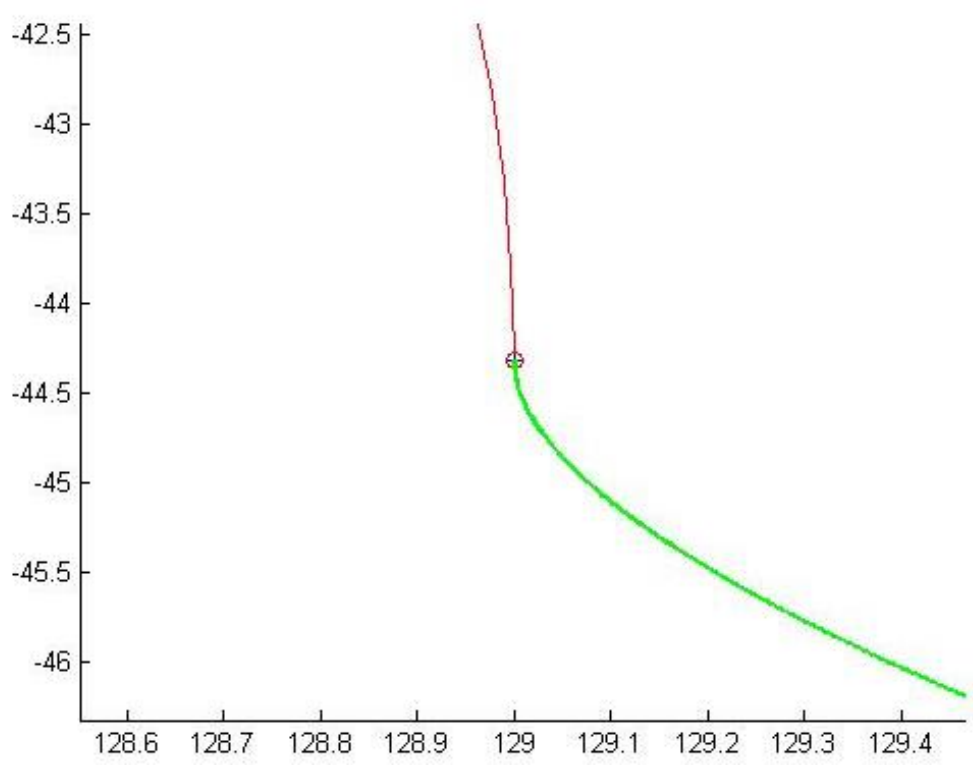

Figura 4.4: Derivada no ponto $\mathrm{P}_{1}$ do trecho 4 . 
A explicação para este comportamento está no módulo dos vetores tangentes nos pontos. No que diz respeito à geometria, é o módulo desses vetores tangentes aos pontos $P_{1}$ e $P_{4}$ que definem a forma da curva. Quanto maiores esses módulos, maiores serão as curvaturas naquelas direções. Para exemplificar, observe a Figura 4.5, que mostra três curvas de Hermite que ligam os pontos $P_{1}=\left[\begin{array}{ll}2 & 7\end{array}\right]$ e $P_{4}=\left[\begin{array}{ll}10 & 1\end{array}\right]$.

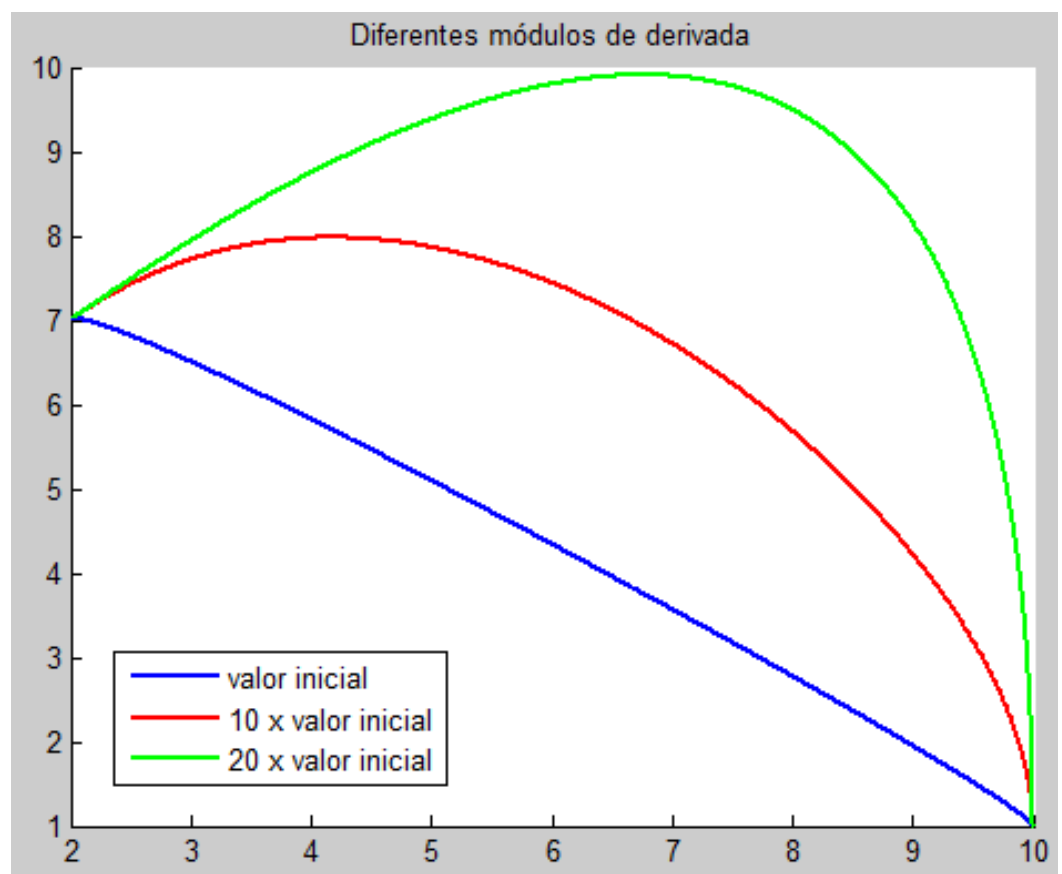

Figura 4.5: Curvas de Hermite para diversos módulos de derivada.

Na curva azul, os vetores tangentes são:

$\overrightarrow{R_{1}}=\left[\begin{array}{ll}1 & 1\end{array}\right]$

$\overrightarrow{R_{4}}=[0-1]$

Na vermelha, são:

$\overrightarrow{R_{1}}=\left[\begin{array}{ll}10 & 10\end{array}\right]$

$\overrightarrow{R_{4}}=[0-10]$

E na curva verde:

$\overrightarrow{R_{1}}=\left[\begin{array}{ll}20 & 20\end{array}\right]$

$\overrightarrow{R_{4}}=\left[\begin{array}{ll}0 & -20\end{array}\right]$

Observe como a curvatura se altera na medida em que o módulo do vetor tangente aumenta. Então, para a concatenação de trechos de corrida, uma solução seria aumentar o módulo dos vetores, porém, é importante lembrar que os 
módulos desses vetores são as velocidades das respectivas curvas a serem concatenadas, as quais não podem ser alteradas aleatoriamente devido às restrições de aceleração e velocidade da pista. Além disso, aumentar o módulo dos vetores geraria uma descontinuidade entre a velocidade da curva ótima do trecho e a curva de concatenação de Hermite.

A solução para este problema foi ajustar a técnica de parametrização da curva de Hermite para tempos maiores que 1. É possível entender a curva de Hermite a partir da análise do parâmetro t, como sendo o tempo que um veículo leva para chegar do início ao final da curva. Vale lembrar que, por definição, uma curva de Hermite liga dois pontos respeitando suas respectivas derivadas no intervalo $t \in[0,1]$. Isso é notável na própria construção da matriz de Hermite:

$x(0)=P_{1_{x}}$

$x(1)=P_{4_{x}}$

$x^{\prime}(0)=R_{1_{x}}$

$x^{\prime}(1)=R_{4 x}$

Fisicamente, na pista teste da Figura 3.5, é impossível que um veículo com tal velocidade consiga fazer o trajeto de concatenação com o parâmetro $t$ variando apenas de 0 a 1 segundo. Então, para tornar viável a utilização do polinômio de Hermite, foi preciso determinar uma nova matriz de Hermite, cujo tempo final $\tau$ pudesse ser diferente de 1 . Ou seja, ao invés de aumentar o módulo da velocidade tangente, se aumentaria o intervalo de tempo.

A nova representação para as restrições do polinômio é dada por:

$$
\begin{aligned}
& x(0)=P_{1_{x}}, x(\tau)=P_{4_{x}}, x^{\prime}(0)=R_{1_{x}}, x^{\prime}(\tau)=R_{4_{x}} \\
& y(0)=P_{1_{y}}, y(\tau)=P_{4_{y}}, y^{\prime}(0)=R_{1_{y}}, y^{\prime}(\tau)=R_{4_{y}}
\end{aligned}
$$

Da mesma forma, a interpolação entre $P_{1}$ e $P_{4}$ se dará por um polinômio de terceiro grau. Logo, tem-se que:

$$
x(t)=\left[\begin{array}{llll}
t^{3} & t^{2} & t & 1
\end{array}\right] \cdot C_{x}
$$


Onde,

$\overrightarrow{C_{x}}=\left[\begin{array}{l}a \\ b \\ c \\ d\end{array}\right]_{x}$

Substituindo-se os pontos e suas respectivas derivadas, obtém-se:

$$
\begin{aligned}
& x(0)=P_{1_{x}}=\left[\begin{array}{llll}
0 & 0 & 0 & 1
\end{array}\right] \cdot \overrightarrow{C_{x}} \\
& x(\tau)=P_{4_{x}}=\left[\begin{array}{llll}
\tau^{3} & \tau^{2} & \tau & 1
\end{array}\right] \cdot \overrightarrow{C_{x}} \\
& x^{\prime}(0)=R_{1_{x}}=\left[\begin{array}{llll}
0 & 0 & 1 & 0
\end{array}\right] \cdot \overrightarrow{C_{x}} \\
& x^{\prime}(\tau)=R_{4_{x}}=\left[\begin{array}{llll}
3 \tau^{2} & 2 \tau & 1 & 0
\end{array}\right] \cdot \overrightarrow{C_{x}}
\end{aligned}
$$

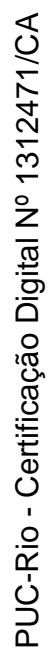

Assim, a nova matriz de Hermite é dada por:

$$
M_{H}=\left[\begin{array}{cccc}
0 & 0 & 0 & 1 \\
\tau^{3} & \tau^{2} & \tau & 1 \\
0 & 0 & 1 & 0 \\
3 \tau^{2} & 2 \tau & 1 & 0
\end{array}\right]^{-1}=\left[\begin{array}{cccc}
\frac{2}{\tau^{3}} & -\frac{2}{\tau^{3}} & \frac{1}{\tau^{2}} & \frac{1}{\tau^{2}} \\
-\frac{3}{\tau^{2}} & \frac{3}{\tau^{2}} & -\frac{2}{\tau} & \frac{1}{\tau} \\
0 & 0 & 1 & 0 \\
1 & 0 & 0 & 0
\end{array}\right]
$$

Logo, os coeficientes são obtidos a partir das seguintes equações:

$$
\begin{aligned}
& {\left[\begin{array}{l}
a \\
b \\
c \\
d
\end{array}\right]_{x}=\left[\begin{array}{cccc}
\frac{2}{\tau^{3}} & -\frac{2}{\tau^{3}} & \frac{1}{\tau^{2}} & \frac{1}{\tau^{2}} \\
-\frac{3}{\tau^{2}} & \frac{3}{\tau^{2}} & -\frac{2}{\tau} & \frac{1}{\tau} \\
0 & 0 & 1 & 0 \\
1 & 0 & 0 & 0
\end{array}\right] \cdot\left[\begin{array}{l}
P_{1} \\
P_{4} \\
R_{1} \\
R_{4}
\end{array}\right]_{x}} \\
& {\left[\begin{array}{l}
a \\
b \\
c \\
d
\end{array}\right]_{y}=\left[\begin{array}{cccc}
\frac{2}{\tau^{3}} & -\frac{2}{\tau^{3}} & \frac{1}{\tau^{2}} & \frac{1}{\tau^{2}} \\
-\frac{3}{\tau^{2}} & \frac{3}{\tau^{2}} & -\frac{2}{\tau} & \frac{1}{\tau} \\
0 & 0 & 1 & 0 \\
1 & 0 & 0 & 0
\end{array}\right] \cdot\left[\begin{array}{l}
P_{1} \\
P_{4} \\
R_{1} \\
R_{4}
\end{array}\right]_{y}}
\end{aligned}
$$


Na Figura 4.6, estão apresentadas as curvas de Hermite que ligam dois pontos utilizando ambas as matrizes, aquela para $\tau=10$ e a original para o módulo do vetor tangente 10 vezes maior.

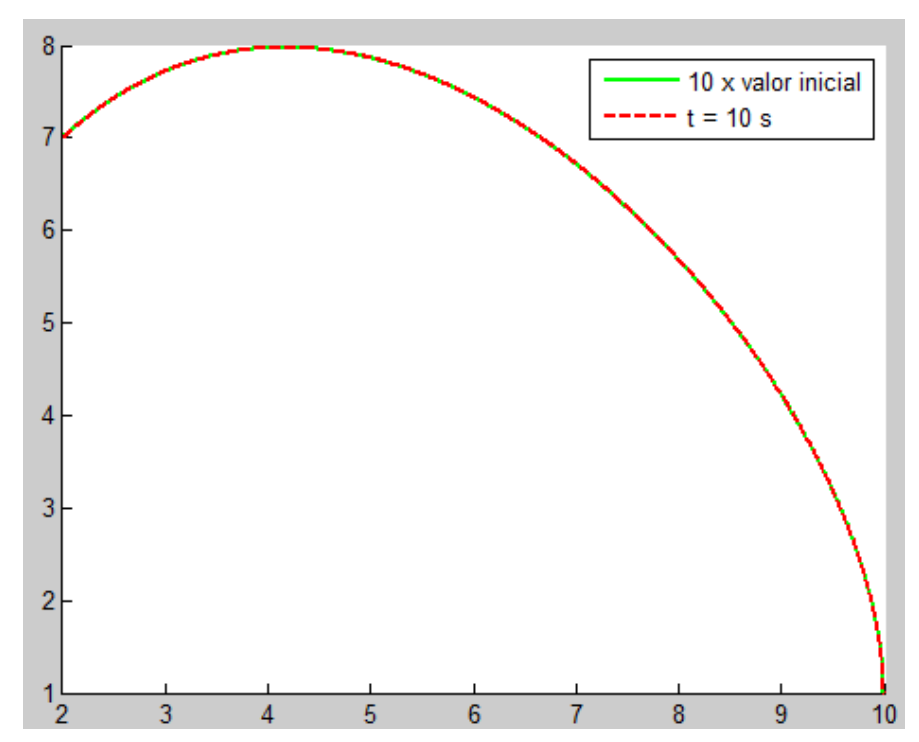

Figura 4.6: Curvas para cada matriz de Hermite.

Observe que as duas curvas são iguais, o que fisicamente é coerente, pois ao aumentar 10 vezes o tempo ou a velocidade, a trajetória obtida é a mesma. Com essa nova matriz que permite que o parâmetro $\tau$ varie de 0 a valores diferentes de 1 , é possível desenvolver um algoritmo que procure o menor parâmetro t para o qual a curva de Hermite de concatenação está inteiramente dentro da pista, sem o inconveniente de precisar aumentar a velocidade dos trechos ótimos independentes.

\subsection{Espiral de Euler}

A espiral de Euler é definida como uma curva cujo raio de curvatura varia linearmente ao longo do seu comprimento. Em projetos de engenharia rodoviária, esta espiral é largamente utilizada como curva de transição com o principal objetivo de ligar geometricamente uma reta e uma curva circular [6]. Esta curva assegura um decrescimento linear do raio de curvatura com o caminho percorrido ao longo do seu desenvolvimento, proporcionando assim uma variação gradual da curvatura. Esta espiral também foi utilizada para determinação da trajetória ótima em trechos curvilíneos em pistas de corridas em Xiong [5]. A utilização se 
resumiu a uma solução para uma curva de $90^{\circ}$, como mostra a Figura 4.7. Esta característica torna a espiral de Euler uma curva adequada para a concatenação de trajetórias em curvas de corrida.

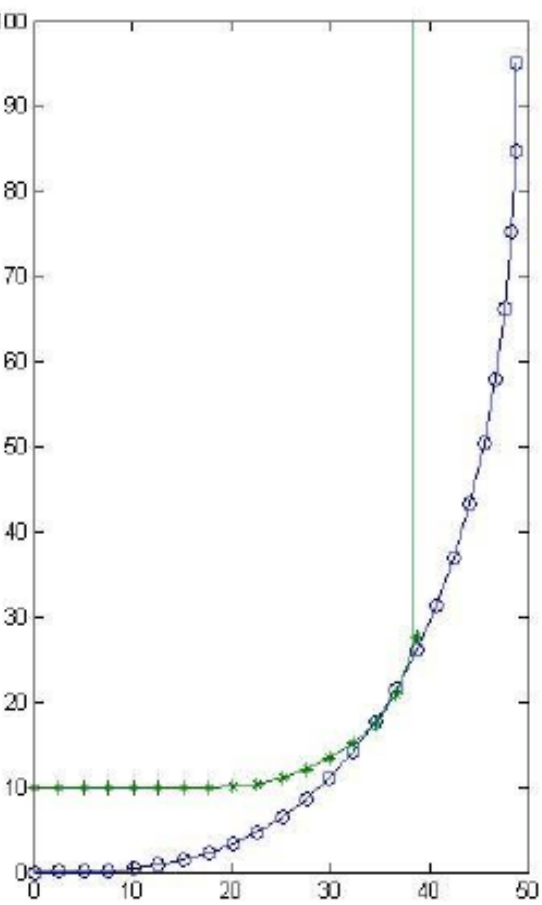

Figura 4.7: Trajetória ótima utilizando a espiral de Euler [5].

Na Figura 4.8, é possível perceber que curvatura da curva começa em zero no ponto $(0,0)$ com o alinhamento reto e aumenta linearmente à medida que se percorre o desenvolvimento da curva. Quando a espiral encontra a curva circular no respectivo ponto de centro, a sua curvatura é igual à da curva circular.

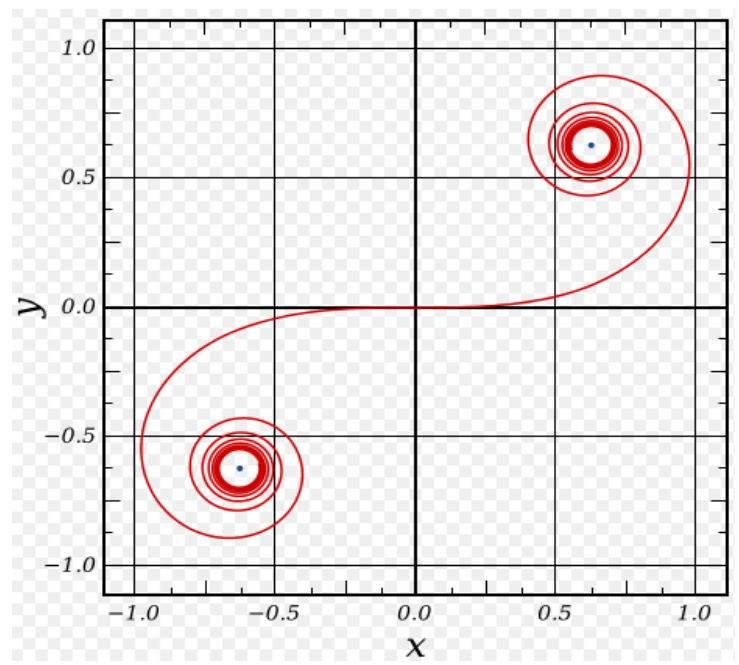

Figura 4.8: Espiral de Euler. 
A espiral de Euler é obtida a partir das funções $S(x)$ e $C(x)$, conhecidas como integrais de Fresnel [7]:

$$
\begin{aligned}
& S(x)=\int_{0}^{x} \operatorname{sen}\left(t^{2}\right) d t=\sum_{n=0}^{\infty}(-1)^{n} \frac{x^{4 n+3}}{(4 n+3)(2 n+1) !} \\
& C(x)=\int_{0}^{x} \cos \left(t^{2}\right) d t=\sum_{n=0}^{\infty}(-1)^{n} \frac{x^{4 n+1}}{(4 n+1)(2 n) !}
\end{aligned}
$$

As derivadas em cada eixo são dadas por:

$$
\begin{aligned}
& d x=C^{\prime}(t) d t=\cos \left(t^{2}\right) d t \\
& d y=S^{\prime}(t) d t=\operatorname{sen}\left(t^{2}\right) d t
\end{aligned}
$$

Logo, o comprimento da espiral medido da origem até um ponto $t_{0}$ é:

$$
L=\int_{0}^{t_{0}} \sqrt{d x^{2}+d y^{2}}=\int_{0}^{t_{0}} d t=t_{0}
$$

Para verificar a variação linear da curvatura ao longo do comprimento da espiral, basta notar que o vetor tangente a curva ao longo da espiral é dado por $\left[\cos \left(\mathrm{t}^{2}\right), \operatorname{sen}\left(\mathrm{t}^{2}\right)\right]$, ou seja, o ângulo ao longo da curva é $\theta=\mathrm{t}^{2}$. Então, a curvatura $\kappa$ é expressa por:

$\kappa=\frac{1}{R}=\frac{d \theta}{d t}=2 t$

Mas, como $t$ é o próprio comprimento da curva, verifica-se a linearidade entre a curvatura e o comprimento da curva.

Apesar da utilização da espiral de Euler apresentar diversas vantagens, ela não possui uma característica dinâmica adequada devido à grande taxa de variação da aceleração centrípeta ao longo da curva. Outro ponto desfavorável a sua utilização é o fato de sua forma paramétrica não ser matematicamente simples, sendo concebida por meio do somatório de integrais. Por esse motivo, a utilização do polinômio de Hermite para a concatenação de trajetórias ótimas de pistas de 
corridas apresenta algumas vantagens em relação à espiral de Euler. Sua forma paramétrica é constituída por simples expressões polinomiais do terceiro grau, acelerando o tempo computacional para o desenho e análise das curvas. Adicionalmente, o procedimento para achar a curva ótima de Hermite para concatenação é mais simples, sendo necessária apenas a variação do tempo $\tau$ até que a curva encontrada seja a de menor tempo possível respeitando-se os limites de aceleração e velocidade da pista de corrida. Para a espiral de Euler, este processo envolveria a variação do raio da curva ao final da espiral e do comprimento da curva.

Além disso, a curva de terceiro grau é a melhor aproximação para uma espiral de Euler. Utilizando a matriz de Hermite apresentada no item anterior, é possível observar na Figura 4.9 uma espiral de Euler e uma curva de Hermite ligando dois pontos. Elas são muito próximas e, devido a simplicidade da representação do polinômio de Hermite, a determinação das velocidades e acelerações ao longo da curva, se dá por simples derivação das equações de Hermite.

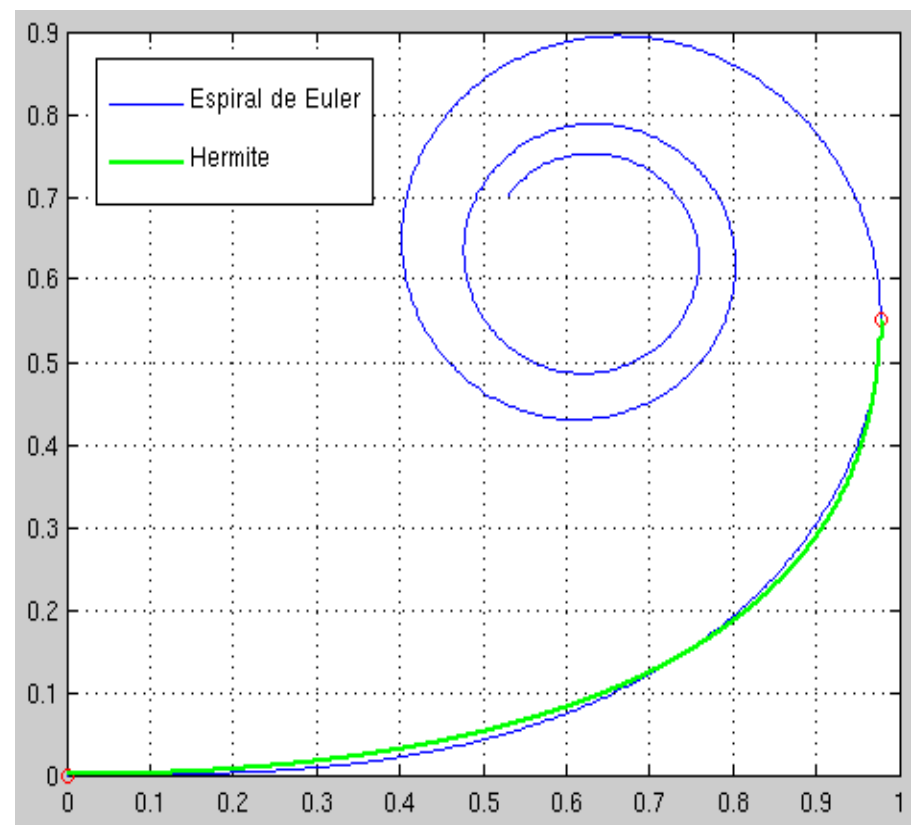

Figura 4.9: Espiral de Euler e Polinômio de Hermite.

Já na Espiral de Euler, o cálculo da velocidade do veículo ao longo da espiral, que não é trivial. Pelas próprias características de construção da curva, a derivada é sempre nula e, logo, não é representativa da aceleração tangencial de um veículo ao longo de uma pista de corrida. Em Xiong [5], é desenvolvido um 
método onde a curva é discretizada e a velocidade tangencial é calculada para cada ponto, utilizando a força de atrito na pista, e a relação $\kappa \cdot v^{2}=\mu \cdot g, \operatorname{com} \mu$ arbitrário e correspondente ao coeficiente de atrito na pista.

\subsection{Análise dinâmica das curvas propostas}

Neste trabalho, a análise dinâmica do veículo será feita em duas dimensões (x, y). Na curva de Hermite, os pontos da curva são definidos pela equação paramétrica $[\mathrm{x}(\mathrm{t}), \mathrm{y}(\mathrm{t})]$.

O comprimento s de uma curva paramétrica é dado por:

$s=\int_{0}^{t} \sqrt{\left(\frac{d x}{d t}\right)^{2}+\left(\frac{d y}{d t}\right)^{2}} d t$

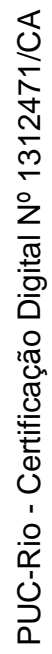

Assim define-se a variação de $s$ ao longo do tempo como:

$$
\frac{d s}{d t}=\sqrt{\left(\frac{d x}{d t}\right)^{2}+\left(\frac{d y}{d t}\right)^{2}}
$$

O ângulo $v(n u)$ do vetor tangente ao longo da curva (em relação ao eixo x) é definido na Figura 4.10 como Path angle.

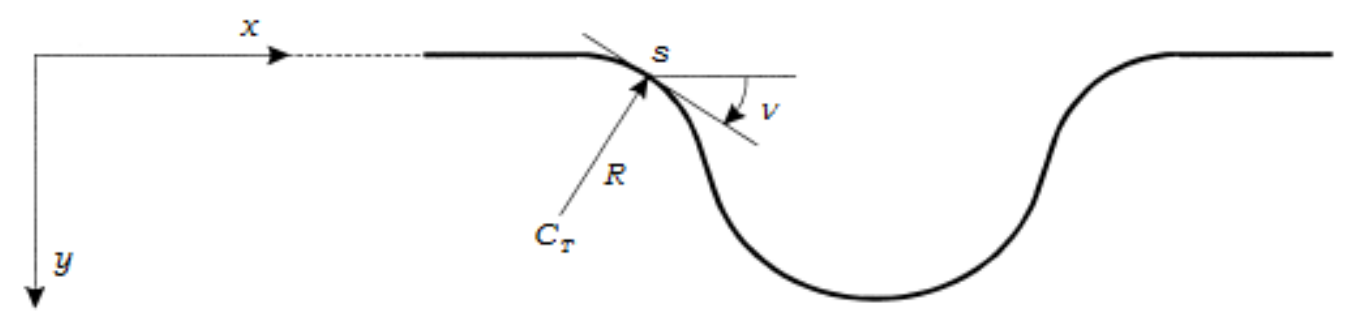

Figura 4.10: Ângulo ao longo da curva.

Observando-se a figura acima, pode-se escrever:

$$
\frac{d x}{d s}=\cos v, \quad \frac{d y}{d s}=\operatorname{sen} v, \quad \frac{d y}{d x}=\tan v
$$


Consequentemente:

$v=\arctan \left(\frac{d y}{d x}\right)$

Onde $\frac{d y}{d x}$ pode ser definido como:

$\frac{d y}{d x}=\frac{d y}{d t} \cdot \frac{d t}{d x}=\frac{\frac{d y}{d t}}{\frac{d x}{d t}}$

É importante ressaltar que, para o cálculo ser feito corretamente, é preciso que o arco tangente seja calculado no quadrante correto. A curvatura $\kappa_{p}$ e o raio $R_{p}$ da curva estão relacionados ao ângulo tangente à curva pela seguinte relação:

$$
\kappa_{p}=\frac{1}{R_{p}}=\frac{d v}{d s}
$$

Da mesma forma, esta derivada pode ser obtida por meio da seguinte relação:

$\frac{d v}{d s}=\frac{\frac{d v}{d t}}{\frac{d s}{d t}}$

Por fim, a velocidade tangencial ao longo da curva é dada por $\mathrm{v}=\frac{\mathrm{ds}}{\mathrm{dt}}$, a aceleração tangencial é $\mathrm{a}_{\mathrm{t}}=\frac{\mathrm{dv}}{\mathrm{dt}}$ e a aceleração normal é $\mathrm{a}_{\mathrm{n}}=\frac{\mathrm{v}^{2}}{\mathrm{R}_{\mathrm{p}}}$.

Nas figuras a seguir, são apresentadas as análises de algumas curvas de curvatura e raio conhecidos para validação das equações apresentadas acima. Como, para algumas curvas, não é conhecida a expressão da posição ao longo do tempo, foi feita uma derivação numérica (diferenças finitas) para o cálculo dos resultados, que consiste na razão entre o vetor variação de posição por uma variação de tempo $(\Delta t)$, tão pequena quanto se queira. 
Na Figura 4.11, são apresentados o ângulo, a curvatura e o raio, bem como a velocidade tangencial e a aceleração tangencial ao longo de um trecho curvilíneo de raio 2 e centro no ponto $(3,4)$. Observe que os resultados estão coerentes com o esperado, já que para um trecho circular de 0 a $\pi / 2$, a aceleração tangencial é nula, o ângulo tangente varia linearmente de $90^{\circ}$ a $180^{\circ}$ e o raio é constante 2 . Do ponto de vista físico, ao supor um veículo realizando esta trajetória de comprimento $\pi \mathrm{m}$ à velocidade constante de $2 \mathrm{~m} / \mathrm{s}$, ele levaria $1,5708 \mathrm{~s}$ para completar o trajeto. Esta curva é similar àquela que representa o percurso ótimo em uma curva de $90^{\circ} \mathrm{em}$ uma pista de corrida.
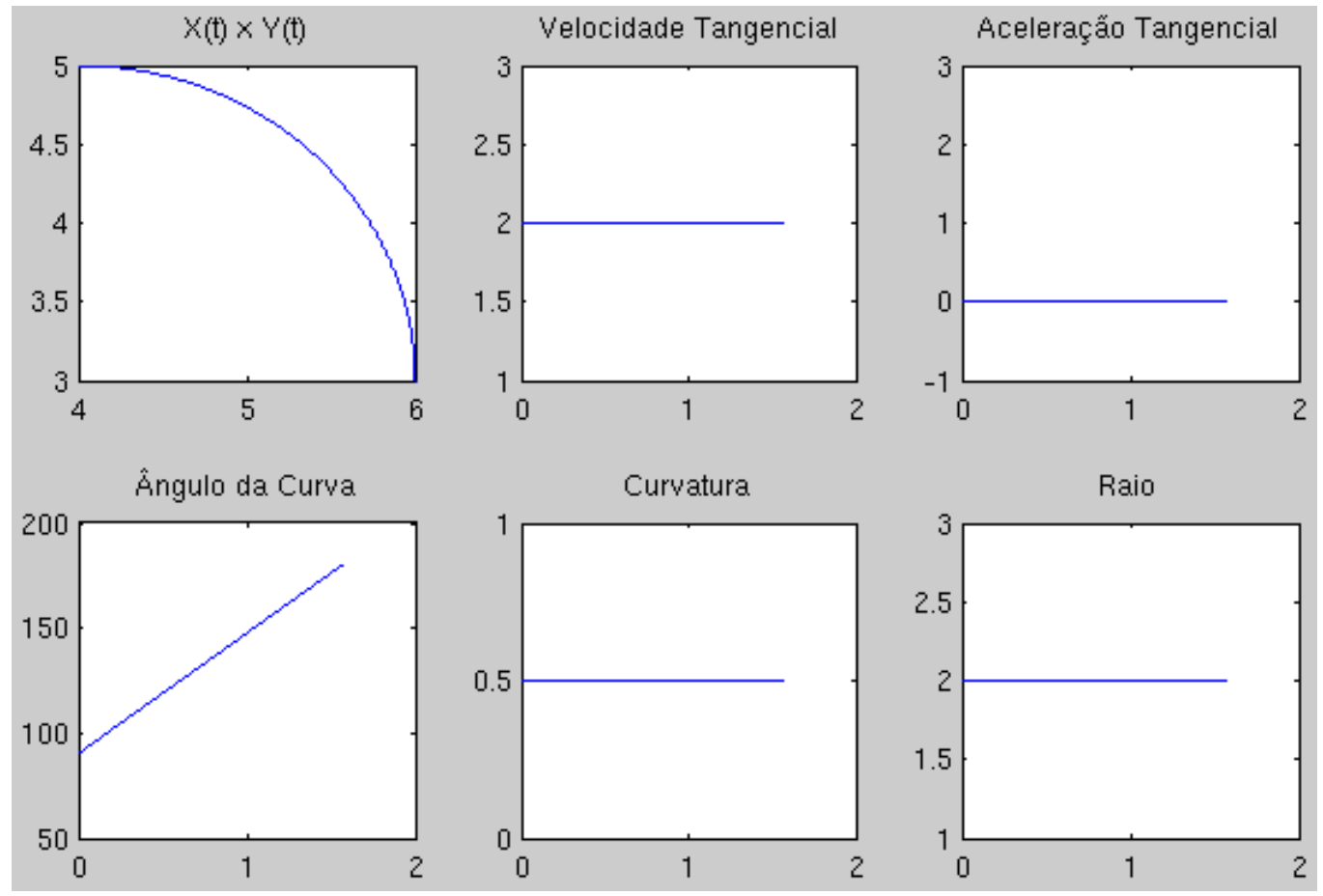

Figura 4.11: Resultados para uma curva circular.

Na Figura 4.12, são apresentados os resultados para um arco de uma espiral de Euler. Observe que a curvatura varia linearmente ao longo do tempo com coeficiente angular 2 e o ângulo tangente de forma quadrática, como demonstrado na secção 4.2. Como na espiral de Euler o comprimento da curva é o tempo, logo a velocidade tangencial ao longo da curva é constante igual 1. Analisando novamente sob um ponto de vista físico, um veículo completaria esta trajetória de comprimento $1,2910 \mathrm{~m}$ com uma velocidade constante de $1 \mathrm{~m} / \mathrm{s}$, em 1,2910s. 

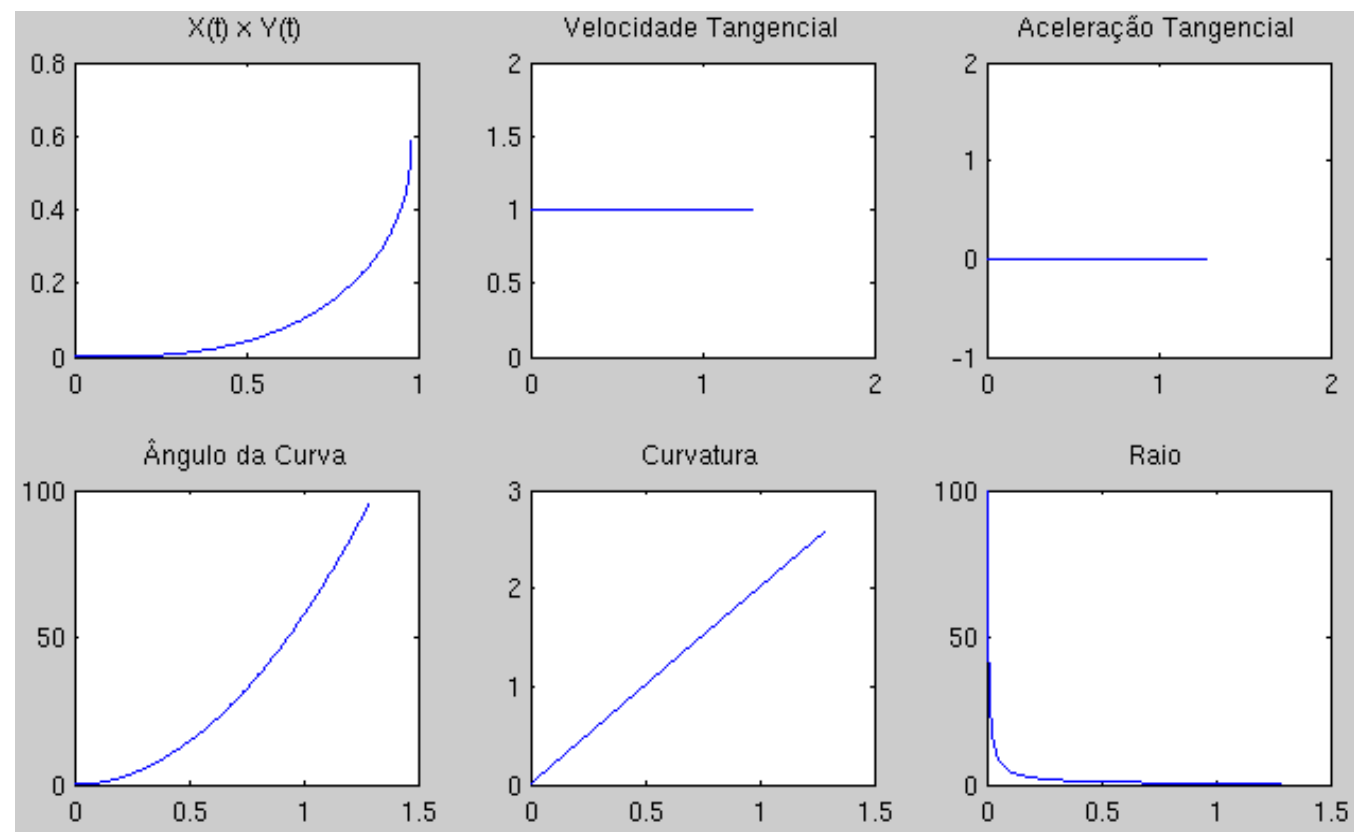

Figura 4.12: Resultados para uma espiral de Euler.

$\mathrm{Na}$ espiral de Euler, como o vetor tangente tem valor constante ao longo da trajetória, a velocidade tangencial não descreve bem a dinâmica de um veículo de corrida. Por isso, como mostra Xiong [5], para se utilizar a espiral de Euler como trajetória ótima para curvas em pistas de corrida é preciso recalcular a velocidade do veículo em cada ponto da trajetória utilizando a relação entre a aceleração normal e a força centrípeta, sendo necessário conhecer previamente os valores de coeficiente de atrito da pista. Utilizando a curva de Hermite, os valores de velocidade tangencial são exatamente aqueles obtidos pela derivada da posição.

Por fim, na Figura 4.13 estão os resultados para a curva de Hermite que melhor aproxima o trecho de espiral de Euler estudado na Figura 4.9. O ângulo tangente varia de forma similar à espiral de Euler, mas, por se tratar de um polinômio do terceiro grau, a velocidade tangencial não é constante ao longo da trajetória. Esse é um dos pontos que torna a curva de Hermite qualificada para a aplicação neste trabalho. Ela estima melhor o movimento de um veículo de corrida, já que o piloto dificilmente mantém sua velocidade constante ao longo do movimento, freando na entrada da curva e acelerando na saída, exatamente como varia o vetor tangente em uma curva de Hermite. O comprimento desta curva, segundo à Equação 4.23 é de 1,2568m. Sendo percorrido à velocidade apresentada na Figura 4.13, um veículo levaria 1,365s para concluir o trajeto. 

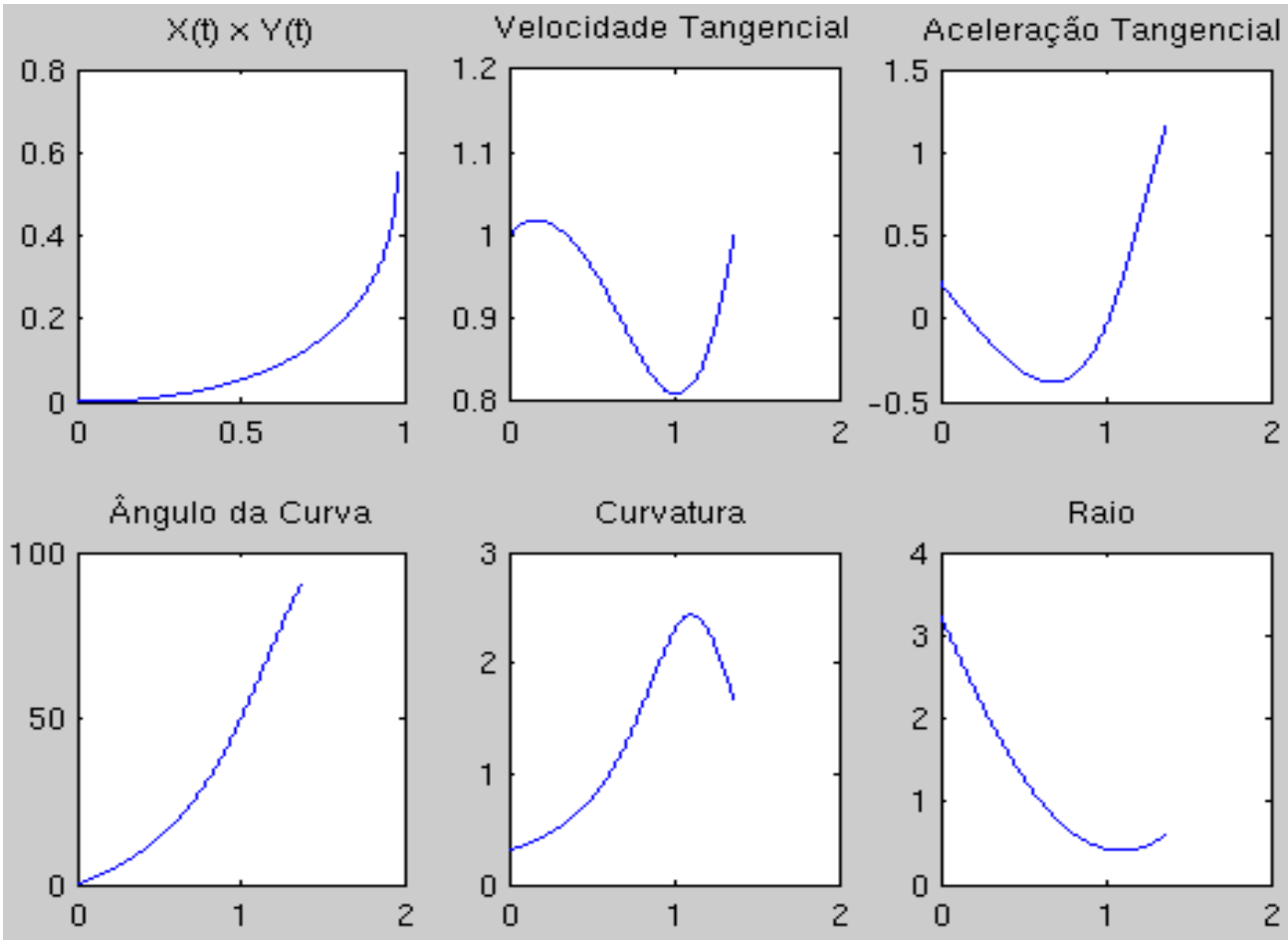

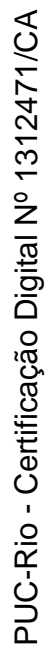

Figura 4.13: Resultados para uma curva de Hermite. 


\section{Algoritmo para Concatenação}

Uma vez analisados os aspectos dinâmicos associados às curvas de Hermite e tendo confirmado a elegibilidade dessa curva para aplicação neste projeto, foi desenvolvido um algoritmo de concatenação. O algoritmo consiste em buscar o tempo $\tau$ que gera a curva de menor comprimento dentro dos limites da pista e cujas restrições de aceleração tangencial e normal sejam respeitadas. Vale ressaltar que, tratando-se de uma curva de Hermite, ao aumentar o parâmetro de tempo final $\tau$ da curva, o comprimento total também será maior, de forma que a curva de menor comprimento será também a curva de menor tempo. Um dos maiores desafios na implementação deste algoritmo foi garantir que as restrições de aceleração normal e tangencial não fossem violadas. Como a concatenação está sendo feita a partir de uma curva polinomial cúbica, a aceleração também irá variar ao longo da curva de forma polinomial, logo, é preciso garantir que todos os máximos e mínimos das curvas de aceleração estejam dentro dos limites. Em alguns casos, como será discutido adiante, não é encontrada uma solução dentro das restrições propostas.

O algoritmo foi desenvolvido em Matlab ${ }^{\circledR}$, por ser uma linguagem de ampla utilização hoje em dia, fácil acesso e possuir funções eficientes para solução de problemas de otimização com restrições. Na implementação do algoritmo de concatenação foram utilizadas duas funções da biblioteca Optimization Toolbox, do Matlab ${ }^{\circledR}$ : fminbnd e fmincon.

As funções desta biblioteca de otimização do Matlab ${ }^{\circledR}$ apresentam ainda outras vantagens importantes: elas são fáceis de usar, são eficientes em termos de custo computacional, é possível escolher especificamente o algoritmo com que o problema será resolvido e os parâmetros de simulação podem ser determinados e modificados com facilidade. A função fmincon é especialmente utilizada para resolver problemas de otimização de uma ou mais variáveis com restrições lineares ou não lineares, da forma representada pela Equação 5.1. 


$$
\left\{\begin{array}{lll}
\operatorname{Min}_{x} f(x) & \\
\text { s.t. } & A \cdot x \leq B & \text { (restrições lineares) } \\
& A e q \cdot x=B e q & \text { (restrições lineares) } \\
& C(x) \leq 0 & \text { (restrições não lineares) } \\
& C e q(x)=0 & \text { (restrições não lineares) } \\
x^{l} \leq x \leq x^{u} & \text { (limites) }
\end{array}\right.
$$

A função fmincon implementa quatro diferentes algoritmos: interior point, SQP (Sequential Quadratic Programming), active set and trust region reflective. É possível escolher explicitamente um deles ou deixar que a própria função escolha o melhor algoritmo baseado nos dados de entrada. Para a aplicação neste trabalho, foram testados os diferentes algoritmos disponíveis para a função fmincon e o algoritmo interior point foi o que apresentou melhores resultados em termos de eficiência e robustez. Além disso, ele garante que durante o processo de otimização nenhuma iteração irá apresentar um valor de $\tau$ fora do intervalo permitido, o que poderia causar um erro na execução do algoritmo. Para maiores detalhes sobre o método dos pontos interiores, consultar as referências [17] e [18].

A outra função que será utilizada é a fminbnd. O objetivo desta função é minimizar funções lineares ou não lineares de apenas uma variável, com limites superior e inferior conhecidos. Ela será utilizada numa sub-rotina do algoritmo de concatenação das trajetórias ótimas independentes. A vantagem de se utilizar a função fminbnd reside no fato de ela ser mais simples e, portanto, ideal para se aplicar em problemas de uma variável sem restrições.

A geração das trajetórias ótimas de cada curva independente já foi estudada anteriormente neste trabalho. Além das próprias curvas, o algoritmo gera também um resumo dos dados que serão utilizados para a concatenação desses trechos e mostra na janela de comando do Matlab ${ }^{\circledR}$, como mostra a Figura 5.1. O algoritmo de concatenação vai utilizar os pontos de entrada e saída das curvas e suas respectivas velocidades (constantes nas trajetórias individuais) no processo de otimização.

$\mathrm{Na}$ Figura 5.1 é possível perceber que as trajetórias das curvas independentes são sempre geradas com a aceleração normal máxima e a aceleração tangencial nula. 


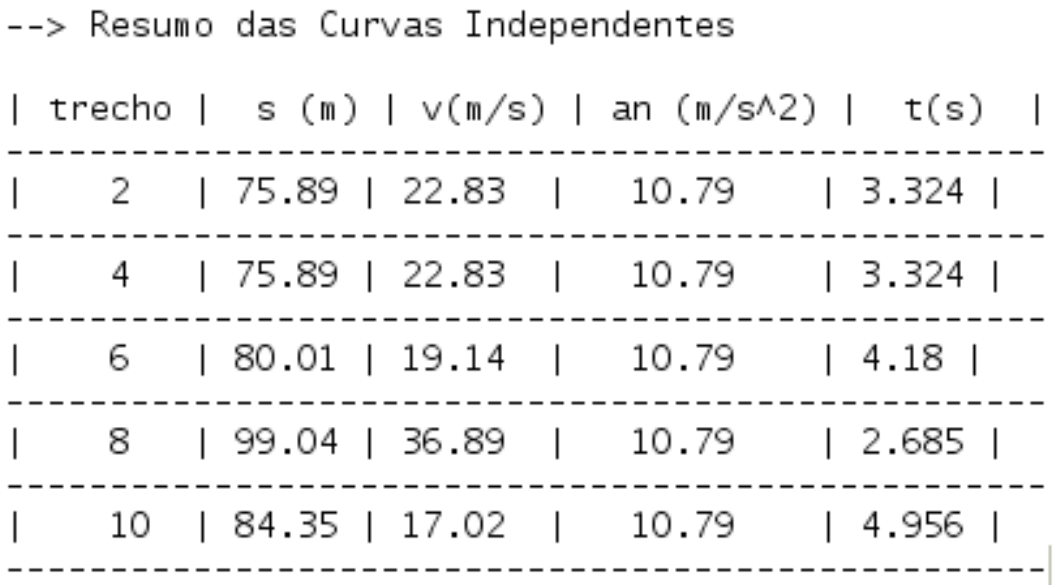

Figura 5.1: Resultados da geração de trajetórias ótima para curvas.

O próximo passo é determinar os pontos que serão concatenados pela curva de Hermite. Conforme discutido na seção 4.1, nos trechos em curva, a melhor abordagem para manter uma velocidade de saída maior é concatenar os pontos de saída de cada curva. A Figura 4.2 ilustrou o processo de identificação dos pontos $P_{1}$ e $P_{4}$ e dos vetores $\overrightarrow{R_{1}}$ e $\overrightarrow{R_{4}}$ para traçar a curva de Hermite.

$\mathrm{O}$ trecho ilustrado na Figura 4.4 pertence à pista teste, utilizada para o desenvolvimento e testes do algoritmo de determinação das curvas de Hermite. No entanto, podem existir curvas de menor ângulo ou de raios muito pequenos para as quais as trajetórias ótimas dos trechos independentes não estão inteiramente dentro da pista. Na pista teste, isso não acontece em nenhuma das curvas. Como exemplo de situações em que os pontos P1 e/ou P4 estejam fora da pista, foi apresentado o Circuito de Catalunha, na Figura 3.9. Como o circuito é muito mais complexo, ele apresenta curvas em que os pontos de entrada e saída não estão dentro dos limites geométricos da pista, sendo necessário escolher pontos diferentes de concatenação. Para estas configurações de trajetórias ótimas, será estudada a melhor forma de se escolher os pontos para concatenação. As opções avaliadas consistem em se concatenar as duas curvas pelos seus respectivos ápices ou concatenar ápices com as saídas das curvas seguintes.

Uma vez identificados os pontos de concatenação, foram modeladas as restrições e funções objetivos das rotinas de otimização. $O$ processo de concatenação foi modelado de forma diferente para trechos em curva e para trechos retos, uma vez que as restrições são diferentes. O tipo de concatenação é identificado através da direção e sentido dos vetores tangentes no ponto inicial e 
final do trecho a ser concatenado. Se os vetores tangentes são paralelos, têm mesmo sentido e as curvas ótimas individuais não se interceptam, a concatenação é uma reta, caso contrário, é uma curva.

O primeiro processo a ser discutido será a modelagem da concatenação de trechos em curva. Ela foi dividida em dois problemas. O primeiro consiste em, dada uma curva de Hermite, determinar o tempo - menor parâmetro $\tau$ - para o qual a distância entre o ponto da curva neste determinado tempo e o centro da restrição correspondente da pista seja mínima. O segundo consiste em determinar a curva de Hermite de menor tempo cujo ponto de distância mínima do centro da restrição esteja dentro da pista.

\subsection{Algoritmo para sub-rotina do processo de otimização}

A primeira parte do problema de otimização foi implementar uma sub-rotina que irá ser chamada pela rotina principal em cada iteração do processo. Esta subrotina implementa o problema de otimização que consiste em determinar o ponto de uma curva de Hermite mais perto do centro da restrição interna da pista, como ilustra a Figura 5.2 para um caso particular em que se devem concatenar os pontos $P_{1}$ e $P_{4}$ em uma curva de $90^{\circ}$.

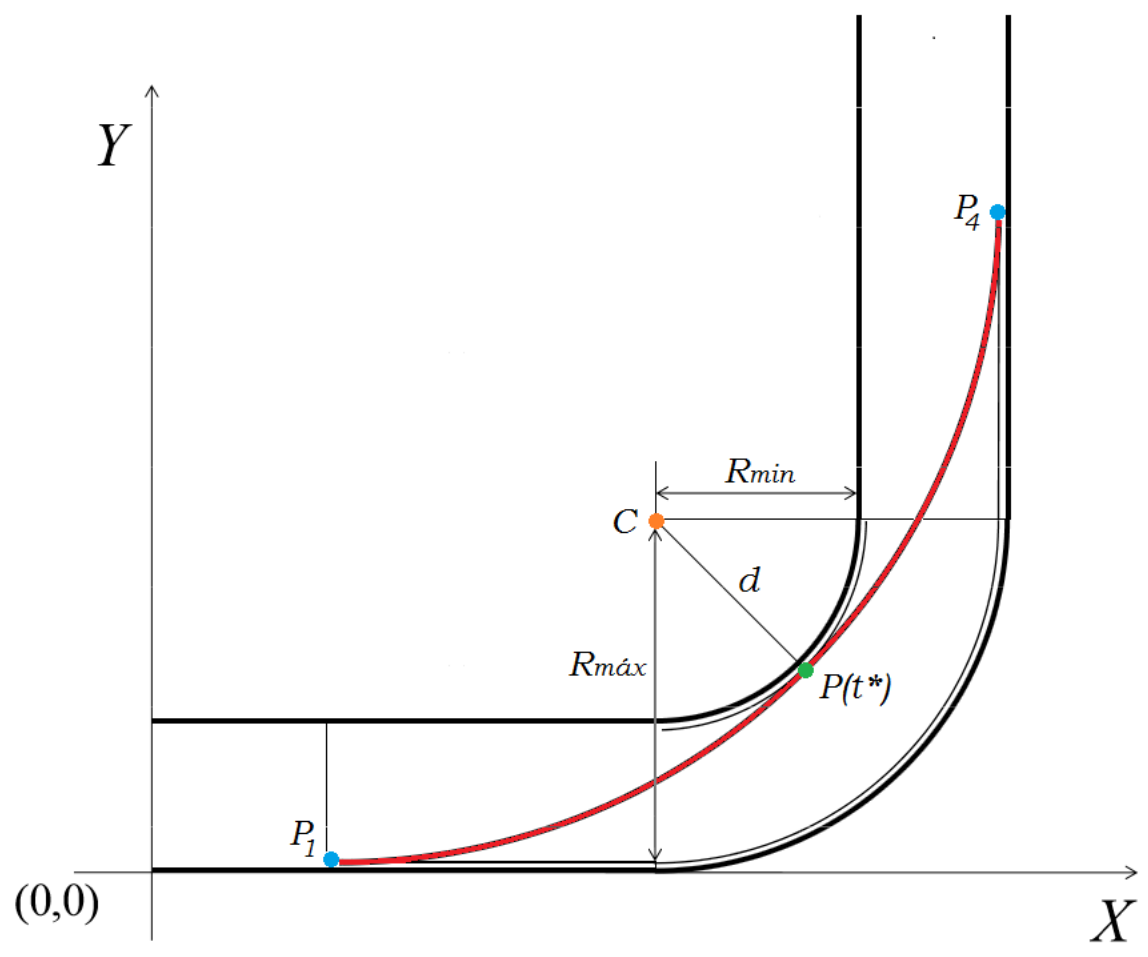

Figura 5.2: Modelo do problema de otimização - achar o ponto mais perto do centro da restrição interna. 
No exemplo da Figura 5.2, o ponto mais perto do centro da restrição marcado como $\mathrm{C}$ - é o ponto marcado em verde $\mathrm{P}\left(\mathrm{t}^{*}\right)$, que é a coordenada correspondente na curva de Hermite ao tempo ótimo t*.

A modelagem matemática do problema é:

$\min _{t} d^{2}=(P(t)-C)^{2}$

s.t. $0 \leq t \leq \tau$

Da seção 4.1 foi mostrado que, a partir da matriz de Hermite, cada ponto pertencente à curva é descrito pela expressão apresentada na Equação 5.3.

$P(t)=(x(t), y(t))$

$x(t)=a_{x} t^{3}+b_{x} t^{2}+c_{x} t+d_{x}$

$y(t)=a_{y} t^{3}+b_{y} t^{2}+c_{y} t+d_{y}$

Os coeficientes são conhecidos e calculados para uma curva de tempo conhecido $\tau$. Desta forma, conhecendo as coordenadas do centro da restrição interna da pista $C=\left(x_{c}, y_{c}\right)$, o problema pode ser descrito da seguinte forma:

$$
\begin{aligned}
\min _{t} \quad d^{2} & =\left(\sqrt{\left(x(t)-x_{c}\right)^{2}+\left(y(t)-y_{c}\right)^{2}}\right)^{2} \\
& =\left(x(t)-x_{c}\right)^{2}+\left(y(t)-y_{c}\right)^{2}
\end{aligned}
$$

s.t. $0 \leq t \leq \tau$

A escolha em usar $d^{2}$ ao invés de apenas $d$ reside no fato de que, como se trata de um problema de minimização, o algoritmo tentaria escolher um ponto cuja distância fosse negativa e logo menor, porém em módulo, mais distante. Ao utilizar $d^{2}$ esse problema é resolvido. É importante ressaltar que o modelo descreve um problema sem restrições cuja função objetivo possui apenas uma variável, logo a ferramenta escolhida para a solução do problema de otimização é a função fminbnd, já apresentada anteriormente. A Figura 5.3 mostra o resultado da otimização para diversas curvas de Hermite com o parâmetro $\tau$ variando entre $0,01 \mathrm{~s}$ e $5 \mathrm{~s}$. 


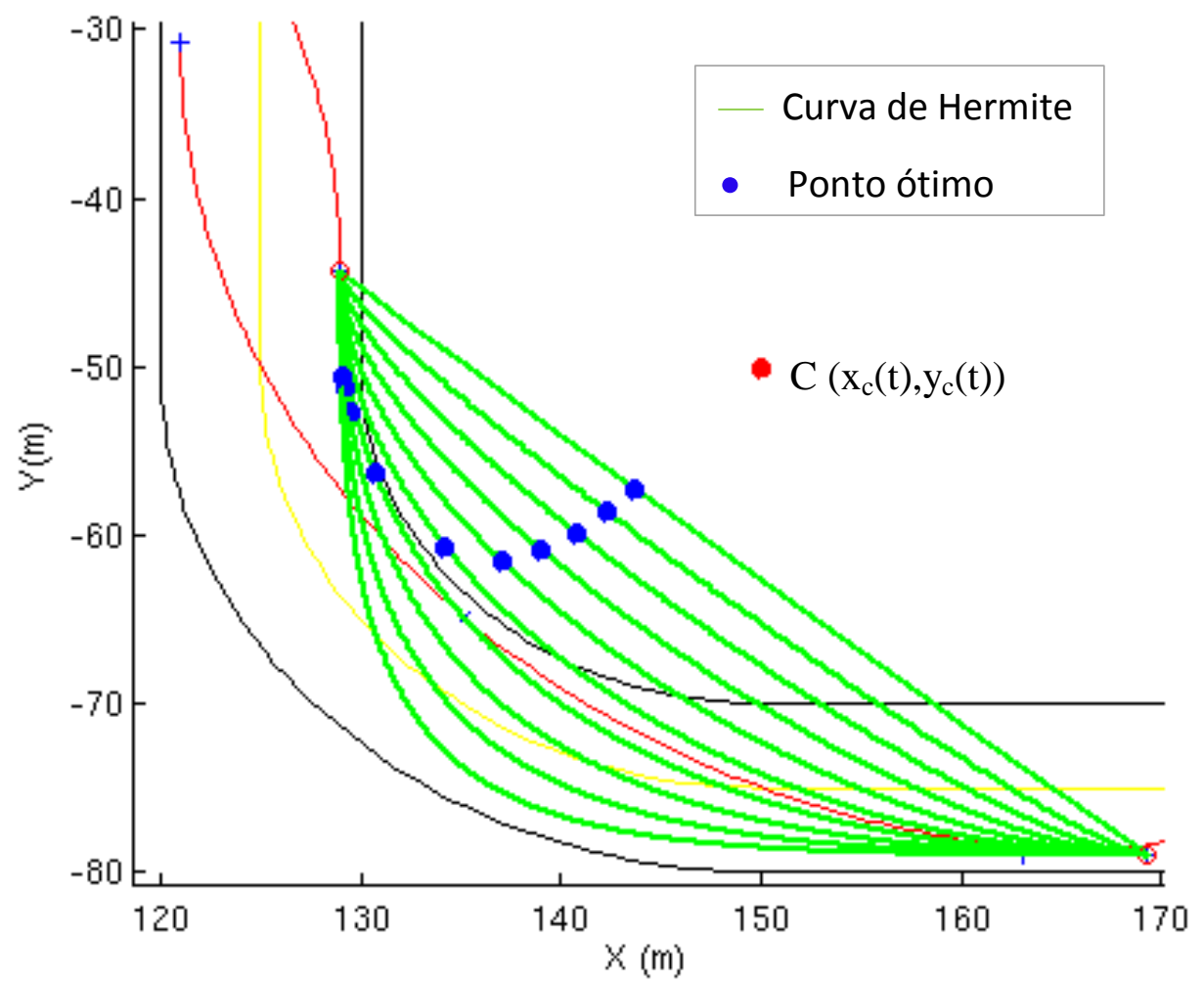

Figura 5.3: Resultado do fminbnd para algumas curvas de Hermite.

Na Figura 5.3, o ponto ótimo está marcado pelo ponto azul, as curvas de Hermite são as verdes e o centro do raio mínimo da pista está identificado como o ponto $\mathrm{C}$, marcado com um ponto vermelho.

Com esses resultados, é possível concluir que a modelagem proposta descreve bem o problema, já que a solução obtida condiz com os resultados esperados. Além disso, o tempo computacional para a solução deste problema ficou em torno de $0,8 \mathrm{~s}$ em média por curva, o que é bastante eficiente.

\subsection{Concatenação dos trechos em curva: modelo sem restrições de aceleração}

Uma vez que se sabe qual é o ponto de uma determinada curva de Hermite que está mais perto do centro da restrição de raio interno da pista, a solução do problema de concatenação se resume a encontrar a curva de Hermite cuja distância entre este ponto e o centro da restrição seja mínima. É claro que, neste problema, devem ser modeladas algumas restrições que garantam que a solução seja uma curva inteiramente contida nos limites da pista. Além disso, as restrições 
que atestam os limites de aceleração normal e tangencial do veículo devem ser consideradas.

Primeiramente foi modelado e testado o problema sem a inclusão das restrições de aceleração. A modelagem do problema proposto é a seguinte:

$$
\begin{array}{ll}
\min _{\tau} & d_{h}=\left(P(\tau)_{\text {fminbnd }}-R_{\text {min }}{ }^{2}\right)^{2} \\
\text { s.t. } & P(\tau)_{\text {fminbnd }}-R_{\text {máx }}{ }^{2} \leq 0 \\
& \tau_{\min } \leq \tau \leq \tau_{\max }
\end{array}
$$

É possível notar que, pela própria construção da função objetivo, espera-se obter a curva tangente a pista, ou seja, a curva cuja distância entre o ponto mais perto de $\mathrm{C}$ e o ponto $\mathrm{C}$ seja igual ou mais próxima possível do próprio raio interno da pista. A primeira restrição foi incluída para garantir que a curva não ultrapasse o raio externo na pista no trecho a ser concatenado e a segunda, garante os limites superior e inferior para o parâmetro $\tau$.

Para a concatenação da pista teste, os limites foram definidos como $\tau_{\min }=0,05 \mathrm{~s}$ e $\tau_{\max }=10 \mathrm{~s}$. Estes valores foram escolhidos com base em testes experimentais com o algoritmo, nos quais foi determinado o menor valor de tempo para o qual a curva de Hermite gerada não apresentasse valores fisicamente impossíveis de aceleração tangencial e o maior valor de tempo que não fizesse a curva degenerar e formar um loop. Eventualmente, dependendo das distâncias, estes limites deverão ser redefinidos para outros circuitos.

Ressalta-se ainda, pelo mesmo motivo citado na implementação da subrotina apresentada anteriormente, que a utilização do quadrado da distância impede que o algoritmo apresente soluções negativas por ser um problema de minimização. Esta modelagem, diferente do anterior, possui restrições não lineares. Nesse caso, a função fminbnd não pode ser utilizada e por isso, a função escolhida para a solução deste problema foi a fmincon, também já apresentada anteriormente neste trabalho.

O resultado obtido está ilustrado na Figura 5.4. 


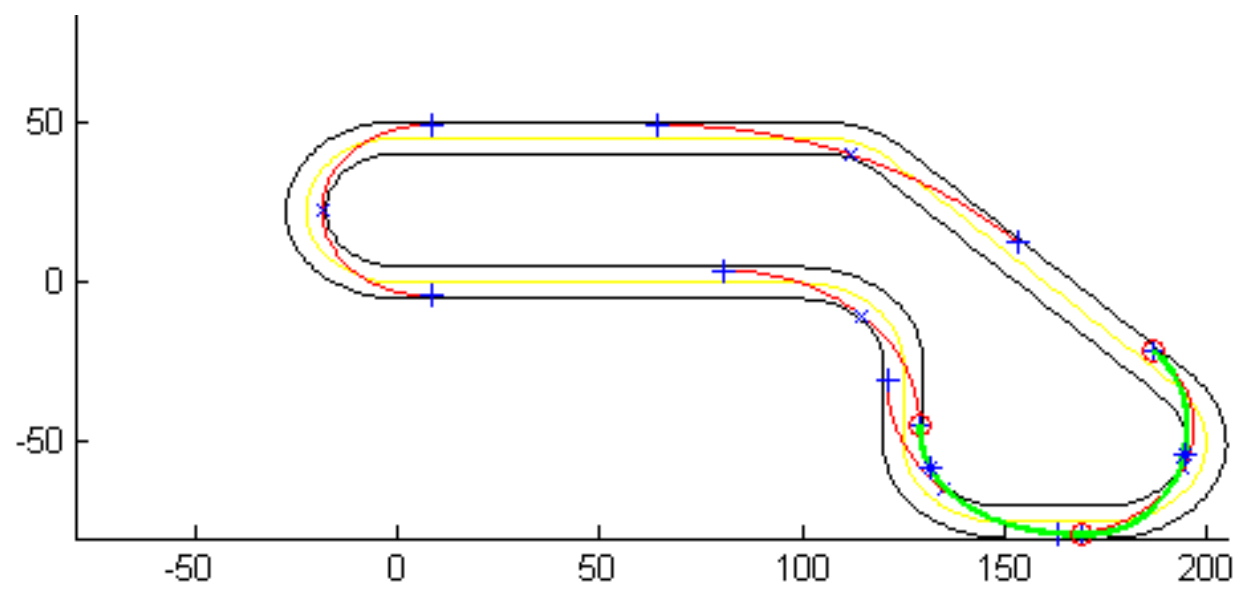

Figura 5.4: Resultado do fmincon para as curvas da pista teste.

Na Figura 5.4, como esperado, a curva ótima dada como resultado da otimização (em verde) é a curva tangente à pista no raio interno, confirmando assim a confiabilidade do modelo. O ponto mais perto do centro da curva da pista está representado pelo asterisco azul. O algoritmo encontrou a curva de Hermite cujo ponto mais perto fosse o ponto tangente, ou seja, a distância entre o ponto mais perto e o centro da curva de restrição é o próprio $R_{\min }$. A tangência entre a curva e a pista pode ser mais bem verificada na Figura 5.5, que apresenta os trechos concatenados mais detalhados.

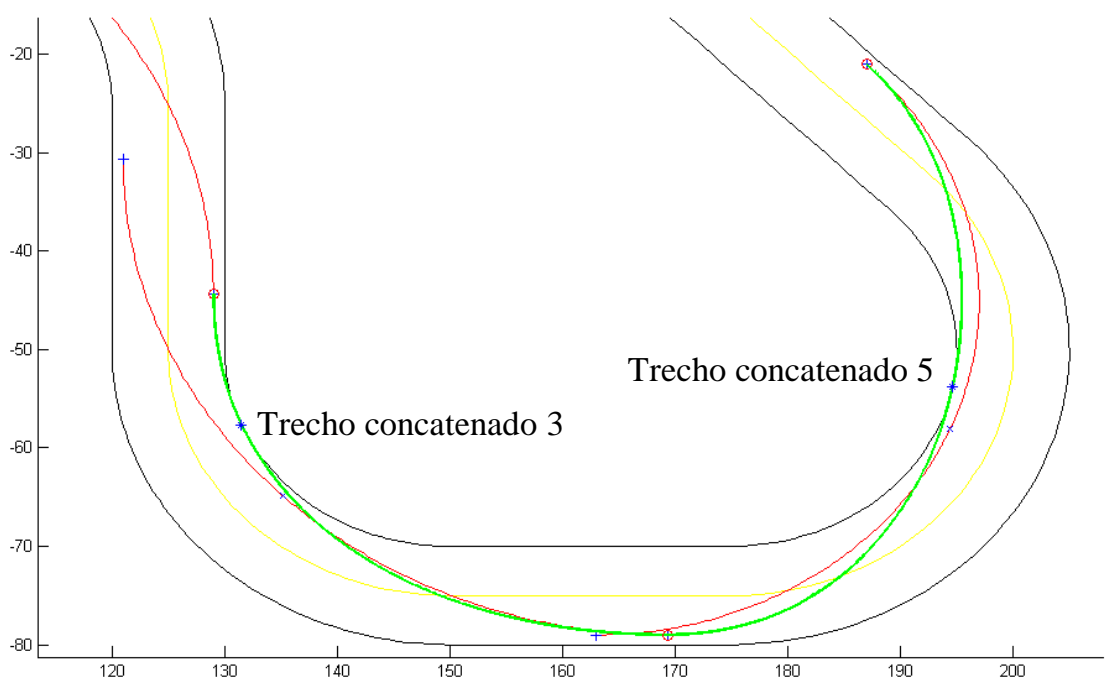

Figura 5.5: Trechos concatenados sem restrição de aceleração mais detalhados.

O algoritmo que percorre todos os trechos concatenando apenas as curvas levou cerca de 10s para concatenar os trechos em curva da pista teste, o que é um resultado bastante eficiente, dado que o algoritmo se utiliza de duas rotinas de 
otimização e uma delas - fminbnd - é repetida em todas as iterações. No entanto, ao se analisar as acelerações tangencial e normal nas curvas de Hermite apresentadas como solução, verificou-se que as mesmas ultrapassaram os limites máximos do veículo, que foram definidos como: $a_{n}=1,1 \mathrm{~g}=10,79 \mathrm{~m} / \mathrm{s}^{2} \mathrm{e}$ $a_{t}=0,5 g=4,905 m / s^{2}$ [19]. O algoritmo desenvolvido gera também um relatório com o comprimento da curva, o tempo de percurso, a aceleração tangencial e normal máxima de cada uma das curvas de concatenação. O relatório para a pista teste está mostrado na Figura 5.6.

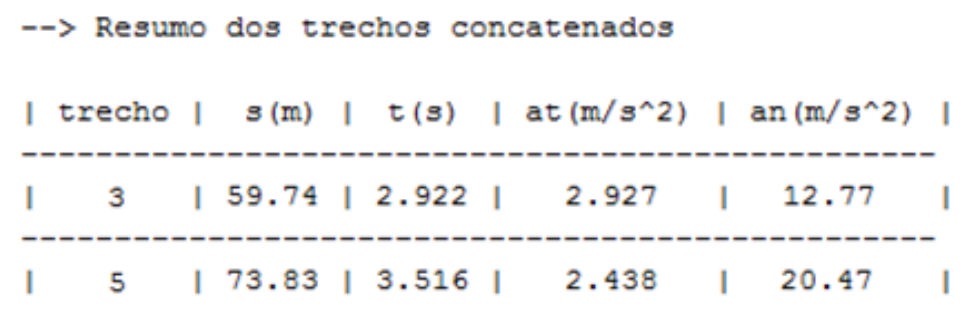

Figura 5.6: Resumo dos trechos concatenados da pista teste.

As Figuras 5.7 e 5.8 mostram como variaram a velocidade e as acelerações nos trechos concatenados.
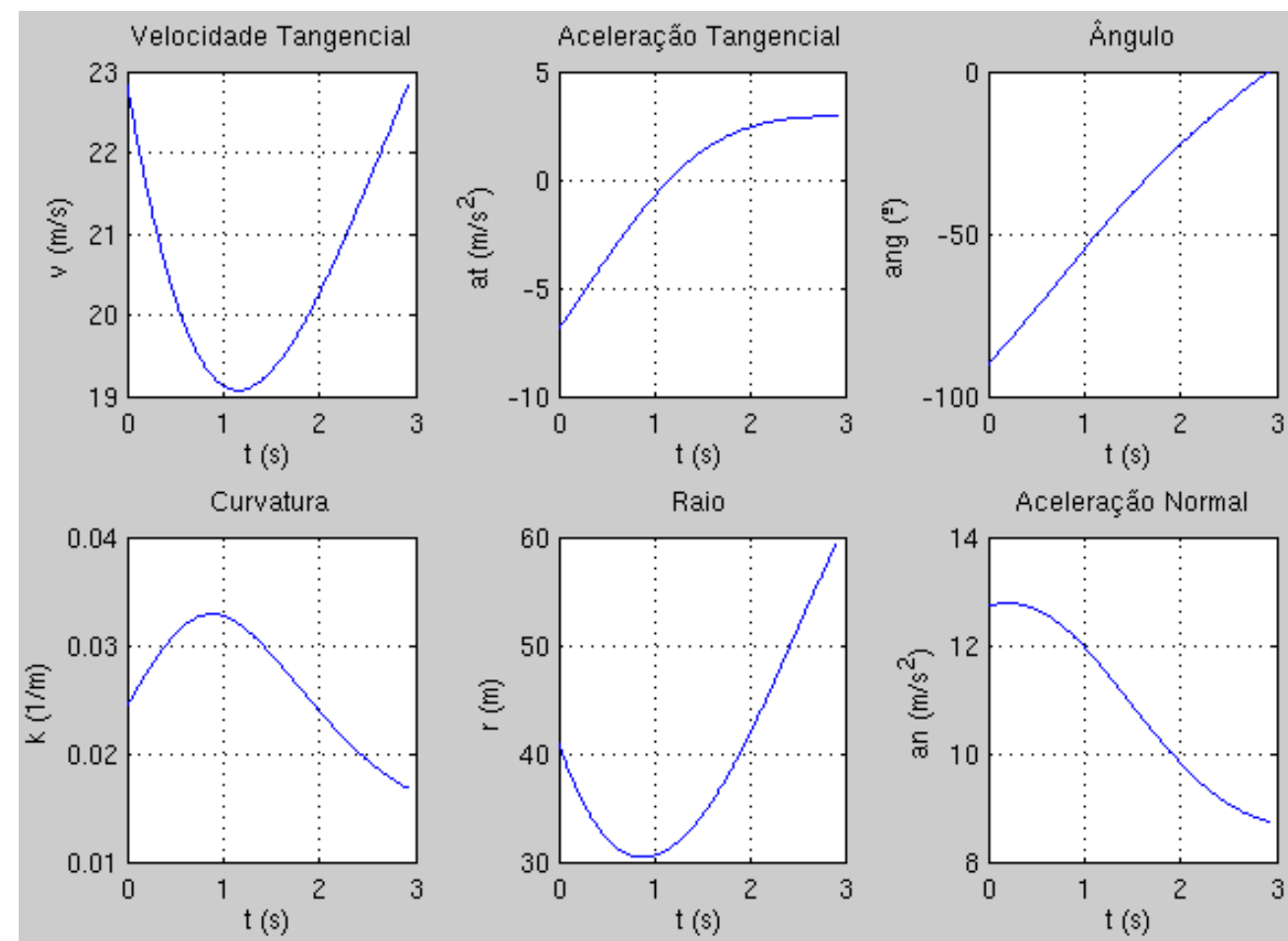

Figura 5.7: Velocidade e acelerações para o trecho concatenado 3. 

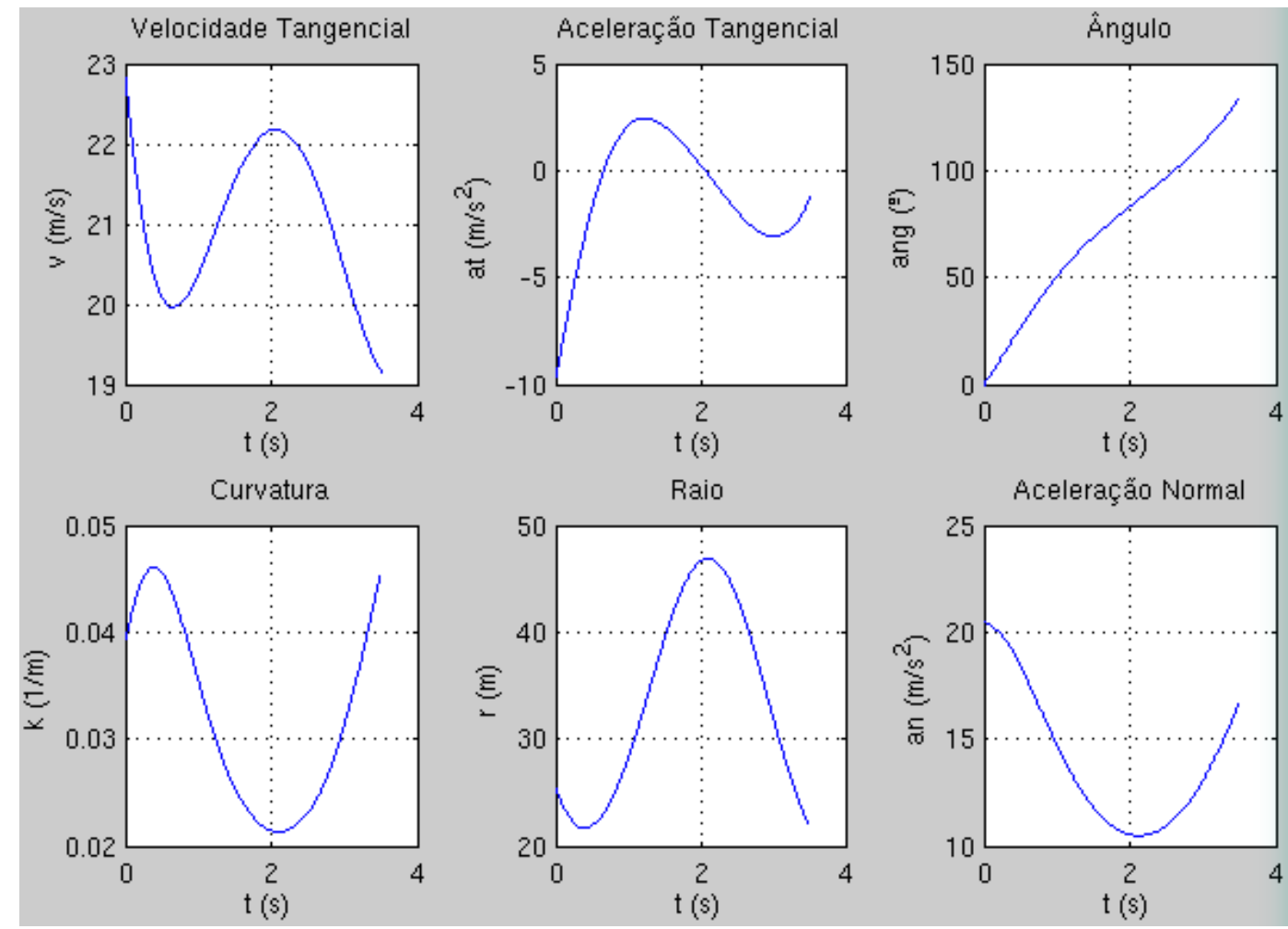

Figura 5.8: Velocidade e acelerações para o trecho concatenado 5.

Observe nas Figuras 5.6, 5.7 e 5.8 as acelerações tangenciais máximas de ambas as curvas se mantiveram dentro do limite, porém as acelerações normais máximas não. As curvas tangentes à pista que ligam os pontos de saída são muito “fechadas", levando a um aumento da aceleração normal que precisa ser feita no trajeto, especialmente no momento de entrada na curva. Ainda, as velocidades no início e no final do trajeto são exatamente aquelas pré-definidas, garantindo que a concatenação por curva de Hermite respeita as derivadas nos pontos inicial e final.

Quanto à variação da velocidade no tempo, elas estão bastante coerentes com o que se espera de um piloto em uma curva deste tipo. No trecho concatenado 3, a velocidade diminui na entrada da curva com aceleração tangencial negativa indicando frenagem. Uma vez passada a entrada curva, a aceleração fica positiva para aumentar a velocidade na saída da curva. Este resultado é bastante satisfatório, pois foi um dos motivos da concatenação pelos pontos de saída ter sido escolhida: redução de velocidade na entrada da curva, porém ganho de velocidade na saída. No trecho concatenado 5, o comportamento é similar ao do trecho concatenado anterior, porém como a curva é muito fechada, no final do trecho a velocidade precisa reduzida novamente para que se chegue no segundo ponto de concatenação com a velocidade desejada. 


\subsection{Concatenação dos trechos em curva: modelo com restrições de aceleração}

Tendo-se analisado os resultados do algoritmo para um modelo sem restrições de aceleração, verificou-se que as mesmas extrapolavam os limites dinâmicos do veículo. A análise ainda assim se mostrou válida para comprovar a eficiência do algoritmo desenvolvido, que foi capaz de apresentar uma solução dentro do esperado para o modelo proposto. De forma a se obter um resultado mais compatível com a realidade, o algoritmo foi modificado para ser executado incluindo as restrições de aceleração normal e tangencial do veículo. A função objetivo permaneceu a mesma e três novas restrições foram acrescentadas, a limitação as acelerações tangencial positiva, tangencial negativa (frenagem) e normal. O modelo alterado está representado pela Equação 5.6, i.e.:

$\min _{\tau} \quad d_{h}=\left(P\left(\tau^{*}\right)_{\text {fminbnd }}-R_{\min }{ }^{2}\right)^{2}$

s.t. $P\left(\tau^{*}\right)_{\text {fminbnd }}-R_{\text {máx }}{ }^{2} \leq 0$

$$
\begin{aligned}
& \max \left(a_{t}\right)-a_{t_{\max }} \leq 0 \\
& \max \left(a_{n}\right)-a_{n_{\max }} \leq 0 \\
& \max \left(a_{f}\right)-a_{f_{\text {max }}} \leq 0 \\
& \tau_{\text {min }} \leq \tau \leq \tau_{\max }
\end{aligned}
$$

Os percursos ótimos de concatenação obtidos como resultados para este modelo estão na Figura 5.9.

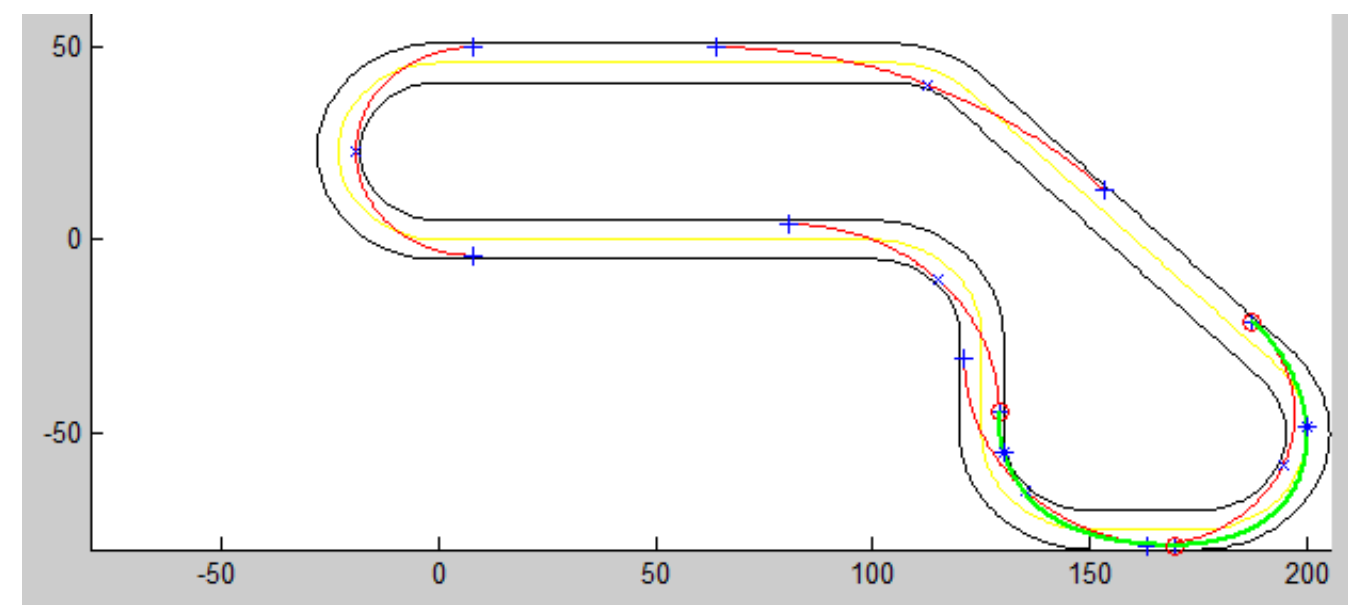

Figura 5.9: Resultado para a modelagem com restrições de aceleração. 
As curvas obtidas têm as curvaturas mais suaves e não são tangentes ao raio interno da pista. A Figura 5.10 mostra os trechos concatenados mais detalhadamente.

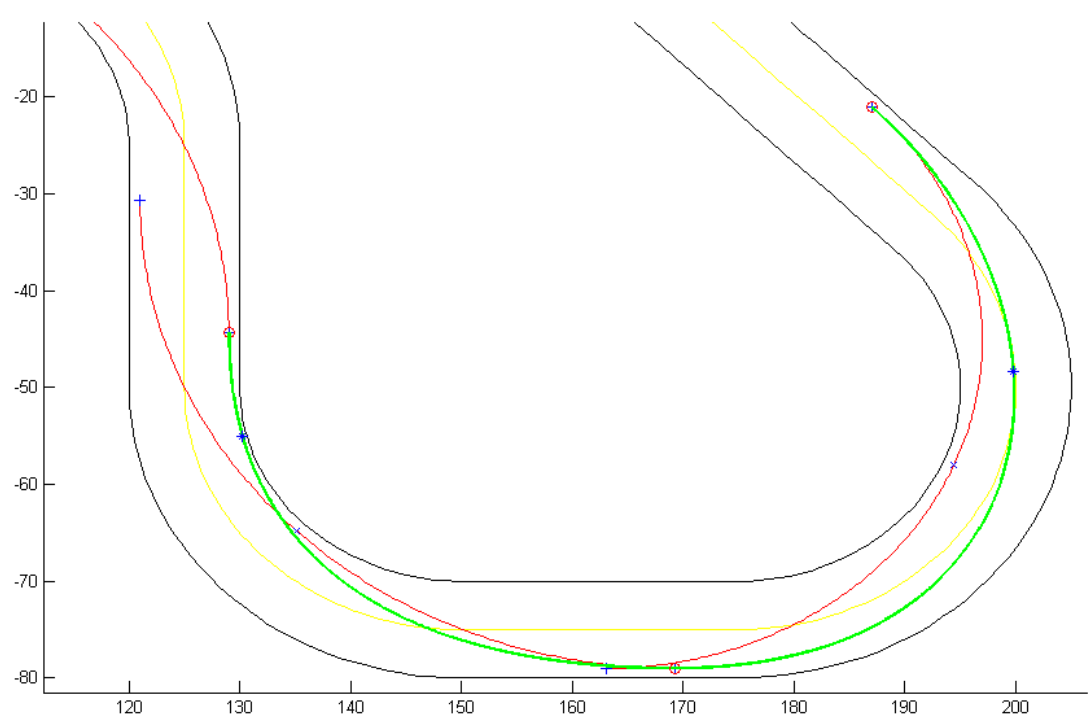

Figura 5.10: Trechos concatenados mais detalhados.

O relatório de concatenação gerado para este modelo está apresentado na Figura 5.11. Como esperado do modelo, nenhuma das restrições ultrapassou os limites de aceleração propostos.

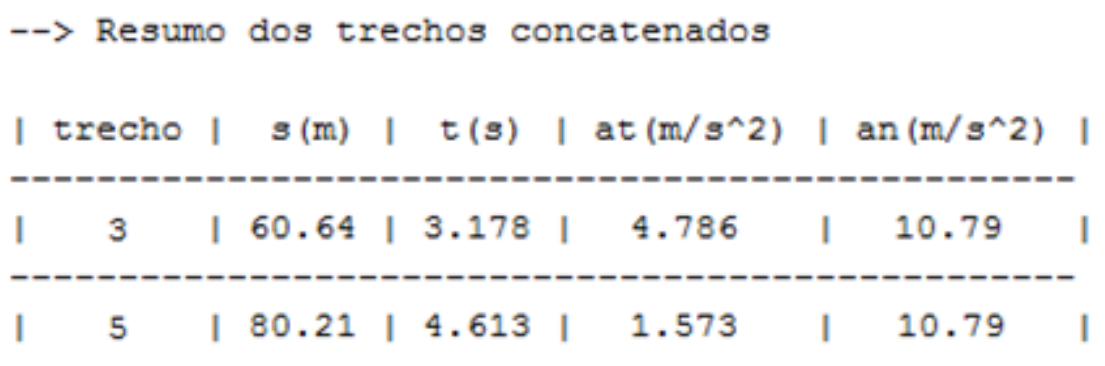

Figura 5.11: Relatório de concatenação para otimização com restrições de aceleração.

As Figuras 5.12 e 5.13 apresentam as variações de velocidade e aceleração nos trechos concatenados com as restrições de aceleração incluídas no modelo. 

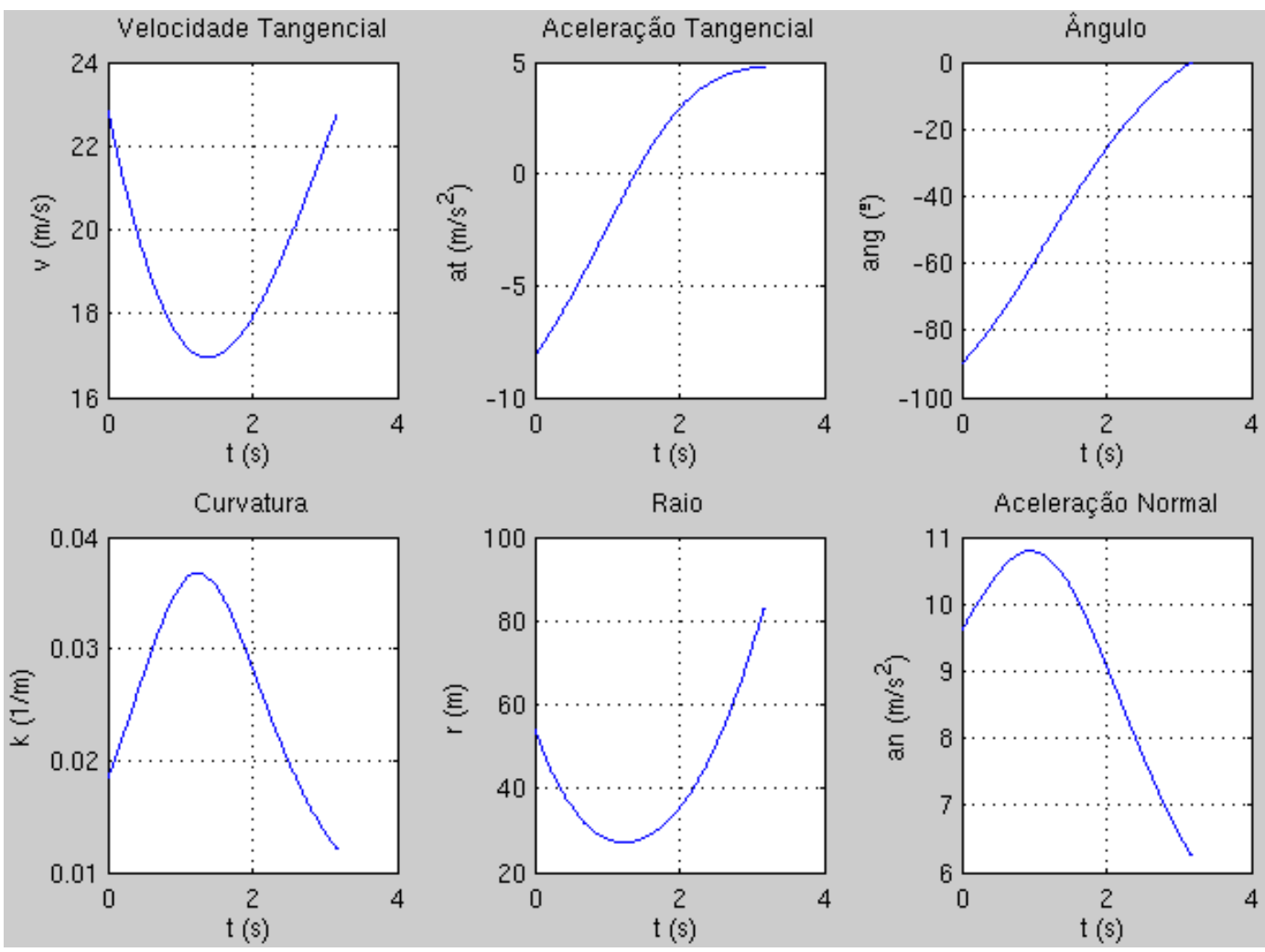

Figura 5.12: Velocidade e acelerações para o trecho concatenado 3 com restrição de aceleração.
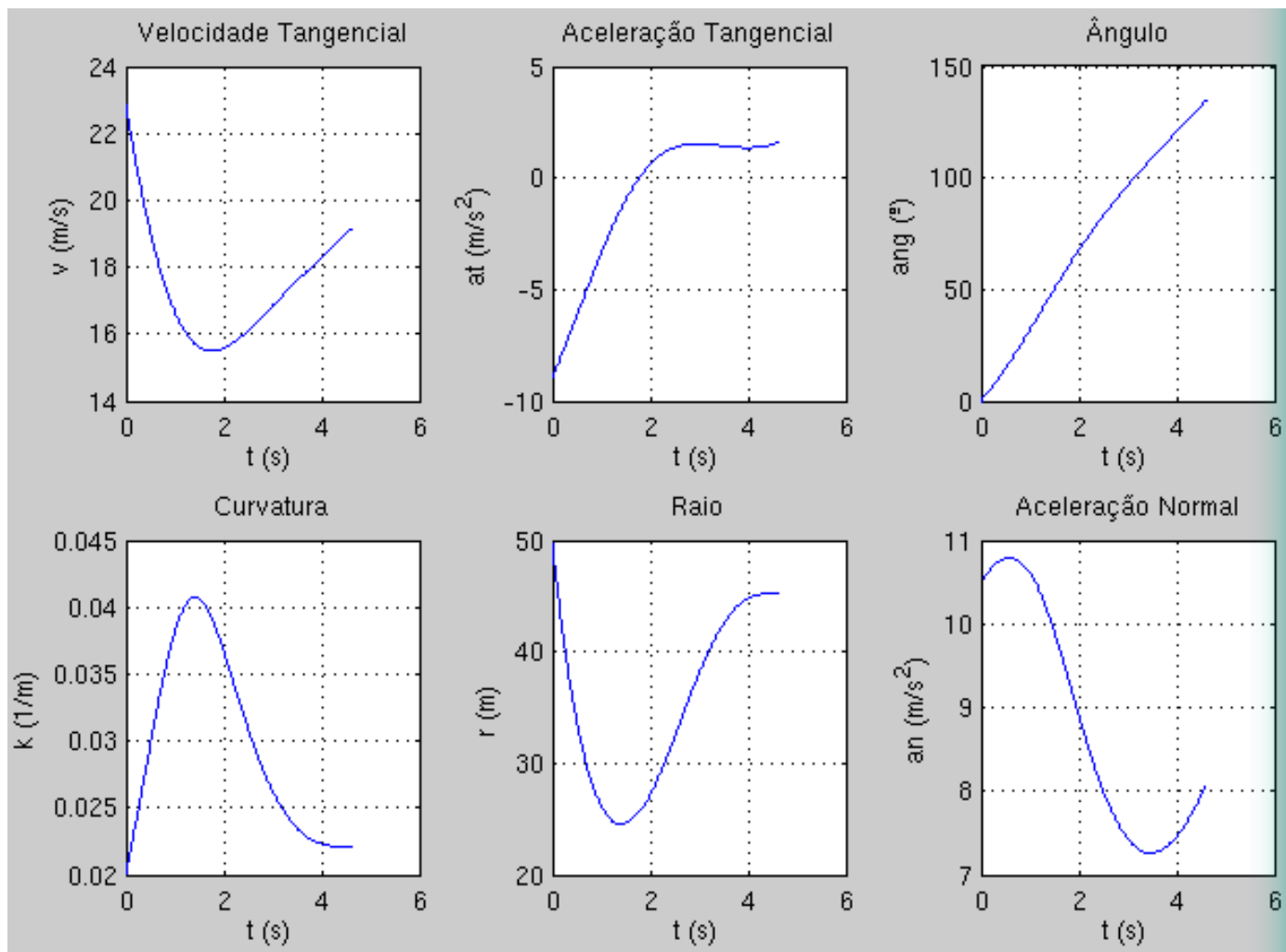

Figura 5.13: Velocidade e acelerações para o trecho concatenado 5 com restrição de aceleração. 
Primeiramente, constata-se que a modelagem descreveu bem o problema a ser resolvido, uma vez que ambas as acelerações máximas encontradas estão dentro dos limites propostos, como mostra a Figura 5.11. Na Figura 5.12, é possível perceber que os resultados estão muito parecidos com os obtidos no problema sem restrição. A diferença é que a aceleração tangencial aumentou, já que a aceleração normal foi reduzida. A variação da curvatura também ficou mais suave.

$\mathrm{Na}$ Figura 5.13, diferentemente do resultado obtido sem restrições de aceleração, o comportamento da curva no trecho concatenado 5 está mais parecido com o trecho concatenado 3, com frenagem na entrada da curva e aceleração na saída. No entanto, para que houvesse redução da aceleração normal máxima no trajeto, a curvatura precisou variar de forma mais suave, afastando o ápice da curva do ponto de tangência da pista. Esse resultado é bastante razoável considerando que o ponto de entrada na curva é mais adiantado do que o ponto de início da trajetória ótima individual neste trecho. Quanto à eficiência computacional, o algoritmo com as restrições de aceleração levou cerca de $35 \mathrm{~s}$ para finalizar a pista teste, num notebook padrão i5, sistema operacional Linux.

\subsubsection{Verificação das acelerações no Círculo de Aderência}

Além de verificar se as restrições de acelerações normal e tangencial impostas no problema de otimização foram respeitadas, é preciso também verificar se todas as acelerações obtidas encontram-se dentro do círculo de aderência formado pelos limites de aceleração utilizados para os testes dos algoritmos. Como já foi explicado na seção 2.3.1, essa verificação permite inferir se o veículo proposto consegue realizar a trajetória obtida sem derrapar ou perder estabilidade.

Para o trecho 3, a Figura 5.14 mostra as acelerações obtidas em relação ao círculo de aderência. A partir deste resultado, observa-se que o início da trajetória acontece fora do círculo e, apesar de a desaceleração longitudinal e aceleração normal empregadas estarem dentro dos limites individuas, a aceleração total do veículo excede a capacidade máxima. Com o condutor desacelerando quase que ao máximo para entrar na curva, o veículo não consegue realizar uma curva tão 
fechada e que necessite de tamanha aceleração normal. Em termos práticos, o veículo está derrapando no sentido tangente por não poder impor aceleração normal o suficiente (restrito por características dinâmicas, como potência no motor).

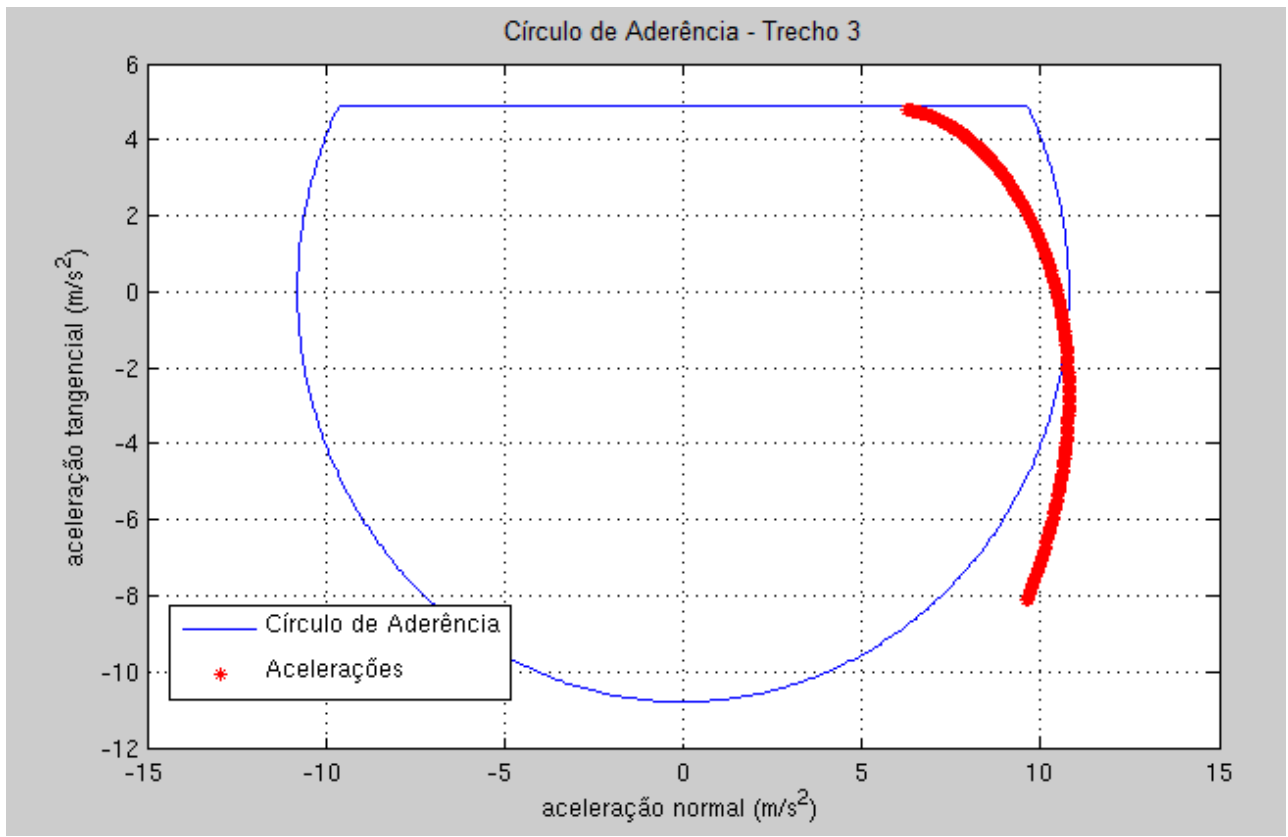

Figura 5.14: Acelerações e Círculo de Aderência para o trecho 3.

A Figura 5.15 mostra as acelerações obtidas em relação ao círculo de aderência para o trecho 5 .

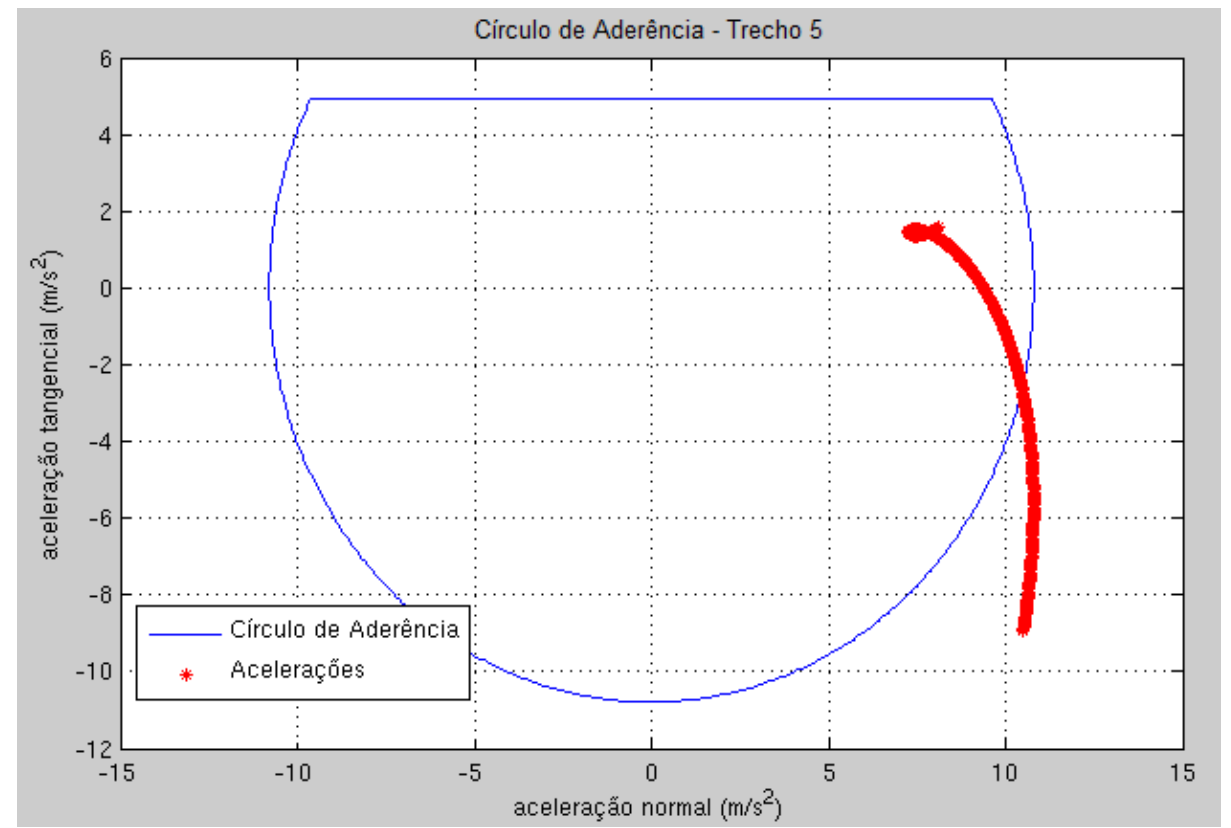

Figura 5.15: Acelerações e Círculo de Aderência para o trecho 5. 
O mesmo comportamento acontece para a concatenação do trecho 5. Como a curva é maior que $90^{\circ}$ e, mais fechada que a anterior, a trajetória exige demais da aceleração normal no início da trajetória, mas também precisa de desaceleração para entrada na curva, excedendo a capacidade máxima do veículo.

Uma alternativa seria incluir uma nova restrição no modelo de otimização, que, além de impor os limites individuais das acelerações normal e tangencial, impõe também o limite de aceleração total, como mostra a Equação 5.7, ou seja:

$\max \left(\sqrt{a_{t}^{2}+a_{n}^{2}}\right)-a_{t_{\text {tot }} \text { max }} \leq 0$

Para definir $a_{\text {tot }}$ max tal que esta restrição represente o círculo de aderência, basta analisar a Figura 5.16.

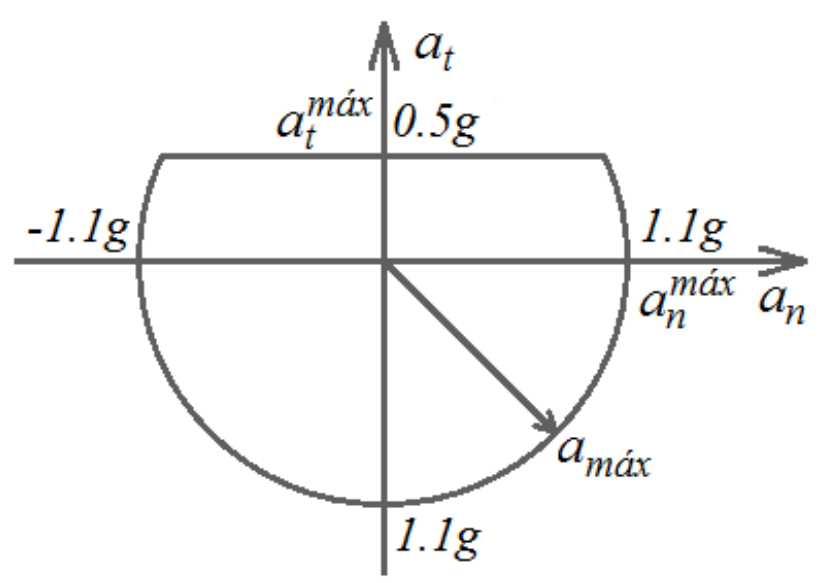

Figura 5.16: Círculo de Aderência para as acelerações limites deste modelo.

Apesar de parecer intuitivo, definir $a_{\text {tot } \max }$ como $\sqrt{a_{t_{\text {max }}^{2}}^{2}+a_{n_{\text {max }}^{2}}^{2}}$ não caracteriza corretamente o círculo de aderência, pois ambas as acelerações não podem atingir seu valor máximo simultaneamente. Assim, o limite para a aceleração total deve ser o raio do círculo, contanto que os limites de cada aceleração individual continuem sendo observados.

Logo, para definir corretamente as restrições, a aceleração total máxima deve ser definida como:

$$
a_{t_{\text {max }}}=a_{n_{\max }}
$$


O modelo completo fica, então, da seguinte forma:

$\min _{\tau} \quad d_{h}=\left(P\left(\tau^{*}\right)_{\text {fminbnd }}-R_{\text {min }}{ }^{2}\right)^{2}$

s.t. $P\left(\tau^{*}\right)_{\text {fminbnd }}-R_{\text {máx }}{ }^{2} \leq 0$

$$
\begin{aligned}
& \max \left(a_{t}\right)-a_{t_{\text {max }}} \leq 0 \\
& \max \left(a_{n}\right)-a_{n_{\text {max }}} \leq 0 \\
& \max \left(a_{f}\right)-a_{f_{\text {max }}} \leq 0 \\
& \max \left(\sqrt{a_{t}^{2}+a_{n}^{2}}\right)-a_{n_{\text {max }}} \leq 0 \\
& \tau_{\text {min }} \leq \tau \leq \tau_{\text {max }}
\end{aligned}
$$

O resultado obtido para a nova formulação está apresentado na figura abaixo e o resumo das acelerações para os trechos concatenados está na Figura 5.18.

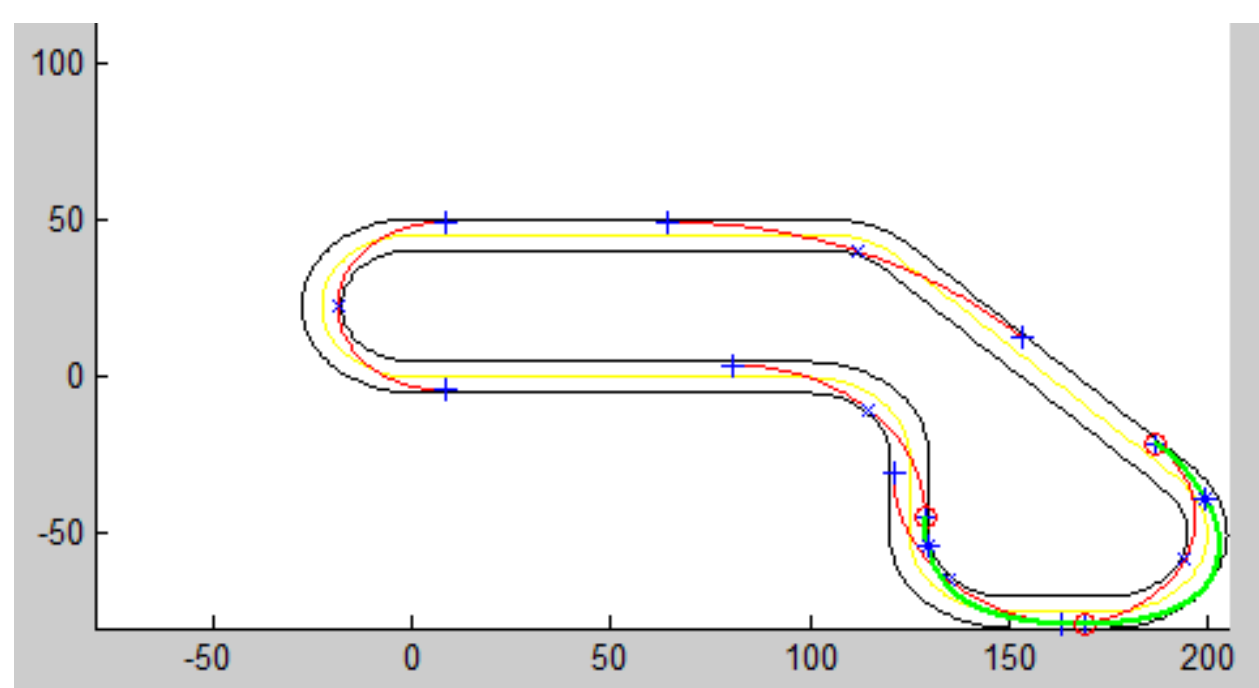

Figura 5.17: Resultado para o modelo com as restrições do círculo de aderência.

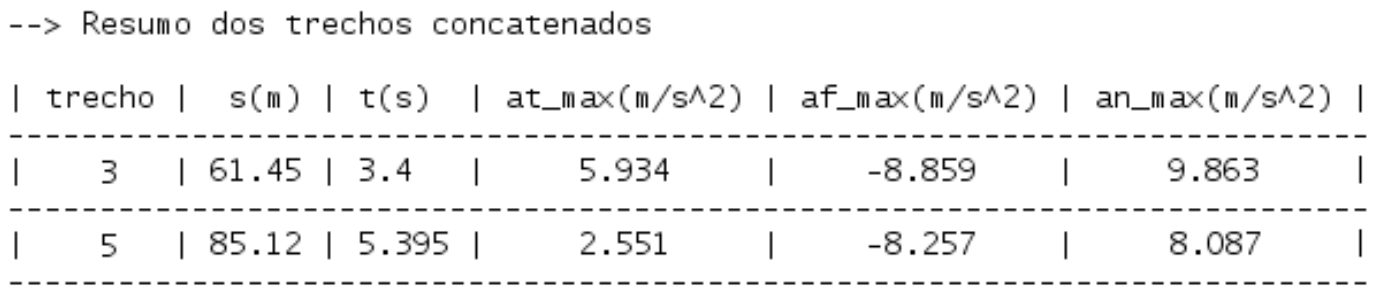

Figura 5.18: Resumo dos trechos concatenados com restrição do círculo de aderência.

A Figura 5.19 mostra as acelerações e velocidade no trecho concatenado 3. 

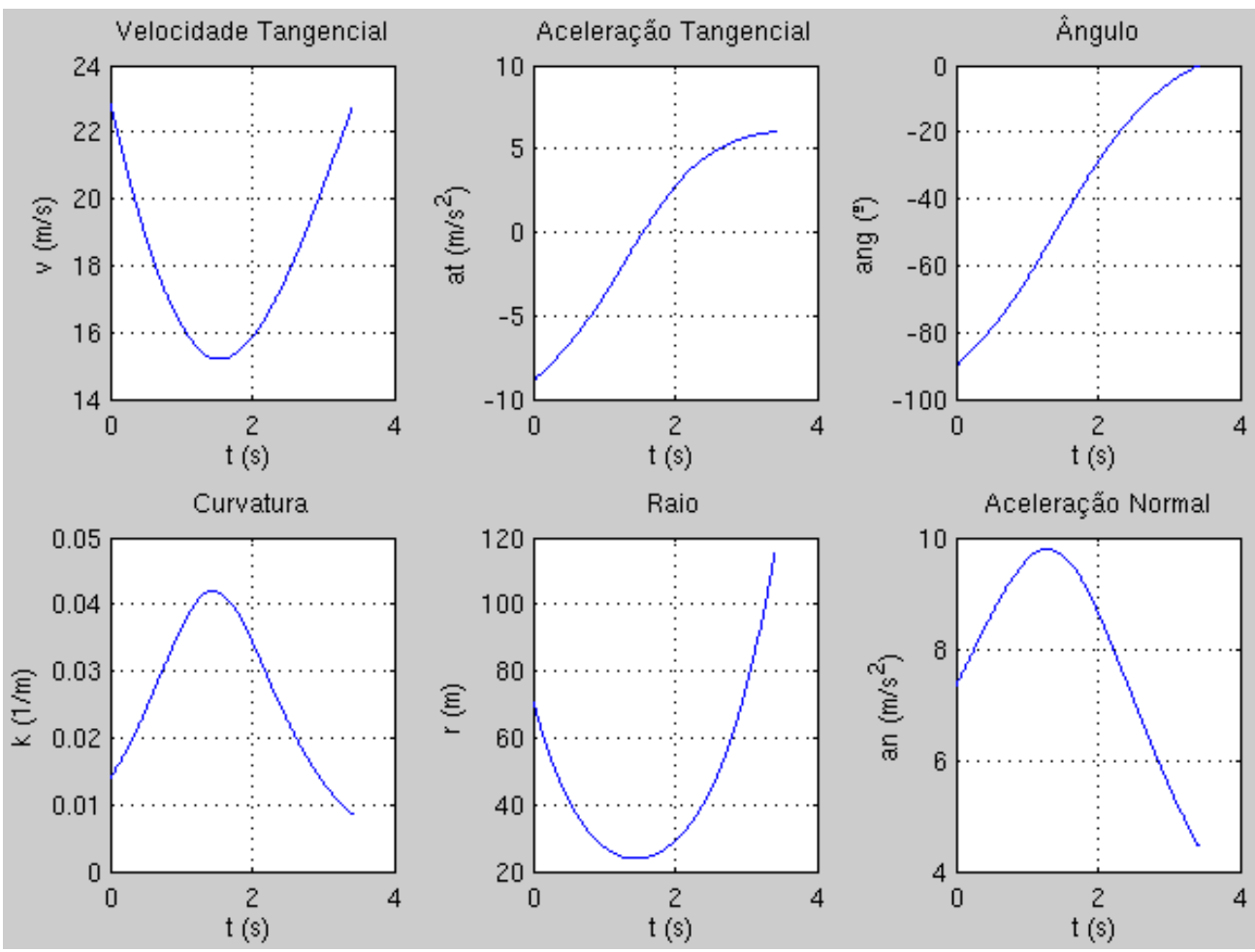

Figura 5.19: Velocidade e acelerações para o trecho concatenado 3 com restrição do círculo de aderência.

Tanto na Figura 5.17, como na Figura 5.19, observa-se que o trecho 3 permaneceu com uma trajetória muito próxima ao modelo anterior, apresentando características similares, que não respeitam o círculo de aderência. De fato, a função fmincon retornou a seguinte flag de saída para este trecho: No feasible solution found. Em efeitos práticos, isso significa que o algoritmo não conseguiu encontrar uma curva cuja função objetivo apresentasse um valor melhor que o obtido, e não houve nenhum valor de $\tau$ para o qual a curva respeitasse todas as restrições impostas pelo modelo. Nos casos como esse, em que não existe solução que respeite todas as restrições, a função de otimização fmincon retorna o resultado que minimiza a restrição de maior valor.

Analisando o círculo de aderência apresentado na Figura 5.20, observa-se que, de modo geral, as acelerações foram deslocadas para o centro do círculo, mas no início da trajetória o problema de excesso de aceleração normal ainda persiste e a aceleração tangencial na saída da curva também excedeu o limite máximo. A conclusão que pode ser tirada deste resultado é que, apesar dos pontos e velocidades de entrada e saída sempre serem respeitados, as características da curva de Hermite não permitem uma solução que respeite as restrições do círculo de aderência. 


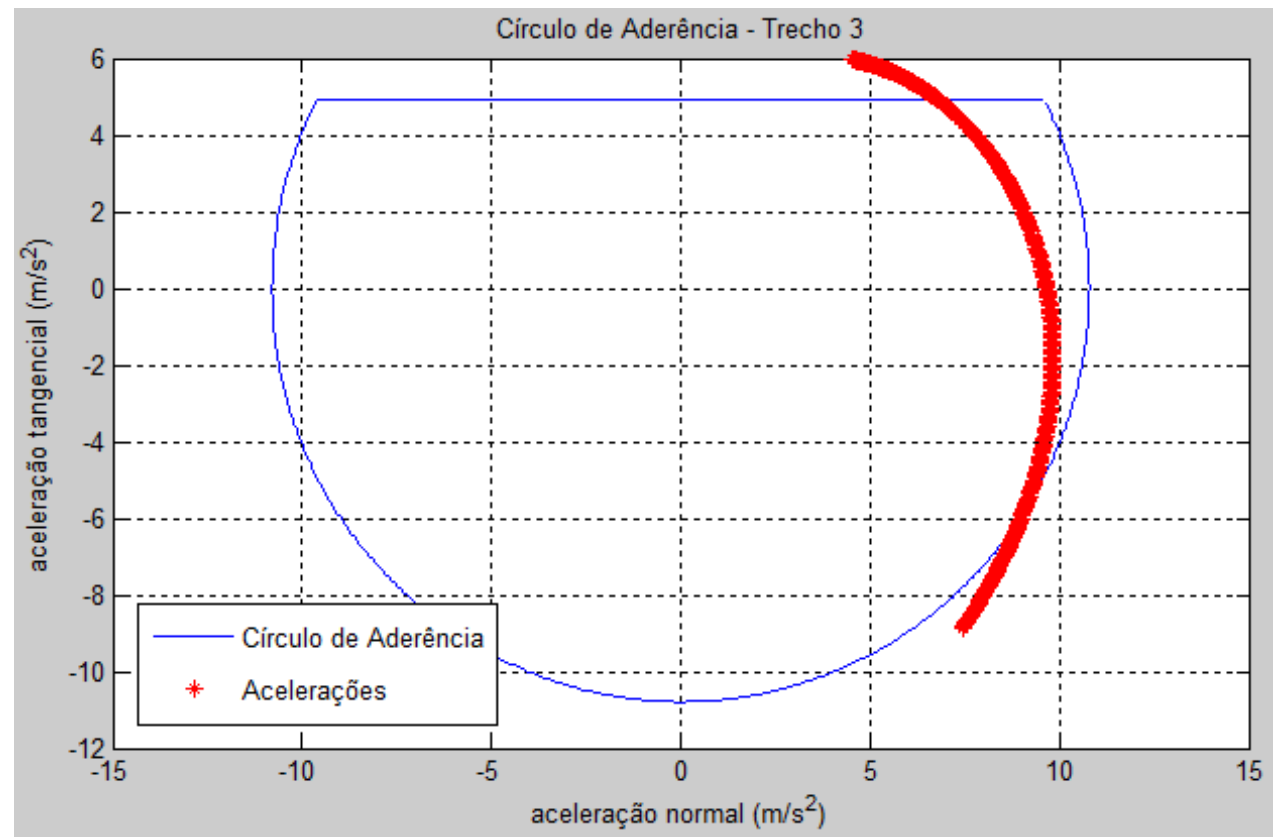

Figura 5.20: Acelerações do trecho 3 com restrição do círculo de aderência.

Para verificar esta afirmação com mais cuidado, foram calculadas as acelerações normal, tangencial e total, para valores de $\tau$ variando entre $1,5 \mathrm{~s}$ e $5 \mathrm{~s}$, com precisão de 0,05 s e os resultados obtidos estão representados por meio de um gráfico de $\tau(\mathrm{s}) \times$ acelerações $\left(\mathrm{m} / \mathrm{s}^{2}\right)$, apresentado na Figura 5.21.

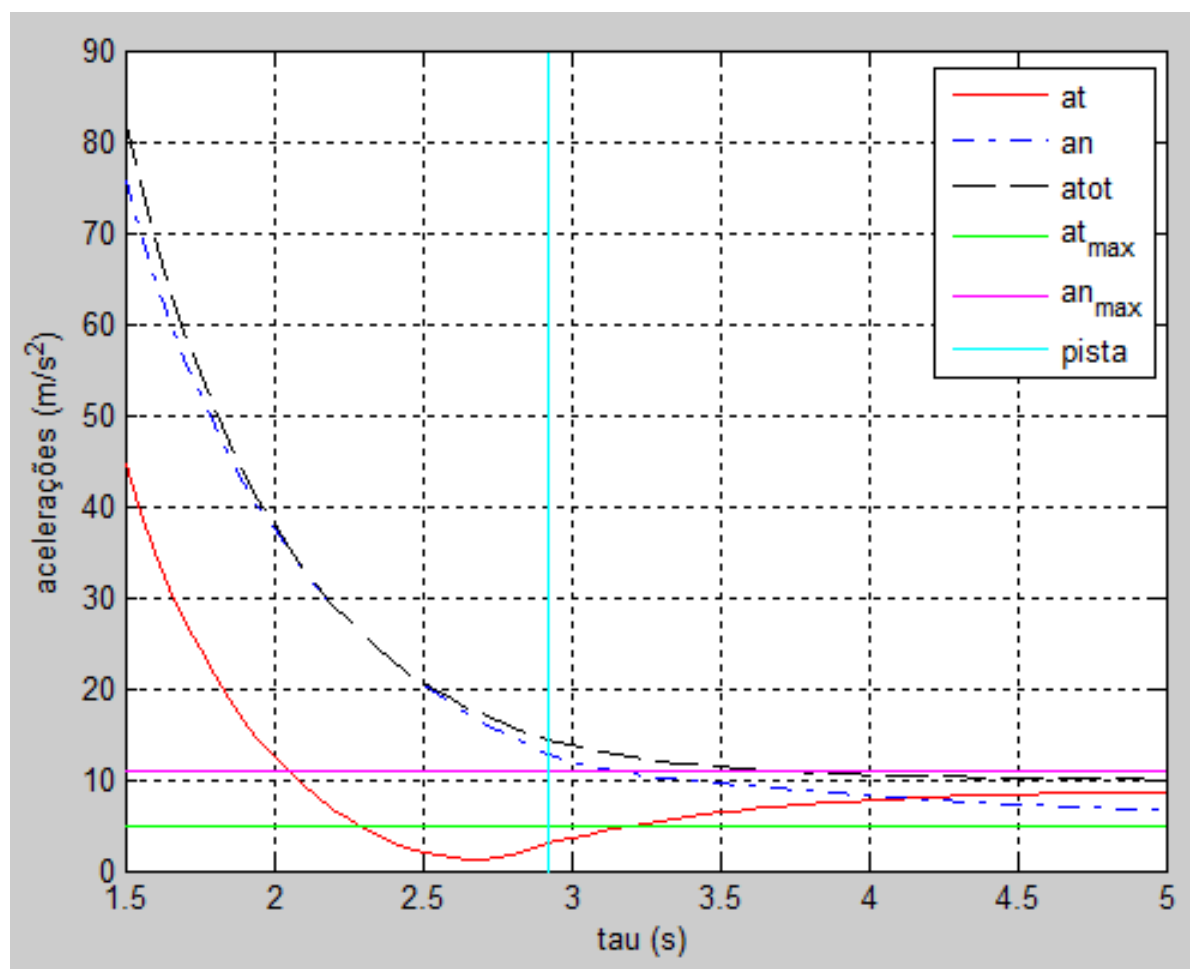

Figura 5.21: Gráfico das acelerações obtidas para diversos valores de $\tau$. 
No gráfico, foi marcado com uma linha vertical o valor de 2,922s porque, como verificado na seção 5.1, este é o valor de $\tau$ para o qual a trajetória é tangente à pista no raio interno para a curva do trecho 3 , assim qualquer trajetória de $\tau$ menor que este valor não estará dentro dos limites de restrição geométrica da pista. Foi marcado ainda com linhas horizontais o limite máximo de aceleração tangencial $\left(4,905 \mathrm{~m} / \mathrm{s}^{2}\right)$ e de aceleração normal $\left(10,791 \mathrm{~m} / \mathrm{s}^{2}\right)$.

Nota-se que realmente não existem valores de $\tau$ em que a curva de aceleração tangencial esteja abaixo da linha de $4,905 \mathrm{~m} / \mathrm{s}^{2}$ e, simultaneamente, a aceleração normal e total estejam abaixo da linha de $10,791 \mathrm{~m} / \mathrm{s}^{2}$. Apenas o ponto 3,178 s, que foi o resultado do processo de otimização sem restrições de aceleração total, apresenta a aceleração tangencial e normal nos limites, porém a aceleração total não, como foi verificado pela análise do círculo de aderência.

Quanto ao trecho 5, o resultado das acelerações no círculo de aderência está apresentado na Figura 5.22 e os perfis de velocidade e aceleração do trecho estão representados na Figura 5.23.

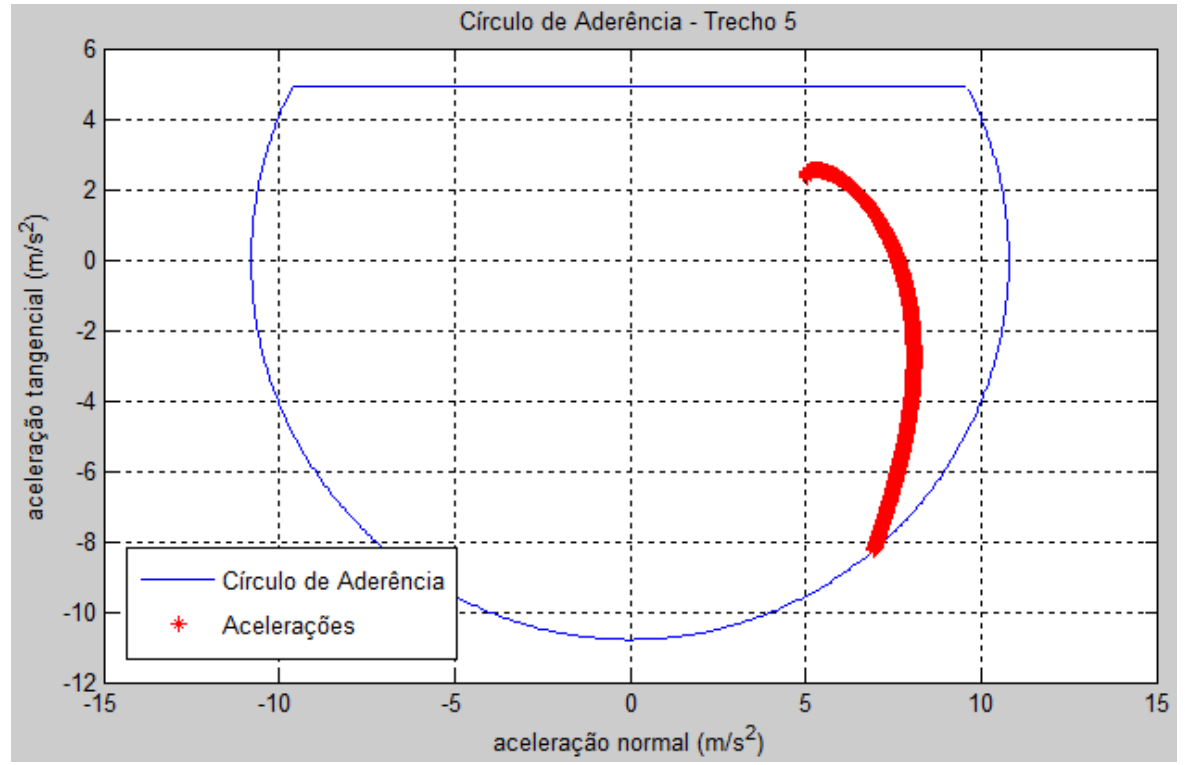

Figura 5.22: Acelerações do trecho 5 com restrição do círculo de aderência.

Observa-se que todas as acelerações ao longo da trajetória estão contidas dentro do círculo de aderência. No início da trajetória, existe a desaceleração para entrada na curva (aceleração tangencial negativa) ao mesmo tempo em que a aceleração normal aumenta. Perto do fim da trajetória, a aceleração tangencial aumenta, sem atingir o valor máximo. Na Figura 5.17, nota-se que esta curva foi 
feita na forma mais "aberta" possível, atingindo o raio externo da curva, para reduzir a aceleração normal no trecho.
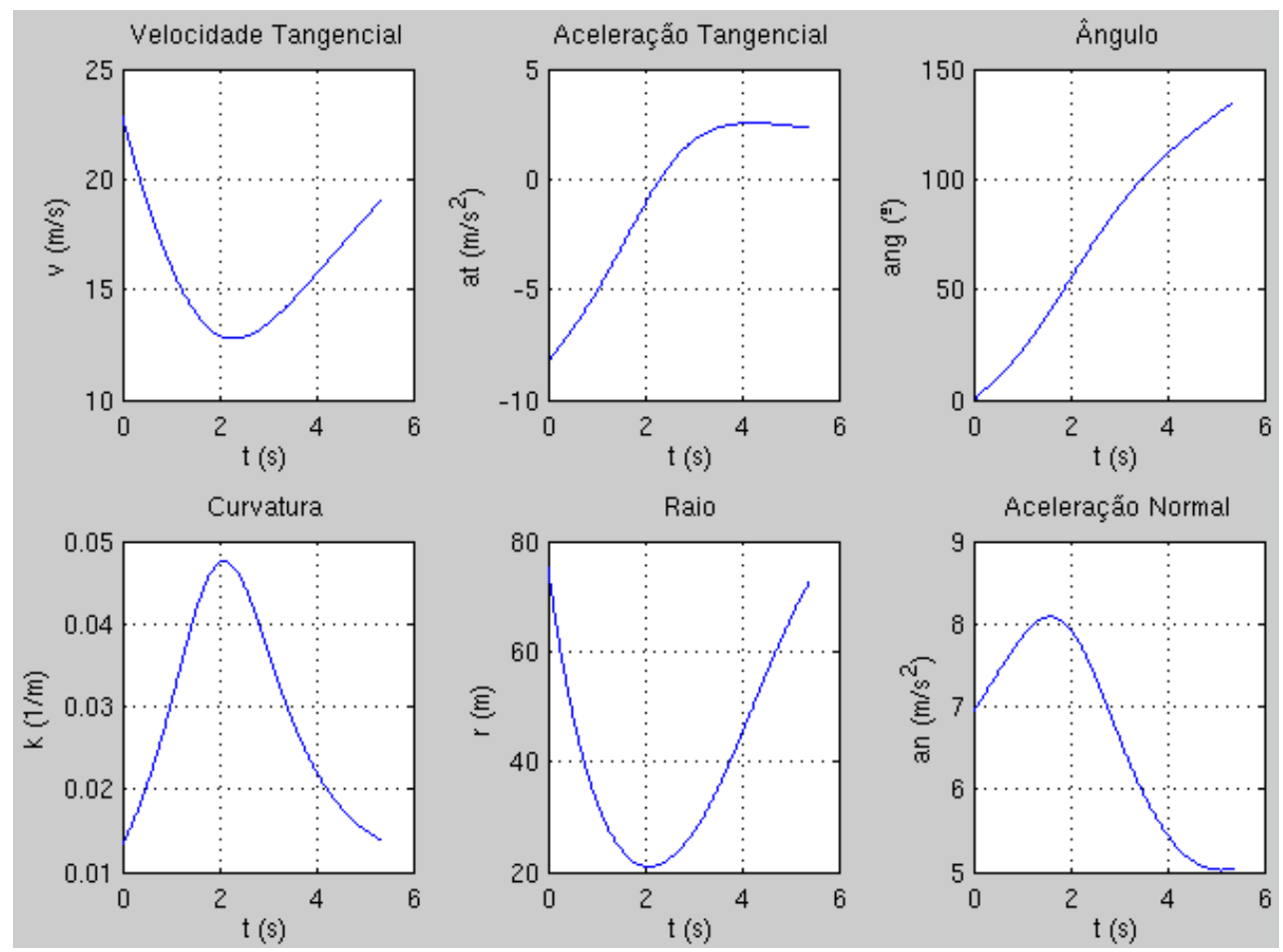

Figura 5.23: Velocidade e acelerações para o trecho concatenado 5 com restrição do círculo de aderência.

\subsection{Concatenação dos trechos retilíneos}

A concatenação dos trechos retos é mais simples, pois não há a componente correspondente a aceleração centrípeta, reduzindo o número de restrições do problema. Primeiramente, serão tratadas as concatenações entre curvas de direções diferentes que possuem um trecho reto entre si sem que haja interseção entre as curvas, como o caso do trecho em destaque na figura abaixo.

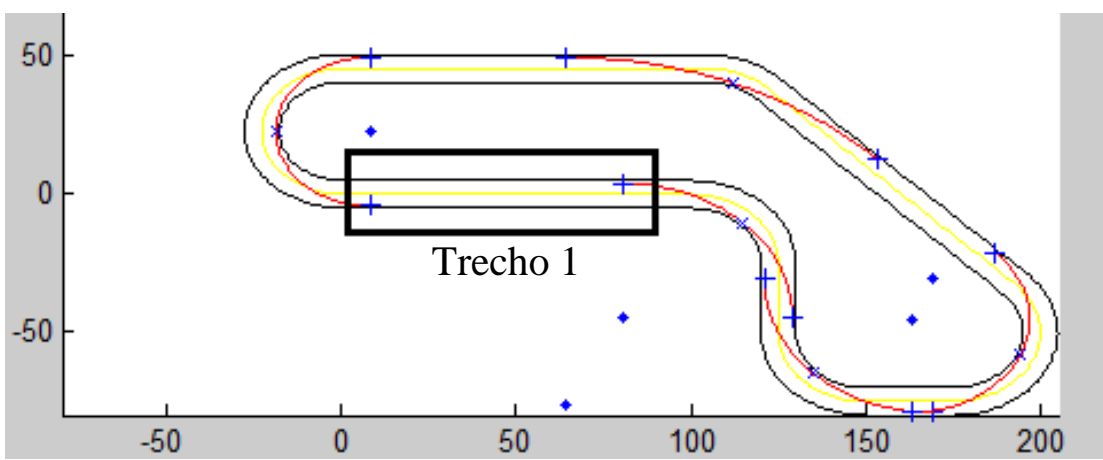

Figura 5.24: Trecho reto entre curvas de direções diferentes. 
Para trechos como esse, a concatenação consiste em determinar a curva de Hermite que conecta o ponto de saída da curva anterior com o ponto de entrada da curva seguinte, respeitando as velocidades em ambos os pontos. A função objetivo neste caso é o comprimento da curva e a variável a ser determinada é $\tau$, de forma que o algoritmo deva determinar o valor de $\tau$ para o qual o comprimento da curva de Hermite correspondente seja mínimo, respeitando a restrição de aceleração tangencial máxima e mínima. O modelo matemático fica da seguinte forma:

$$
\begin{array}{ll}
\min _{\tau} \quad s=\int_{0}^{\tau} \sqrt{\left(\frac{d x}{d t}\right)^{2}+\left(\frac{d y}{d t}\right)^{2}} \mathrm{dt} \\
\text { s.t. } \quad & \max \left(a_{t}\right)-a_{t_{\max }} \leq 0 \\
& \max \left(a_{f}\right)-a_{f_{\max }} \leq 0 \\
& \tau_{\min } \leq \tau \leq \tau_{\max }
\end{array}
$$

Onde:

$$
\begin{aligned}
& x(t)=a_{x}(\tau) \cdot t^{3}+b_{x}(\tau) \cdot t^{2}+c_{x}(\tau) \cdot t+d_{x}(\tau) \\
& y(t)=a_{y}(\tau) \cdot t^{3}+b_{y}(\tau) \cdot t^{2}+c_{y}(\tau) \cdot t+d_{y}(\tau)
\end{aligned}
$$

A definição dos coeficientes $a_{x}(\tau), b_{x}(\tau), c_{x}(\tau), d_{x}(\tau)$ foi mostrada nas equações 4.15 e 4.16 .

Similar com os trechos em curva, a função utilizada para a otimização também foi a fmincon.

Como a curva de Hermite, por definição, respeita a direção das derivadas dos pontos final e inicial e o vetor tangente a eles é paralelo às restrições da pista, a curva obtida no processo de otimização só violaria as restrições geométricas para valores muito grandes de $\tau$, onde a solução seria degenerada. Como foram impostos os limites superior e inferior de $\tau$ para os quais a curva não degenera, sabe-se que o resultado da otimização estará dentro da pista.

O resultado está na Figura 5.2. Nota-se que a curva é feita de forma suave na troca de lados da pista e não de forma brusca, se aproximando menos de uma reta. Isso mostra que as restrições de aceleração são de extrema importância, uma 
vez que a curva de menor comprimento entre esses dois pontos se aproximaria muito de uma reta, caso não houvesse restrição alguma.

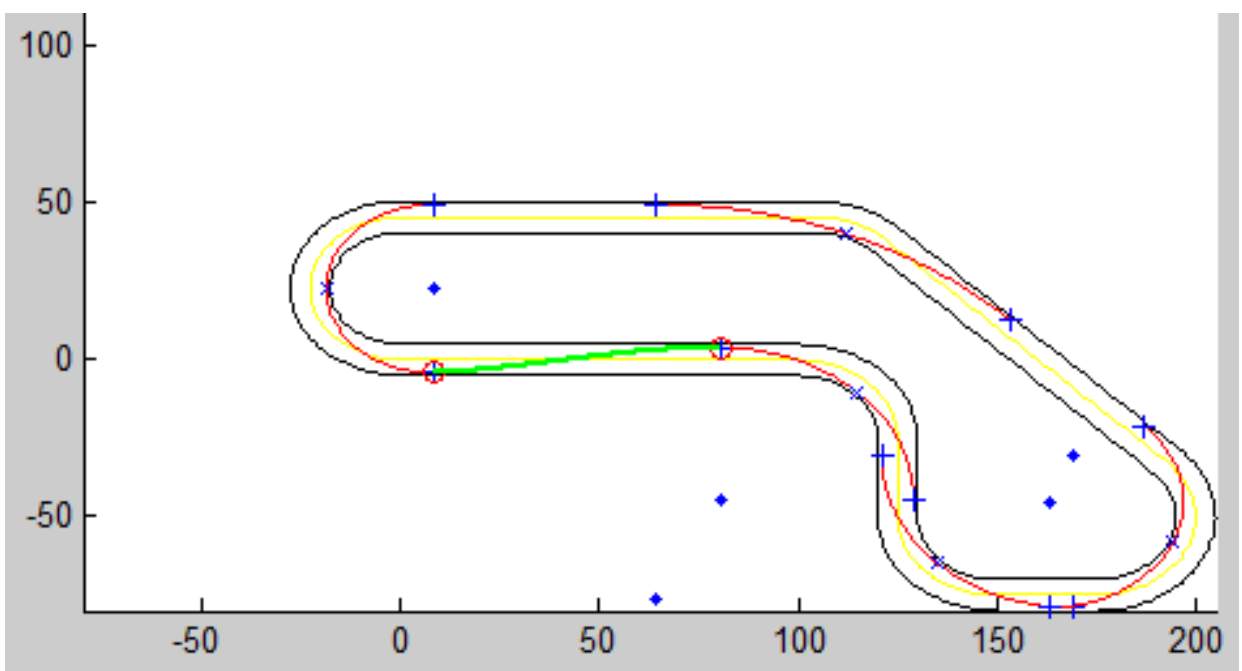

Figura 5.25: Resultado da concatenação para o trecho destacado.

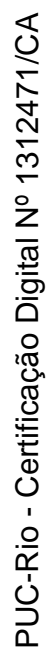

A Figura 5.23 mostra as acelerações e velocidades no trecho.

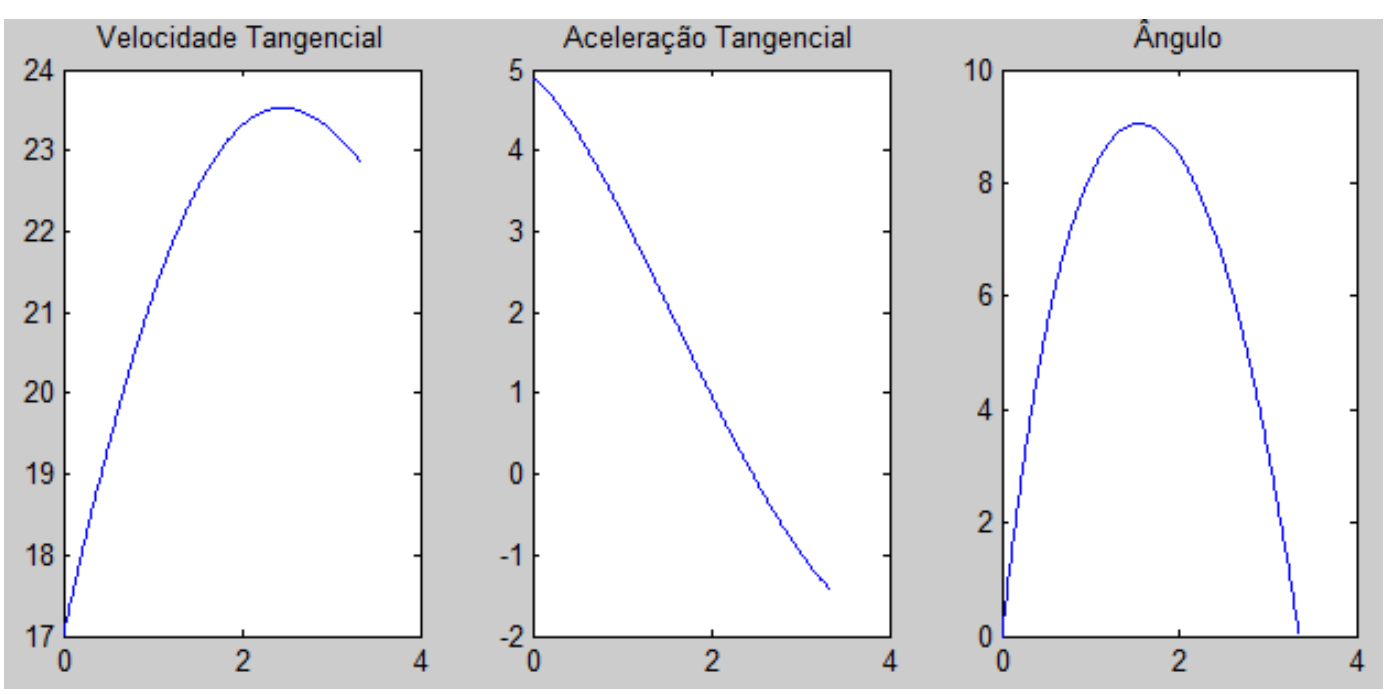

Figura 5.26: Características dinâmicas da curva obtida.

Observa-se que os limites de aceleração foram respeitados e, também, as velocidades de entrada e saída. O veículo apresenta um comportamento coerente, acelerando na saída da curva de $180^{\circ}$ e reduzindo a velocidade ao entrar na curva seguinte. O percurso para este trecho tem comprimento total de $73,2009 \mathrm{~m}$ e dura $3,35 \mathrm{~s}$. 
Por fim, avaliam-se os outros dois casos em que o trecho deve ser concatenado por uma reta. Para estes casos, o algoritmo consiste em determinar a curva de Hermite que concatena os dois trechos respeitando as restrições de aceleração tangencial. Novamente, a função objetivo será o comprimento total da pista e o modelo para otimização fica igual ao descrito na Equação 5.9. Pelo mesmo motivo citado anteriormente, as restrições geométricas não precisaram ser incluídas. O resultado obtido para os trechos retos está apresentado na Figura 5.24.

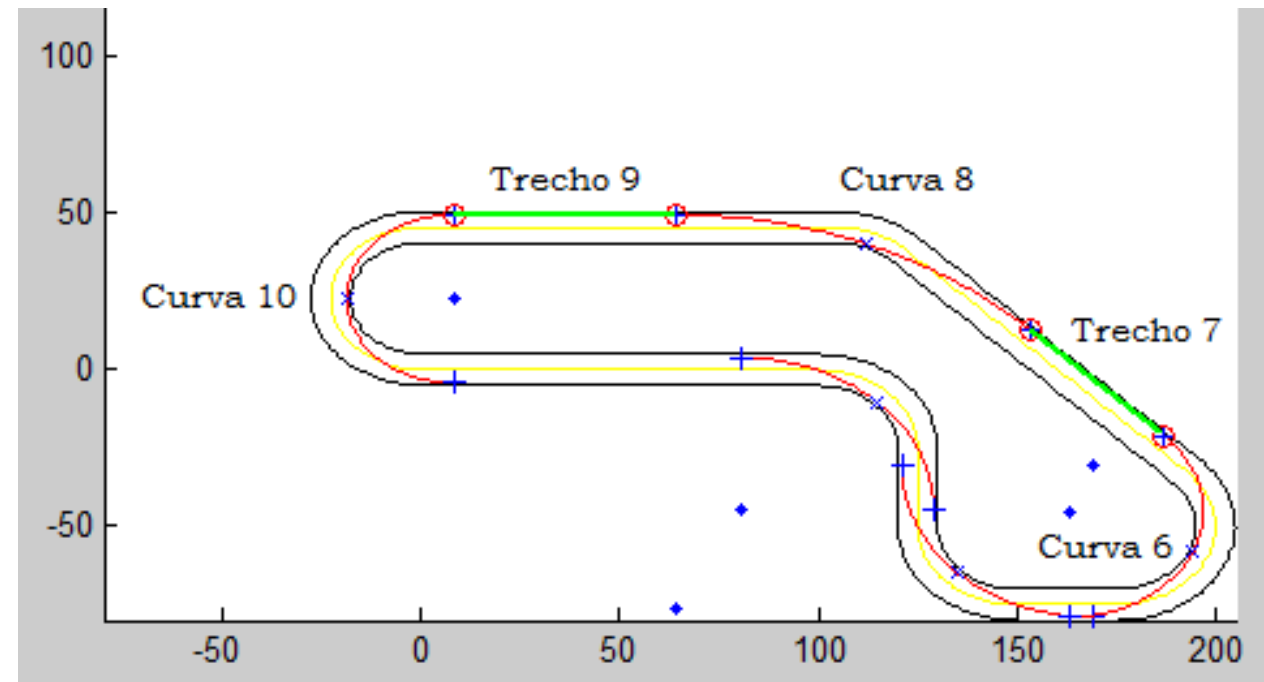

Figura 5.27: Resultado para concatenações com trechos retos.

Para concatenações estritamente retílineas como as dos trechos 7 e 9, facilmente observa-se que o espaço percorrido é sempre o mesmo, o que não constitui uma boa função objetivo para a minimização. Neste caso, a função objetivo deve ser o próprio $\tau$, de forma que o algoritmo encontre o menor valor de $\tau$ para o qual as restrições de aceleração tangencial não sejam violadas. O modelo do problema de otimização para esses casos é:

$$
\begin{array}{ll}
\min _{\tau} \tau & \\
\text { s.t. } & \max \left(a_{t}\right)-a_{t_{\max }} \leq 0 \\
& \max \left(a_{f}\right)-a_{f_{\text {max }}} \leq 0
\end{array}
$$


O resumo do tempo total de cada concatenação, o espaço total percorrido e as acelerações máximas nos trechos estão descritos na Figura 5.25, que é uma imagem do retorno do algoritmo na tela do Matlab ${ }^{\circledR}$. Pela figura, nota-se que a aceleração máxima foi respeitada na concatenação do trecho 9 , porém não no trecho 7. Primeiramente, será analisada a concatenação feita pelo algoritmo para o trecho 9.

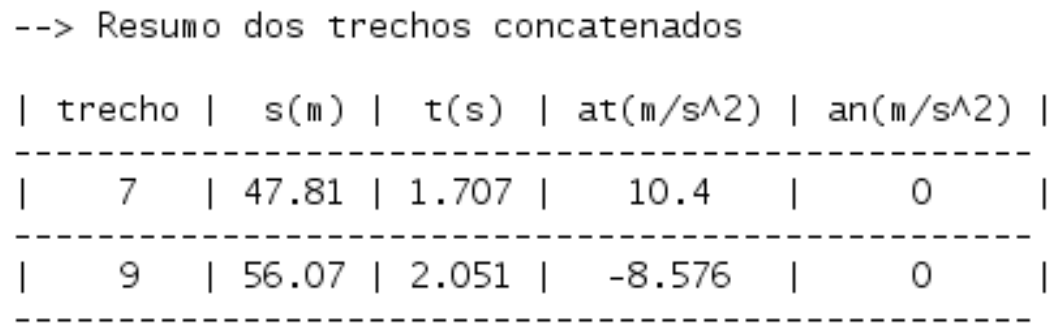

Figura 5.28: Resumo dos trechos concatenados em reta.

Anteriormente, foram definidas as velocidades de cada trecho ótimo independente assumindo que eles são feitos com aceleração normal máxima e tangencial nula e, com isso, definidos os módulos dos vetores tangentes nas curvas, necessários para a concatenação por curvas de Hermite. Com esses dados (apresentados na Figura 5.1), espera-se que, no trecho 9, o veículo saia de uma curva 8 com velocidade $36,89 \mathrm{~m} / \mathrm{s}$ e entre na curva seguinte com velocidade 17,02m/s. Sabe-se que o algoritmo de concatenação utilizando curvas de Hermite resulta em acelerações variáveis no tempo, no entanto, para os casos de trechos retos, pode-se analisar a concatenação como um movimento uniformemente variado (MUV). Sabendo as velocidades inicial e final e o espaço total a ser percorrido, pode se calcular a aceleração constante mínima necessária para concluir o trajeto, usando a equação de Torricelli [20]:

$v_{f}^{2}=v_{0}^{2}+2 \cdot a t \cdot \Delta s$

$(17.02)^{2}=(36.89)^{2}+2 \cdot a \cdot 56,07$

$a=-9.5527 \mathrm{~m} / \mathrm{s}^{2}$

Logo, um movimento uniformemente variado com desaceleração constante de $9,5527 \mathrm{~m} / \mathrm{s}^{2}$ seria uma concatenação aceitável, pois este valor está dentro dos 
limites do círculo de aderência. Analisando quanto tempo o veículo levaria para concluir o trajeto com esta aceleração constante, tem-se:

$$
\begin{aligned}
& s=s_{0}+v_{0} t+\frac{1}{2} a t^{2} \\
& s-s_{0}=v_{0} t+\frac{1}{2} a t^{2} \\
& 56.07=36.89 t+\frac{1}{2}(-9.5527) t^{2} \\
& t_{1}=2.0802 s ; t_{2}=5.6432 \mathrm{~s}
\end{aligned}
$$

O tempo a ser considerado é 2,0802 s porque depois deste tempo a velocidade obtida é exatamente a velocidade final requerida, como mostra a Equação 5.14:

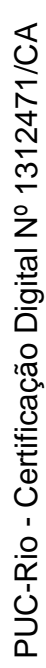

$v_{f}=v_{0}+a t$

$v_{f}=36.89-9.5527 \cdot 2.0802=17.019 \mathrm{~m} / \mathrm{s}$

Avaliando as acelerações no trecho 9, foram obtidos os resultados que estão ilustrados na Figura 5.26.

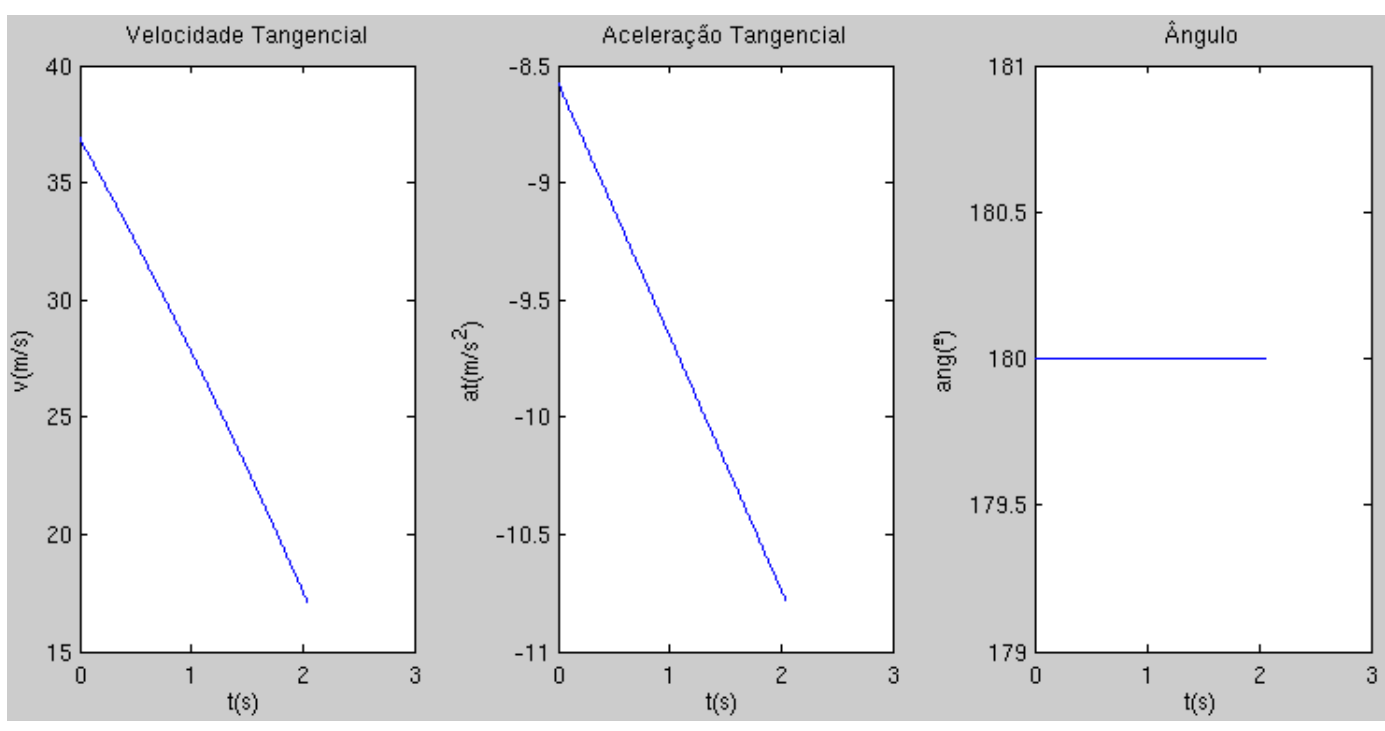

Figura 5.29: Acelerações para concatenação do trecho 9 da pista teste.

Nota-se que a concatenação feita pelo algoritmo não possui aceleração constante, mas é coerente com o esperado, pois para reduzir a velocidade dentro do espaço disponível, é preciso frear durante todo o trajeto com uma média de 
aceleração de $-9,55 \mathrm{~m} / \mathrm{s}^{2}$. Com a aceleração proposta pelo algoritmo, o veículo conclui o trajeto em 2,051 s, que é menos que o tempo obtido com desaceleração constante mostrado na Equação 5.13.

Quanto ao trecho 7, espera-se que o veículo saia da curva 6 com velocidade $19,14 \mathrm{~m} / \mathrm{s}$ e entre na curva seguinte com velocidade $36,89 \mathrm{~m} / \mathrm{s}$, percorrendo um espaço em linha reta de 47,81m. Analisando este trecho como um MUV, tem-se que:

$$
\begin{aligned}
& v_{f}^{2}=v_{0}^{2}+2 \cdot a \cdot \Delta s \\
& (36.89)^{2}=(19.14)^{2}+2 \cdot a \cdot 47.81 \\
& a=10.4 \mathrm{~m} / \mathrm{s}^{2}
\end{aligned}
$$

Com o espaço disponível, não é possível chegar à velocidade desejada sem ultrapassar o limite de aceleração tangencial de tração, que é $4,905 \mathrm{~m} / \mathrm{s}^{2}$. A análise dinâmica da curva de concatenação obtida pela otimização está na Figura 5.27 e é coerente com os cálculos apresentados na Equação 5.15.

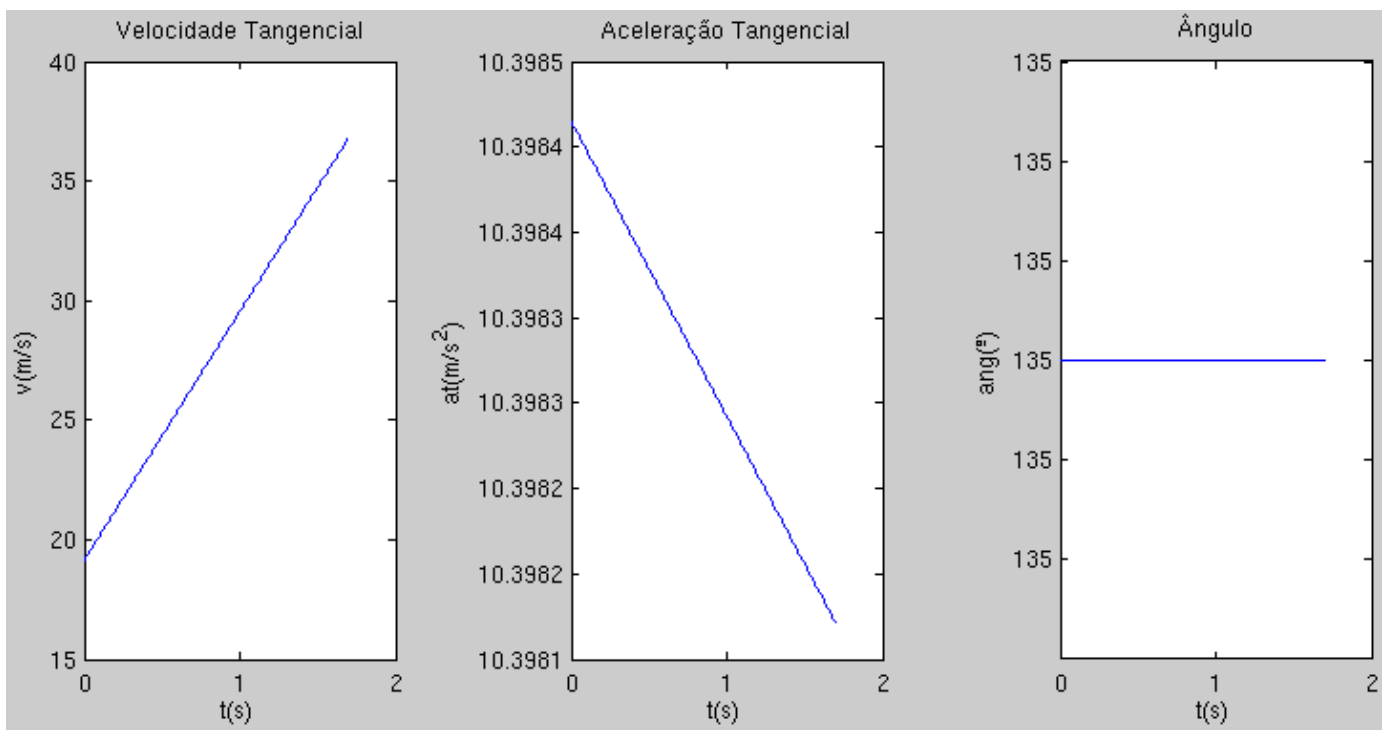

Figura 5.30: Acelerações para concatenação do trecho 7 da pista teste.

Para esta concatenação, o algoritmo retornou a flag No feasible solution found, porque, de fato, não existe curva que concatene estes pontos, dadas as velocidades inicial e final estipuladas, sem ultrapassar o limite de aceleração tangencial. Verifica-se então, que usar a maior aceleração normal nas curvas individuais pode não ser sempre a melhor opção. Para solucionar este problema, 
usando a aceleração tangencial máxima constante durante o trajeto, é possível definir a velocidade máxima com que o veículo pode entrar na curva seguinte, ou seja:

$v_{f}^{2}=v_{0}^{2}+2 \cdot a \cdot \Delta s$

$v_{f}^{2}=(19.14)^{2}+2 \cdot 4.905 \cdot 47.81$

$v_{f}=22.094 \mathrm{~m} / \mathrm{s}$

Dado esse valor, tem-se a alternativa de reduzir a velocidade com que é feita a curva 8 para 22,094m/s constante. Desta forma, a aceleração normal nesta curva seria menor e corresponde à calculada na Equação 5.17, que é menor que a máxima permitida, ou seja:

$a_{n}=\frac{v^{2}}{R}=\frac{22.094^{2}}{126.0966}=3.87 \mathrm{~m} / \mathrm{s}^{2}$

$\mathrm{O}$ raio $\mathrm{R}$ desta curva foi determinado previamente e apresentado na Tabela 3.3. Como a curva 8 corresponde a $45^{\circ}$ da circunferência (ver Tabela 3.2), o tempo levado para concluir a curva com essa velocidade será de:

$t=\frac{\Delta s}{v}=\frac{\left(\frac{\pi}{4}\right) \cdot R}{v}=\frac{\left(\frac{\pi}{4}\right) \cdot 126.0966}{22.094}=4.482 \mathrm{~s}$

Refazendo as concatenações para a nova velocidade da curva 8, as concatenações dos trechos 7 e 9 apresentarão novos resultados. A Figura 5.28 mostra o resumo para a nova concatenação destes trechos:

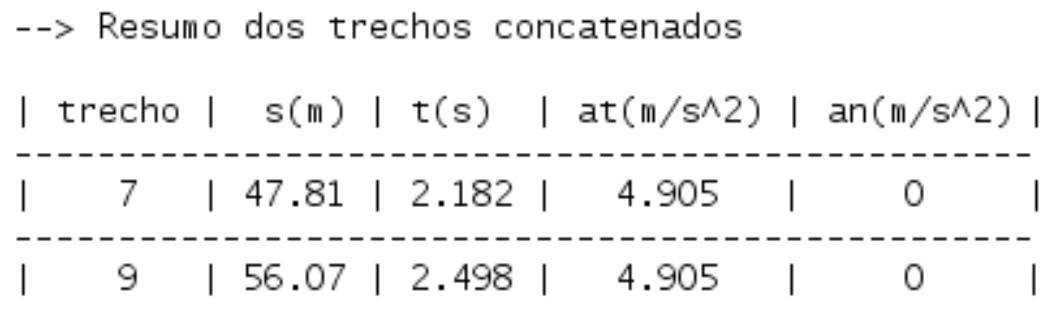

Figura 5.31: Resultados para a concatenação com velocidade reduzida. 
Para analisar os resultados do algoritmo, as Figuras 5.29 e 5.30 mostram como a velocidade e a aceleração tangencial varia no tempo. Nota-se que ambas a aceleração máxima e desaceleração máxima foram respeitadas para nova condição. O comportamento da velocidade obtida consiste em acelerar na saída da curva e frear na entrada da curva seguinte, usando o máximo possível as capacidades de aceleração longitudinal.

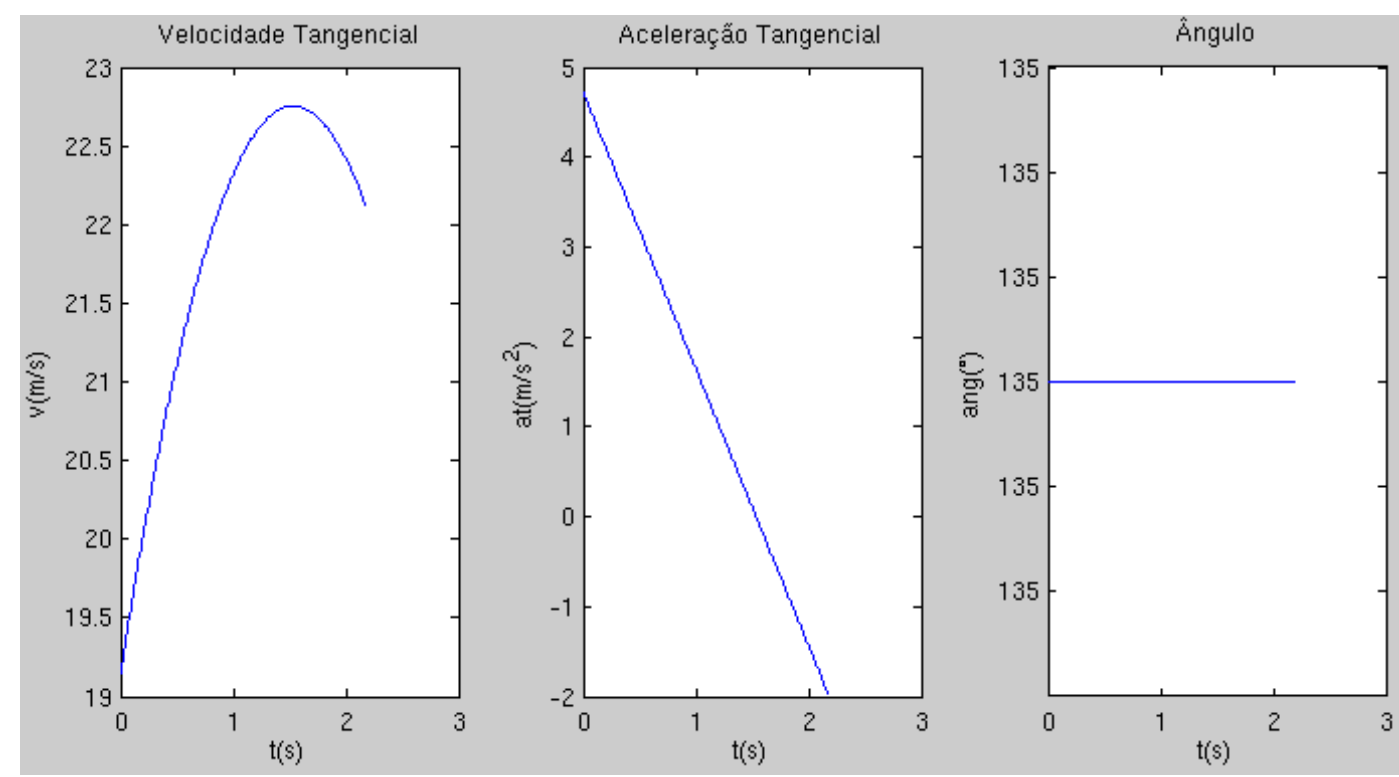

Figura 5.32: Novo resultado para o trecho concatenado 7.

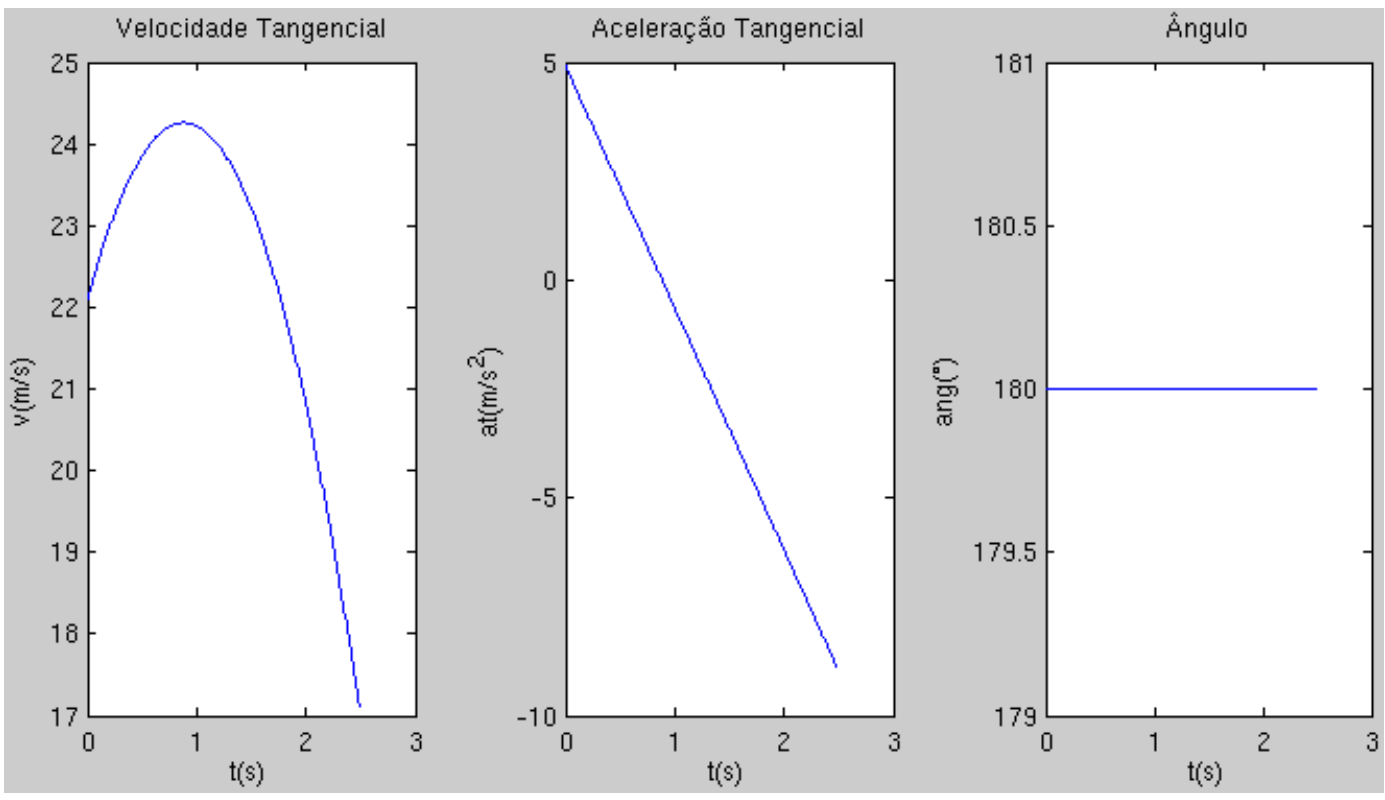

Figura 5.33: Novo resultado para o trecho concatenado 9. 


\subsection{Resultado final para a concatenação da pista teste}

Ao longo do processo de formulação do algoritmo, foi possível dividir as concatenações da pista teste em três tipos possíveis: concatenação entre curvas, concatenações entre curvas de direções diferentes que possuem um trecho reto entre si sem intersecção entre as curvas e concatenações entre curvas de direções iguais que possuem um trecho reto entre si sem intersecção entre as curvas. Para cada caso, foi proposto um modelo de otimização para encontrar a melhor curva de Hermite para a concatenação. O resultado final para a pista completa está apresentado na Figura 5.34.

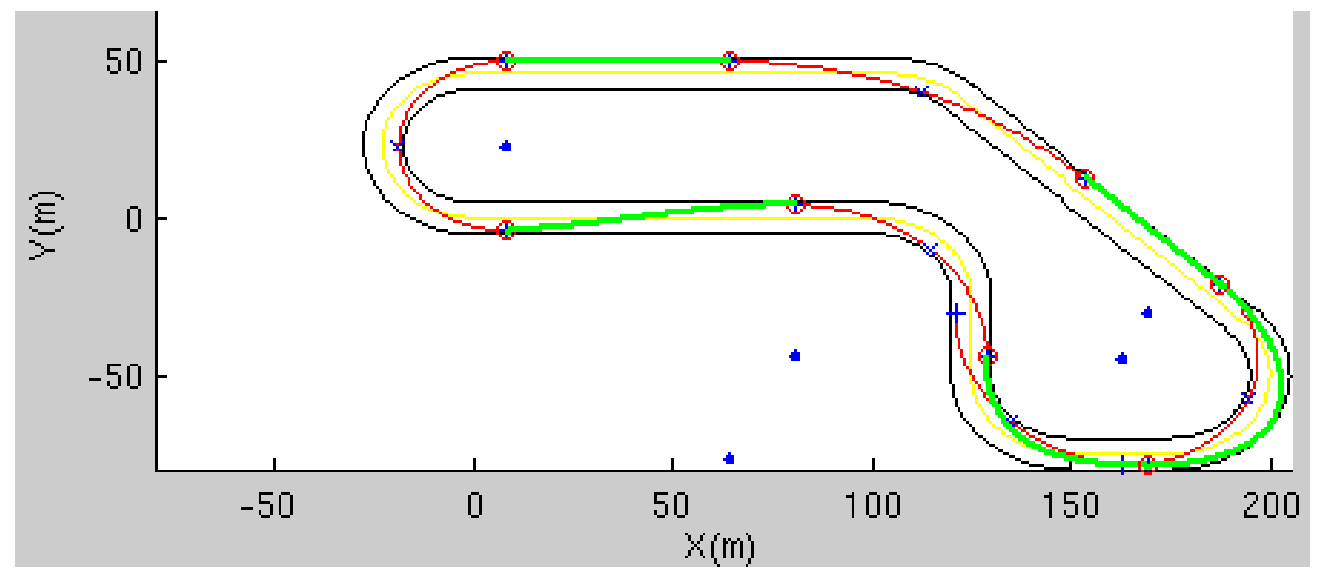

Figura 5.34: Resultado completo para a pista teste.

Para a concatenação entre curvas foi desenvolvido um modelo que procura a curva cujo ponto mais perto do centro da pista esteja a uma distância mínima do mesmo. A intenção é achar a curva de menor comprimento (e logo, menor tempo, já que o tempo de percurso na curva de Hermite é o próprio parâmetro $\tau$, proporcional ao comprimento da curva) que concatena os dois trechos, respeitando as restrições geométricas da pista e os limites de aceleração do veículo. Os pontos escolhidos para concatenação sempre eram os pontos de saída das curvas independentes. Os resultados mostraram que, devido às próprias características de uma curva de Hermite, ela não é a mais adequada para a concatenação em alguns casos.

Para a concatenação entre curvas de direções diferentes, como não havia intersecção entre as mesmas, a concatenação foi feita entre a saída da curva atual e a entrada da curva seguinte. Como as derivadas tinham a mesma direção, mas os 
pontos não estavam do mesmo lado da pista, a curva de concatenação deveria representar uma troca de pistas suave. Os resultados obtidos foram bastante satisfatórios. Para o caso de concatenação entre curvas de mesma direção, a curva de concatenação deve ser uma reta e o modelo proposto encontra a curva de menor tempo que respeita os limites de aceleração.

O algoritmo identifica qual é o tipo de concatenação a ser feita utilizando a relação entre as direções das derivadas nos pontos de início e fim da concatenação e aplica o modelo correto para cada caso.

As características dinâmicas de cada curva ótima independente e dos trechos concatenados são resumidas em uma tabela gerada pelo próprio algoritmo, apresentada na figura seguinte.

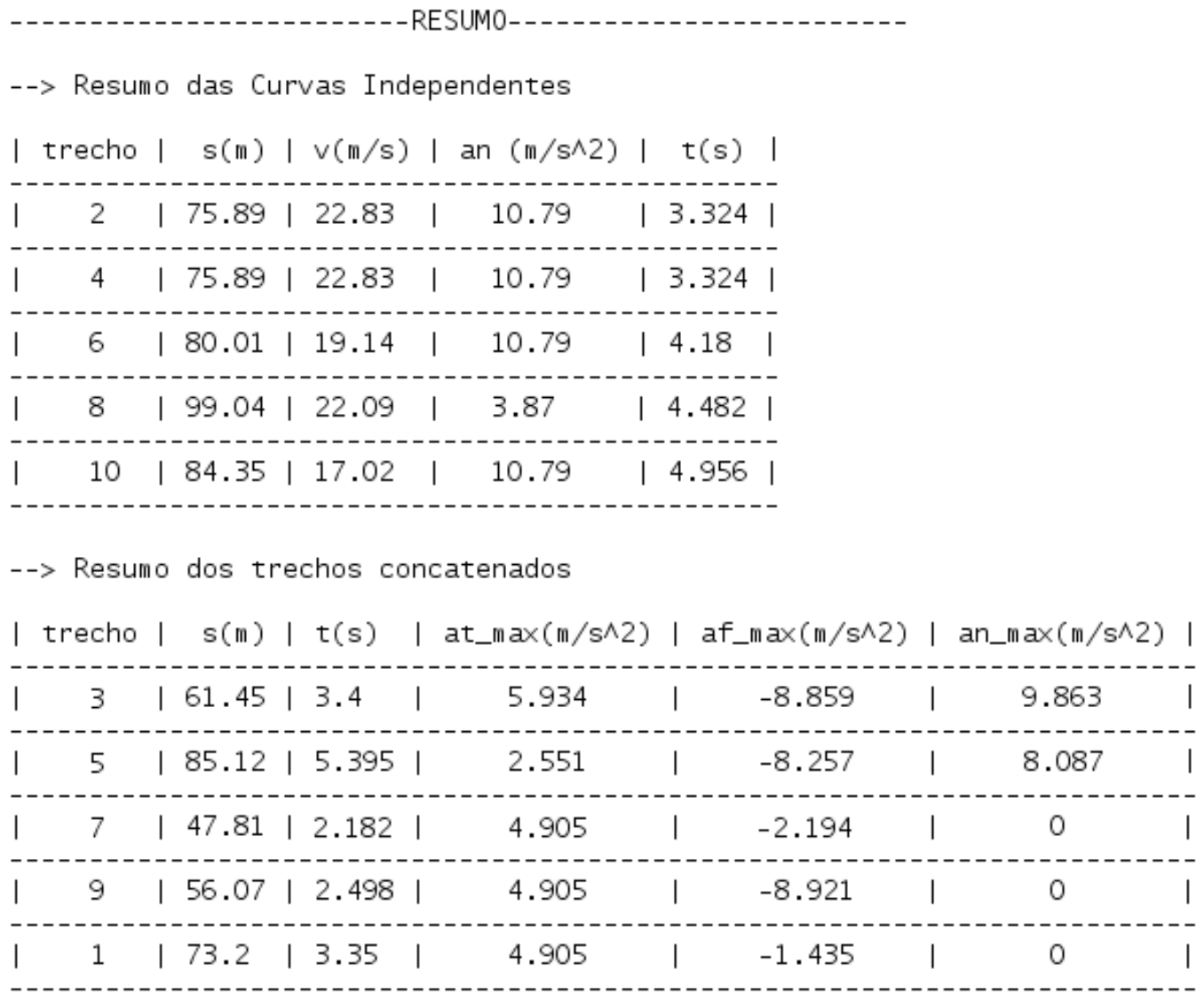

Aceleração tangencial máxima veículo: $4.905 \mathrm{~m} / \mathrm{s} \wedge 2$

Aceleração frenagem máxima veículo: $-10.791 \mathrm{~m} / \mathrm{s} \wedge 2$

Aceleração norma1 máxima veícu1o: $10.791 \mathrm{~m} / \mathrm{s} \wedge 2$

Tempo do algoritmo $=29.31 \mathrm{~s}=0.4885 \mathrm{~min}$

Figura 5.35: Resultados dinâmicos para a pista teste. 
Na Figura 5.35, é possível perceber que o principal problema foi o trecho concatenado número 3, em que se chegou à conclusão de que não existe curva de Hermite que concatenasse os pontos respeitando todos os limites do círculo de aderência, o que significa dinamicamente que o veículo perderia estabilidade e deslizaria ao fazer a curva proposta. Uma possível solução seria variar o ponto de entrada até que a solução encontrada seja viável.

Outra mudança que precisou ser feita foi na velocidade da curva número 8 , que precisou ser reduzida para o veículo pudesse atingir a velocidade de entrada da curva em tempo hábil, considerando o espaço entre as curvas. Esta alteração, no entanto, não surgiu de uma limitação da técnica utilizada, e sim, do fato de que o veículo escolhido não tinha capacidade para aceleração tanto em tão pouco tempo. E já que as curvas ótimas independentes não levam em consideração esses fatores a priori, a redução é completamente aceitável.

O espaço total percorrido pelo veículo foi de 582,93m em um tempo total de percurso de 29,587s. Quanto ao gasto computacional, o algoritmo levou 29,31s (num notebook padrão i5, sistema operacional Linux) para concluir todo o processo de concatenação, o que é consideravelmente eficiente, dada a quantidade de processamento que o modelo de otimização exige.

\subsection{Resultados para a pista de Barcelona}

Ao longo deste capítulo, a pista teste foi utilizada para o desenvolvimento e verificação do algoritmo de concatenação de trajetórias ótimas individuais a partir de curvas de Hermite. Os resultados foram analisados levando-se em consideração as acelerações tangencial, normal e total do percurso, e a geometria da pista. Como pontos positivos, a restrição geométrica nunca foi violada e nem as velocidades nos pontos inicial e final da curva de concatenação. Com relação às acelerações, mesmo quando uma delas apresentava valores fora das restrições, o algoritmo conseguiu encontrar a melhor curva possível para as outras restrições.

Uma das facilidades que o algoritmo desenvolvido apresenta é que ele foi formulado de tal maneira que a troca da função de interpolação seja simples, conhecendo sua equação paramétrica em relação ao tempo. Além disso, podem-se trocar os pontos de início e fim das curvas de concatenação para teste com razoável facilidade, sendo necessário apenas definir a regra para escolha de tais 
pontos. O algoritmo é genérico e pode ser aplicado a qualquer circuito, uma vez que se tenha seu perfil modelado no Matlab ${ }^{\circledR}$.

Duas pistas foram apresentadas na seção 3 para testes do algoritmo: a pista teste, que não foi montada com base em nenhum circuito existente, apenas com trechos retos e em curva pertinentes para análise; e a pista de Barcelona, que aproxima o circuito de Fórmula 1 de Catalunha - Barcelona, Espanha - por meio de retas e arcos de circunferência. Os resultados para a pista teste já foram apresentados e discutidos. Nesta seção serão apresentados os resultados do algoritmo desenvolvido para esta pista.

As trajetórias ótimas individuais de cada curva da pista de Barcelona foram mostradas na Figura 3.9 e na Figura 5.36 está apresentado o resultado completo da concatenação para a pista de Barcelona.

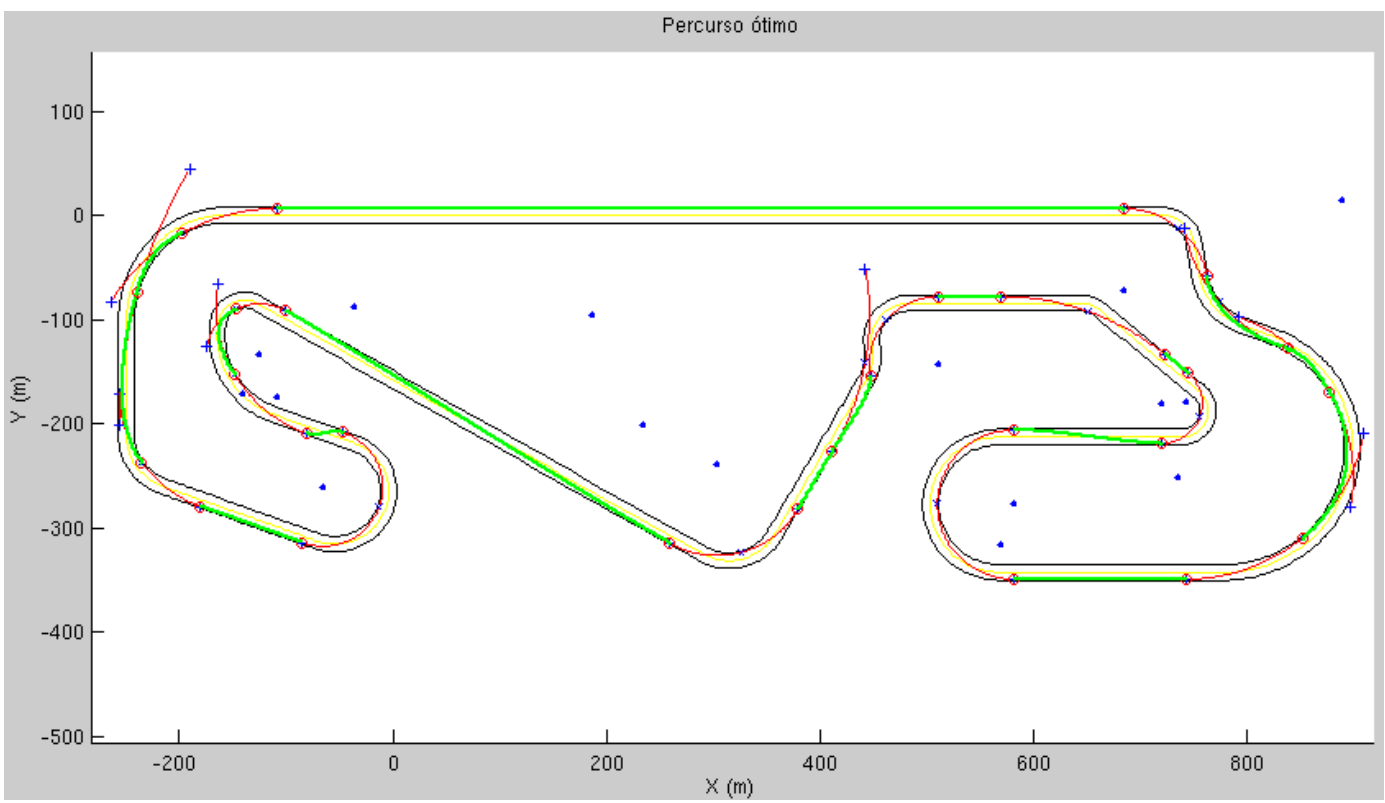

Figura 5.36: Resultado completo para a concatenação da pista de Barcelona.

Na pista de Barcelona existem alguns tipos de curvas que não foram tratadas pela pista teste, como, por exemplo, os casos em que o ponto de saída (ou de entrada) da trajetória individual está fora da pista. Isso acontece em diversas curvas neste circuito. A escolha de pontos, então, deve ser feita de outra forma. Para estes casos, os pontos $P_{1}$ e $P_{4}$ e os vetores $\overrightarrow{R_{1}}$ e $\overrightarrow{R_{4}}$ foram escolhidos como os ápices das curvas, porque estes pontos estão sempre dentro da pista e desta forma, mantém-se o ápice no centro geométrico da curva. 
Foram, no total, 16 trechos concatenados utilizando-se exatamente as mesmas funções objetivo e restrições da pista teste para cada caso: concatenação em curvas, em trechos retos com troca de lados na pista ou em trechos retos sem troca de lados. No entanto, uma nova condição foi adicionada, acrescentando os casos em que a concatenação foi feita pelos ápices. Nesses casos, o modelo de otimização utilizado foi o mesmo para concatenações em curva (mostrado na Equação 5.8), incluindo as restrições geométricas e de aceleração tangencial, normal e total. Além disso, como as distâncias para este circuito são maiores, os limites da variável $\tau$ precisaram ser reajustados para $\tau_{\min }=0,05 \mathrm{~s}$ e $\tau_{\max }=40 \mathrm{~s}$.

Na Figura 5.36, uma das concatenações parece ter uma forma que foge do resultado esperado para uma curva de Hermite, que é a concatenação do trecho 22, apresentada com detalhe na Figura 5.37.

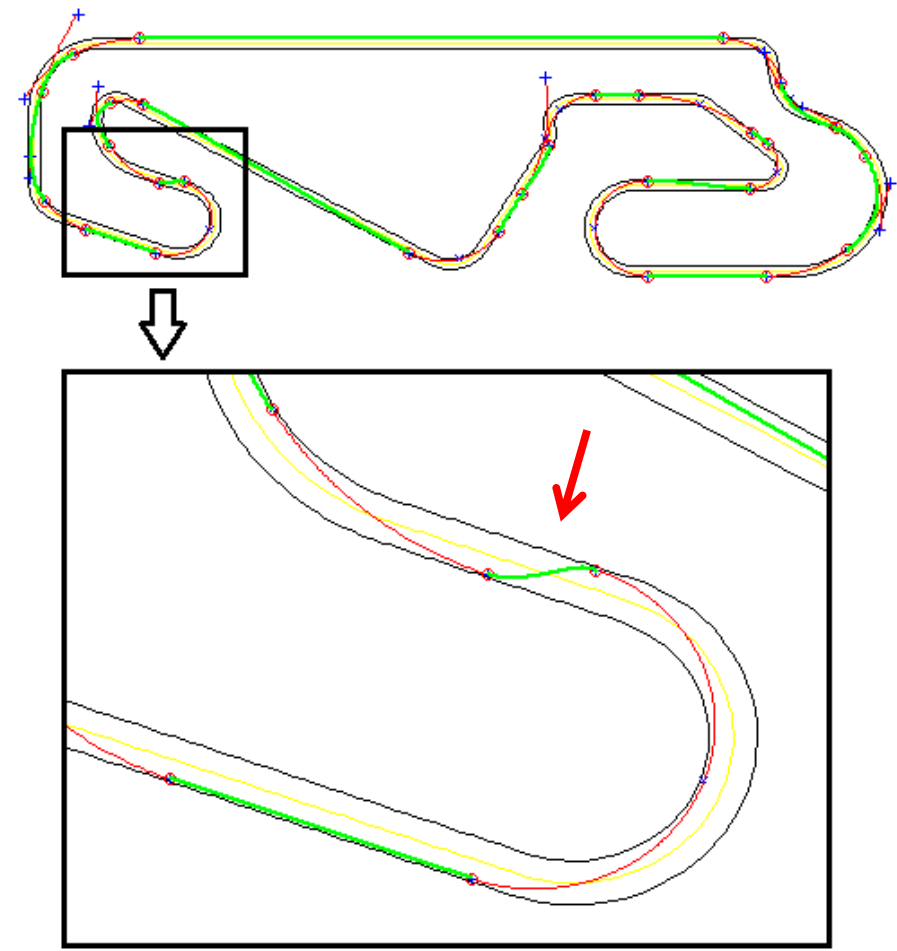

Figura 5.37: Trecho concatenado 22 da pista de Barcelona.

Analisando a forma da curva com mais cuidado, ela se caracterizaria pela troca gradual entre os lados da pista, mas como a distância entre os pontos é pequena, a troca se tornou, de fato, um pouco brusca. Uma alternativa seria escolher um ponto para concatenação na trajetória individual da curva anterior um pouco antes do ponto de saída em si, mas a direção do vetor tangente não seria 
mais igual ao do ponto de entrada da curva seguinte, o que geraria uma nova condição de concatenação. Para facilitar o entendimento, a Figura 5.38 descreve a numeração dos trechos da pista de Barcelona.

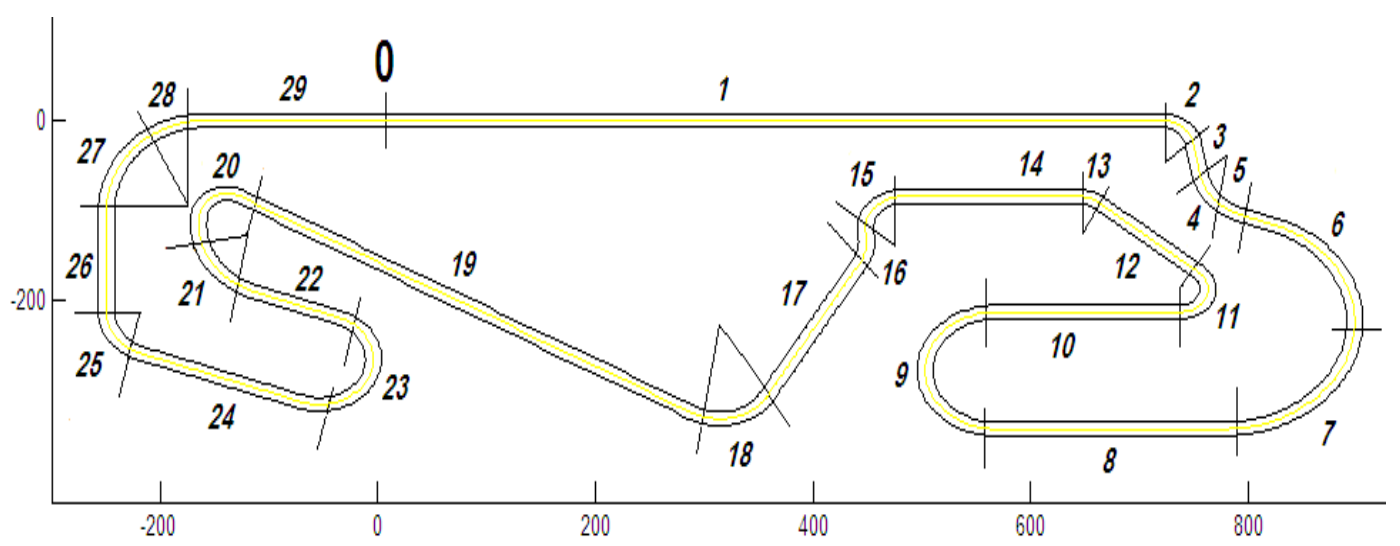

Figura 5.38: Trechos numerados da pista de Barcelona

O algoritmo gera um resumo das acelerações máximas de cada trecho, tanto para as trajetórias ótimas individuais, quanto para as curvas concatenadas. O resumo para as trajetórias ótimas independentes está apresentado na Figura 5.39.

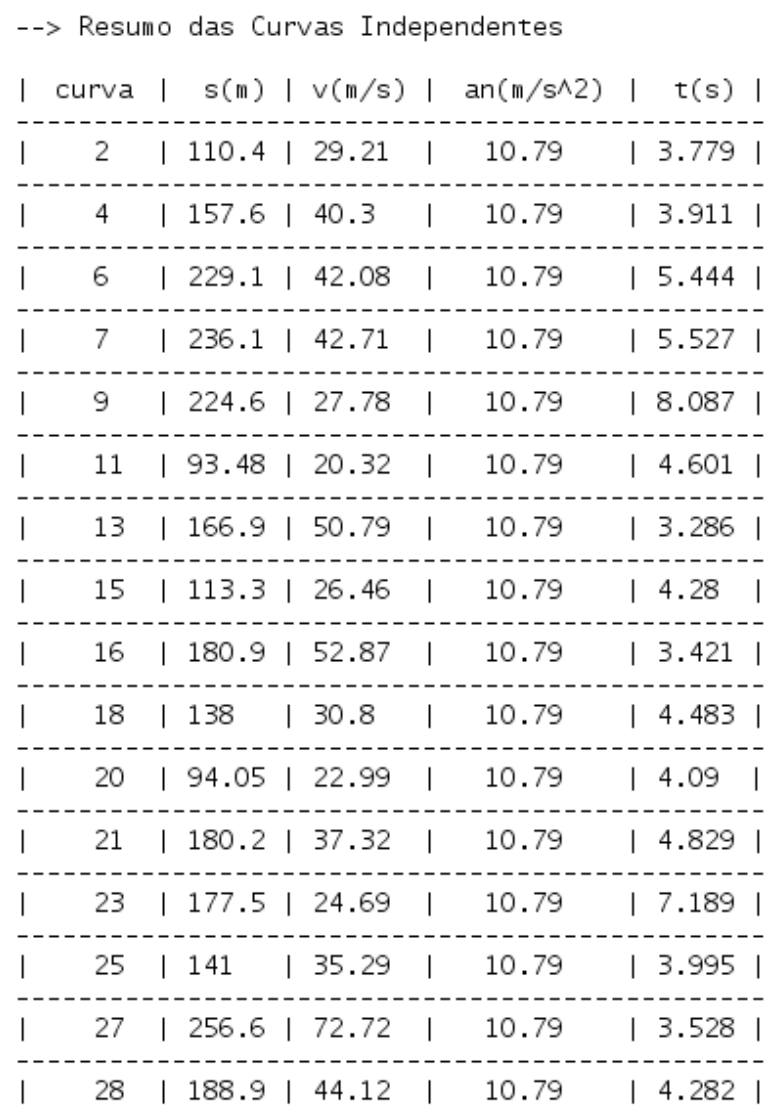

Figura 5.39: Resumo das trajetórias ótimas independentes da pista de Barcelona. 
Os limites de aceleração para concatenação da pista de Barcelona mantiveram-se os mesmos que foram utilizados para a pista teste. Todas as trajetórias ótimas individuais foram mantidas na maior aceleração normal para análise dos resultados. Isso fez com que algumas velocidades ficassem muito altas nos trechos individuais (como na curva 27), gerando alguns problemas na concatenação dos trechos, que serão comentados a seguir. Observe, por exemplo, que da curva 25 para a curva 27 , a variação de velocidade é quase de $40 \mathrm{~m} / \mathrm{s}$ em muito pouco espaço, o que claramente não será possível de ser executado por um veículo cujo limite de tração máximo é de $4,905 \mathrm{~m} / \mathrm{s}^{2}$. Isso acontece em diversos trechos ao longo da pista. A Figura 5.40 mostra um resumo para os trechos concatenados por curvas de Hermite.

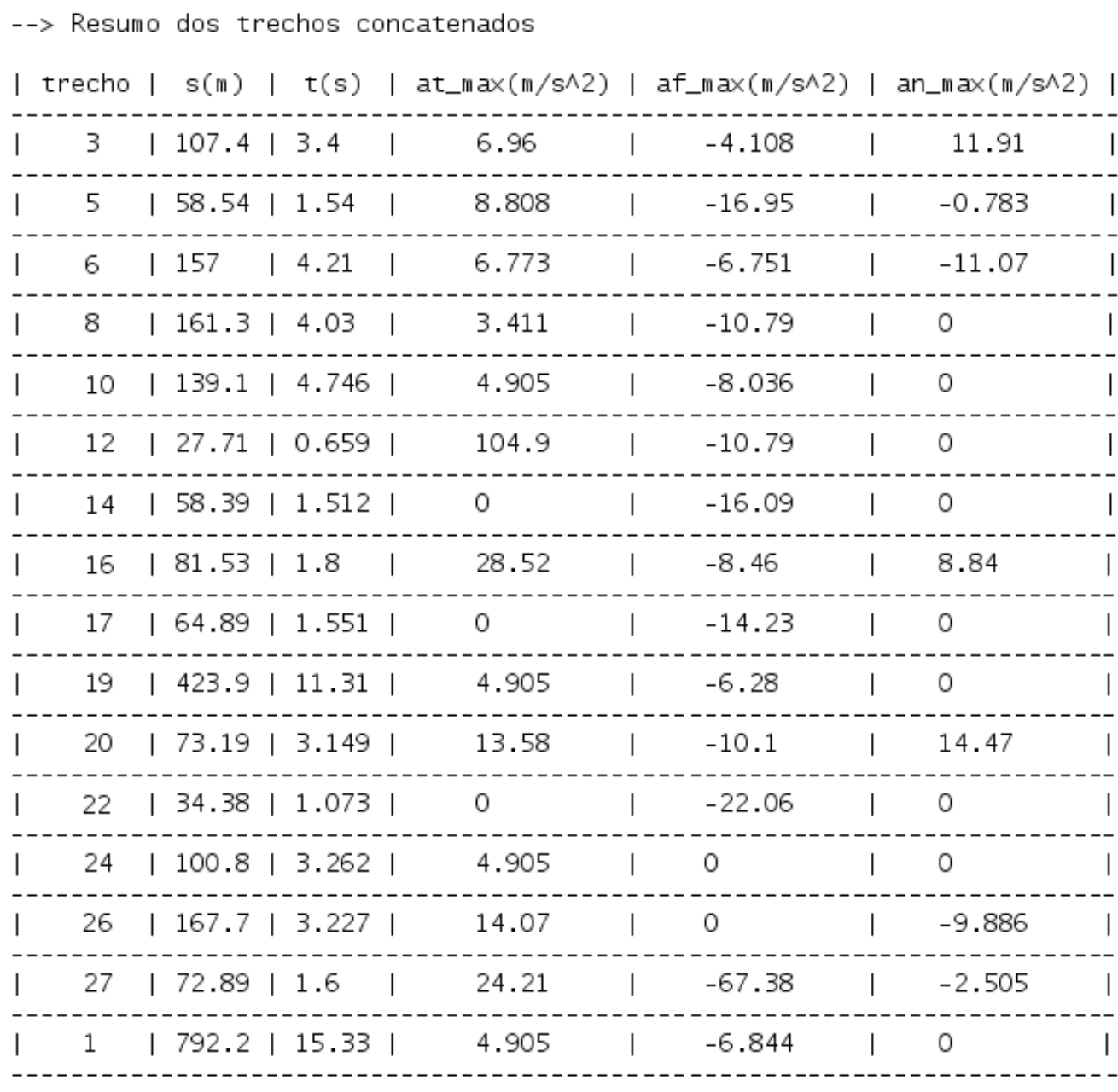

Limit values for accelarations: at_max $=4.905 \mathrm{~m} / \mathrm{s} \wedge 2$

af_max $=-10.791 \mathrm{~m} / \mathrm{s} \wedge 2$

an_max $=10.791 \mathrm{~m} / \mathrm{s} \wedge 2$

Algorithm Time $=117.8 \mathrm{~s}=1.9633 \mathrm{~min}$

Figura 5.40: Resumo dos trechos concatenados da pista de Barcelona. 
Quanto aos trechos em curva, observa-se que o sinal da aceleração normal está compatível com todas as curvas executadas. As curvas para a direita têm aceleração normal negativa e as curvas para a esquerda têm aceleração normal positiva. Esta característica do modelo não foi evidente na pista teste, pois todas as curvas eram no mesmo sentido. Em algumas curvas, as restrições não foram todas respeitadas, mas o algoritmo conseguiu sempre satisfazer pelo menos uma das restrições e apresentou a melhor curva de Hermite possível. As restrições geométricas foram respeitadas em todos os casos.

Os trechos 12, 17 e 22, concatenados em reta, apresentaram aceleração tangencial acima do limite, pois em todos os três casos a reta deveria concatenar duas curvas com velocidades muito diferentes em pouco espaço, o que não seria possível, nem mesmo mantendo a aceleração tangencial máxima constante de $4,905 \mathrm{~m} / \mathrm{s}^{2}$ ou a desaceleração máxima constante de $-10,791 \mathrm{~m} / \mathrm{s}^{2}$. Ou seja, o veículo proposto não é capaz de realizar este trecho e as velocidades das trajetórias ótimas individuais devem ser reduzidas até que o trajeto seja possível, fazendo com que algumas trajetórias individuais não sejam executadas com a máxima aceleração normal, como aconteceu na pista teste.

\subsubsection{Verificação das acelerações e velocidades na pista de Barcelona}

Para cada trecho concatenado, são calculados os valores no tempo das principais características dinâmicas das curvas de Hermite, que são: a velocidade tangencial, as acelerações tangencial e normal, o ângulo, a curvatura e o raio ao longo da trajetória. As Figuras a seguir mostram as características dinâmicas de cada trecho, na mesma ordem em que a concatenação foi feita. 

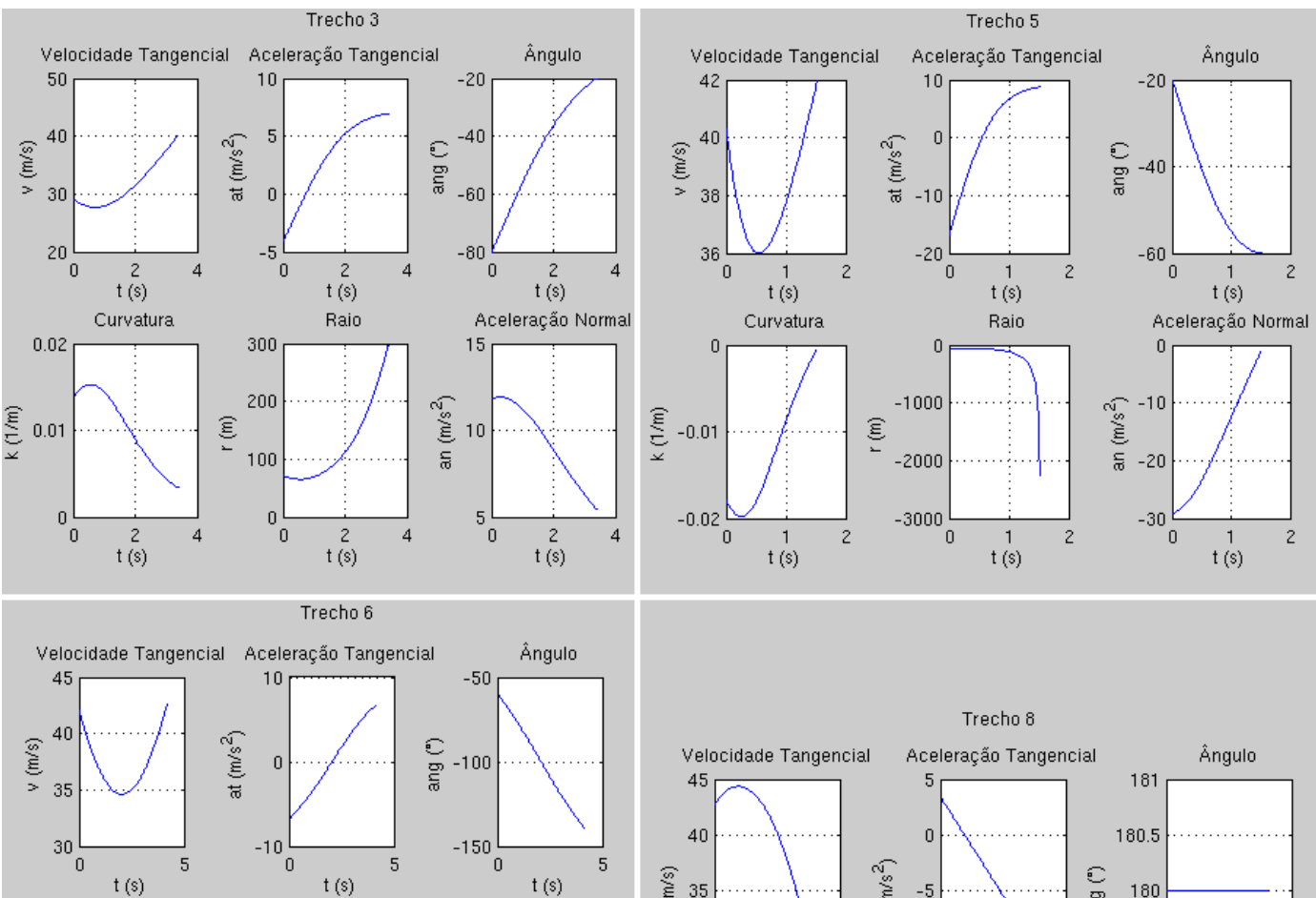

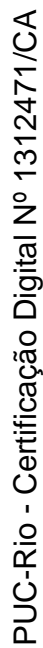
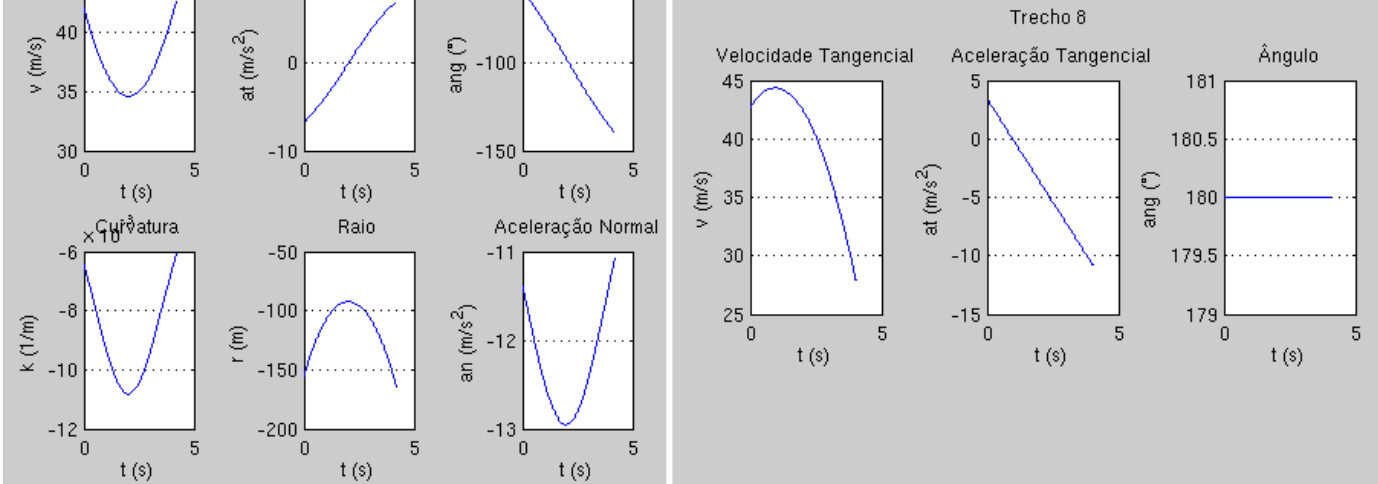

Figura 5.41: Dinâmica dos trechos concatenados 3, 5, 6 e 8.

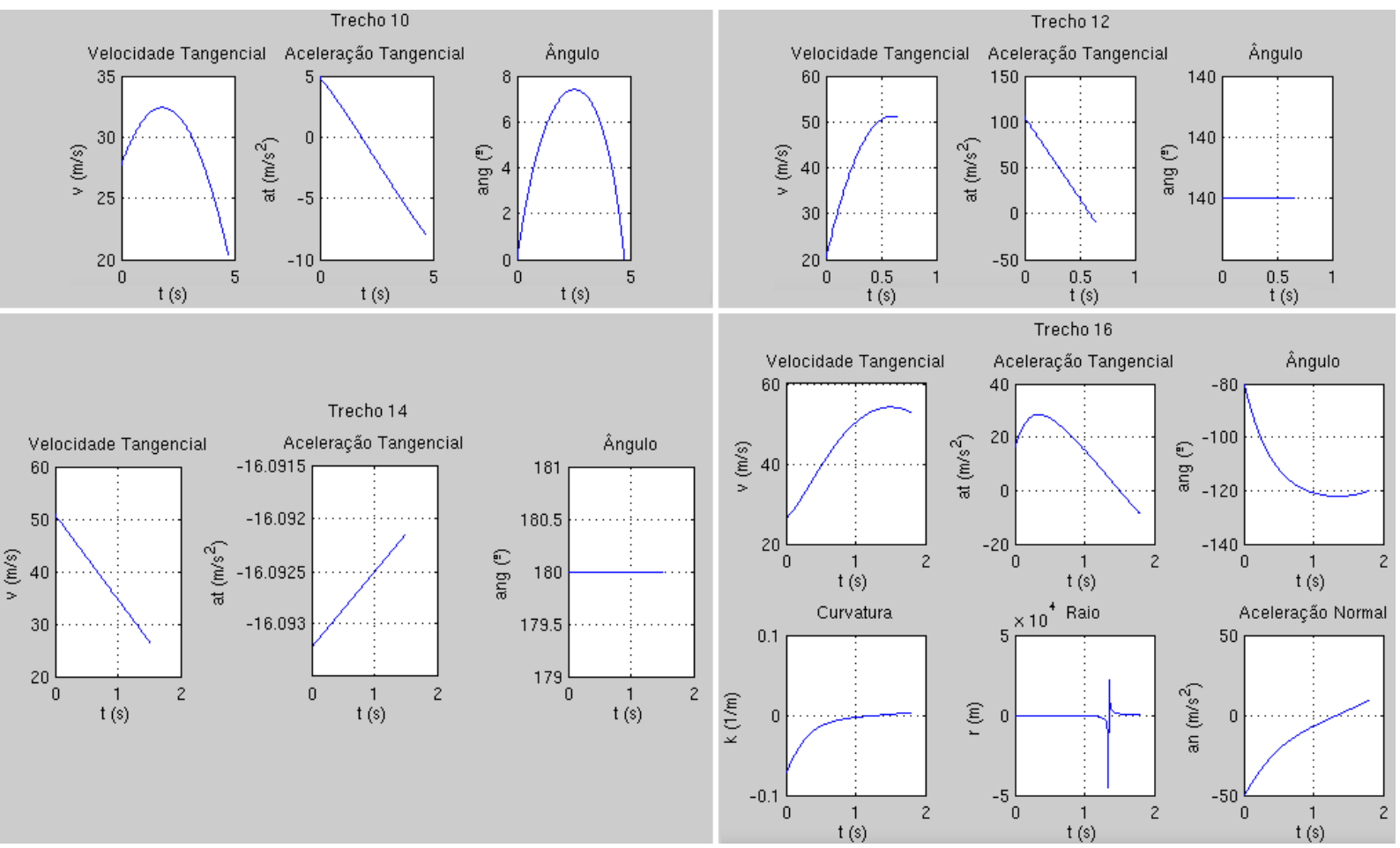

Figura 5.42: Dinâmica dos trechos concatenados 10, 12, 14 e 16. 


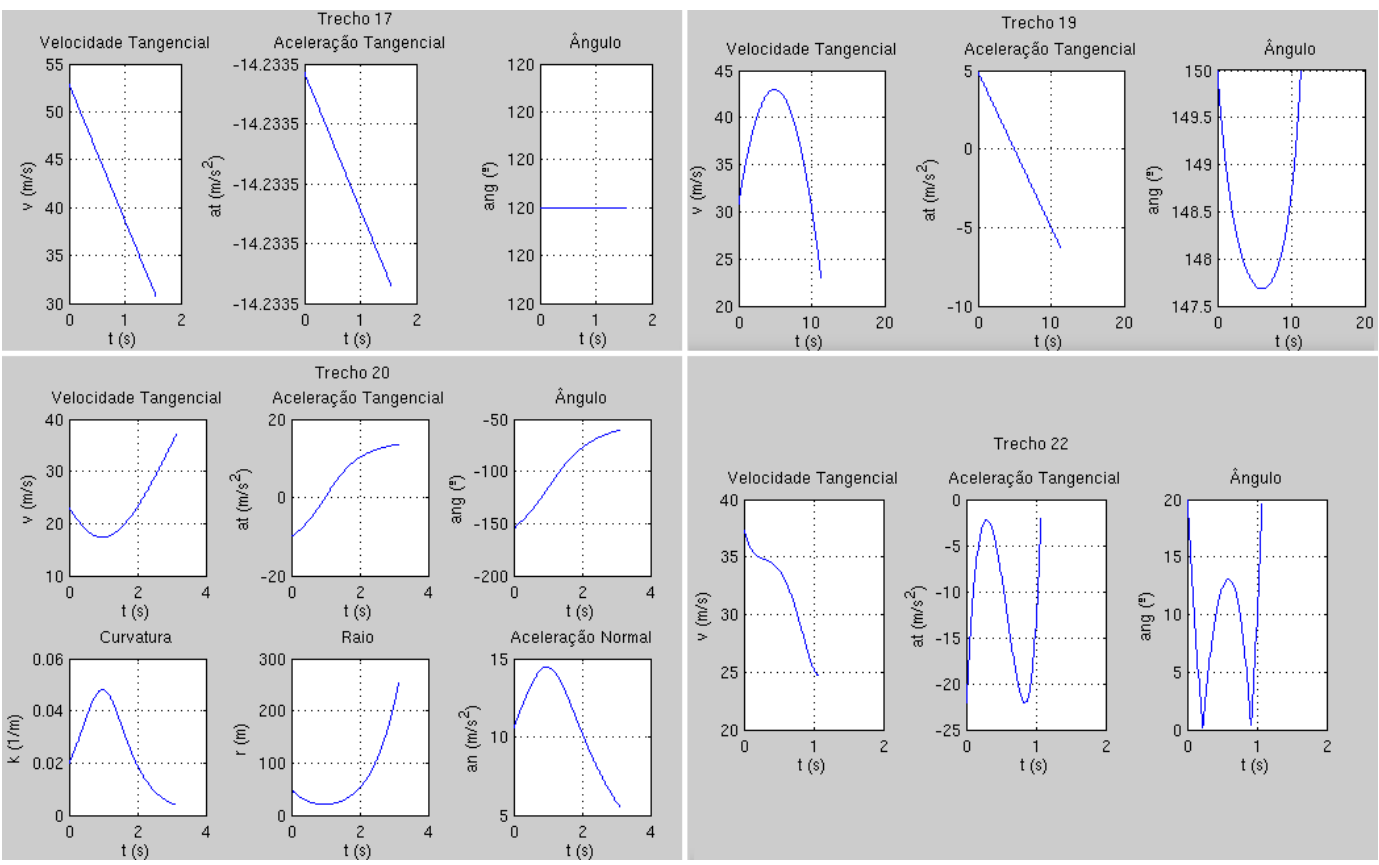

Figura 5.43: Dinâmica dos trechos concatenados 17, 19, 20 e 22.

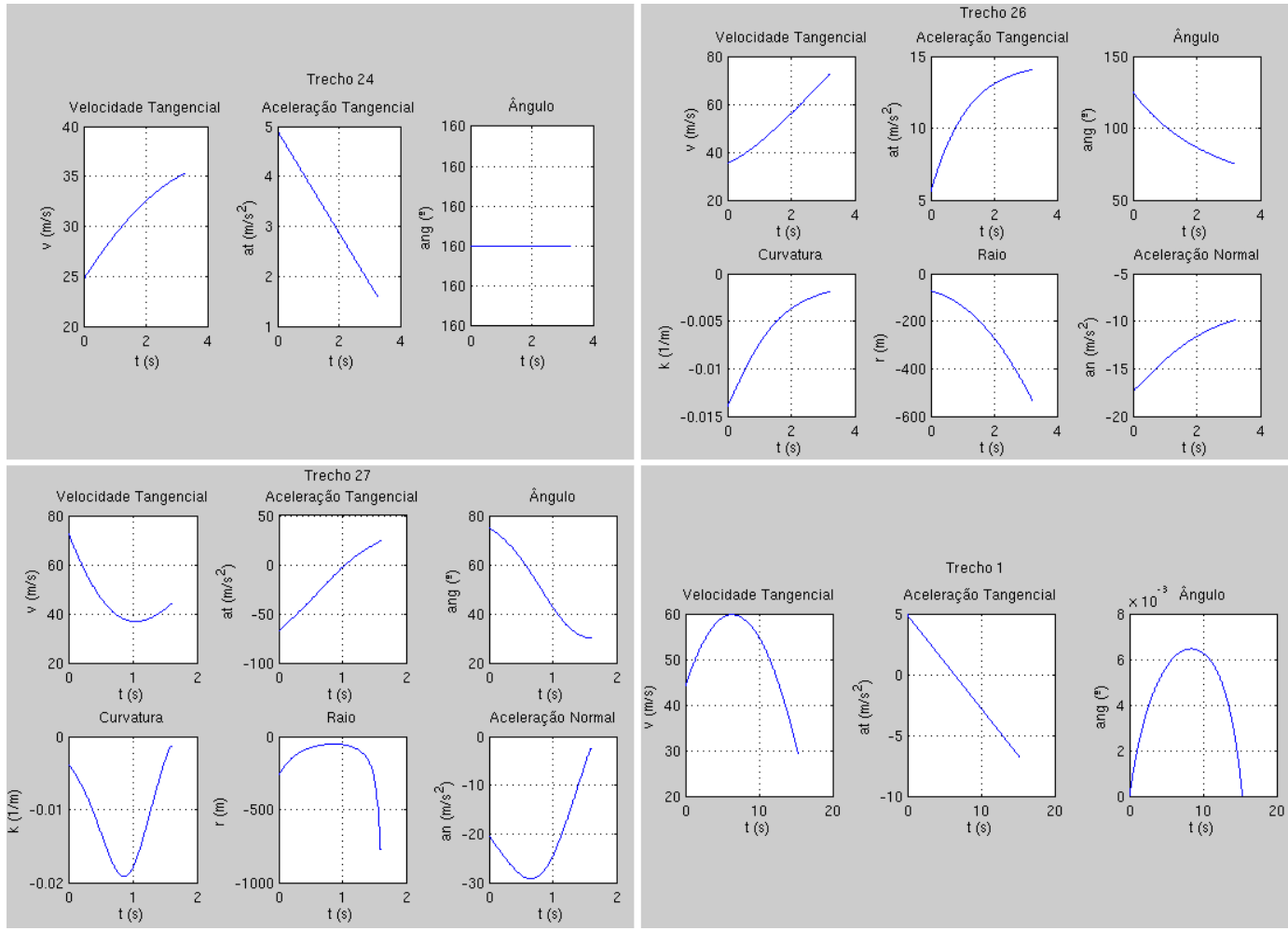

Figura 5.44: Dinâmica dos trechos concatenados 24, 26, 27 e 1

Em geral, os perfis de velocidade estão bem coerentes com o esperado. Nas concatenações em curva, a velocidade é reduzida na entrada da curva e aumenta na saída; e nas concatenações em reta, a velocidade aumenta no início por causa da saída da curva anterior e reduz no final, para a entrada na curva seguinte. Em 
alguns casos de concatenação por retas, a aceleração foi mantida ao máximo e constante para que fosse possível realizar o trajeto em tempo mínimo e em outros casos, na desaceleração máxima possível. Tanto o ângulo, quanto a curvatura e o raio calculados nos trechos são compatíveis com as trajetórias obtidas. Nos casos em que uma das acelerações não foi respeitada, o perfil de aceleração proposto é o mínimo necessário para a execução do trajeto mantendo-se as velocidades previamente obtidas nas trajetórias ótimas individuais.

Como a pista de Barcelona é mais complexa que a pista teste e apresenta mais trechos para concatenação, o algoritmo levou quase 2 minutos para computar o trajeto completo, no mesmo computador. $\mathrm{O}$ espaço total percorrido na pista de Barcelona foi de 3965,23m em 109,46s. Quanto à forma geométrica da trajetória obtida, está bem similar com a obtida a partir da solução do problema de controle ótimo, apresentada por Casanova [11] e mostrada na Figura 5.45.

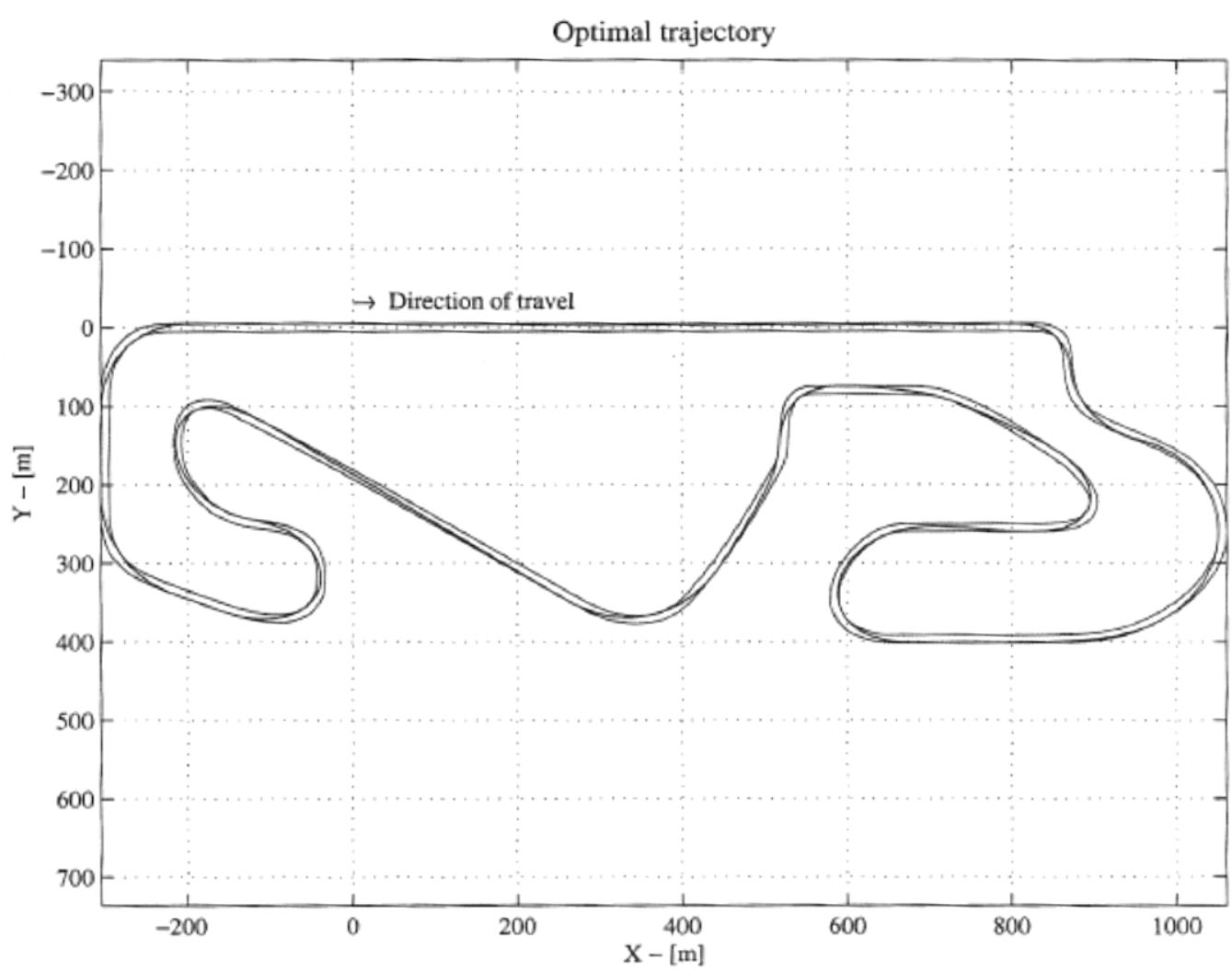

Figura 5.45: Trajetória da pista de Barcelona obtida pela computação do problema de controle ótimo [11].

É importante ressaltar que a comparação feita aqui leva em consideração apenas o traçado geométrico das duas trajetórias e não seus respectivos tempos, já 
que os veículos utilizados para a simulação nos dois casos foram diferentes. $\mathrm{O}$ veículo utilizado por Casanova [11] é um veículo típico para competições em Fórmula 1 e com limites de aceleração e velocidade muito maiores que os utilizados neste trabalho, que são mais compatíveis com um veículo de passeio. No entanto, observe na Figura 5.46 que a comparação entre os dois traçados é bastante satisfatória.

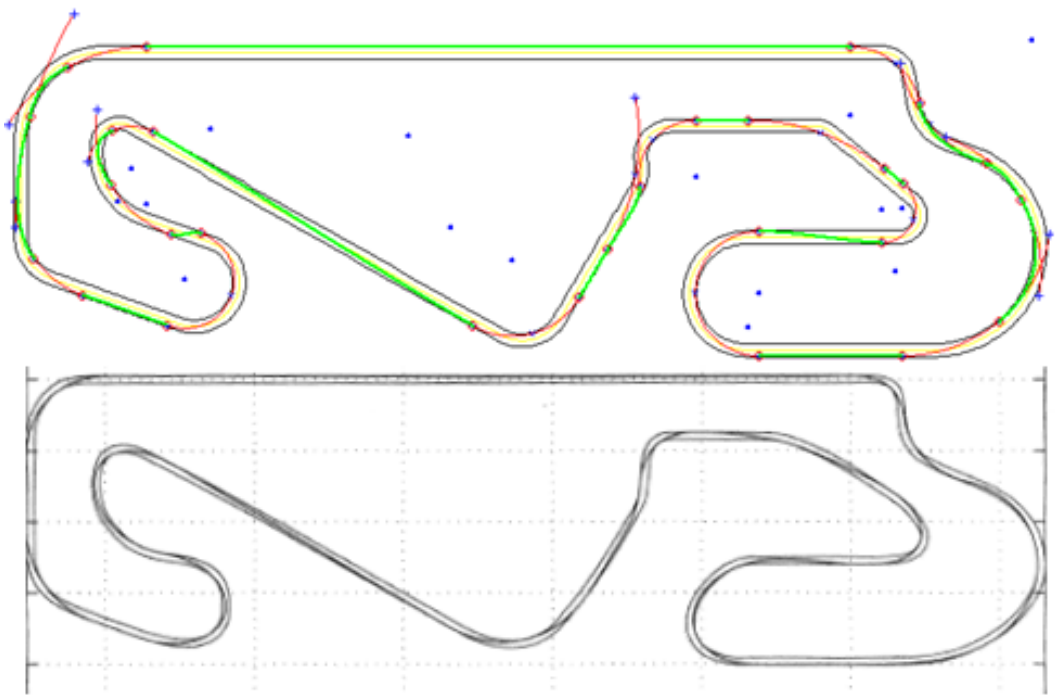

Figura 5.46: Comparação entre o traçado obtido por concatenação e por controle ótimo

Além disso, no site oficial do campeonato de Formula 1 está disponível a reconstrução da trajetória feita por um piloto profissional no circuito de Barcelona por meio de sensores embarcados (não necessariamente ótima), que também está próxima da trajetória obtida pelo algoritmo. A Figura 5.46 mostra o trajeto feito pelo piloto.

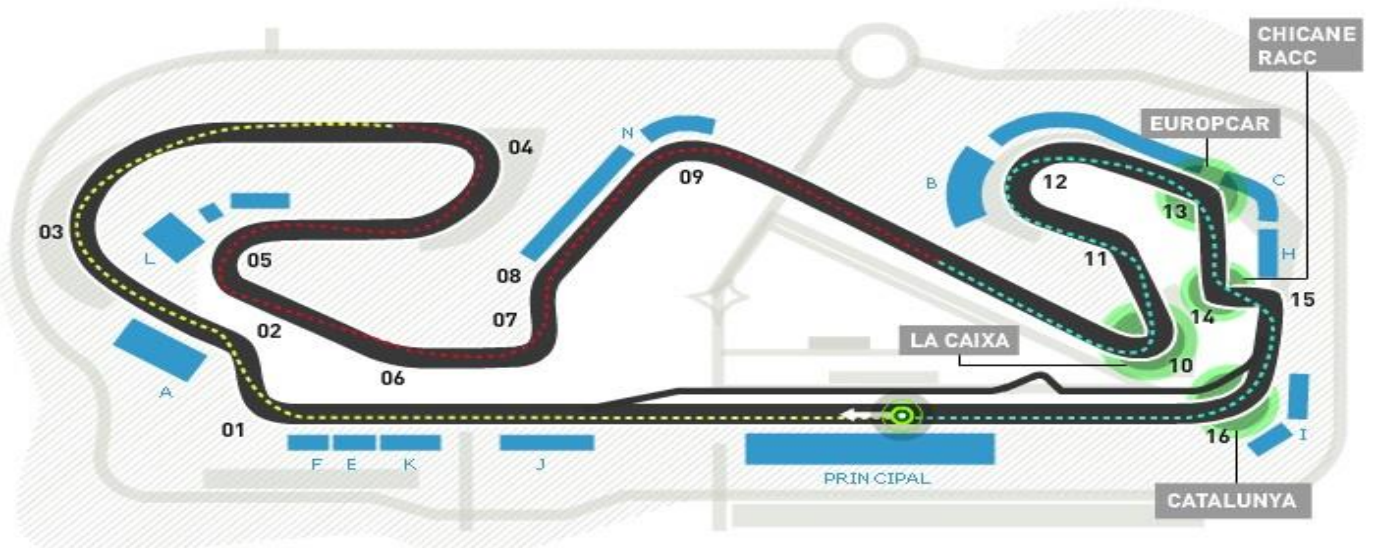

Figura 5.47: Trajetória do circuito de Barcelona obtida no site do campeonato de Fórmula 1 [21]. 


\section{Controle Ótimo}

$\mathrm{Na}$ área de dinâmica de veículos, a abordagem por controle ótimo vem sendo amplamente utilizada na solução de problemas de trajetória de tempo mínimo [11], de melhor curva de velocidade em manobras de tempo mínimo [14], na análise da influência de algumas características dinâmicas do veículo na sua trajetória [10], entre outros. No entanto, apesar de os problemas de controle ótimo estarem bem consolidados do ponto de vista teórico, sua solução numérica ainda é um desafio computacional.

Nesta seção será apresentada uma alternativa às técnicas de otimização com restrição para determinação de trajetórias ótimas de circuitos, baseada na abordagem por controle ótimo. Neste trabalho, apenas a modelagem do problema é discutida, com sugestões de técnicas para sua solução. Primeiramente será apresentada uma visão geral da definição e solução matemática de problemas de controle ótimo, que pode ser encontrada com mais detalhes em Kirk [22].

\subsection{O problema geral de controle ótimo}

Em geral, o objetivo de um sistema de controle é determinar o sinal de controle $\mathrm{u}(\mathrm{t})$ que leva a resposta de um sistema dinâmico a um certo nível desejado. Similarmente, o problema de controle ótimo consiste em calcular o sinal de controle $u(t)$ que leva um sistema dinâmico de um nível para outro e minimiza algum índice de desempenho específico do sistema, denotado como J. Desta forma, para o controle ótimo, a entrada ótima $\mathrm{u}^{*}(\mathrm{t})$ é tal que $\mathrm{J}\left(\mathrm{u}^{*}(\mathrm{t})\right)<\mathrm{J}(\mathrm{u}(\mathrm{t}))$ para todo $\mathrm{u}^{*}(\mathrm{t}) \in \mathrm{U}\left[\mathrm{t}_{0}, \mathrm{t}_{\mathrm{f}}\right]$, o que significa que $\mathrm{u}^{*}(\mathrm{t})$ faz com o que o índice de desempenho apresente um valor menor do que qualquer outro valor de $u(t)$ possível [22].

Considere o seguinte sistema dinâmico:

$\dot{x}(t)=f(x(t), u(t), t)$ 
onde $\mathrm{x}(\mathrm{t})$ é o estado e u(t) é a entrada do sistema.

Para o dado sistema, o índice de desempenho a ser minimizado em um problema de controle ótimo pode ser definido de forma genérica como:

$J(u(t))=h\left(x\left(t_{f}\right), t_{f}\right)+\int_{t_{0}}^{t_{f}} L(x(t), u(t), t) d t$

onde o termo $h\left(x\left(t_{f}\right), t_{f}\right)$ representa o desempenho associado ao estado final do sistema dinâmico e o termo $\int_{t_{0}}^{t_{f}} L(x(t), u(t), t d t$ representa o desempenho do sistema ao longo do intervalo de controle $\left[\mathrm{t}_{0}, \mathrm{t}_{\mathrm{f}}\right]$.

Uma vez definido o índice de desempenho, o problema de controle ótimo pode ser enunciado da seguinte forma: encontrar o sinal de controle $\mathrm{u}^{*}(\mathrm{t}) \in \mathrm{U}\left[\mathrm{t}_{0}, \mathrm{t}_{\mathrm{f}}\right]$, a ser aplicado durante o intervalo de controle, de modo a

conduzir o estado do sistema dinâmico a uma trajetória $\mathrm{x}^{*}(\mathrm{t})$ que minimiza $J(u(t))$.

Para a maioria dos casos, o problema de tempo mínimo pressupõe a inclusão das restrições correspondentes ao modelo dinâmico do sistema, de ponto inicial e final da trajetória e as restrições para a variável de controle u(t). A formalização do modelo matemático para o problema de otimização está representado na Equação 6.3:

$$
\left\{\begin{aligned}
& \min _{u(t) \in U} J(u(t))=h\left(x\left(t_{f}\right), t_{f}\right)+\int_{t_{0}}^{t_{f}} L(x(t), u(t), t) d t \\
& \text { s.t. } \quad \dot{x}=f(x(t), u(t), t) \\
& x\left(t_{0}\right)=x_{0} \\
& x\left(t_{f}\right)=x_{f} \\
& u_{L} \leq u(t) \leq u_{U}
\end{aligned}\right.
$$

Para a solução deste problema de otimização com restrições é aplicada a técnica dos multiplicadores de Lagrange, onde incluem-se as restrições de igualdade na função objetivo ponderadas por multiplicadores $\lambda(t)$. A maior vantagem da utilização desta abordagem é que ela permite a solução do problema sem a necessidade de se resolver explicitamente as restrições do problema. Desta 
forma, como artifício para definir diretamente a relação entre $u(t)$ e x(t), define-se o índice de desempenho aumentado como sendo:

$$
\begin{aligned}
J_{a}(u(t))= & h\left(x\left(t_{f}\right), t_{f}\right)+ \\
& +\int_{t_{0}}^{t_{f}}[L(x(t), u(t), t)+\lambda(t) \cdot(f(x(t), u(t), t)-\dot{x})] d t
\end{aligned}
$$

onde $\lambda(t)$ é denominado co-estado do sistema dinâmico.

A função Hamiltoniana é definida por:

$H(x(t), u(t), \lambda(t), t)=L(x(t), u(t), t)+\lambda(t) \cdot f(x(t), u(t), t)$

E substituindo (6.5) em (6.4), temos que:

$J_{a}(u(t))=h\left(x\left(t_{f}\right), t_{f}\right)+\int_{t_{0}}^{t_{f}}[H(x(t), u(t), \lambda(t), t)+\lambda(t) \cdot \dot{x}] d t$

Uma vez definido o índice de desempenho aumentado, é preciso estabelecer as condições para as quais a entrada de controle é ótima e o índice de desempenho é mínimo. Utilizando os princípios de cálculo variacional [22], sabe-se que o sinal $\mathrm{x}^{*}(\mathrm{t})$ que minimiza um determinado funcional $\mathrm{J}$, expresso por:

$J=\int_{a}^{b} L(t, x(t), \dot{x}(t))$

é aquele que satisfaz a equação de Euler-Lagrange, ou seja:

$\frac{\partial L}{\partial x}-\frac{d}{d t}\left(\frac{\partial L}{\partial \dot{x}}\right)=0$

Aplicando a equação de Euler-Lagrange no funcional aumentado da Equação 6.6, são obtidas as condições necessárias para garantir que uma dada entrada de controle $\mathrm{u}^{*}(\mathrm{t})$ é ótima e minimiza o índice de desempenho. As condições são apresentadas na Equação 6.9, i. e.: 


$$
\begin{aligned}
& \dot{x}^{*}(t)=\frac{\partial H}{\partial \lambda}\left(\dot{x}^{*}(t), u^{*}(t), \lambda^{*}(t), t\right)=f\left(x^{*}(t), u^{*}(t), t\right) \\
& \dot{\lambda}^{*}(t)=-\frac{\partial H}{\partial x}\left(\dot{x}^{*}(t), u^{*}(t), \lambda^{*}(t), t\right) \\
& 0=\frac{\partial H}{\partial u}\left(\dot{x}^{*}(t), u^{*}(t), \lambda^{*}(t), t\right) \\
& \forall t \in\left[t_{0}, t_{f}\right]
\end{aligned}
$$

Na Equação 6.9, a primeira condição é conhecida como equação de estado, a segunda como equação de co-estado e a última deriva-se do princípio mínimo de Potryagin [22], que estabelece que a função Hamiltoniana deve possuir o valor extremo na condição de controle ótimo, ou seja:

$H\left(x^{*}(t), u^{*}(t), \lambda^{*}(t), t\right) \leq H\left(x^{*}(t), u(t), \lambda^{*}(t), t\right)$

$\forall t \in\left[t_{0}, t_{f}\right]$

Quando satisfeito ao longo de uma trajetória, o princípio mínimo de Pontryagin é uma condição necessária para o ótimo.

A solução do problema consiste então em resolver o sistema de equações apresentado em (6.9), obtendo os valores do estado $x^{*}(\mathrm{t})$, do co-estado $\lambda^{*}(\mathrm{t})$ e da entrada de controle $\mathrm{u}^{*}(\mathrm{t})$. Observe que, para $n$ variáveis de estado e $m$ entradas de controle, têm-se um sistema de $2 n+m$ equações. Além disso, se forem consideradas as restrições de fronteira de $\mathrm{x}\left(\mathrm{t}_{0}\right)$ e $\mathrm{x}\left(\mathrm{t}_{\mathrm{f}}\right)$, acrescentam-se as seguintes restrições:

$x^{*}\left(t_{0}\right)=x_{0}$

$x^{*}\left(t_{f}\right)=x_{f}$

Por fim, o problema de controle ótimo se resume a solução de um sistema de equações diferencias com restrições de fronteira, que normalmente apresenta uma solução computacional complicada. 


\subsection{Problemas de mínimo tempo}

Como explicado brevemente na seção anterior, o objetivo do controle ótimo é determinar o sinal de controle $\mathrm{u}^{*}(\mathrm{t})$ que leva um sistema dinâmico de um estado inicial $\mathrm{x}\left(\mathrm{t}_{0}\right)=\mathrm{x}_{0}$ para um estado final $\mathrm{x}\left(\mathrm{t}_{\mathrm{f}}\right)=\mathrm{x}_{\mathrm{f}}$ no menor tempo possível. Logo, $\mathrm{o}$ problema de trajetória ótima em pistas de corrida pode claramente ser descrito e resolvido como um problema de controle ótimo tendo como índice de desempenho o tempo, como mostra a Equação 6.12, i. e.:

$J=t_{f}-t_{0}=\int_{t_{0}}^{t_{f}} d t$

A seguir, será apresentada a solução do problema de mínimo tempo para uma classe de sistemas dinâmicos descritos pela seguinte equação de estado:

$\dot{x}(t)=a(x(t), t)+b(x(t), t) \cdot u(t)$

e cujo conjunto de controles admissíveis deve satisfazer à seguinte restrição:

$u_{L} \leq u(t) \leq u_{U}$

Primeiramente, incluem-se as equações dinâmicas na função objetivo usando multiplicadores de Lagrange, de forma que o índice de desempenho aumentado seja expresso como:

$J_{a}(u(t))=\int_{t_{0}}^{t_{f}} 1+\lambda(t) \cdot(a(x(t), t)+b(x(t), t) \cdot u(t)-\dot{x}) d t$

A partir da Equação 6.15, tem-se que a função Hamiltoniana é dada por:

$H(x(t), u(t), \lambda(t), t)=1+\lambda(t) \cdot[a(x(t), t)+b(x(t), t) \cdot u(t)]$ 
De acordo com o princípio mínimo, é necessário que a seguinte expressão seja satisfeita:

$1+\lambda^{*}(t) \cdot\left[a\left(x^{*}(t), t\right)+b\left(x^{*}(t), t\right) \cdot u^{*}(t)\right]$

$\leq 1+\lambda^{*}(t) \cdot\left[a\left(x^{*}(t), t\right)+b\left(x^{*}(t), t\right) \cdot u(t)\right]$

o que implica diretamente em:

$\lambda^{*}(t) \cdot b\left(x^{*}(t), t\right) \cdot u^{*}(t) \leq \lambda^{*}(t) \cdot b\left(x^{*}(t), t\right) \cdot u(t)$

Desta forma, a solução do problema consiste em minimizar a Equação (6.19) dentro da faixa de controles admissíveis apresentada na Equação 6.14, ou seja:

$\lambda^{*}(t) \cdot b\left(x^{*}(t), t\right) \cdot u(t)$

A solução óbvia é: se o valor do coeficiente de $\mathrm{u}(\mathrm{t})$ é positivo, $\mathrm{u}^{*}(\mathrm{t})$ deve ser o menor valor de controle admissível $\left(\mathrm{u}_{\mathrm{L}}\right)$; caso contrário, se o coeficiente de $\mathrm{u}(\mathrm{t})$ é negativo, $\mathrm{u}^{*}(\mathrm{t})$ deve ser o maior valor de controle admissível $\left(\mathrm{u}_{\mathrm{U}}\right)$. Assim, a solução do problema de tempo mínimo é dada por:

$u^{*}(t)= \begin{cases}u_{L}, & \text { se } \lambda^{*}(t) \cdot b\left(x^{*}(t), t\right)>0 \\ u_{U}, & \text { se } \lambda^{*}(t) \cdot b\left(x^{*}(t), t\right)<0 \\ \text { Indeterminado, } & \text { se } \lambda^{*}(t) \cdot b\left(x^{*}(t), t\right)=0\end{cases}$

A Equação 6.20 é a definição matemática do chamado princípio Bang-bang, que estabelece que, para um sistema da forma (6.13) e faixa de controles admissíveis da forma (6.14), então o controle ótimo que obtém a resposta de menor tempo é aquele de maior esforço durante todo o intervalo de controle [22]. A ideia por trás do princípio é bastante intuitiva, pois é natural esperar que um piloto, por exemplo, tente manter a aceleração ou a frenagem no nível máximo possível para atingir seu destino mais rápido.

Apesar de representar a solução mais simples do problema de tempo mínimo, a estratégia de controle Bang-bang não é indicada para aplicação neste 
trabalho por diversos motivos. Primeiramente, o chaveamento entre a aceleração máxima e a frenagem máxima ao longo do trajeto não caracteriza o comportamento real de um piloto de corrida. Adicionalmente, o controle de máximo esforço constante gera um elevado consumo de combustível, degradação muito mais rápida dos pneus e leva o veículo a sofrer numerosos esforços físicos que podem causar a ruptura de componentes mecânicos.

Assim, além de poder ser constituído por um complexo sistema de equações (dependendo da quantidade de variáveis do sistema dinâmico), outra dificuldade da solução de problemas de tempo mínimo a partir de controle ótimo é que a solução normalmente tende a ser do tipo Bang-bang.

\subsection{Modelagem do problema de controle ótimo}

Uma parte importante da definição do problema de controle ótimo é a sua modelagem. Tanto as equações dinâmicas, como as restrições do problema têm que representar com precisão as características do problema, caso contrário, a solução não será a ótima, especialmente em problemas de trajetória de mínimo tempo, em que existem inúmeras formas possíveis de partir de um ponto $\mathrm{x}_{0} \mathrm{e}$ chegar a um ponto $\mathrm{x}_{\mathrm{f}}$. $\mathrm{O}$ modelo de otimização é constituído pelas equações dinâmicas do sistema, as condições de contorno e as restrições da trajetória.

\subsubsection{Variáveis de estado e restrições do problema}

Como discutido no capítulo 2, o modelo de veículo utilizado para o problema de otimização será o de uma partícula orientada. As variáveis de estado do sistema dinâmico são:

$$
\begin{aligned}
& x_{1}(t)=v(t) \\
& x_{2}(t)=\psi(t) \\
& x_{3}(t)=x(t) \\
& x_{4}(t)=y(t)
\end{aligned}
$$


onde $\mathrm{v}(\mathrm{t})$ é a velocidade tangencial do veículo, $\psi(\mathrm{t})$ é o ângulo do veículo em relação a trajetória, $x(t)$ e $y(t)$ correspondem a posição do centro de massa do veículo em relação ao eixo global $\mathrm{X}$ e ao eixo global $\mathrm{Y}$, respectivamente. Estas variáveis estão ilustradas na Figura 6.1. A variável $\rho(t)$ representa o raio da trajetória, que também pode ser definido como o inverso de sua curvatura $\kappa(\mathrm{t})$.

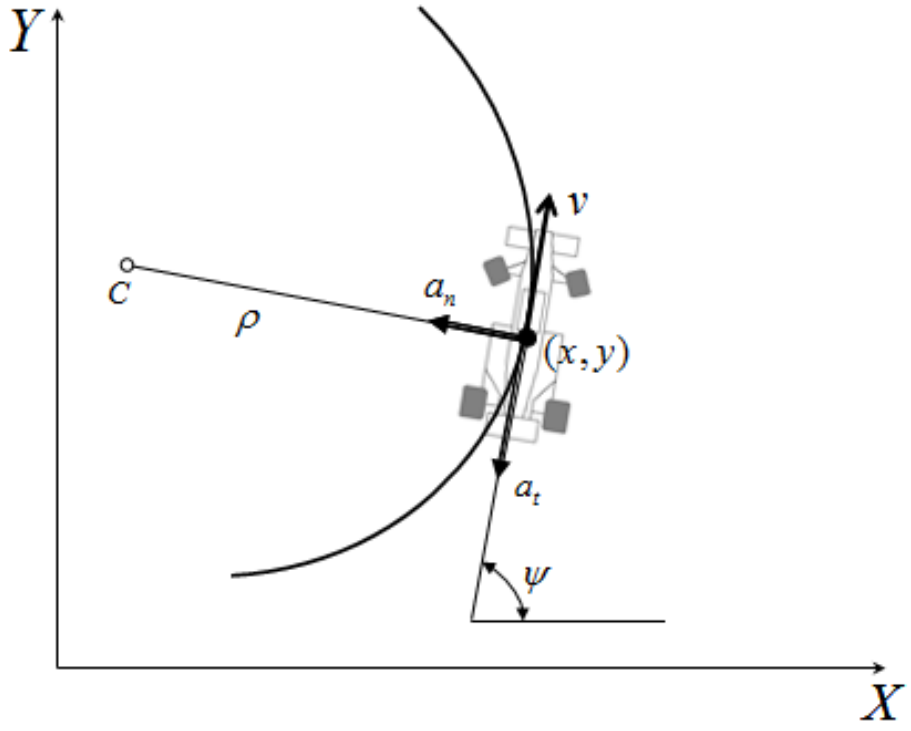

Figura 6.1: Variáveis do modelo dinâmico do veículo

As entradas do modelo são definidas como as acelerações tangencial e normal impostas ao veículo, ou seja:

$u_{1}(t)=a_{t}(t)$

$u_{2}(t)=a_{n}(t)$

Definidas as variáveis de estado do problema, as equações diferenciais que caracterizam o sistema dinâmico estão apresentadas nas equações (observe que o sistema de equações diferenciais é não-linear, o que torna a sua solução não trivial, como será discutido adiante neste capítulo):

$$
\begin{aligned}
& \dot{x}_{1}(t)=u_{1}(t) \\
& \dot{x}_{2}(t)=\frac{u_{2}(t)}{x_{1}(t)} \\
& \dot{x}_{3}(t)=x_{1}(t) \cdot \cos \left(x_{2}(t)\right)
\end{aligned}
$$


$\dot{x}_{4}(t)=x_{1}(t) \cdot \operatorname{sen}\left(x_{2}(t)\right)$

O próximo passo é definir as restrições do problema: os limites superior e inferior das variáveis de entrada e as restrições correspondentes ao limite geométrico da pista. Quanto aos limites das entradas $\mathrm{u}_{\mathrm{i}}(\mathrm{t})$, serão utilizados os mesmos valores adotados no algoritmo de concatenação apresentado na seção anterior:

$-10.791 \mathrm{~m} / \mathrm{s}^{2} \leq u_{1}(t) \leq 4.905 \mathrm{~m} / \mathrm{s}^{2}$

$-10.791 \mathrm{~m} / \mathrm{s}^{2} \leq u_{2}(t) \leq 10.791 \mathrm{~m} / \mathrm{s}^{2}$

Quanto às restrições geométricas, elas são mais complicadas de modelar utilizando equações parametrizadas em relação ao tempo, uma vez que o tempo não é uma variável fixa neste problema. Uma alternativa para a modelagem dos limites geométricos da pista consiste em descrever o movimento da partícula a partir de coordenadas circulares $s_{1}, s_{2}$ e $\alpha$, onde $s_{1}$ representa a distância percorrida pelo veículo ao longo da linha central da pista, s s representa a distância do veículo perpendicular à linha central e $\alpha$ é o ângulo entre a orientação do veículo e a reta tangente à linha central $[10,13]$. A utilização desta mudança de coordenadas facilita consideravelmente a formulação da inequação de restrição geométrica. As Figuras 6.2 e 6.3 ilustram as coordenadas utilizadas.

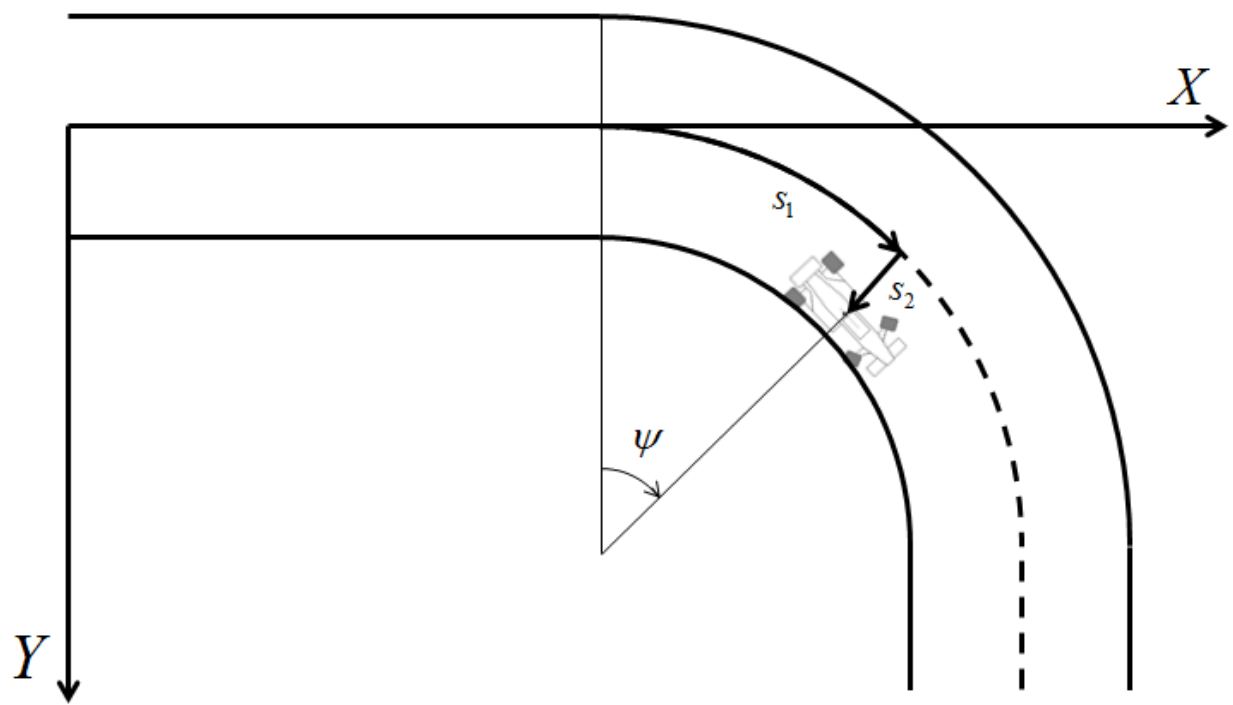

Figura 6.2: Coordenadas $s_{1}$ e $s_{2}$ do veículo através do centro da linha da pista 


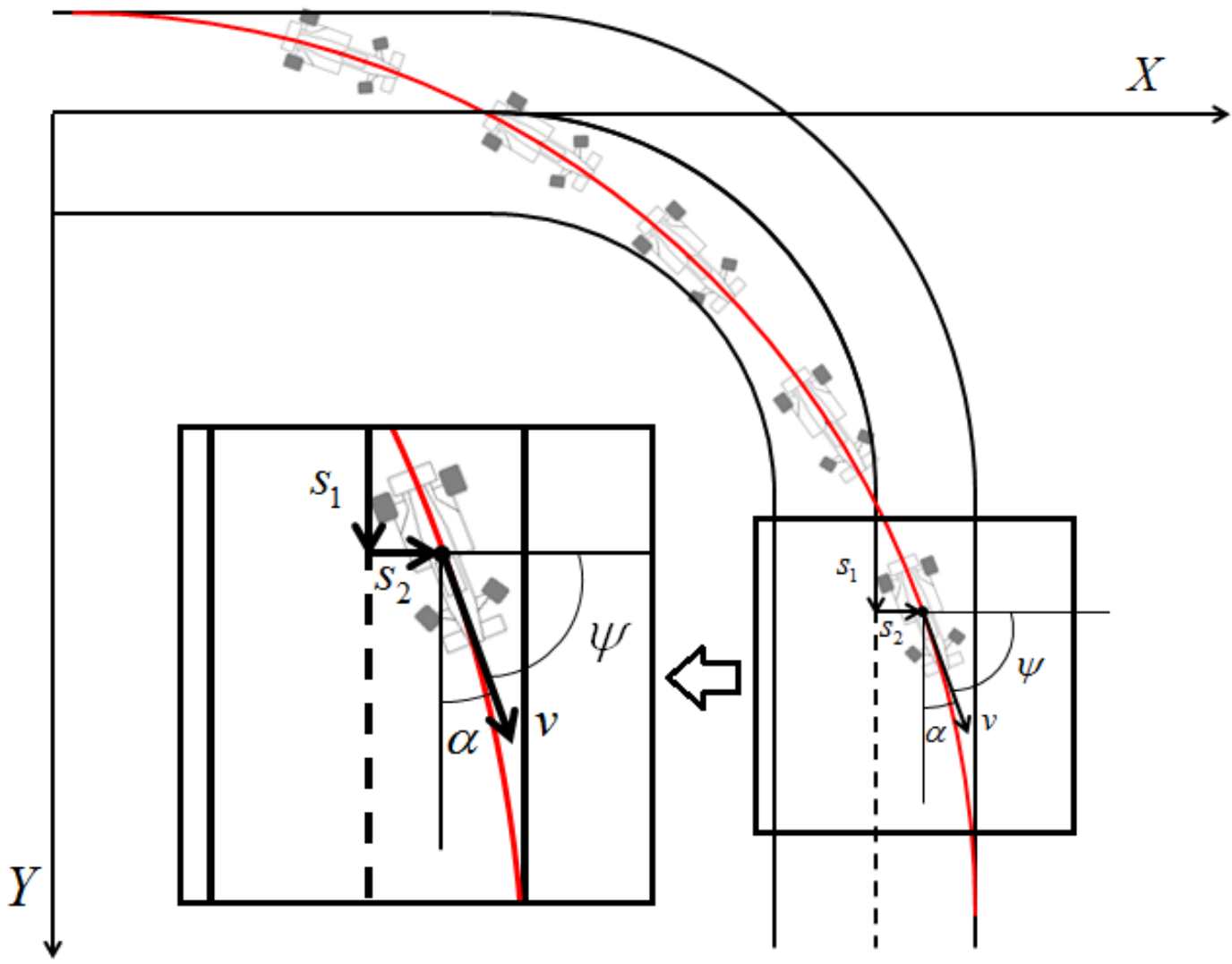

Figura 6.3: Representação do ângulo $\alpha$

Neste ponto, é necessário definir a relação entre as coordenadas circulares $\mathrm{s}_{1}, \mathrm{~s}_{2}$ e $\alpha$ e as coordenadas absolutas $x, y$ e $\psi$.

Considere que é conhecida a equação paramétrica da linha central da pista em relação ao tempo, definida como $\left(x_{c}(\mathrm{t}), y_{c}(\mathrm{t})\right)$; e seu ângulo tangente definido como $\psi_{c}(\mathrm{t})$. No entanto, é conveniente parametrizar as variáveis em função da distância percorrida ao longo da linha central $s_{1}$ ao invés do tempo, para que se possa inserir a variável $s_{1}$ na descrição da forma da pista e também porque o tempo não é definido neste modelo.

Para isso, pode-se começar escrevendo a curvatura da linha central em função de $s_{1}$, ou seja:

$\kappa_{c}\left(s_{1}\right)=\frac{d \psi_{c}}{d s_{1}}=\frac{d \psi_{c}}{d t} \cdot \frac{d t}{d s_{1}}=\frac{d \psi_{c}}{d t} \cdot \frac{1}{v}=\kappa_{c}(t) \cdot \frac{1}{\sqrt{\dot{x}_{c}^{2}+\dot{y}_{c}^{2}}}$

O ângulo $\psi_{c}\left(s_{1}\right)$ e as equações paramétricas $\left(x_{c}\left(s_{1}\right), y_{c}\left(s_{1}\right)\right)$ em função de $s_{1}$ são obtidos a partir das relações mostradas a seguir. 
Como já foi dito, o ângulo tangente à trajetória é obtido a partir da integração da sua curvatura, ou seja:

$\psi_{c}\left(s_{1}\right)=\int \kappa_{c}\left(s_{1}\right) d s_{1}$

A relação entre o ângulo tangente e a curvatura de uma trajetória é definida como:

$$
\begin{aligned}
& \cos \left(\psi_{c}\left(s_{1}\right)\right)=\frac{d x_{c}}{d s_{1}} \\
& \operatorname{sen}\left(\psi_{c}\left(s_{1}\right)\right)=\frac{d y_{c}}{d s_{1}}
\end{aligned}
$$

De onde se deriva:

$$
\begin{aligned}
& x_{c}\left(s_{1}\right)=\int \cos \left(\psi_{c}\left(s_{1}\right)\right) d s_{1} \\
& x_{c}\left(s_{1}\right)=\int \cos \left(\psi_{c}\left(s_{1}\right)\right) d s_{1}
\end{aligned}
$$

Logo, a partir da equação paramétrica no tempo da linha central da pista $\left(x_{c}(\mathrm{t}), y_{c}(\mathrm{t})\right)$ e das Equações 6.29, 6.30 e 6.31 é possível definir o ângulo tangente $\psi_{c}\left(s_{1}\right)$ e a equação paramétrica da linha central $\left(x_{c}\left(s_{1}\right), y_{c}\left(s_{1}\right)\right)$, em função de $s_{1}$.

Consequentemente, é possível descrever a posição do veículo em coordenadas absolutas $(x, y)$ como:

$$
\begin{aligned}
& x=x_{c}\left(s_{1}\right)-s_{2} \cdot \operatorname{sen}\left(\psi_{c}\left(s_{1}\right)\right) \\
& y=y_{c}\left(s_{1}\right)+s_{2} \cdot \cos \left(\psi_{c}\left(s_{1}\right)\right)
\end{aligned}
$$

A partir da Figura 6.3, a coordenada circular $\alpha$ pode ser definida como:

$$
\psi=\psi_{c}\left(s_{1}\right)-\alpha
$$


Observe que, para uma pista de largura $2 l_{2}$, quando $s_{2}$ assume um valor constante igual a $l_{2}$, a curva obtida corresponde a borda externa da pista e, para um valor $\mathrm{s}_{2}$ constante de $-l_{2}$, a curva corresponde a borda interna da pista. Ainda, se o veículo estiver seguindo exatamente a linha central, $\alpha$ é igual a zero e o ângulo tangente à trajetória do veículo é igual ao ângulo tangente à linha central da pista.

A posição do veículo em coordenadas circulares deve ser incluída nas variáveis de estado. Para tanto, basta relacionar as derivadas das coordenadas cartesianas com as circulares para se obter as equações diferenciais de $s_{1}, s_{2}$ e $\alpha$. A partir das equações dinâmicas do veículo, sabe-se que:

$\dot{x}=v \cdot \cos (\psi)$

$\dot{y}=v \cdot \operatorname{sen}(\psi)$

Substituindo (6.35) em (6.34), obtém-se:

$\dot{s}_{1}=\frac{v \cdot \cos (\alpha)}{1-s_{2} \cdot \operatorname{sen}\left(\dot{\psi}_{c}\left(s_{1}\right)\right)}$

$\dot{s}_{2}=v \cdot \operatorname{sen}(\alpha)$

$\dot{\alpha}=\dot{\psi}_{c}\left(s_{1}\right) \cdot s_{1}-\dot{\psi}$

As variáveis de estado anteriormente definidas como $\mathrm{x}$ e $\mathrm{y}$, serão substituídas por s1 e s2. A curvatura da linha central da pista $\psi_{c}$ e sua derivada são funções conhecidas.

Representando a trajetória do veículo pelas coordenadas circulares $s_{1}, s_{2}$ e $\alpha$, a restrição da pista pode ser definida simplesmente como:

$-l_{2} \leq s_{2} \leq l_{2}$

onde $l_{2}$ é a metade da largura da pista, que para este trabalho será um valor constante, mas pode ser definido como uma função de $s_{1}$. Não é preciso impor restrições na variável $s_{1}$, pois ela já é definida de forma que só varia ao longo da linha central da pista e logo, não viola os limites físicos da pista de corrida. 
Finalmente, as equações de estado do modelo depois da mudança de coordenadas estão apresentadas são dadas por:

$\dot{x}_{1}=\dot{v}=u_{1}$

$\dot{x}_{2}=\dot{\psi}=\frac{u_{2}}{x_{1}}$

$\dot{x}_{3}=\dot{\alpha}=\dot{\psi}_{c}\left(x_{4}\right) \cdot x_{4}-\dot{x}_{2}$

$\dot{x}_{4}=\dot{s}_{1}=\frac{x_{1} \cdot \cos \left(x_{3}\right)}{1-x_{5} \cdot \operatorname{sen}\left(\dot{\psi}_{c}\left(x_{4}\right)\right)}$

$\dot{x}_{5}=\dot{s}_{2}=x_{1} \cdot \operatorname{sen}\left(x_{3}\right)$

Este conjunto de equações será referenciado daqui em diante como $F(\boldsymbol{x}, \dot{\boldsymbol{x}}, \boldsymbol{u}, t)$.

\subsubsection{Função objetivo e condições de fronteira}

A função objetivo de um problema de controle ótimo é definida pelo funcional a ser minimizado, representado de forma geral na Equação 6.38, como foi discutida na seção 6.1 .

$J=\int_{t_{0}}^{t_{f}} L(\dot{\boldsymbol{x}}, \boldsymbol{x}, \boldsymbol{u}, t) d t$

Normalmente, em um problema de mínimo tempo, a função $\mathrm{L}(\boldsymbol{x}, \boldsymbol{u}, t)$ é definida como 1 , de forma que o objetivo seja encontrar a trajetória que leve o veículo de $x_{0}$ pata $x_{\mathrm{f}}$ em menor tempo, respeitando as restrições e condições de fronteira existentes. No entanto, para este trabalho, a formulação foi um pouco diferente. O objetivo será maximizar o espaço percorrido ao longo linha central da pista para um tempo final fixo T. Assim, ao invés de se obter a trajetória de menor tempo entre dois pontos fixos, obtém-se a trajetória de maior espaço percorrido em um tempo fixo. Essa formulação é baseada na que foi utilizada por Cossalter et al [13]. A escolha em utilizar essa formulação se justifica no modelo dinâmico proposto, que contempla como variável de estado o espaço percorrido na linha central e ainda, pelo fato de as equações que resolvem um problema de controle 
ótimo serem mais simples para modelos com tempo final fixo [22]. Assim, o funcional a ser minimizado é descrito na Equação 6.39.

$J=\int_{0}^{T}-1 \cdot d s_{1}=\int_{0}^{T}-\frac{\dot{s}_{1}}{V_{0}} d t$

$\mathrm{O}$ sinal é negativo por se tratar de um problema de maximização. $\mathrm{O}$ fator $\mathrm{V}_{0}$ é um valor para garantir que a trajetória não seja feita de forma tão rápida que a velocidade do veículo possa atingir valores fisicamente inviáveis.

Como foi definido no item anterior, o modelo deste problema possui restrições de variáveis de entrada e de estado formuladas por inequações. Em modelos não-lineares como esse, a manipulação de restrições formadas por inequações não é muito simples. A alternativa é incluir essas restrições como penalidade na função objetivo, de forma que ela assuma um valor muito grande caso alguma das restrições seja violada.

Tais restrições são as de aceleração tangencial máxima e mínima no trajeto e os limites geométricos da pista na sua largura.

$$
\begin{aligned}
a_{t_{\text {min }}} & \leq u_{1} \leq a_{t_{\text {máx }}} \\
a_{n_{\text {min }}} & \leq u_{2} \leq a_{n_{\text {máx }}} \\
-l_{2} & \leq x_{5} \leq l_{2}
\end{aligned}
$$

Para cada restrição, é incluída uma penalidade na função objetivo da seguinte forma:

$L(\dot{\boldsymbol{x}}, \boldsymbol{x}, \boldsymbol{u}, t)=$

$\left[-\frac{\dot{x}_{4}}{V_{0}}+\left(\frac{x_{5}}{l_{2}}\right)^{2 k}+\left(\frac{\sqrt{u_{1}^{2}+u_{2}^{2}}}{a_{n_{\text {máx }}}}\right)^{k}+\left(\frac{u_{1}}{a_{t_{\text {máx }}}}\right)^{k}+\left(\frac{u_{2}}{a_{n_{\text {máx }}}}\right)^{k}\right]$

Onde o termo k é um valor inteiro proporcional ao peso dado para cada restrição. Eles podem ser diferentes em cada um dos termos dependendo da necessidade. 
O primeiro termo é o mais importante e garante que a distância percorrida na linha central $s_{1}$ seja maximizada. $O$ segundo termo corresponde a restrição geométrica da pista em sua largura, que está ao quadrado para restringir os valores positivos e negativos de $\mathrm{s}_{2}$. Esse valor pode ser maior caso seja necessário aumentar o peso desta restrição no problema, contanto que seja um expoente par. Os dois últimos termos correspondem às restrições de aceleração tangencial e normal e a aceleração total, para que a trajetória encontrada respeite o círculo de aderência.

Em relação às condições de fronteira iniciais e finais, algumas precisaram ser impostas. O ângulo tangente à trajetória $\psi$ e o ângulo entre a trajetória e a linha central da pista $\alpha$ começam necessariamente de zero, para que a trajetória comece perpendicular a linha central. A velocidade tangencial inicial e final não foi imposta, podendo ser livre, assim como a distância perpendicular a linha de centro da pista $\mathrm{s}_{2}$. A distância ao longo da linha de centro $\mathrm{s}_{1}$ começa em zero para garantir que a trajetória parta do início da pista e não tem ponto final definido, já que o objetivo é que ela seja a maior possível. As restrições de fronteira são então:

$\psi(0)=0 \rightarrow x_{2}(0)=0$

$\alpha(0)=0 \rightarrow x_{3}(0)=0$

$s_{1}(0)=0 \rightarrow x_{4}(0)=0$

\subsubsection{Formalização do modelo e técnicas para a solução}

Uma vez tendo sido definido as variáveis de estado do problema, as restrições e as condições de contorno, a definição do problema de otimização é apresentada na Equação 6.43.

$$
\left\{\begin{aligned}
& \min _{u \in U} J= \int_{0}^{T} L(\dot{\boldsymbol{x}}, \boldsymbol{x}, \boldsymbol{u}, t) d t \\
& \text { s.t. } \quad \begin{array}{l}
\dot{\boldsymbol{x}}=F(\boldsymbol{x}, \dot{\boldsymbol{x}}, \boldsymbol{u}, t) \\
\\
x\left(t_{0}\right)=x_{0}
\end{array}
\end{aligned}\right.
$$


Onde $L(\dot{\boldsymbol{x}}, \boldsymbol{x}, \boldsymbol{u}, t)$ foi definido na Equação 6.41 e já inclui as restrições de desigualdade como penalidades; e $F(\boldsymbol{x}, \dot{\boldsymbol{x}}, \boldsymbol{u}, t)$ é o conjunto das equações diferenciais dinâmicas do sistema, definidas na Equação 6.37.

Tendo sido formulado o modelo, é possível definir o índice de desempenho aumentado como:

$J_{a}=\int_{t_{0}}^{t_{f}}\left[L(\dot{\boldsymbol{x}}, \boldsymbol{x}, \boldsymbol{u}, t)+\lambda^{T}(t) \cdot(F(\boldsymbol{x}, \dot{\boldsymbol{x}}, \boldsymbol{u}, t)-\dot{\boldsymbol{x}})\right] d t$

$\mathrm{Na}$ equação acima, $\lambda^{T}(t)$ são os multiplicadores de Lagrange e tem dimensão $1 \times n$, onde $n$ é o número de equações de estado do modelo. Neste problema, $n$ vale 5 .

A partir de 6.44, define-se a função Hamiltoniana como:

$H(\boldsymbol{x}, \dot{\boldsymbol{x}}, \boldsymbol{u}, \boldsymbol{\lambda}, t)=L(\dot{\boldsymbol{x}}, \boldsymbol{x}, \boldsymbol{u}, t)+\lambda^{T}(t) \cdot F(\boldsymbol{x}, \dot{\boldsymbol{x}}, \boldsymbol{u}, t)$

O objetivo então é encontrar o controle $\mathrm{u}^{*}(\mathrm{t})$ que extremize o funcional $\mathrm{J}$ e, a partir dele, determinar os valores ótimos das variáveis de estado $\mathrm{x}(\mathrm{t})$. Para um problema de controle ótimo desta classe, em que $\mathrm{t}_{\mathrm{f}}$ é fixo e $\mathrm{x}\left(\mathrm{t}_{\mathrm{f}}\right)$ é livre, a Equação 6.46 mostra as condições para que um dado controle $\mathrm{u}^{*}(\mathrm{t})$ seja ótimo [22].

$\dot{\boldsymbol{x}}^{*}(t)=\frac{\partial H}{\partial \lambda}\left(\boldsymbol{x}^{*}, \dot{\boldsymbol{x}}^{*}, \boldsymbol{u}^{*}, \lambda^{*}, t\right)=F\left(\boldsymbol{x}^{*}, \dot{\boldsymbol{x}}^{*}, \boldsymbol{u}^{*}, t\right)$

$\dot{\lambda}^{*}(t)=-\frac{\partial H}{\partial x}\left(\boldsymbol{x}^{*}, \dot{\boldsymbol{x}}^{*}, \boldsymbol{u}^{*}, \lambda^{*}, t\right)$

$0=\frac{\partial H}{\partial \boldsymbol{u}}\left(\boldsymbol{x}^{*}, \dot{\boldsymbol{x}}^{*}, \boldsymbol{u}^{*}, \lambda^{*}, t\right)$

$x^{*}\left(t_{0}\right)=x_{0}$

Observe que este problema possui 5 equações diferenciais de estado $\dot{\boldsymbol{x}}^{*}(t)$, mais 5 equações diferenciais de co-estado $\dot{\lambda}^{*}(t)$, mais 2 equações diferenciais correspondentes ao Príncipio Mínimo de Potryagin $\partial H / \partial \boldsymbol{u}$, mais 3 equações provenientes das condições iniciais propostas, totalizando 15 equações, o que requer considerável custo computacional. 
A solução do problema de otimização se resume então à solução de um sistema de equações diferenciais não-linear com condições de contorno. Infelizmente, essa solução não é muito simples. Existem alguns métodos para solução de problemas deste tipo, cuja maioria é baseada na utilização de uma estimativa inicial da solução e depois a aplicação de algum método iterativo para ajustar esta solução inicial estimada até que todas as condições da Equação 6.46 sejam satisfeitas.

O método de Máximo Declive (Steepest Descent) é um exemplo que utiliza esta técnica. Começando com a variável iterativa i igual a 0 (zero), o método consiste em atribuir um valor inicial para $\mathbf{u}^{\mathbf{i}}(\mathrm{t})$ para o controle e, para este valor, resolver o sistema de equações composto por $\dot{\boldsymbol{x}}(t)$ e $\dot{\boldsymbol{\lambda}}(t)$ respeitando as condições iniciais determinadas no modelo, gerando como solução o estado $x^{\mathrm{i}}(\mathrm{t}) \mathrm{e}$ o co-estado $\lambda^{i}(t)$. Então, deve-se verificar se para estes resultados o princípio de mínimo é satisfeito, ou seja:

$$
\frac{\partial H^{0}}{\partial \boldsymbol{u}}\left(\boldsymbol{x}^{i}(t), \boldsymbol{u}^{i}(t), \lambda^{i}(t), t\right) \leq \gamma
$$

Onde $\gamma$ deve ser tão pequeno quanto se deseja ser a precisão da solução.

Caso a Equação 6.47 não seja satisfeita, o processo deve ser repetido quantas vezes for necessário até que a condição seja satisfeita. Para cada iteração seguinte, o valor de $\mathrm{u}(\mathrm{t})$ é definido como:

$$
\boldsymbol{u}^{i+1}(t)=\boldsymbol{u}^{i}(t)-\tau \cdot \frac{\partial H^{0}}{\partial \boldsymbol{u}}
$$

Onde o valor do passo $\tau$ pode ser definido de forma experimental ou definido dinamicamente de forma que ele tenha uma ordem de grandeza similar à variação do índice de desempenho para cada iteração.

Como outros métodos, pode se citar Quasilinearization e Gradiente Projection [22,23], baseados também em técnicas iterativas. Existe ainda outra classe de métodos, utilizada por Casanova [11], que não utiliza as condições de otimalidade mostradas aqui ou o principio mínimo de Potryagin, mas consiste em converter o problema de controle ótimo em um problema de Programação Não- 
Linear e resolvê-lo usando técnicas de programação matemática, como Sequential Quadratic Programming (SQP). Existem ainda algumas funções próprias para a solução de problemas diferenciais com restrição de contorno em softwares como Matlab $^{\circledR}$ ou em funções do Numerical Recipes [24]. A dificuldade em utilizá-los está no fato de que o problema precisa ser modelado da maneira específica requerida pela função, o que nem sempre é possível. 


\section{Conclusões e Trabalhos Futuros}

Ao longo dessa dissertação, foram apresentados dois métodos bastante diferentes para a solução do problema de trajetória de tempo mínimo. Foram discutidas a modelagem do problema, a solução para o modelo proposto em cada caso e os resultados foram analisados para inferir sobre a eficiência de cada método empregado.

A primeira abordagem para a obtenção da trajetória de menor tempo em uma pista de corrida apresentada neste trabalho consiste em obter as trajetórias ótimas para cada curva da pista individualmente e em seguida, concatena-las a partir de seus pontos de saída. Para casos em que algum dos pontos de saída está fora da pista, a concatenação é feita pelos ápices. Estas trajetórias individuais foram obtidas a partir da análise geométrica do problema, sabendo que o trajeto de menor tempo é o arco de circunferência que tangencia a pista no centro geométrica da curva. Então, foi feita uma análise com alguns tipos de curvas para inferir aquela cujas características dinâmicas fossem mais compatíveis com a dinâmica do veículo para ser utilizada no processo de concatenação. A curva de Hermite foi escolhida porque sua forma paramétrica é constituída por simples expressões polinomiais do terceiro grau, acelerando o tempo computacional para o desenho e análise das curvas. Além disso, devido à simplicidade da representação do polinômio de Hermite, a determinação das velocidades e acelerações ao longo da curva se dá por simples derivação das equações de Hermite.

Os resultados obtidos foram considerados satisfatórios do ponto de vista da otimização, pois respeitaram todas as restrições impostas pelo projeto sempre que possível e o algoritmo desenvolvido foi eficiente computacionalmente. No entanto, do ponto de vista de dinâmica de veículos, muitas trajetórias ultrapassaram o limite de capacidade do veículo proposto. Algumas alterações podem ser propostas para testes e melhoria do algoritmo neste aspecto, como sugestão para trabalhos futuros. Primeiramente, utilizar um modelo do veículo com mais variáveis, que inclua as forças relacionadas ao movimento dos eixos do 
veículo, pode deixar a modelagem do problema mais realista, bem como os seus resultados. Outro ponto importante para melhoria seria, ao invés de concatenar as trajetórias ótimas individuais sempre pelos pontos de saída, verificar a concatenação por outros pontos, de formar a adiantar a entrada nas curvas. E por fim, uma abordagem interessante também seria alterar os ápices das trajetórias ótimas independentes de forma que eles não estejam sempre no centro geométrico da curva, mas adiantados ou atrasados quando necessário, como é feito na realidade por muitos pilotos de corrida.

Como pontos positivos do algoritmo de concatenação têm-se a eficiência computacional e o fato de que as velocidades de entrada e saída estipuladas para as curvas são sempre respeitadas, assim como as restrições geométricas da pista. A implementação é simples e o algoritmo é genérico para ser aplicado a qualquer circuito. Além disso, ele é capaz de gerar gráficos com todos os perfis de velocidade e aceleração ao longo da pista. O ponto negativo principal é o fato de algumas trajetórias obtidas excederem a capacidade dinâmica do veículo, o que está mais associado à curva de concatenação escolhida, do que com o algoritmo em si. Como sugestão para futuros trabalhos, pode-se estudar a viabilidade da utilização de outras curvas de concatenação, como combinações de exponenciais ou senóides e cossenóides, por exemplo. Outra sugestão seria ainda modificar o modelo de otimização para incluir também restrições de velocidade máxima e mínima nas trajetórias ótimas individuais, evitando curvas feitas com velocidades muito altas. Cabe ressaltar ainda que as restrições geométricas foram particularmente complicadas de modelar, mas a utilização de uma função de otimização já disponível na biblioteca de funções do Matlab ${ }^{\circledR}$ facilitou o foco no desenvolvimento de um modelo de otimização que descrevesse com precisão as restrições envolvidas no problema.

Foi apresentado também um modelo para o problema de otimização proposto utilizando controle ótimo, onde se definiu todas as equações de estado do modelo dinâmico do veículo, a função objetivo e as condições de otimalidade para a solução. O problema de controle ótimo foi então descrito como um sistema de equações diferenciais com condições de contorno. Foram discutidas algumas soluções computacionais para o problema, com base no que já foi feito na literatura. Como trabalho futuro, sugere-se aplicar alguns dos métodos discutidos para a solução do modelo de controle ótimo proposto e comparar o gasto 
computacional de cada um com dos métodos com o gasto computacional do algoritmo de concatenação por curvas de Hermite. A trajetória ótima obtida por controle ótimo pode ser muito útil para comparação e validação dos resultados obtidos com técnicas de otimização com restrições. 


\section{Referências Bibliográficas}

[1] Simon, B., Cossalter, V., Massaro, M., Peretto M., "Application of the "Optimal Maneuver Method" for enhancing racing motorcycle performance", SAE International, Motorsports Engineering Conference, 2008.

[2] Carrera, D.Z.H, "Determinação da Trajetória de Veículos Terrestres a Alta Velocidade em Pistas Pré-definidas através de Técnicas de Otimização”, Rio de Janeiro, 2006, Dissertação de Mestrado, DEM/PUC-Rio.

[3] Edmonson, C., "Fast Car Physics", The Johns Hopkins University Press, USA, 2011.

[4] Milliken, W. F., Milliken, D. L., "Race car vehicle dynamics", SAE International, USA, 1995.

[5] Xiong, Y., "Race Line Optimization", thesis submitted to MIT, September 2010.

[6] Arakawa, M., "Contribuição ao estabelecimento do comprimento desejável da espiral de transição em rodovias rurais e urbanas”, São Paulo, Escola Politécnica da Universidade de São Paulo, 2012. Dissertação de Mestrado em Engenharia de Transportes.

[7] Ávila, G., "Contatos de Curvas, Círculo Osculador e Integrais de Fresnel”, Matemática Universitária, No. 2, Dezembro de 1985, pp. 75-85.

[8] Ribeiro, S., "Determinação e Controle da Trajetória Ótima de um Veículo Terrestre em um Traçado Fechado Pré-Definido". Rio de Janeiro, 2009, Dissertação de Mestrado, DEE/PUC-Rio.

[9] Ramanata, P., "Optimal Vehicle Path Generator Using Optimization Methods", Master Thesis submitted to Virginia Polytechnic Institute, Blacksburg, Virginia, 1998. 
[10] Casanova, D., Sharp, R.S., and Symonds, P., "Minimum Time Manoeuvring: The Significance of Yaw Inertia", Vehicle System Dynamics, 34, pp. 77-115, 2000 .

[11] Casanova, D., "On Minimum Time Vehicle Manoeuvring: The Theoretical Optimal Lap”, PhD Thesis submitted to Cranfielf University, 2000.

[12] Casanova, D., Sharp, R.S., and Symonds, P., "Construction of race circuit geometry from on-car measurements", Technical Note, Proc Instn Mech Engrs, Vol 215 Part D, IMechE, 2001.

[13] Cossalter, V., Da Lio, M., Lot, R., Fabbri, L., "A general method for the evaluation of vehicle manoeuvrability with special emphasis on motorcycles”, Vehicle System Dynamics, vol. 31, no. 2, pp. 113-135, 1999.

[14] Zhang, L. X., Pan, F. Q., Chen, X. Y., Wang, F. Y., Lu, J., \& Tong, Q. M. (2014). "Vehicle Optimal Velocity Curves for Minimum-Time Maneuver". Advances in Mechanical Engineering, 2014.

[15] Rogers, D., Adams, J., "Mathematical Elements for Computer Graphics", 2nd Edition. Mc Graw Hill, 1990.

[16] Azevedo, E., Conci, A., “Computação Gráfica, Teoria e Prática”. Editora Elsevier, 2003.

[17] Karmarkar, N., “A New Polynomial-Time Algorithm for Linear Programming”, Combinatorica, (4), 373-395, 1984.

[18] Nocedal, J., Wright, S.J., "Numerical Optimization", Springer, New York, 1999.

[19] Speranza Neto, M., "Introdução à Dinâmica de Veículos”, notas de aula ENG1000 - Introdução à Engenharia e ENG1780 - Integradora Básica I, CTC/PUC-Rio, 2012.

[20] Halliday, D., Resnick, R., \& Walker, J. "Fundamentals of Physics". 6th Ed. (John Wiley \& Sons, 2001) ISBN: 0-471-32000-5. 
[21] Formula One Championship - Catalunya Circuit Reconstruction. Disponível em: <http://www.formula1.com/races/in_detail/spain_897/circuit_diagram.html>. Acesso em: 06 dez. 2013.

[22] Kirk, D. E., “Optimal Control Theory: An Introduction”, Prentice-Hall Inc., New Jersey, 1970.

[23] L. Zhang, Y. Zhao, et al, "Research on vehicle handling inverse dynamics based on optimal control", China Mechanical Engineering, vol. 18, no. 16, pp. 2009-2011, 2007.

[24] Press, W. H., Teukolsky, S. A., Vetterling W. T., Flannery, B. P., Numerical Recipies, Cambridge University Press, 1986, 1992. 